\title{
A Cask Fleet Operations Study
}

\author{
Date of lssue: March 1988
}

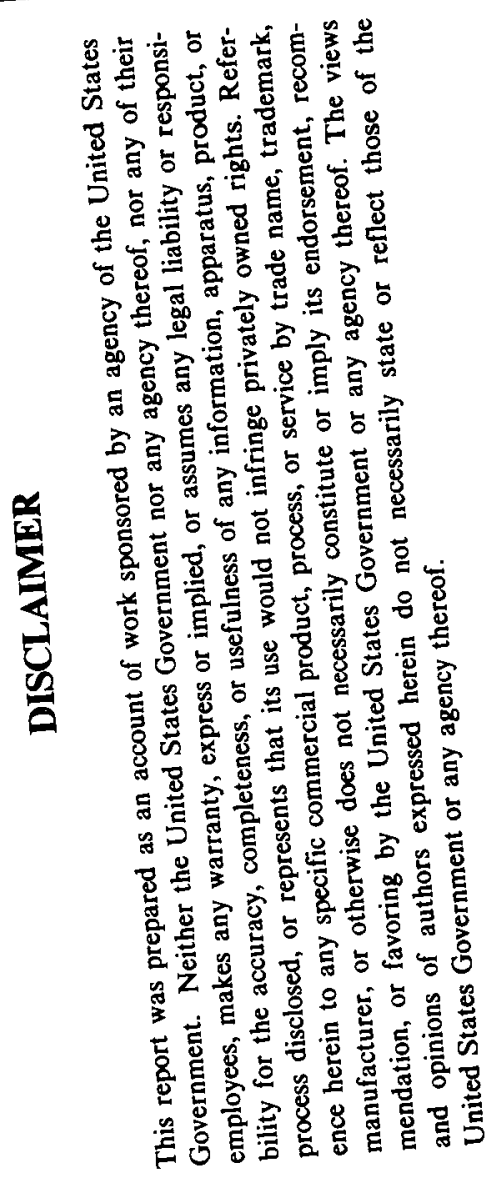

\author{
Report Prepared by \\ Transnuclear, Inc. \\ Two Skyline Drive \\ Hawthorne, New York 10532-2120
}

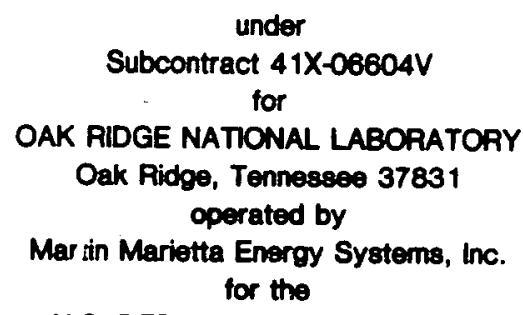

U.S. DEPARTMENT OF ENERGY

under contract DE-ACO5-84OR21400

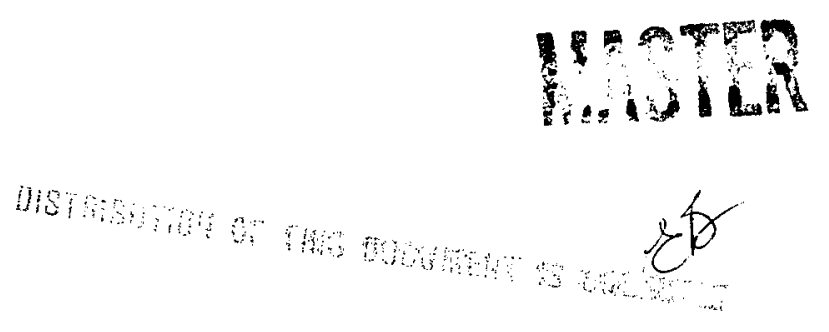




\section{DISCLAIMER}

This report was prepared as an account of work sponsored by an agency of the United States Government. Neither the United States Government nor any agency Thereof, nor any of their employees, makes any warranty, express or implied, or assumes any legal liability or responsibility for the accuracy, completeness, or usefulness of any information, apparatus, product, or process disclosed, or represents that its use would not infringe privately owned rights. Reference herein to any specific commercial product, process, or service by trade name, trademark, manufacturer, or otherwise does not necessarily constitute or imply its endorsement, recommendation, or favoring by the United States Government or any agency thereof. The views and opinions of authors expressed herein do not necessarily state or reflect those of the United States Government or any agency thereof. 


\section{DISCLAIMER}

Portions of this document may be illegible in electronic image products. Images are produced from the best available original document. 



\section{CASK FLEET OPERATIONS STUDY}

Table of contents

\section{Part 1. F leet Usage Experience}

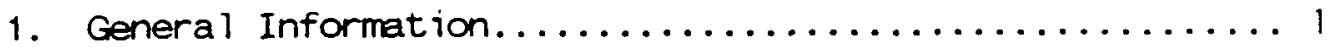

2. Descr ibe the Transport Venicle (Both Road

and Rai1) Usually Used..................... 8

3. Descr ibe the Transportation Process................ 18

4. Preparation for Lifting........................... 34

5. Crane Movement.............................. 51

6. Preparation for Fue l Loading..................... 59

7. Fuel Loading/Cask Sealing...................69

8. Preparation for Shipment/Receiving.............. 75

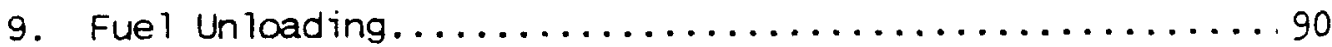

Part II. Maintenance and Repair of cask F leet

1. Hydrostatic Testing/Leak Testing/Thermal

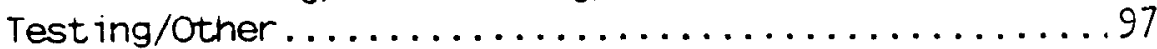

1.1 Hydrostatic Testing......................... 97

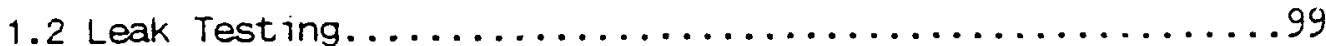

1.3 Humidity Testing............................ 103

1.4 Fusibie Plug Testing...................... 106

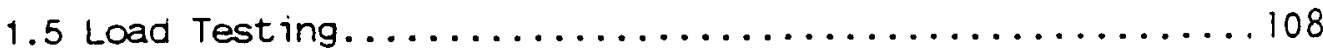

1.6 Radiation Shielding....................... 114

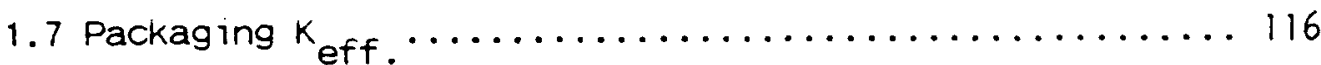

1.8 Thermal Testing...................... 117 
Table of contents

(cont inued)

2. Repair Operations............................ 18

3. Basket Remova 1........................... 121

4. Maintenance Qual ity Assurance Requirements........... 122

$\begin{array}{ll}\text { Attachment I - Certificate of Compliance } & 128\end{array}$

Attachment II - Trailer Data

Attachment III - Transport Data

137

Attachment IV - Operations

Forms

Figures

256 
TN-8 spent Fuel Cask

Aiken Facility Layout

TN-8/9 Transport Trailer

Cask Tiedown Arrangement

Trailer Tarp and Support

Long Bridge Trailer

Cask offloading

Primary Lift Beam Assembly

Secondary Lift Beam Assembly

Lift Beam Pneumatic Control system

Lift Beams in Redundant Configuration

Lift Beams and Support stand

Typical Vehicle Bay Layout

Loaded Cask Contact Dose Rates

Loaded Cask Contact Dose Rates

Empty Cask Contact Dose Rates

Lift Beam Extension

Lid Lifting Sling Arrangement

Cask Bottom Protective Cover

Cask Top Protective Cover

Skirt Assembly

Skirt Fill system

17

18

Cask Test Fittings

Failed Fuel Canister

vacuum Drying System

vacuum Connections

Cask Pressure as a Function of Time

During the Drying Phase 


\section{CASK FLEET OPERATIONS STUDY}

\section{PART 1. FLEET USAGE EXPERIENCE}

1. General Information

a. Describe the current cask fleet by type and number.

Transnuclear's current cask fleet consists of two TN-8L and two TN-9 spent fuel transport casks. One TN-9 cask is owned by Commonwealth Edison Co. (CECo.) of Chicago, but is operated by Transnuclear under a lease agreement. Each TN-8L has a capacity of three typical PWR assembities while each TN-9 will carry seven BWR assemblies. There are no removable or replaceable baskets in these casks. The fuel compartments in each of these casks are in fixed contact with the lead shielding. This lack of interchangeability between PWR and BWR capability is a disadvantage in a small cask fleet. In a large fleet, however, schedules can, and should, be manipulated so that there will be no need to exchange baskets. There are three advantages in not having baskets; first, there is a substantial weight saving for a given payload, second, the efficiency of decay heat dissipation is improved and, third, there is no need to handle and store contaminated baskets.

The casks are carried on custom designed, lightweight, high-strength semi-trailers which are pulled by fouraxle tractors. Each fully loaded cask-trailer 
combination has a gross weight of about 108,000 pounds and a length of about 60 feet, with the exact weight and length dependent upon the tractor used.

In addition to the trailers, Transnuclear makes use of a shipping frame which can be secured to a low-boy type trailer for the shipment of irradiated hardware. Any of the TN-8L or TN-9 casks can be carried by any of the Transnuclear trailers or on this frame.

General descriptions of each Transnuclear cask are given in their NRC Certificates of Compliance (9015 and 9016), and in illustrations from the operating manuals. The Certificates of Compliance are included as Attachment I; details of a cask are shown in Figure 1.

b. Where do the casks receive annual and special maintenance?

Transnuclear has a cask storage and maintenance facility located near Aiken, South Carolina. This facility has the capability to perform many of the periodic and special maintenance activities required by the safety Analysis Report (SAR) and the Certificate of Compliance. Plans have been made to add additional equipment and systems so that all tests can be performed at Aiken except those that require spent fuel in the cask as a heat or radiation source. This latter type of test may be performed at a spent fuel shipping or receiving site. 
TNB SPENT FUEL CASK

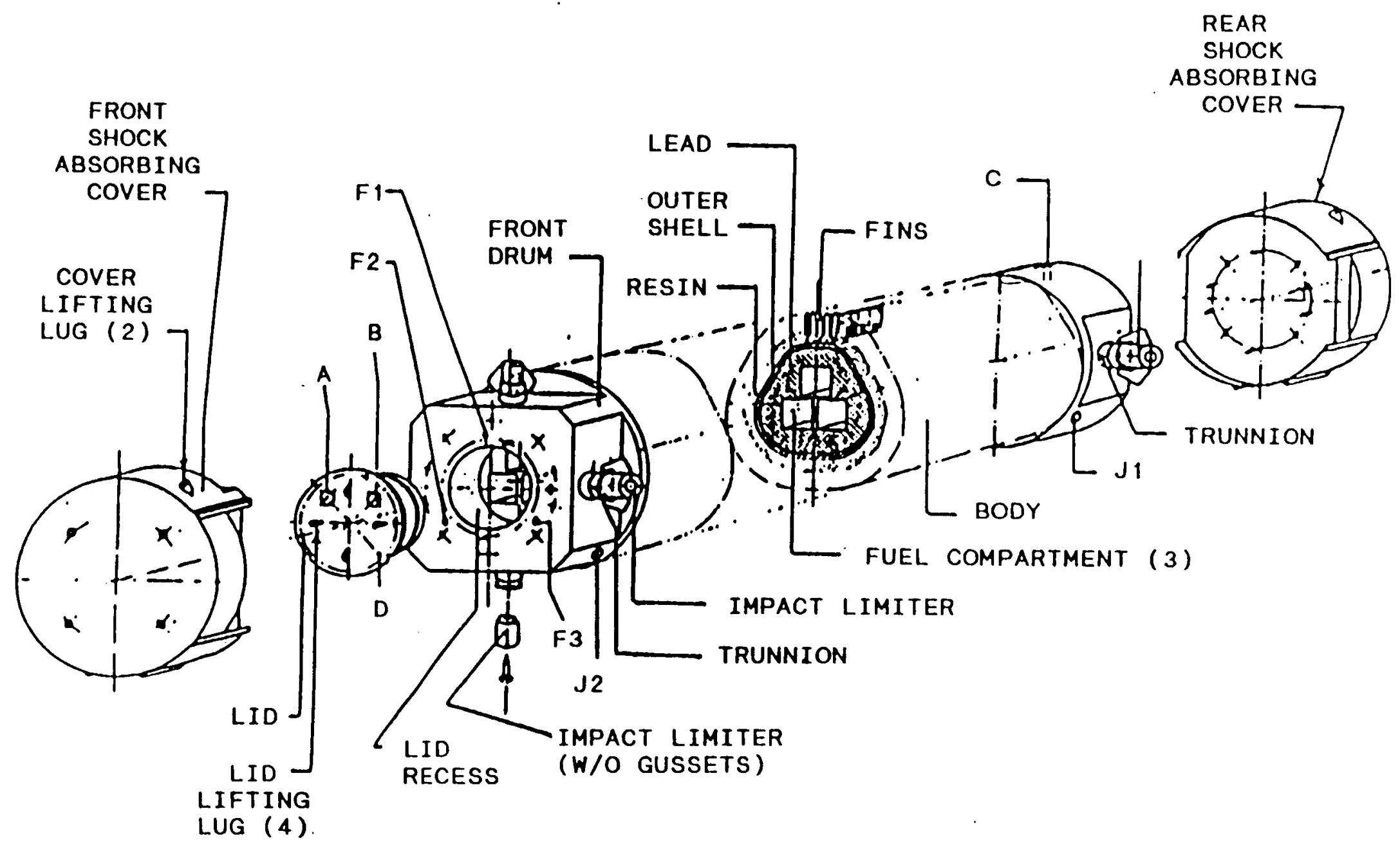


The following tests are performed at the Aiken facility:

1. Humidity Testing (see Part II, Section 1.3)

2. Fusible Plug Testing (Part II, Section 1.4)

3. Load Testing (Part II, Section 1.5)

4. Vacuum Gage Certification (for pressures $>1$ mbar)

It is expected that cavity leak testing will be able to be performed at Aiken in the near future. At the present time Transnuclear's license does not permit opening any penetration into the cask cavity. To allow the cask cavity to be opened, the regulatory agencies must be satisfied that airborne contamination will be adequately controlled. That is not expected to be a major problem for the Aiken facility. The technique for accomplishing the cavity test at the Aiken facility and the equipment required are discussed in Part II, Section 1.2. A new facility designed specifically for cask maintenance will include the appropriate equipment in the original design.

The equipment and services needed to perform all periodic tests are included in the discussion of the individual tests in Part II, Section 1. The equipment is mobile or, in some cases portable, so it is not a driving factor in the design of a maintenance facility.

Tests that can be done only when fuel is in the cask include Radiation Shielding, Packaging $k_{e f f}$, and Thermal Testing. These are discussed in Part II, Sections 1.6, 1.7 and 1.8 respectively. The tests are quite simple as they require only the reading of radiation levels and temperature measurements around the cask. However, any 
facility at which these tests are to be performed wiil have to be 1 icensed to possess irradiated fuel. Therefore, it is more practical to perform these tests in a fuel handing or fuel storage facility.

A floor plan of the Aiken facility is shown in Figure 2 . Note that no special area is designated for testing, as some test work is done out-of-doors when weather permits. It should also be noted that any tests performed on a cask at Aiken are done with the cask in the horizontal position (on a trailer) because no cask lifting equipment is available. The leak testing equipment is being designed for use with the cask in the horizontal position. As this has been shown to be practical, it would appear that this may be the preferred method for a small facility, rather than investing in the 40-ton crane required to upright the cask. Another feature of the equipment designed for leak testing is that it may also be used to exchange cask lids or to remove or attach the bottom lid plate.

If a periodic test is required during an active shipping campaign, Transnuclear's practice is to perform the tests at the cask user's facility. The same is true when maintenance and testing are needed on other anci1lary equipment such as the vacuum drying systems. Of colirse, if the cask is either loaded or unloaded at a site with a collocated maintenance facility, the tests would be performed at the maintenance facility. For ancillary equipment involved in a lengthy campaign, the maintenance and testing will usually be done at the user site. The exception might be for a piece of equipment that requires extensive periodic maintenance. In such an instance, an exchange of equipment would be arranged 
AIKEN FACILITY LAYOUT

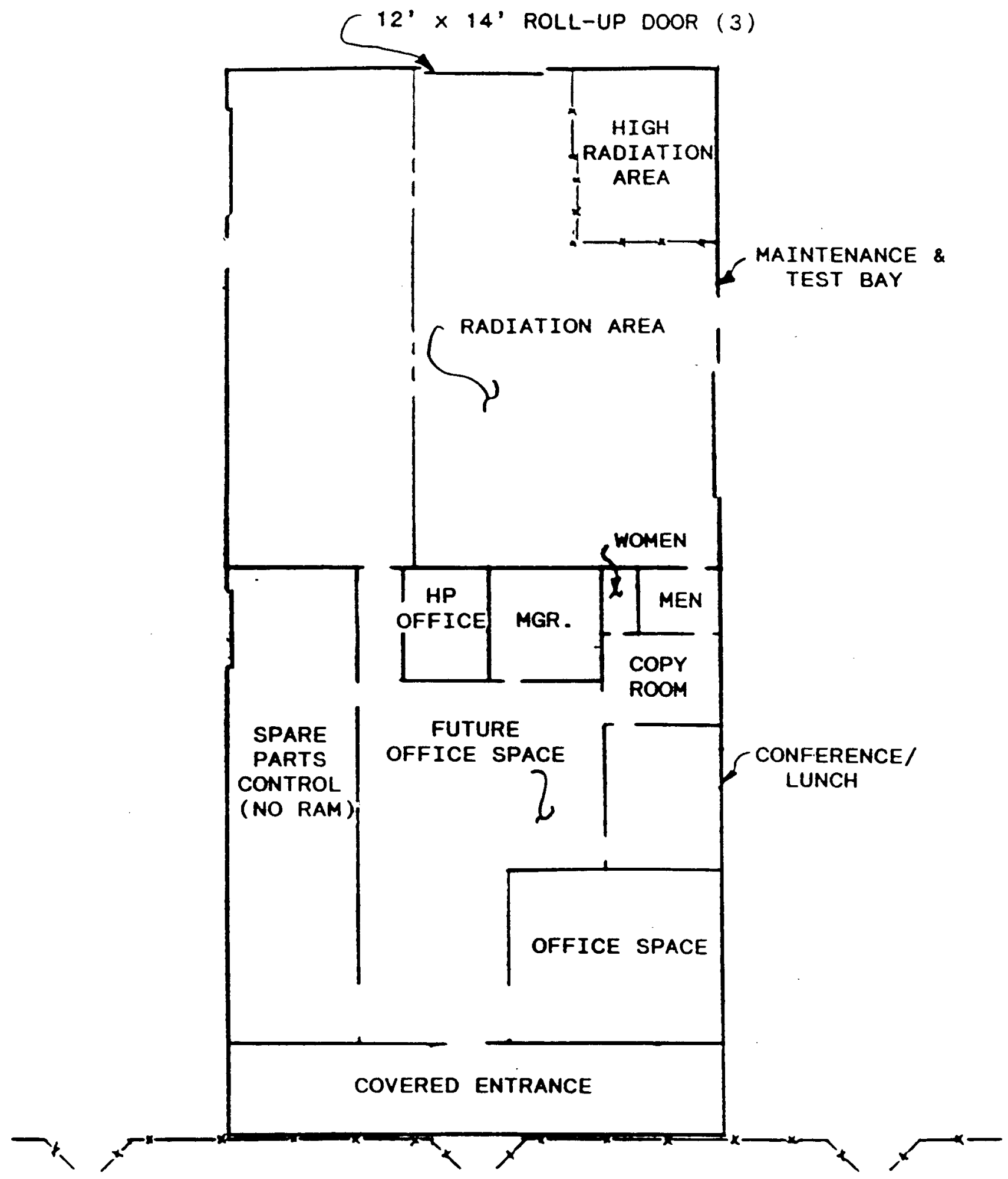

Figure 2

6 
and the maintenance of the equipment taken out of service would be performed at the maintenance facility.

Quality Assurance plays a critical role in the cask testing program. The equipment used in each test must be calibrated within a specified time period to standards traceable to the National Bureau of Standards (NBS). This necessitates an instrument certification program that meets the requirements of NQA-1, or 10 CFR 71 Subpart $H$. Records must be maintained on each test for each cask and on each measurement device, as well as on the qualifications of personnel conducting the tests. As an adjunct to Quality Assurance on cask testing, the replacement parts that may be used as a requisite or result of the testing must also be subject to the same degree of surveillance. Vendors shall be shown to be qualified to supply those components that are related to safety. The shelf life of components susceptible to deterioration through aging shall be documented and shall appear on the packaging of such components. Every spare part in storage that is important to safety must be traceable to its source through paperwork that verifies its acceptability. Testing must be documented in order to substantiate the certification of equipment that is supplied to the users of the equipment. In a small operation of the type conducted at Aiken, records are kept for over 120 items that require periodic recertification. This can be done satisfactorily only with a computer and a formal system for data acquisition and entry. Transnuclear uses R:Base system $V$ for this purpose; a relational data base software package sold by Microrim. 
c. What organization provides the annual and special maintenance?

A11 of the maintenance of Transnuclear-owned equipment is done by Transnuclear personnel, either performing or overseeing the work. If contracted personnel are to be used, such as for liquid penetrant inspection, they work under Transnuclear supervision using procedures that have been either prepared or approved by Transnuclear.

2. Describe the Transport Vehicle (Both Road and Rail) Usually Used

\section{a. Ownership/Operators}

The semi-trailers used for the Transnuclear casks, Figure 3, are identical in design for all four cask systems. Three of the transport vehicles are owned by Transnuclear; the fourth is owned by CECO. Arrangements are made with a commercial carrier to provide a tractor to pull the cask/trailer system. Only those carriers which have four-axle tractors equipped with communications and security equipment as required by the NRC can be used.

The carrier must also have adequately trained drivers and be prepared to meet its emergency response requirements as defined, for example, in ANSI N-14.27 "Carrier and Shipper Responsibilities and Emergency Response Procedures for Highway Transportation Accidents Involving Truckload Quantities of Radioactive Material". Transnuclear has found both Tri-state Motor Transit and MCGil Specialty Carriers to be qual ified as 


\section{TN-B/G TRANSPORT TRAILER}

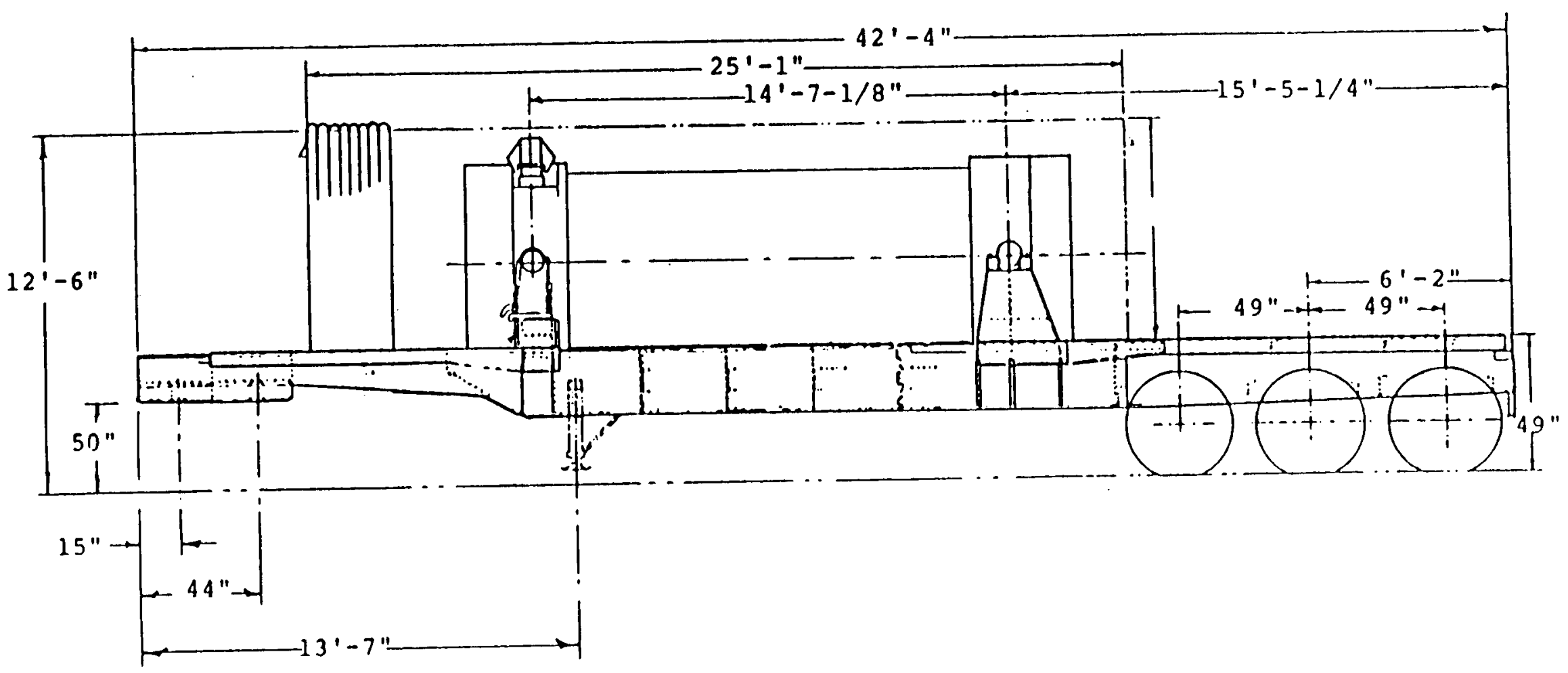

Figure 3 
carriers for spent fuel casks. Both have been used and their performance has been satisfactory.

The TN-8L and TN-9 casks are not routinely transported by rail. When it was necessary to arrange for the movement of three very large casks from the west coast to both the Buffalo, NY area and to Idaho Falls the casks were carried on dedicated shipping cradles on commercially available eight-axle drop center rail cars. The TN-8/9 series casks could be transported by rail using the transport frame on a fiat car, but to date there has been no need to exercise this option.

b. Experience with transporter maintenance

Repairs and maintenance on the semi-trailers are subcontracted to a shop in the vicinity of shipping and/or receiving sites. Inspections are conducted in accordance with a Transnuclear procedure or a procedure approved by Transnuclear. Any welding performed on the trailers must be done by a welder qualified to weld highstrength stee 1 , and in accordance with AWS D-8.8. A record is made of the type and location of each defect, sometimes supplemented with photographs. If a defect is found to be repetitive then the cause is reviewed and corrective action initiated. Modifications to the trailer structure have resulted from these reviews, e.g., the cutting away of the cosmetic welds where crossmembers were welded to the flange of the main support beams, leaving only the structural welds to the webbing intact. 
The Transnuclear systems consist of casks of nearly 40 tons carried on relatively lightweight trailers. This type of trailer is designed to tolerate the substantial twisting and bending which occurs during normal use. These stresses may result in cracks in non-critical members especially at or near welds of the cross-members to the main support beams. Such cracking has been found to be typical of lightweight, heavy-haul transporters. The frequency of the occurrence of defects is not predictable.

The primary load-bearing beams and supports have been essentially free of operations-caused defects. Routine inspection and repair of the trailers is necessary to maintain them in good operating condition. Transnuclear has contracted with a leading manufacturer of highway trailers, with maintenance facilities throughout the country, to inspect the Transnuclear trailers and to perform any necessary maintenance. This is done on a scheduled basis for repetitive shipments or on an asneeded basis for one-time shipments. A detailed chronological record of the inspections and repairs is kept for each of the four trailers. In Attachment II-1 there is an excerpt from one of these trailer maintenance logs. Based on Transnuclear's experience, properly designed and maintained lightweight trailers are acceptable for this application.

The reaction of government inspectors to the detection of a crack is usually rather critical, regardless of whether or not the crack is in an area important to safety or not. Trailers have been put out of service by government inspectors until cracks have been repaired. After one such incident where concern was expressed over 
a crack in the weld of a crossmember to the flange of the main support beam, the shop removed all such welds leaving a gap at those locations. The structure was then considered to be satisfactory.

The design features that contribute to the greatest maintenance problems are (1) the rigid tie-down of the cask to the center portion of the trailer which prevents that portion from absorbing any of the twisting action to which the trailer is subjected and (2) the strains introduced during sharp turns which cause the trailer tires to drag sideways on hard surfaces.

Maintenance of the tractors is the responsibility of the carrier. Transnuclear does not review the maintenance records of tractors because any of several tractors may be used at any given time. Transnuclear personnel have visited both the TSMT and the MCGil facilities on several occasions to observe shop practices and general maintenance.

c. Cask mounting and tie-down equipment

Semi-trailers for the Transnuclear casks are designed to carry only the TN-8L and TN-9 casks. Therefore, the tiedown equipment is built into the trailer frame. Two pylons are located toward the rear of the trailer, one on each of the main longitudinal "I" beams, as shown in Figure 4. - The cask lower trunnions rest on the semicircular top of the pylons and are restrained by a holddown bracket which is fastened to the pylon by two bolts. The cask components that are a part of the tiedown system are designed to resist forces of $10 \mathrm{~g}$ in the 

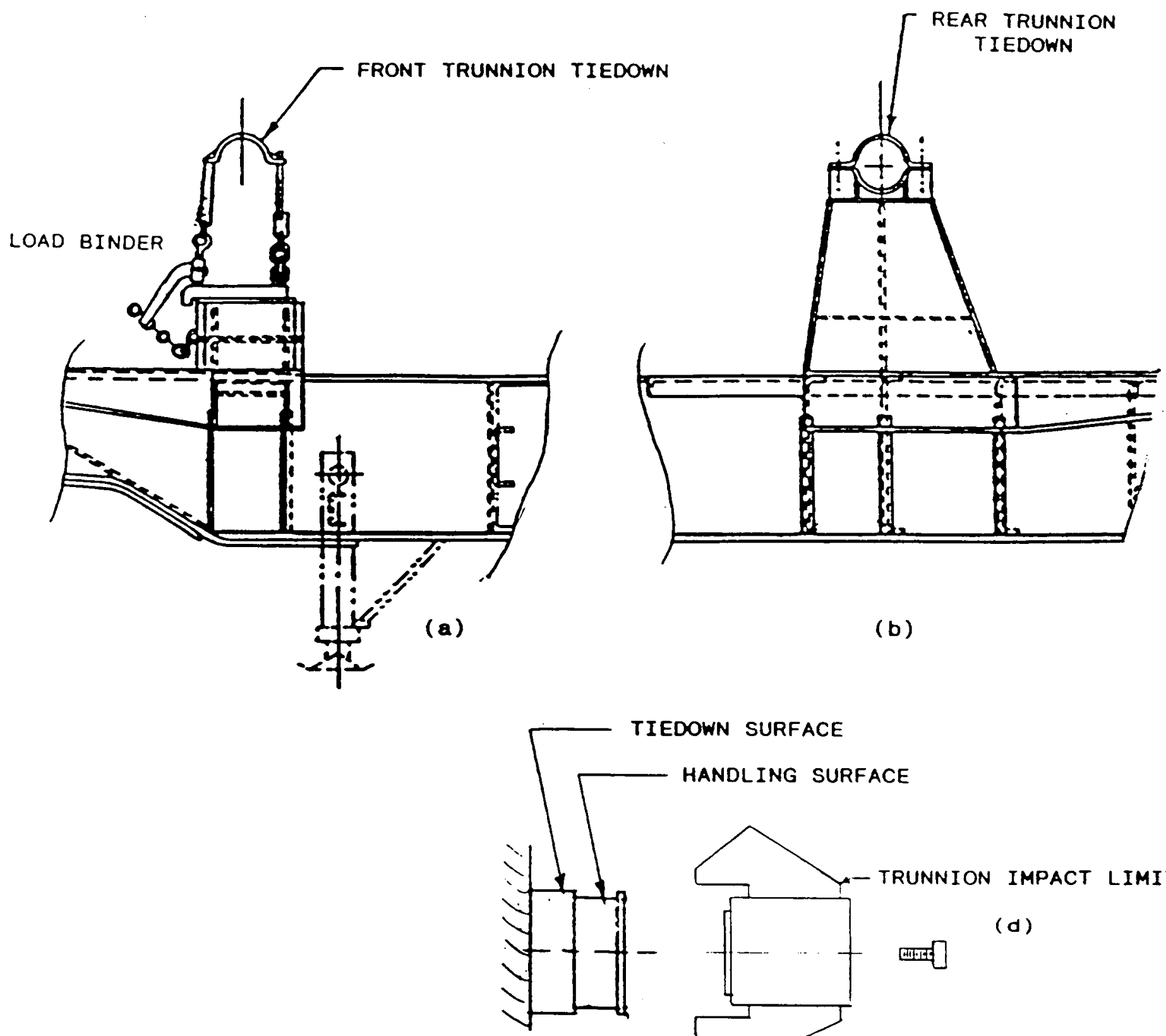

TRUNNION DETAIL

HANDLING SURFACE

(c)

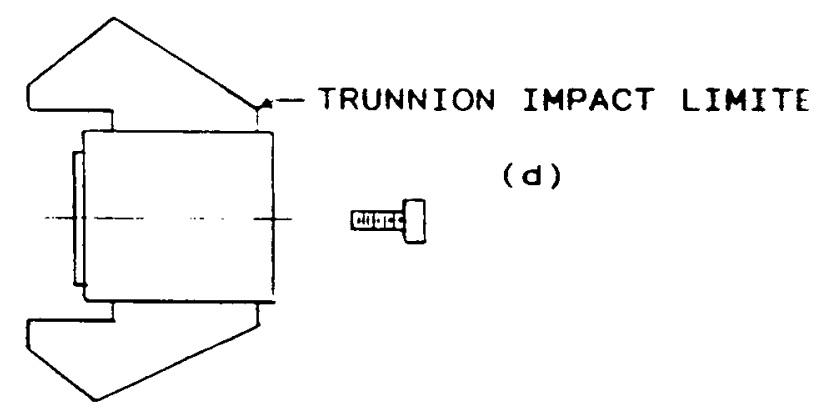

Figure 4 
longitudinal direction, $5 \mathrm{~g}$ in the transverse direction and $2 \mathrm{~g}$ in the vertical direction. These forces are greater than the trailer tie-down components can resist, so that if the cask leaves the trailer the initial damage will be to the trailer and not to the cask.

The front of the trailer includes a slightly elevated platform on which a flat side of the upper end of the cask rests. A tie-down device is used, Figure $4 a$, that fits over the inboard shoulder of the horizontal set of trunnions, Figure $4 \mathrm{C}$. This is a bracket, one end of which is secured by metal chain to the trailer frame while the other end has a combination of chain and "load binder". Manual actuation of the load binder restrains or releases the clamping action. The load binders are secured by safety chains.

The elevated platform that supports the front of the cask is covered with two layers of $1 / 4$ " plastic, sandwiched between two sheets of neoprene. This allows the necessary movement due to thermal expansion to take place between the cask and the support.

One of the four upper trunnions projects downward through the platform and is restrained laterally by a guide bracket with adjustable shim plates.

Although a new cask system design might feature a tiedown arrangement differing from that of the $\mathrm{TN}-8 / 9$, there are no plans to alter the present system.

d. Cask coverings

Each trailer includes a frame-supported, self-storing, roll-back tarpaulin which completely covers the cask 
during transport. See figure 5 for details. This system serves as a personnel barrier and protects the cask from rain and road dirt.

Vents are provided in the tarpaulin and in the trailer to assure air flow over the cask for heat removal, although heat removal by this means is not a requirement of the SAR.

The lower edge of the tarpaulin is equipped with "D" rings at one foot intervals. Beneath the sides of the trailer there are hooks with about the same spacing. Elastic straps, 15 " to 31 " long, with " $\mathrm{s}$ " hooks in each end are used to secure the tarpaulin to the trailer. occasionally, one of these straps will fail and must be replaced by the driver while on the road. Still, this system is considered superior to the single rubber rope originaliy supplied by the manufacturer. When that rope broke, the entire side of the tarpaulin could work loose and suffer wind whip damage.

The cover can be quickly and easily rolled back by two technicians without assistance from a crane or other lifting device.

This type of covering has proved to be exceptionally utilitarian and durable, particularly because of its light weight. It does a good job of protecting the cask from road dirt. An expected life in constant service is about 18 months.

e. Auxiliary equipment, tools, parts

Neither the transport vehicle nor the roll-back covering requires that any special tools accompany the shipment 
TRAILER TARP AND SUPPORT
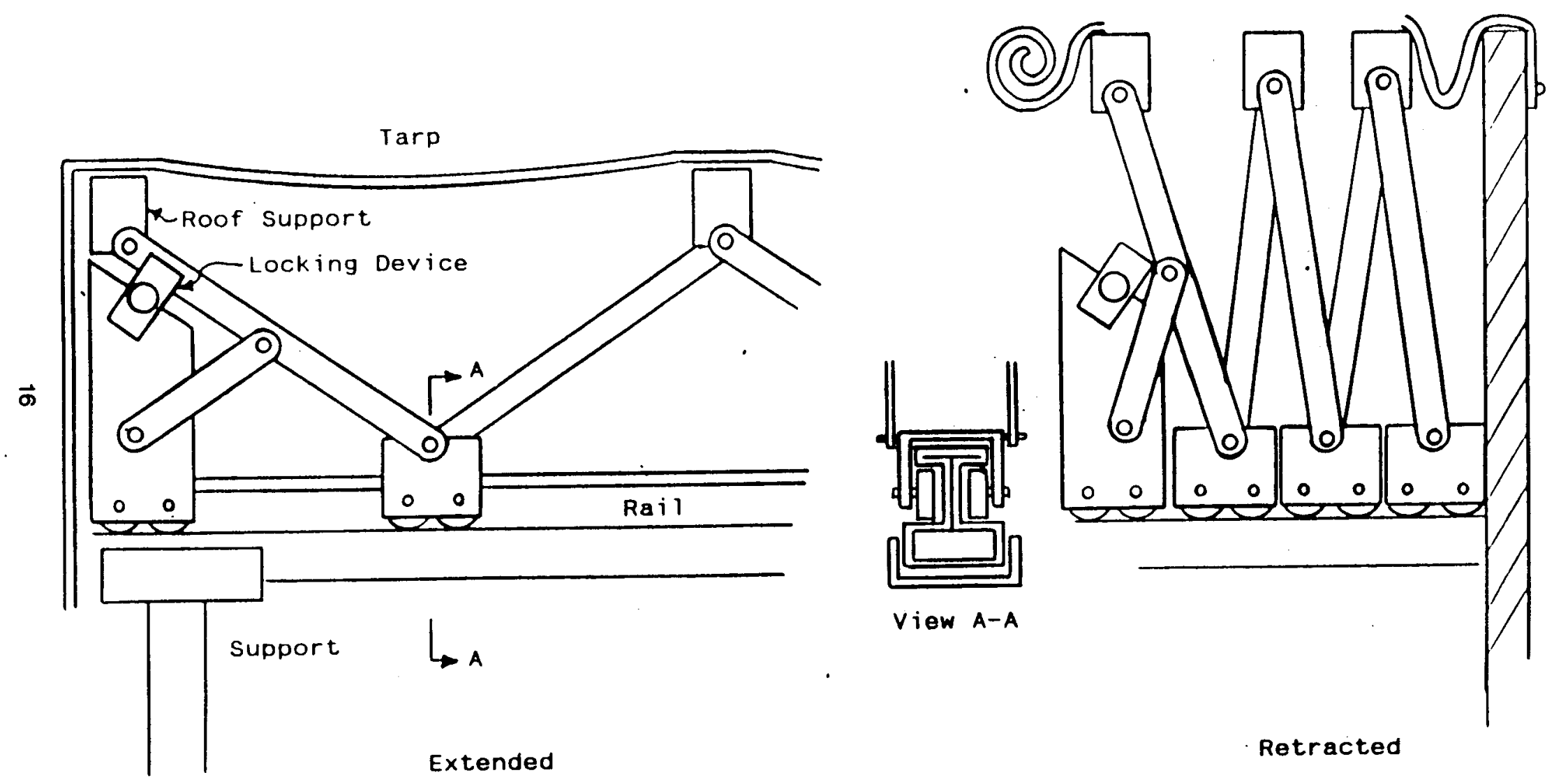

Figure 5 
or be available at the loading or unloading sites. The trailer uses a tire size that is readily available throughout the country. Spare tires and wheels and spare components for the roll-back cover system are on hand at the Aiken maintenance facility. These can be air-freighted to any part of the country in 24 hours. Transnuclear uses Michelin tires exclusively but recognizes that other makes of tire are of equal quality. Because of our experience, we have elected not to carry a spare tire or any other spare parts for the trailer, other than replacement tarpaulin straps. A tire that is kept properly inflated and balanced, on a wheel that is properly lubricated and with brakes in proper adjustment, should last for 80,000 miles. Transnuclear does not use tires that have been regrooved or recapped.

\section{f. Problems/recommendations}

While the technique for cask tie-down is most reliable, it introduces one effect that is not desirable. Because the tie-down is so secure, the section of the trailer between the front and rear tie-down locations cannot twist. Whenever the plane of the trailer axles deviates from the plane of the fifth wheel of the tractor, all of the twisting of the trailer must take place between the axles and the rear tie-down or between the king pin and the front tie-down. This imposes locally some higher stresses on secondary trailer members than if the trailer were free to twist uniformly along its entire length. One solution to this situation would be to use an oscillating fifth wheel on the tractor; one that could be locked into place for highway travel but unlocked for low-speed, off-highway use. Another would 
be to design some oscillation capability into the front tie-down. The rear tie-down should be left rigid to facilitate cask rotation on and off the trailer. The use of a lightweight cradle as an interface between the cask and the trailer has been successful on other cask systems. It is probable that such a cradie could be designed to absorb some of the twisting action without compromising the integrity of the tiedown system.

Tarpaulins will tear during transit if the straps securing the edges are not pulled very tightiy. The elastic straps which are used to secure the tarpaulins have been found to vary greatly in quality from various suppliers. One of the better sources is Erie Rubber Works, Erie, PA. Several spares should be carried by the driver because replacements procured enroute are sometimes of very poor quality.

Many of the problems that have been encountered can be eliminated by using new design concepts. New air ducting designs for closures will keep the cask almost dirt free during transport. Tie-down systems intended to enhance compatibility with robotic operation and ALARA will also tend to be more maintenance free. The details of these concepts are considered by Transnuclear to be proprietary information.

3. Describe the Transportation Process

a. Convoys, escorts

NRC regulations for physical protection of irradiated fuel in transit ( 10 CFR 73.37 ) require escorts for 
a11 shipments. If the vehicle is outside of an urban area the escort need not be armed and can ride in the transport vehicle. However, a transport vehicle within a heavily populated area must be escorted by one or more armed individuals in separate venicles in addition to the escort in the transport vehicle.

NRC defines a heavily populated area as the area within three miles of an urbanized area having a total population of 100,000 persons or more. The Bureau of Census from time to time publishes maps of urbanized areas. The NRC, in NUREG-0561, 1ists 178 urbanized areas in the 48 contiguous states. The shipper and the carrier have the responsibility to determine which roads are inside or outside of a heavily populated area.

Escorts for irradiated fuel shipments must have been trained as required by 10 CFR $73.37(b)(10)$ in order to understand the regulations and their implementation. As members of local law enforcement agencies are exempt from these training requirements, they are the preferred choice for escorts. Use of on-duty local police officers also provides efficient implementation of the emergency response in 10 CFR 73.37(b)(6). Transnuclear has also utilized off-duty police officers from the jurisdiction involved and other jurisdictions as well as private guards with the appropriate training and equipment.

If an on-duty police officer is utilized, only one escort vehicle is required provided it is a marked unit of the local force. Otherwise, front and rear escort venicles are required. 
Individual states may impose requirements in addition to those of the NRC. For example, on import shipments of spent fuel through the seaport of Portsmouth, VA, NRC rules require escorts only while in the heavily populated areas. The state of Virginia, however, requires that all shipments of spent fuel be escorted for the entire time it is within Virginia borders. Transnuclear uses off-duty Portsmouth police officers in two vehicles in the heavily populated area; one vehicle drops off at the boundary, the other continues to the state border.

If two or more casks are traveling in convoy, the escort services may be shared, but if one transport vehicle experiences a breakdown, the others will not be permitted to proceed without obtaining additional escort services.

Close attention must be paid to scheduling of escorts as a spent fuel shipment moves to its destination. The escort should be waiting at the boundary when the shipment arrives in order to prevent delays. However, it must be recognized that state and local police often feel they have more important assignments, so in the interest of maintaining good relationships, it may be necessary for the cargo vehicle to wait for the escort.

There is no consistency in the amount of charges paid for escorts or the basis on which they are levied. In many cases on-duty police officers are provided without charge; in other jurisdictions a flat fee is charged. Arrangements with private guards are usually made on a per mile charge. Some police organizations also use this system. Any generalized example is not meaningful. 
Transnuclear has never had a significant problem or delay in a shipment associated with availability and coordination of escorts.

The many different state and local regulations add to the paperwork, cost and preparation time for shipments. New regulations are frequently added by additional jurisdictions and existing regulations are sometimes amended by choice or overturned by court decisions. This hodgepodge of laws, regulations and requirements mandates a detailed check for each new route to assure that the shipments proceed smoothly.

During the summer of 1987 the Department of Transportation proposed modifications to the Highway Transportation Act. Some of the main points of the proposed legislation would require:

- Federal permits for carriers of extremeiy hazardous materials, including large shipments of radioactive waste and for highway route controlled quantities of radioactive materials.

- Prohibition of state and local governments against enacting legislation that conflicts with Federal rules.

- A more clear definition of state and Federal jurisdiction over hazardous materials, and a streamlining of the procedures needed to determine whether non-Federal regulations can or should be overruled. 
- States would be given a greater role in route selections, but DOT would be given the authority to determine which roads would be available to include in the selection process.

No action had been taken on enacting this legislation as of the end of 1987 .

b. Inspections (pre- and in-transit)

The frequency and intensity of inspections vary considerably from state to state.

The most severe inspections experienced by Transnuclear were those conducted by New York state on the spent fuel shipments from West Valley, New York. New York State required all overweight vehicles carrying Highway Route Controlled Quantities to be inspected prior to being used for shipments. An inspection program was established utilizing personnel from a local truck repair facility and inspectors from the New York Department of Transportation. The vehicles were inspected prior to every shipment and periodically subjected to deceleration tests of the braking system. The deceleration tests initialiy were performed every ten days but later were performed at 30-day intervals. These deceleration tests were performed with the empty cask on the trailer.

The State of Illinois is one of a few states that inspects shipments of spent nuclear fuel that are transported within the state. The procedure involves the coordinated effort of five separate state departments. Inspectors review the shipping papers (Bill of Lading), route plan, drivers' certificates of training, compliance of the packaging to contamination and 
radiation limits, labeling, placarding, physical security and tie-down integrity. The vehicle is given a safety inspection and the drivers' qualifications are verified. Reproductions of the reports that are completed by the inspectors are included as Attachment III. After the inspection, which takes place shortly after entry into the state, the vehicie is escorted to its destination in the state or to the point of exit from the state. A fee of $\$ 1,000$ is charged for each inspection. Transnuclear's performance as determined by these inspections has been favorable.

The pre-shipment inspections that are the responsibility of the shipper are a part of the shipper's site operating procedures. Although they may vary in wording, the intent is to assure full compliance with 49 CFR Subchapter $C$ and 10 CFR Part 71. Such procedures are quite detailed, even to the extent of verifying, for example, that the proper torque has been applied to each bolt of each closure. A copy of the Transnuclear TN-8L generic cask loading procedure, from which individual user sites prepare their site-specific procedure, is included as Attachment IV-1. Similar procedures are provided for all Transnuclear cask models, for both loading and unloading.

Inspections conducted by the carrier on hehalf of Transnuclear differ very little from those for ordinary shipments. It is the carrier's responsibility to verify that the tires are properly inflated, that all lights are in operating order, and that the tarpaulin remains secure. The driver does not have access to the cask or to tie-downs during transport. 
c. Dispatch operations (including procedures, checklists, permits, clearances, etc.)

For each of the spent fuel transport campaigns, Transnuclear assigns a lead traffic coordinator and a backup coordinator and requests that a counterpart and backup be assigned by the shipper to preclude misunderstandings. A project-specific list is prepared which defines the various parties to be notified on a routine basis as well as for emergency situations. These parties are listed by name and telephone number rather than generically by title or position. Each utility (shipper) has a different structure and the notification requirements may differ from one shipper to the next.

The Transnuclear lead traffic coordinator has responsibility for planning the campaign. This includes initial selection of the routes, determination of applicable federal, state and local regulations in all jurisdictions along the route, making arrangements for escorts, and coordination with the customer and carrier.

Interstate highways are given preference in selection of routes. The final selection is made jointly by the carrier and Transnuclear, with consultation with the NRC prior to the application for approval. The NRC route approval includes location of safe havens, definition of radio-telephone efficiency along the route and phone 
numbers for all local law enforcement agencies.

Although spent fuel routes are available to the public, the specific details in the route approval are Safeguards Information. After approval, detailed plans are made, including schedules for all operations. Projectspecific contingency plans for weather related or other delays are put into place.

Transnuclear makes notification to the state representatives as designated by the NRC. Overweight permits must be obtained for $T N-8 L$ and $T N-9$ shipments from each state through which the transporters are scheduled to pass. The permits are obtained by the carrier with input from Transnuclear.

When a shipment is underway, the driver is required to report to the carrier's dispatch center every two hours. Transnuclear is notified of the progress of the shipment and is informed of any unusual occurrences. Transnuclear keeps the receiving facility notified of the estimated time of arrival.

d. Accumulation of road/rail grime

The tarpaulin which completely covers the cask prevents the usual types of road dirt from accumulating on the cask. It also protects the cask from snow. The only times that any significant accumulation of road grime has occurred have been when the trajler has been driven over freshly tarred roads. Under these conditions, very small droplets of tar or heavy oil apparently become airborne and find their way up through the air ducts along the sides of the trailer and onto the cask. This 
happens infrequent $7 y$ and can be removed by spraying with a detergent solution. The quantity of road dirt or grime that might accumulate on a cask is very smal1; certainly less than one pound. The accumulation of ice and snow can be significant in terms of weight. Under certain conditions the accumulation can cause permissible axle loadings to be exceeded, since the cask system is operating near the load limits even in dry weather. State regulators do not waive overload conditions that are caused by ice accumulation.

Road ice and associated grime that may accumulate in cold weather can be removed by washdown or by parking the vehicle in a heated area until the ice melts. The melted material will not be radioactive but should be retained and monitored prior to discharge, with a record kept of the action and the result. A special washdown facility's primary function would be to retain and monitor the wash water. It would not require a truckwash type system nor would such a system be desirable. A 1 " hose with tap water at 100 lbs. pressure should wash away any ice or grime in 30 minutes or less; sufficient to permit the cask to be moved into the unloading bay.

e. In-transit problems (weather, equipment failure, human error)

During the winter transports from west valley to the Dresden Station near Morris, Illinois there were several occasions, perhaps one out of each ten shipments, when bad weather caused minor delays. These ordinarily were of the nature of delaying the start of a shipment until 
the weather cleared or improved. Such delays were a'. matter of hours rather than days and were caused by the condition of local roads between the shipping site and the access to the interstate highway. On one occasion, after bad weather was encountered near the destination, permission was obtained from Argonne National Laboratory to pull the loaded cask and trailer into the Argonne facility, remain overnight and complete the delivery to Dresden the following day. This was not a prearranged "safe haven" because it was not thought that one would be required so near the destination.

Because of the frequent inspections of trailers and tractors, equipment failures were rare. However, on the first shipment from west valley to Dresden, very close to the Indiana-Illinois border, the tractor separated from the trailer as the vehicle was starting up after having come to a stop. On this shipment a 3-axie tractor was being used in combination with an add-on set of axles (known in the trucking business as a "jeep" or "joe-dog") between the tractor and the trailer. Because of the presence of these add-on axles, the front of the trailer was supported independently of the tractor. Therefore, when the tractor separated, the front of the trailer did not fall and the trailer and add-on axles slowly rolled to a stop. The tractor backed up, reconnected and pulled the trailer to the side of the road. Following this incident, a fifth-wheel checklist was instituted for the remainder of the campaign and for the west valley to Oyster creek campaign.

After replacement of the fifth wheel, an examination of the old fifth wheel was conducted by a trailer manufacturer. The cause of the separation was determined 
to be improper locking of the fifth wheel which was probably caused by work performed on the fifth wheel by the owner-operator of the tractor. The cause was not substantiated but was advanced for lack of any other likely cause. All further repair work on the trailer or the tractor was performed by the truck repair facility during the routine inspections. This should not be interpreted that owner-operators' maintenance is generaliy inferior to that of fleet-owned vehicles; drivers who own their vehicles tend to maintain them exceptionally we11.

After the second Dresden shipment and for all the Oyster creek shipments, a four-axle tractor was used in place of the three-axle tractor and add-on axles. The switch was made not because of the failure but more because of maneuvering and handling problems with the add-on axle at Dresden. With the add-on set of axles in place the rig is very difficult to back up because there are pivot points at both the connection of the add-on set and also at the trailer connection. A large majority of the reactor sites require that the trailer be backed into the loading bay. The four axle tractor solves the backing problem but it introduces one of a different type. The loaded three-axle drive wheels of a four-axie tractor make the tractor less responsive to steering during very sharp turns, such as one might find while maneuvering at a reactor site. This is especially true if the driveway is covered with ice or loose gravel. The industry has recognized this disadvantage and has provided such tractors with the ability to use their air systems to raise one of the axle wheel sets off the road when it is desirable to do so. However, some state regulators will not approve of this concept on the 
grounds that the driver may raise the axle while on the highway in order to save wear on that set of tires. Truck owners contend that this argument is invalid because the total wear of eight tires running at a $50 \%$ overload is far more than twelve tires at normal loads. In any case, the steering of the four axle-tractors on the highway responds just as well as for a three-axie tractor, according to the drivers.

On another transport, the tractor engine failed and had to be replaced. The carrier provided a substitute tractor to return the empty cask to West valley and the repaired tractor rejoined the cask and trailer at west valley only a day later. The next shipment from west valley was not held up as a result of the breakdown. A correlation between tractor failures and total cask miles would be meaningless in light of only one failure.

f. Transportation damage to cask or contents

There has been no transportation damage to the cask or to any contents of the $T N-8 L$ or $T N-9$ spent fuel or waste shipments.

Greater than normal internal contamination was experienced during the last half of the West valley to oyster creek campaign. This was very old fuel (about 20 years of pool storage) and it resulted in a bright red crud that was highly radioactive and several flushings were required to remove it from the cask. Neither west valley nor Oyster creek personnel reported any data that would characterize this material as to content or source. 
g. Problems/recommendations

Because the transport process involves many people from at least two locations and at least three organizations who may be several thousand miles apart, experience has shown that advanced planning and coordination would be at the head of a 1 ist of recommendations. Transnuclear always conducts site surveys well in advance of any shipping campaign, to identify any special needs that must be met to assure successful cask handling at the sites. We then oversee dry runs using the cask to verify that operating personnel are adequately trained in the use of the cask and the anciliary equipment. This will uncover nearly all problems except those peculiar to regulatory agencies in states through which the shipment will be carried. A competent carrier will be well aware of regulatory restrictions.

It is almost impossible to plan in detail for all possible incidents but if general procedures are worked out in advance for who gets notified under which instances, a lot of anxiety can be eliminated. It very often appears that in the earliest stages of an incident it is not necessarily the details of the breakdown, accident, etc. Which are important, but rather that the people with some responsibility for the project are notified in a timely fashion of the general aspects of the incident. Lack of established communication channels causes more problems than any other single item. ANSI N14.27 can be referenced as a standard for communications channels to be established prior to the beginning of a shipping campaign. Time spent prior to major campaigns for planning the details for shipping, in-transit procedures and receiving is time well spent 
and will be greatly appreciated not only during evolution of an incident but also during the routine transports.

The public relations aspects of a spent fuel shipping campaign cannot be ignored. Transnuclear's experience with utilities has been that the utilities are quite adamant in their insistence that they handle this aspect of the shipments. This attitude probably would be reversed if DOE took possession of the spent fuel before it left the utility site. Transnuclear agrees that it is most desirable to have only one spokesperson in the event of a need to disseminate information to the public or the media. It is vital, however, that specific contacts be established in the support groups for the exchange of information with the spokesperson. For other occasions, speakers and descriptive material can be supplied to support the utility's position whenever requested. Transnuclear personnel have been summoned to testify as expert witnesses in cases where nuclear transport operations have been challenged, and they have contributed to the rendering of decisions favorable to the operations.

The primary communications problem experienced on the road is that radio-telephone contact is not possible in all areas, especially in the western states. Satellite communication capability should solve this problem.

Interfacing with carriers has not been a problem. The two with whom we work use excellent equipment and well trained drivers. They volunteer suggestions for alternative transport systems. The most recent example of this is the trailer system shown in Figure 6 . This 
LONG BRIDGE TRAILER

(Trait Star Mfg. Co.)

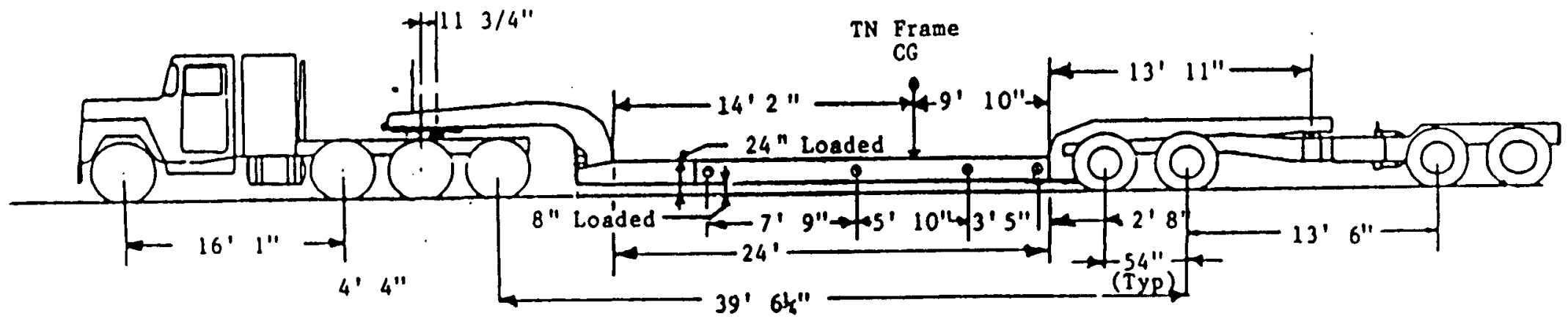

MOOEL TSIOOMG TRAILEP

CaDacity 100, O00 ides. in $10 \mathrm{ft}$ Shown with:

$24^{\prime}$ "Long $x \varepsilon^{\prime}-6$ " wioe Bec

12'-7" Mechanical Goosenech

Air Rice Suspension

Raising and Lowering $k$ it

Detachable Rear

California style $2+2$ Booster

$255 / 70$ F $22.514 P R$ Radials 
particular type of trailer has been tentatively approved by Virginia for the $T N-8 L$ and $T N-9$ casks and is probably acceptable in the majority of the states. Minor modifications might be required to make it universally usable. Transnuclear will be following up with the carrier and with the trailer manufacturer to evaluate the options of using our shipping frame on the trailer as it is now available, or procuring a new shipping frame that will replace a section of the trailer deck. The latter should result in a weight saving.

Inasmuch as Transnuclear's transport equipment was designed specifically for TN casks, we have experienced very little in the way of interface problems. Although the $T N-8 L$ and the $T N-9$ are of different overall lengths, the trunnion spacing is identical for both models so any of the casks may be used on any of the trajlers. The one thing that we would change concerns the bearing surface of the rear pylons. The surface on which the rear trunnions rotate is of formed metal. It would be easier to preclude galling of the trunnion surface if it rotated against a smoother, machined surface.

NRC interface problems are minimal once one accepts the inherent time delays in responses from that agency to routine inquiries. When responses of an urgent nature have been requested, Transnuclear has found that NRC will respond ascordingly, but with no relaxation whatever regarding regulations that have a part in the request.

State and local interface problems are of a more unpredictable nature. Localities can pass laws that impede transports through a given area even though a 
court test of such laws invariably rules against them. Such laws will stand until they are challenged and it is difficult sometimes to learn of their existence. State laws of a similar nature are more rare but these are better publicized.

The problems encountered with commercial repair facilities for trailers have been those of scheduling. These shops will naturally take care of high volume customers preferentially over one-time jobs and this has resulted in the late return of a trailer in at least two instances. A cask fleet maintenance facility would eliminate what little problem there has been in this area.

On-the-road operational problems have been very rare. Transnuclear has no recommendations for this aspect.

\section{Preparation for Lifting}

a. Transport packaging removal

In preparation for removing the packaging from the trailer, straps along the rear vertical edges of the tarpaulin are released, the rear flap is rolled up and secured at roof level. The several, elastic tie-down straps that secure the lower edges of the tarpaulin to the sides of the trailer are removed. The tarpaul in is then pulled forward by two people, one on either side, and secured in the front position. A special frame with roof sections which ride on roller bearings on removable side rails permits this step to be accomplished quickly and easily. Positive, quick release 
locks hold the covering in either the fully extended or fully retracted position. Some details of the sliding tarpaulin are shown in Figure 5.

Shock absorbing covers are removed from both ends of the cask by attaching a crane and sling to lugs on each cover (Figure 7 ) and removing the four bolts which secure each cover to the cask. Transnuclear has found it expedient to include a manually operated chain hoist between the crane and the shock absorbing cover to provide the operator with a better feel for necessary elevation changes to permit the cover to slide easily away from the cask. This also is a safety measure. A crane operator does not have the feel to senso overloads caused by minute movements, but the manually operated lift cannot exert sufficient force to damage a lug. Two people usually work together to remove each of these shock absorbing covers; however, the removal may be accomplished by one person in about the same amount of time if the crane can be operated by a pendant or radio control.

Each trunnion impact limiter (Figure $4 d$ ) is held in place by one bolt. One person can remove an impact limiter in about one minute. There are six such limiters; one on each trunnion.

The front tie-down ( $F$ igure $4 a$ ) is released by removing a load binder from each front trunnion. Each rear tiedown (Figure $4 b$ ) is released by removing two bolts that hold a bracket in place over the cask rear trunnion as it rests on the support pylon. 
CASK OFFLOADING

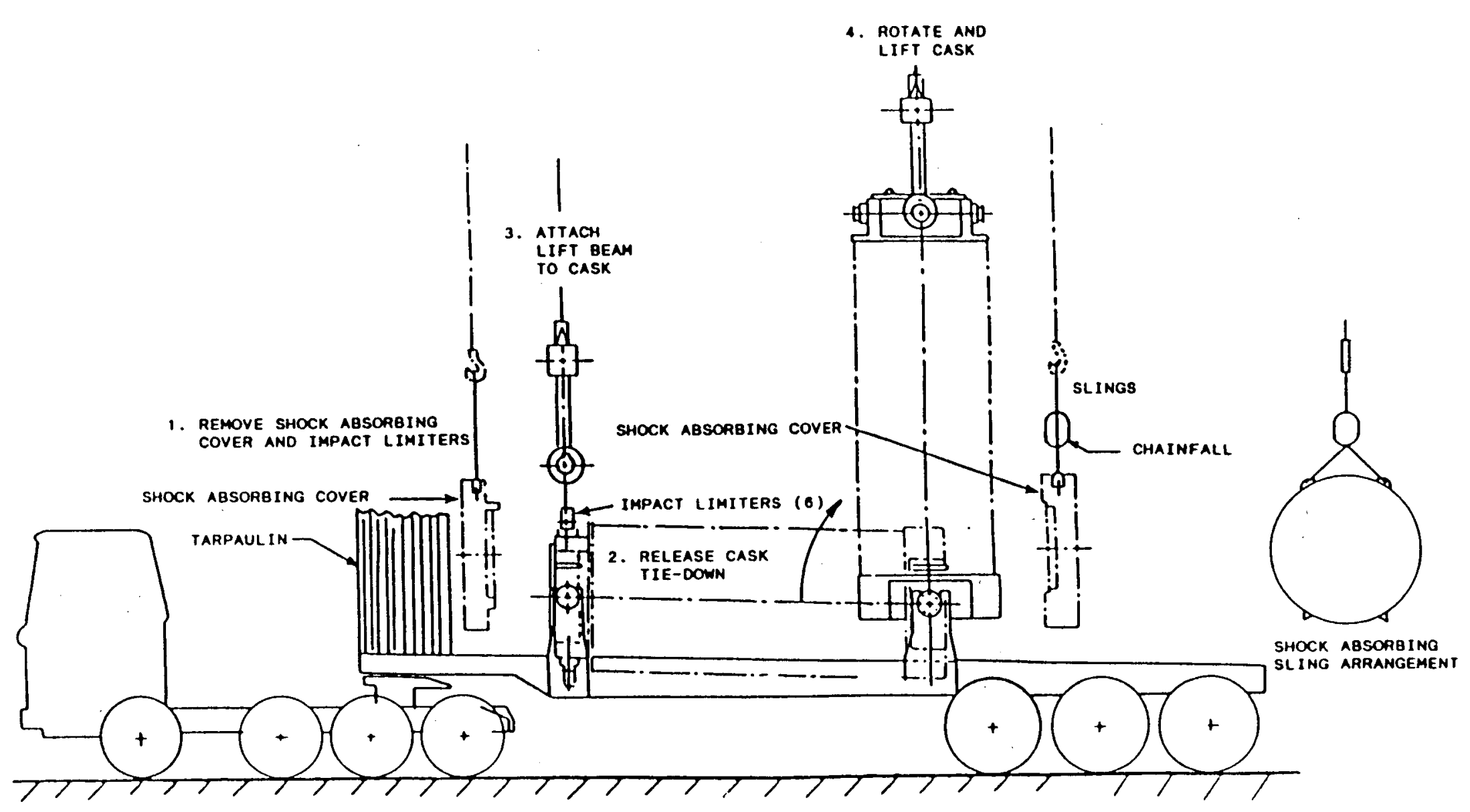


The cask is now ready for removal from the trailer. A pneumatically powered remotely activated 1 ifting beam, Figures $8 a, 8 b$ and $8 c$, is lowered onto the front trunnions. The beam aligns itself on the inner shoulders of the trunnions such that the lifting arms will engage the outer shoulders when the air controls are activated. A combined vertical and horizontal crane motion rotates the cask to the vertical position from which it is lifted from the trailer. The operation of the lifting beam is described in the generic operating procedure, Attachment IV-1.

b. Storage requirements for auxiliary equipment

The shock absorbing covers will stand alone without support and may be stored on the trailer deck if the trailer is not to be moved. They can also be stored on the floor alongside the trailer. If stored outside, they should be protected by a tarpaulin. The trunnion impact iimiters occupy very little space and may be stored on the trailer deck or any other convenient location. The lifting beam usualiy remains attached to the main crane throughout the cask handling operation; however, a stand is provided for storage. Lifting beams are sometimes used in pairs for redundant mode lifting, as shown in Figure 9 , so some of the stands are desigred to support a pair of such beams (Figure 10). These stands will require an area of about five feet by six feet. Newer shipping containers are in the process of being designed such that the lower half of the metal container will function as the beam support stand. Layouts of typical truck bays are shown in Figure 11 , with storage space requirements for each item of 
PRIMARY LIFT BEAM ASSEMBLY
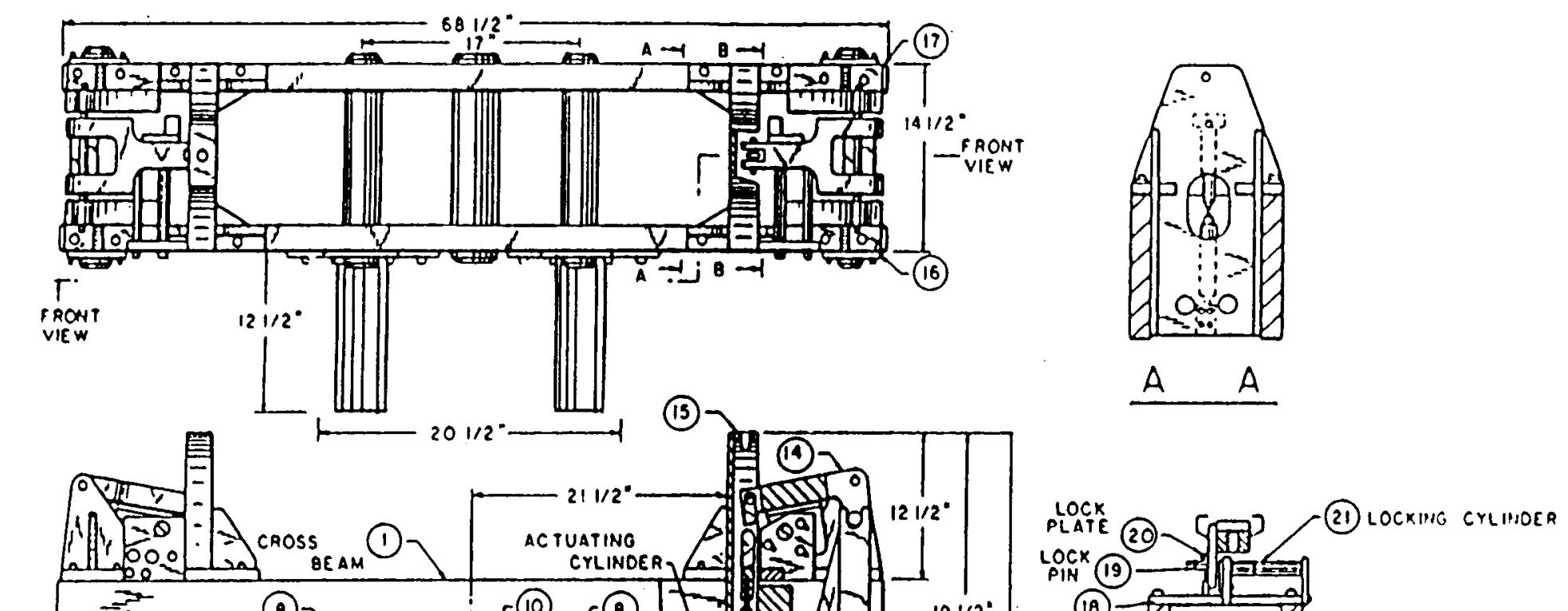

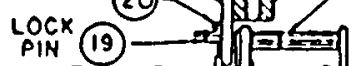

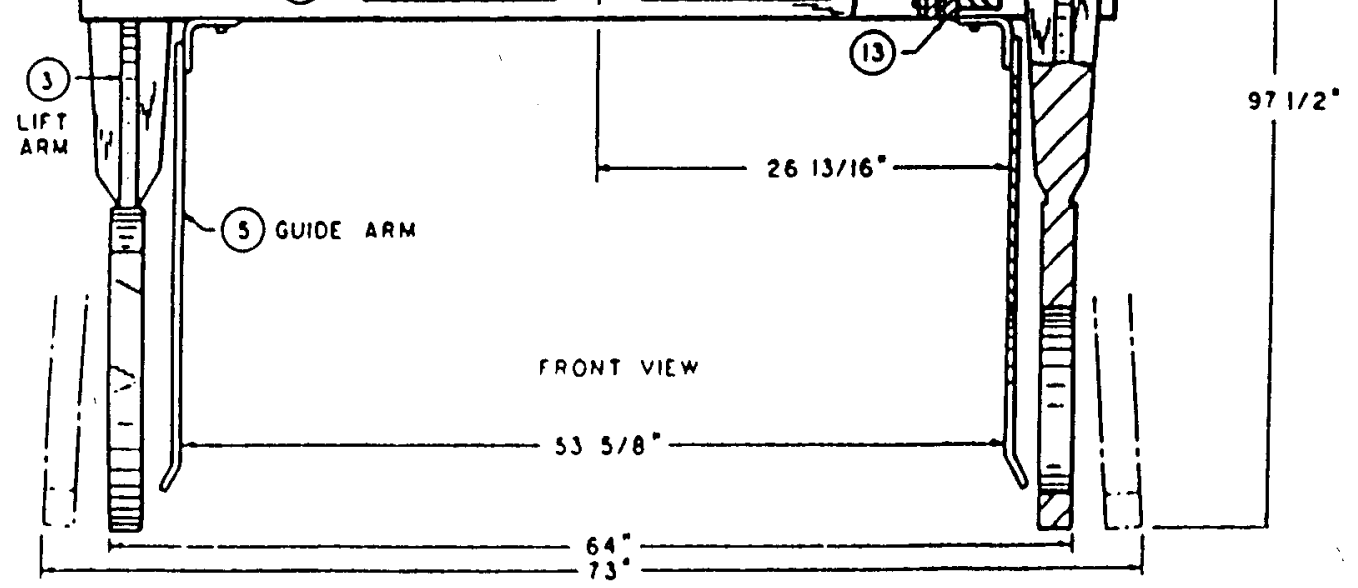


SECONDARY LIFT BEAM ASSEMBLY
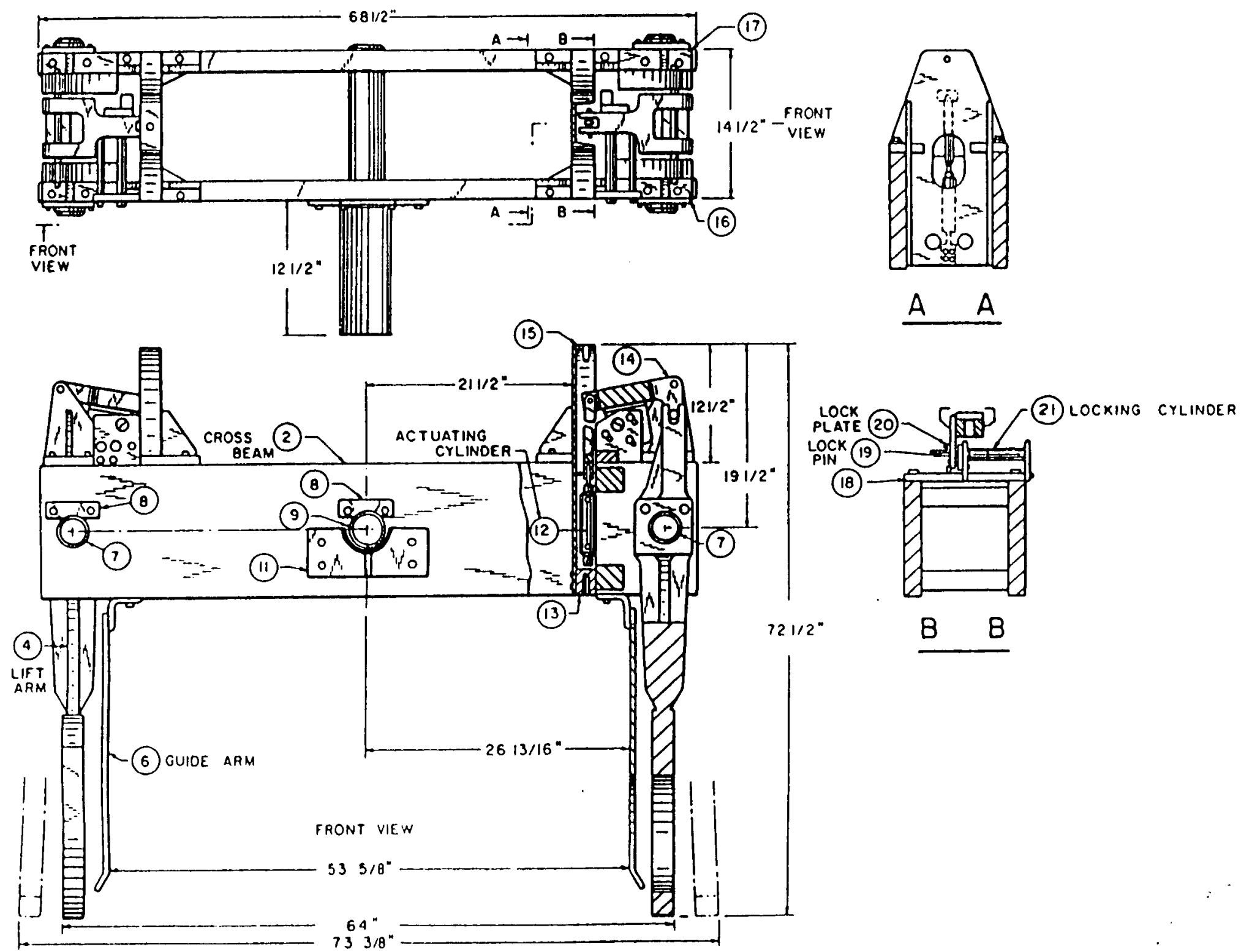

Figure $8 b$ 
LIFT BEAM PNEUMATIC CONTROL SYSTEM

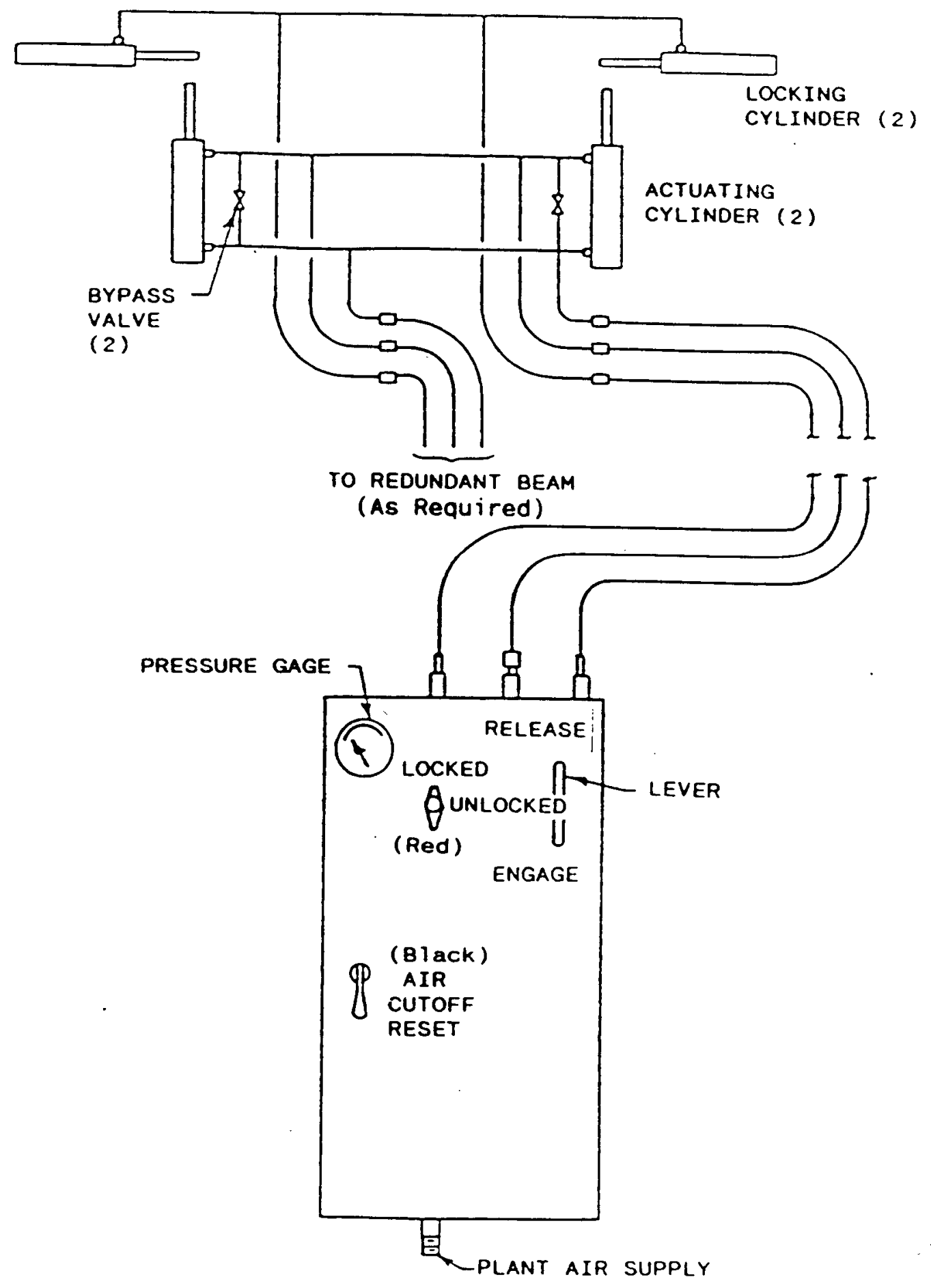

Figure $8 c$ 


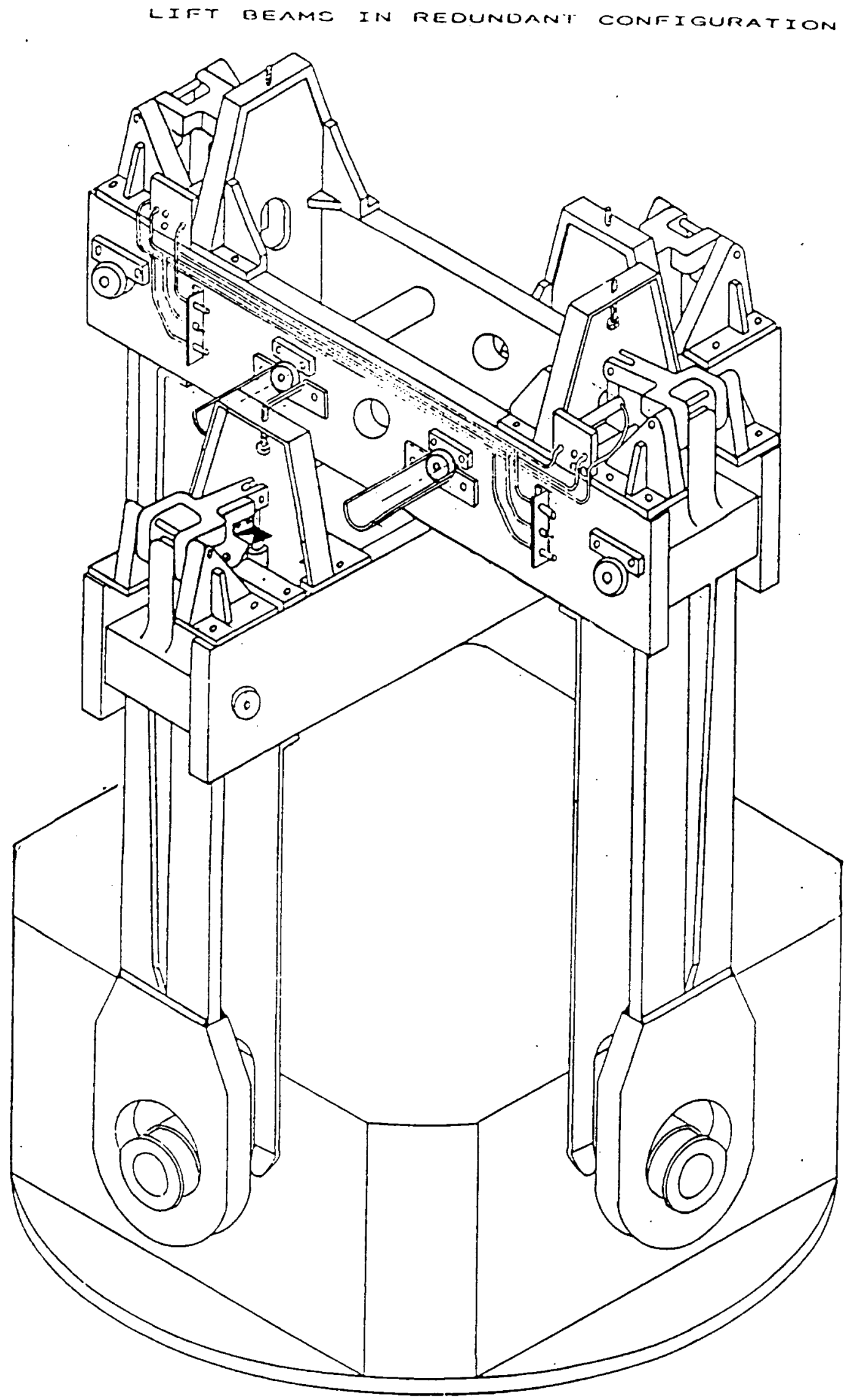




\section{LIFT BEAMS AND SUPPORT STAND}
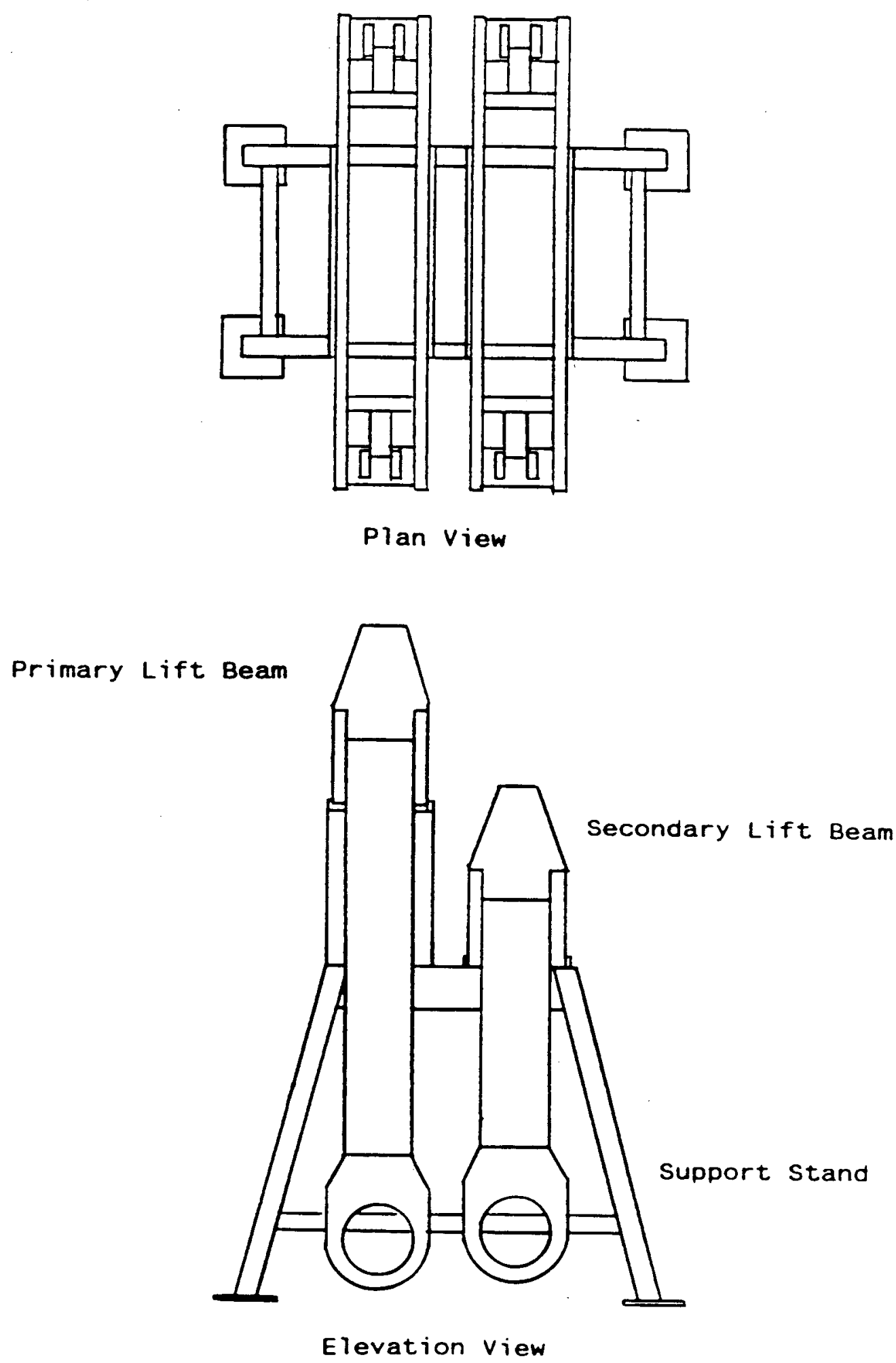

Figure 10 
TYPICAL VEHICLE BAY LAYOUT

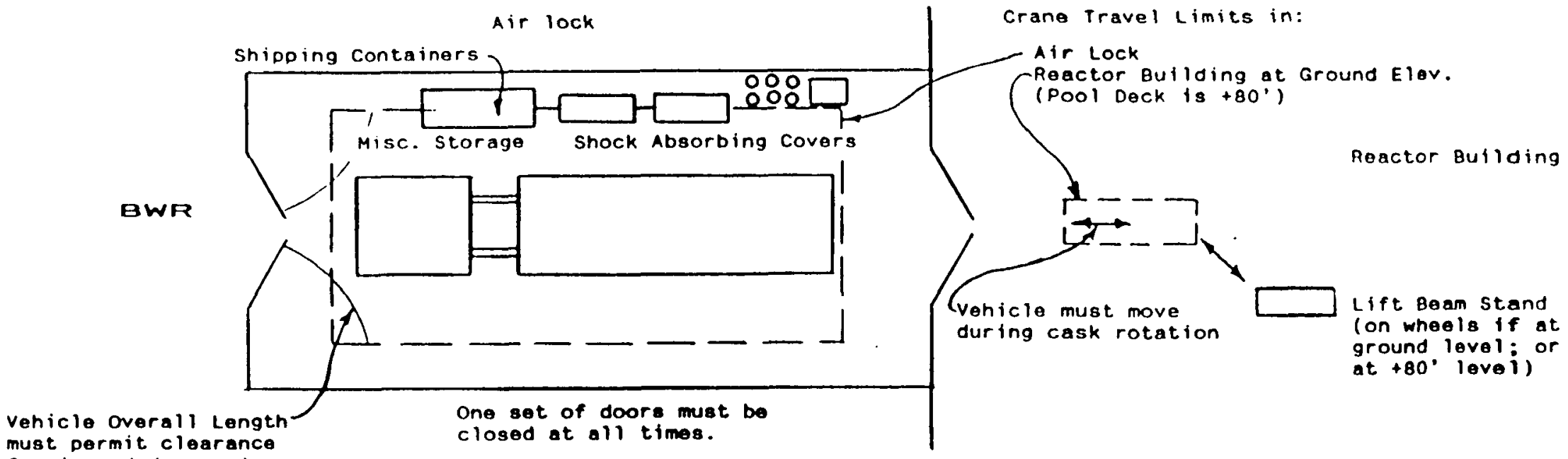

must permit clearance

closed at all times.

for inward door swing.

PWR

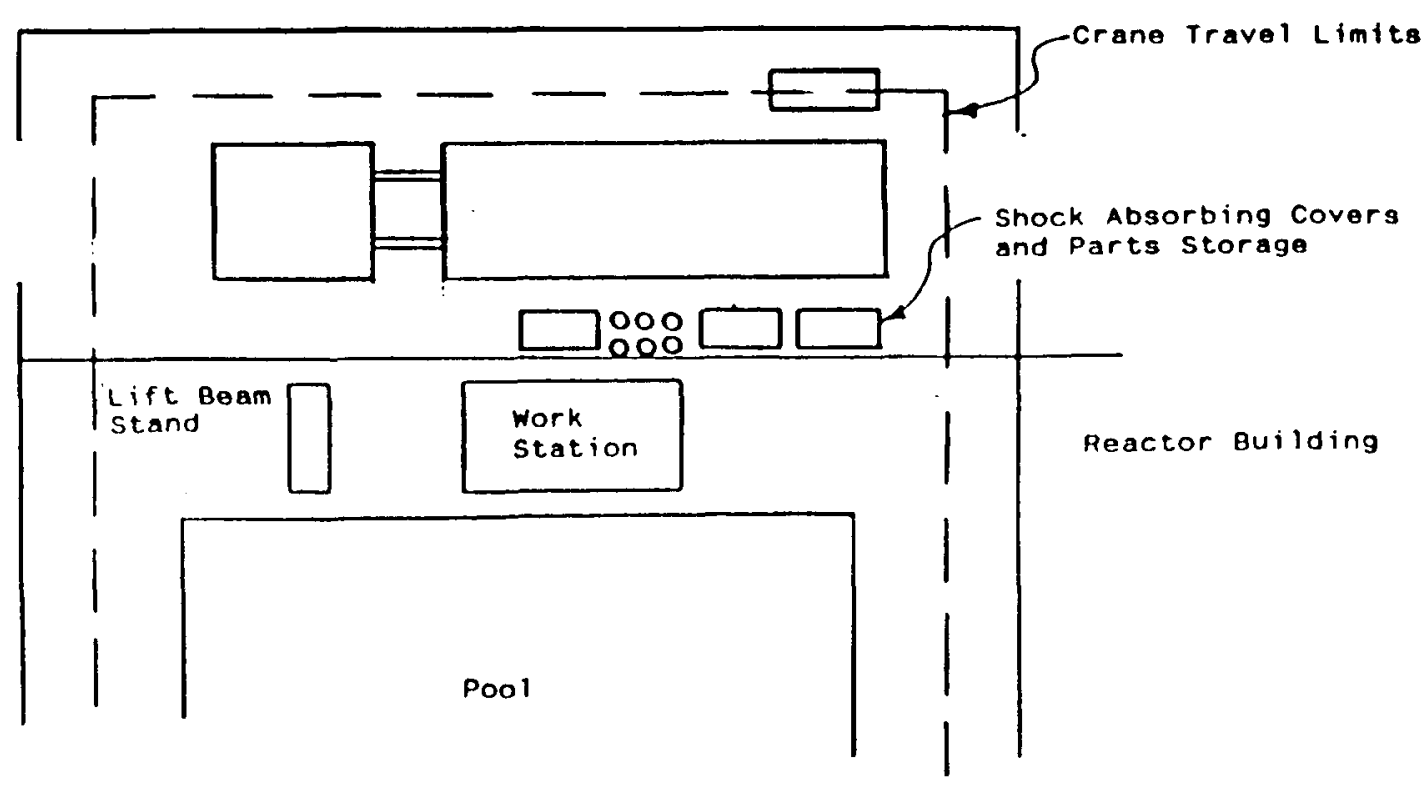


ancillary equipment. Note how the constraints on crane travel affect the utilization of storage space.

c. Operating times

Operating times will vary from one hour to one shift for the performance of the operations to prepare a cask for lifting, and the elapsed time is not necessarily a function of crew size. Operating times for each step along with personnel requirements, etc. are presented in Attachment IV-2. Variations in operating times are also given in Attachment IV-2, along with some of the causes that have been experienced. The time variances shown therein do not assume that any of the variance is a part of a learning curve. If, for example, the auxiliary hook from the main crane can be used for handing the shock absorbing covers the operation will go much more quickly than if a mobile crane is used. A reasonable range of time for this task is about one-half to two hours. Time differences that are attributable to the manner in which personnel are assigned are discussed in section $6 . d$.

d. Special equipment and tools

The lifting beam is the only item that is designated as special equipment during this phase of the operation. Lifting beams are designed, tested and operated in accordance with ANSI N-14.6. The chain hoist is an offthe-shelf item and the wire rope slings can be assembled and load tested (with certifications) by any competent shop. All wrenches, sockets, etc. are commercially 
available. A complete list of all required tools and equipment is supplied by Transnuclear. As a rule, Transnuclear supplies all special tools, Table IV-3, and. spare parts, Table IV-4, while the customer supplies ali of the off-the-sheif tools, Table IV-5.

e. Grime removal experience

Grime removal is required very infrequently. Only after some unusual incident, such as traveling over a freshly tarred road, will grime removal be required. This can be accomplished by spraying the cask in the work station. If there is an accumulation of ice and road dirt on the trailer, it can be washed off before moving the trailer into the cask handling bay. Cask and trailer wash water should be directed to a radwaste system or to a holding basin where it may be retained until measurements have obtained for a decision as to disposition. An essentially dust-free cask surface is the norm.

f. Damage experience

Damage to the Transnuclear casks has been very limited. There have been instances of galling of the trunnion surfaces as the cask is rotated onto or off of the trailer, and there has been some minor bending of fins. Galling may take place between the lifting arms and the front trunnions or between the trailer tie-down sockets and the rear trunnions. Galling is attributable to insufficient quantities of lubricant on the bearing surfaces, or to the use of other than Never-Seez $(R)$ as 
a lubricant. Nuclear grade Never-Seez is a lubricant consisting of molybdenum disulfide with colloidal nickel in suspension, resulting in superior anti-galling characteristics. Galled surfaces are dressed in the field using a new, clean, fine-toothed, flat file. Only upset metal that extends beyond the original surface is removed. No effort is made to blend out depressions or gouges.

g. Radiological experience

Radiological doses to operators during this phase of the operation are minimal with an empty cask. Dose rate maps of empty and loaded Transnuclear casks are shown in Figures 12 and 13. These dose rates are for fuel that has been out of the reactor for ten or more years and it must be remembered that these casks were designed for fuel cooled for only 150 days. Estimated dose rates of newer generation casks which have been designed specifically for 10-year-cooled fuel will be substantially greater; probably near the limit permitted by 10 CFR 71 .

h. Auxiliary equipment/maintenance

The lifting beams are the only items of auxiliary equipment used during this part of the operation; their maintenance requirements are minimal. Cask lifting devices are tested in accordance with ANSI N-14.6. This can be physical load testing, as described in Part II, section 1.5 or it may be by dye penetrant testing. ANSI N-14.6 stipulates annual testing with a two month leeway. Visual inspections are performed each time a piece 
LOADED CASK CONTACT DOSE RATES Beta-Gámma and Neutron (mR/hr)
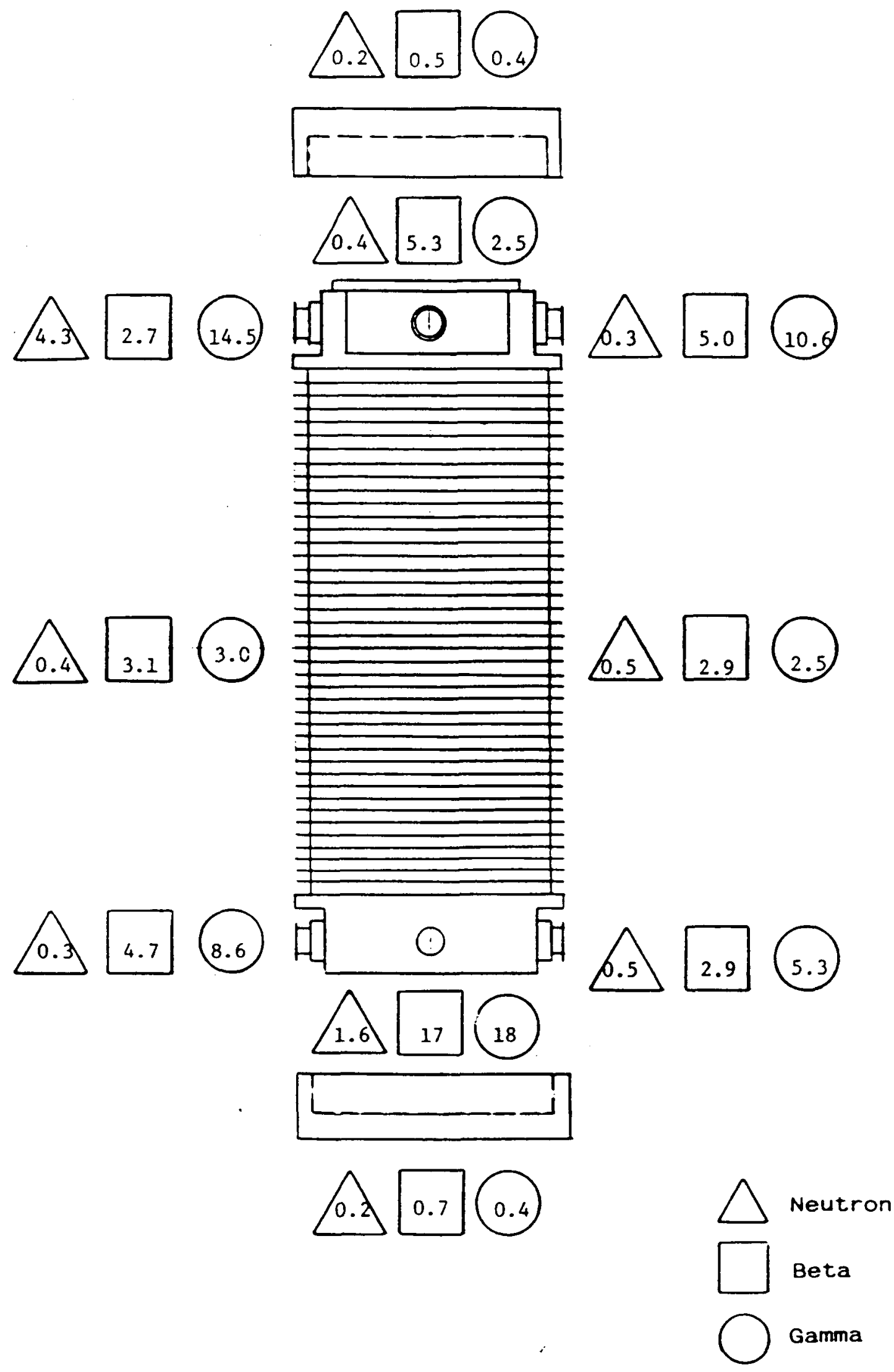
LOADED CASK CONTACT DOSE RATES Beta-Gamma and Neutron (mR/hr)
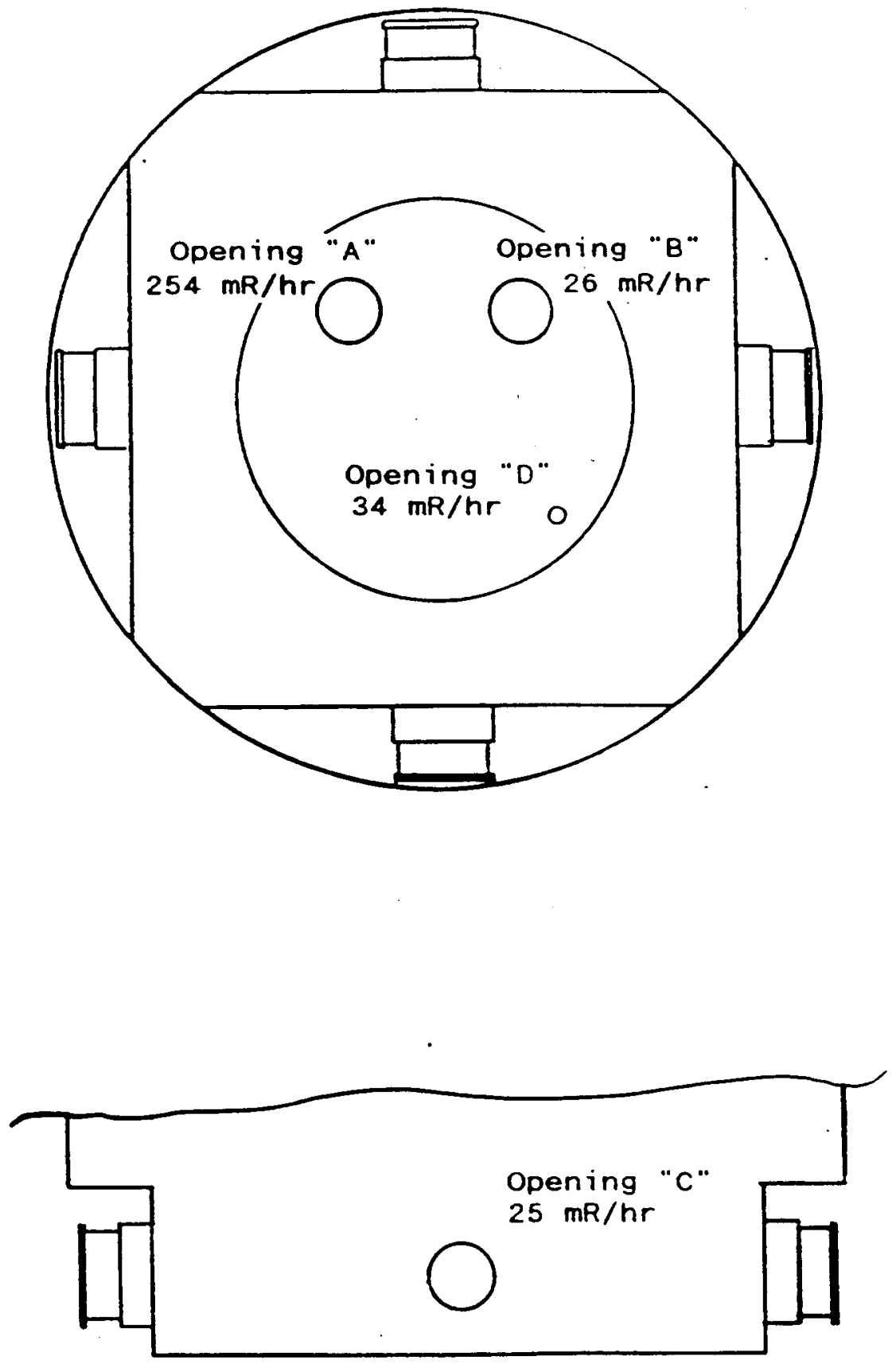

Figure $12 a$ 
EMPTY CASK CONTACT DOSE RATES Beta-Gamma and Neutron (mR/hr) (covers Removed)

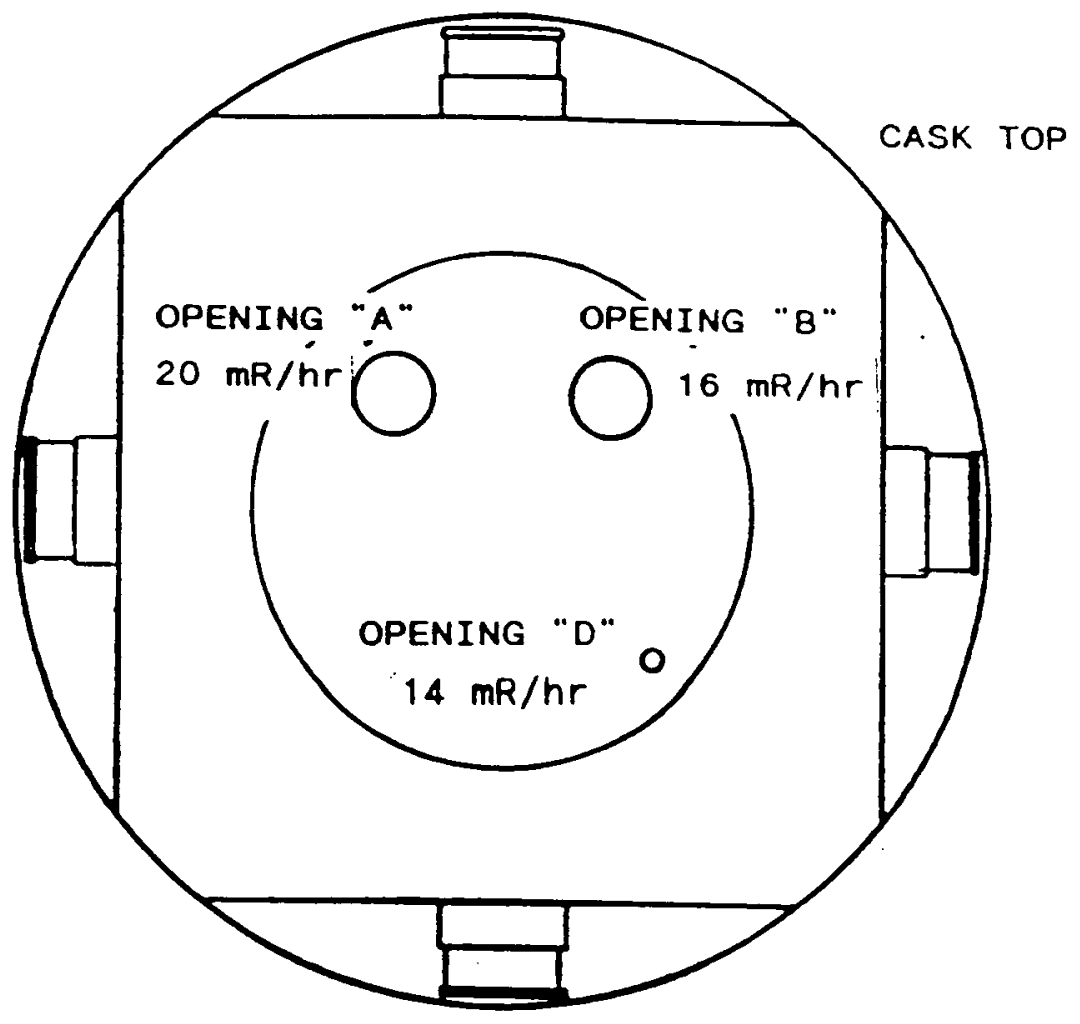

CASK BOTTOM

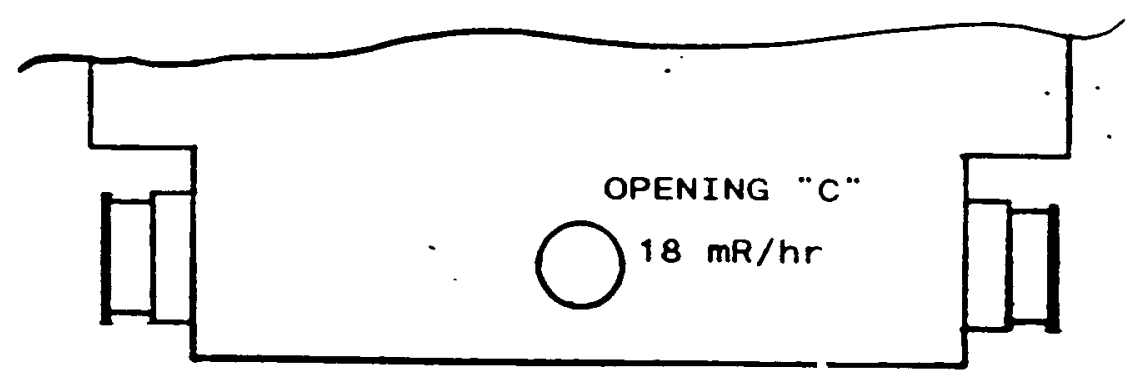

Figure 13 
of equipment is sent from or received at the Aiken facility. During long campaigns, Transnuclear personnel visit the user site and inspect the Transnuclear-owned equipment. Equipment is repainted on an as-needed basis, using paints recommended in ANSI $\mathrm{N}-14.6$ to assure that chemicals in the paint will have no deleterious affect on the metal. If a lifting beam shows evidence of galling damage, it is repaired in the same manner as that described in Part I, Section $4 . f$ for the repair of a galled trunnion. The annual load testing and alignment check are sufficient for the most part. Each beam has four metal, hinged flags that indicate in which position the arms are locked. This is to facilitate underwater observation. These flags will sometimes require minor adjustments to assure their free movement. Air hoses may break a quick-connect fitting if insufficient slack is available during cask movement. Replacement is quick and easy. Air leaks in the system have been nonexistent.

i. Problems/recommendations

Transnuclear has not experienced any significant problems in this phase of the operations. Improvements can be made by implementing developments made since this equipment was designed. These developments are oriented toward improvements in ALARA compliance and remote operation compatibility. Transnuclear has developed tiedown systems that can be released or engaged very quickly either manually or remotely. Shock absorbing covers can be removed or installed in a fraction of the time required for present equipment, again either manually or remotely. Techniques are available for 
storing shock absorbing covers on the trailer bed as quickly as they can be stored alongside the trailer and securely enough to permit over the road travel in this configuration. This type of development work is considered proprietary. While it is recommended that al1 new cask systems include features similar to these, modifications to existing casks that will not likely be used in a remotely operated environment simply cannot be justified. Further, since the $T N-8 / 9$ casks were designed for fuel cooled for only 150 days and they are being used to haul fuel cooled for five years or more, there is no need or justification for added shielding. These casks will probably provide more radiation protection to operators than the generation of casks that will replace them, because the newer casks will be designed to meet allowable regulatory dose rates with ten-year-cooled fue 1 .

\section{Crane Movement}

a. Special equipment and tools

The Transnuclear lifting beams are designed for use, in sets of two, in the redundant mode utilizing the whiting double reeved redundant hooks (Figure 9 ). Either of the pair of beams may be used independentiy for nonredundant lifting. In the single-use mode they can be accommodated by almost any reactor cask crane hook, whether open palm or eye. For some redundant systems (those not using the whiting system) special adaptors may be required to hang the lift beam from the hook. Lift beams are attached to crane hooks without the use of special tools. The controllers for the lift beams 
are furnished as a part of each system. These are described in the attachment to Figure $8 \mathrm{a}$.

Experience has shown that radio controls on cask cranes can contribute significantly to minimizing cask turnaround time. Cranes equipped with pendant controls function almost as well as those with radio controls.

Some facilities do not permit the crane hook to be immersed in the spent fuel pool. These usually make use of a step or shelf at about half the depth of the pool on which the cask is placed while an extension is attached to the cask lifting system. The extension permits the cask to be lowered to the bottom of the pool without submerging any part of the crane in the pool. The extension is fabricated especially for each site because of the differences in clearances, etc., among sites. Extensions (sometimes referred to as hook adaptors) consist of two parallel plates with reinforced areas at either end to accommodate 1 ifting pins. In use, the upper end of the extension is pinned to the crane hook and the lower end is pinned to the lifting beam. It should be noted that extensions are designed and fabricated to the QA standards of 10 CFR 71 subpart $H$, and must be load tested annually in accordance with ANSI N-14.6. A typical extension is shown in Figure 14.

b. Storage requirements for auxiliary equipment

Storage requirements for equipment associated with crane operations includes space for a lift beam storage stand which occupies an area about five feet by six feet. 
LIFT BEAM EXTENSION

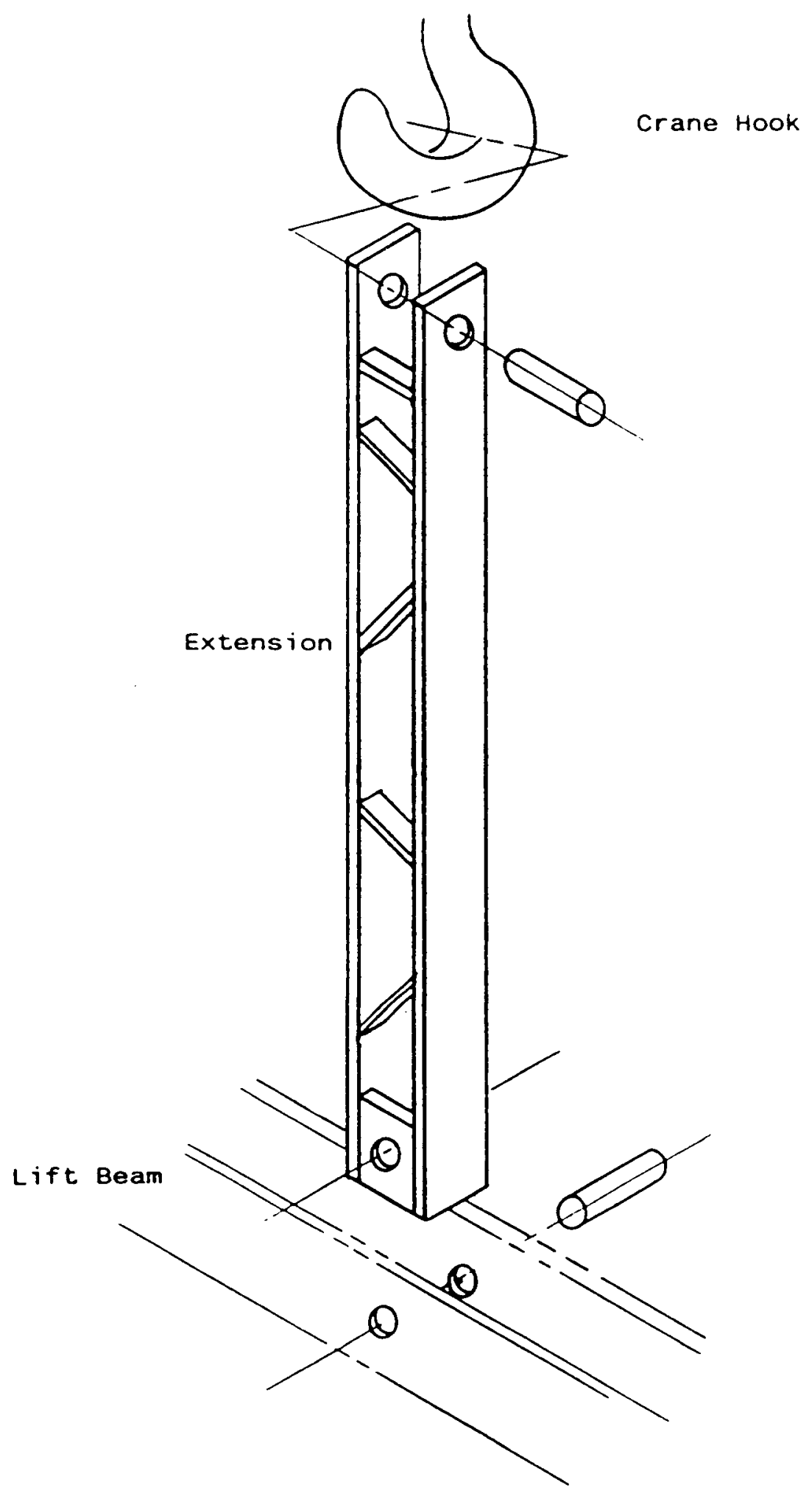

Figure 14 
If the site requires the use of a 1 ift beam extension then there must be a location in which to store it when it is not in use. Further, this location must be such as to provide ready access to the extension by the crane for attachment or removal. Some sites elect to store extensions vertically in their pools. In this manner they are accessible and require minimum movement in use. They also may become quite contaminated during long storage periods. Since storage mode and contamination interact, some additional comments regarding this relationship are warranted. Sites that store extensions out of the pool will need to decontaminate them to some extent after each use and may elect to store them in a plastic covering to preclude any airborne contamination. Since these extensions must be 1 iquid penetrant inspected annually when in use, the contamination picked up during long-term pool storage can be a problem for the inspectors.

c. Operating times

A lift beam can be attached to or removed from a crane hook in about five minutes. Crane travel time in some facilities, especially BWR sites, may add up to half an hour to this time if the beam is being stored at a level other than that at which it is to be used.

d. Operator training/experience

Only qualified, well-trained crane operators should be permitted to handle spent fuel casks. This training is not provided by Transnuciear nor do Transnuclear personnel ever operate crane systems belonging to 
others. Instruction is provided by Transnuclear

personnel to site operators who will be responsible for the operation of Transnuclear lifting beams or any other lifting devices supplied by Transnuclear. Crane operators are observed and coached during the first few times they rotate the cask onto or from the trailer. specificaliy, their technique in handling the cask just prior to separation from the trailer is critical in preventing a sudden lateral movement of the top portion of the cask. This can occur if the full weight of the cask is transferred to the lower trunnions because of insufficient hook elevation when the cask is almost vertical. A similar condition can occur when the cask is being replaced onto the trailer.

e. Damage experience

The TN-8L and TN-9 casks make use of a plastic skirt that surrounds the finned area of the cask body. See Figure 18. Clean water flows through this annulus while the cask is in the pool to preclude contact of the fins by pool water. There have been three instances in which the water 1 ines leading to or from this skirt arrangement have been damaged by moving the cask too near a pool wall. These instances have occurred while the cask was not submerged in the pool so the only damage was to the water lines and these were easily replaced. As a result of these incidences, the skirt filling system was modified to utilize only one 2 " 1 ine rather than two. The water effluent 1 ine was replaced by a 2 "ball shutoff valve. Figure 19 indicates a water supply connection change that must be made once the annulus is filled with water. Failure to do this, or permitting 
SKIRT ASSEMBLY

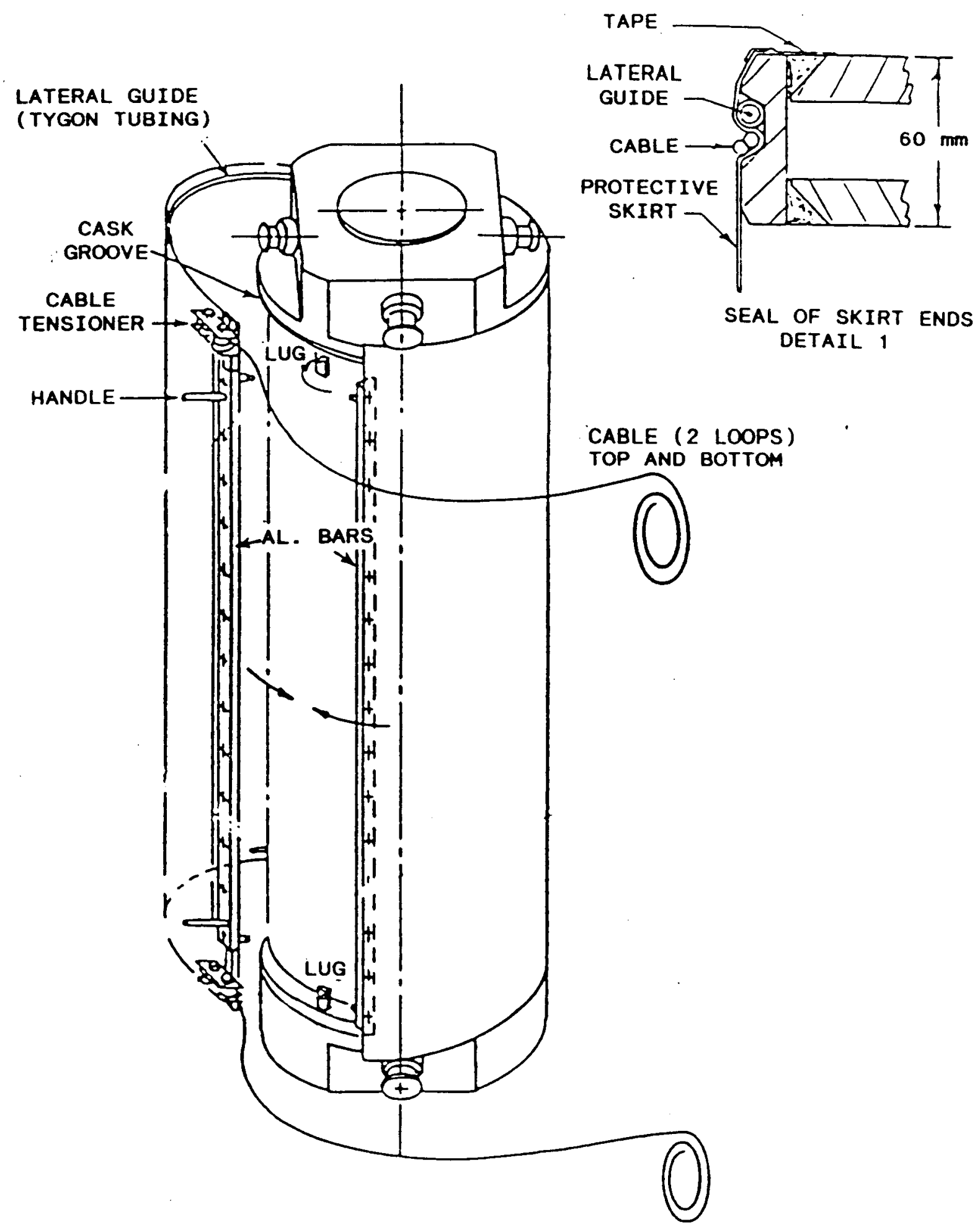

Figure 18 
SKIRT FILL SYSTEM

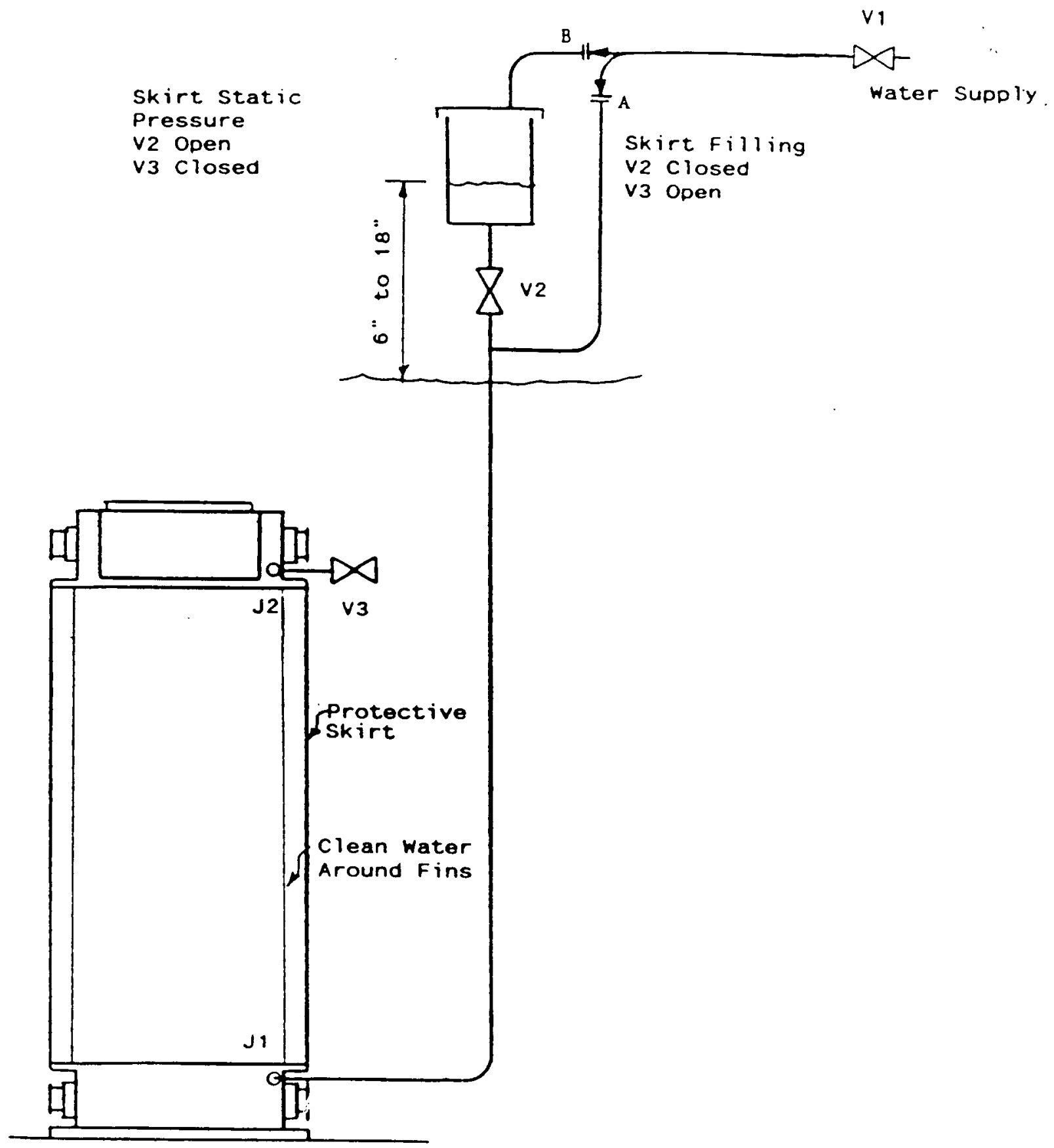

Figure 19 
the water level inside the skirt to become several feet higher than the pool surface, will result in a skirt failure either by splitting the skirt or by puling the upper or lower edge from beneath the cables (and tearing off the lateral guides in the process). Each of these modes of failure has been experienced one time.

\section{f. Problems/recommendations}

Problems associated with crane movements have been minimal. Some of the reactor sites have very 1 imited hook heights for efficient cask handing and some require that unusual paths be followed while moving a cask from one point to another. It is anticipated that such factors will be considered in the design of cask handling facilities at DOE operations. Hook heights should be a minimum of 30'above any obstacle over which a cask must pass. A cask should not be required to pass within $5^{\prime}$ of any obstacle on its side. Personnel pinch points between a swinging cask and any structure should be avoided absolutely. As previously mentioned, radio controls for cask crane operation are most desirable. Utilities such as compressed air, electrical outlets or water are necessary only at cask work stations, not during crane travel.

Crane speeds, either horizontally or vertically, are not as critical as the ability to initiate and maintain very slow movement. Without this ability, crane speeds must be severely restricted in order to avoid excess loadings imposed by sudden stops and starts. Acceptable crane operational criteria are given in NUREG-0612 "Control of Heavy Loads at Nuclear Power Plants", July, 1980. 
6. Preparation for Fue 1 Loading

a. Special equipment

Transnuclear provides a sling system for lifting the cask lid. The sling is normally attached to the lifting beam so that the lid removal and installation is done when the lifting beam is released from or engaged to the cask. Various modified designs have been required to accommodate crane hook extensions or other site related differences. A typical lid lifting sling is depicted in Figure 15 .

Another item of special equipment may be required if the station's fuel handing grapple is too large in cross section to enter the fuel compartment of the cask. In this case, a special grapple may be required for cask loading. Transnuclear has designed and supplied grapples at Dresden, West valley, Oyster Creek, Oconee and McGuire stations.

Transnuclear supplies a quarter-inch thick plastic cover for the bottom of the cask (Figure 16) to protect it from contamination or small objects on the pool floor. A stainless steel sheet metal cover (Figure 17), used to protect the lid sealing surfaces while the cask is being loaded with fue $\overline{\text {, is }} \bar{i}$ lso furnished. The plastic bottom protective cover can become grossly contaminated if the pool floor is not clean. In this case it is considered expendable and it is the responsibility of the user to dispose of it as contaminated waste at the completion of the campaign. The seal surface protective cover routinely becomes only slightly contaminated. It can be 


\section{LID LIFTING SLING ARRANGEMENT}

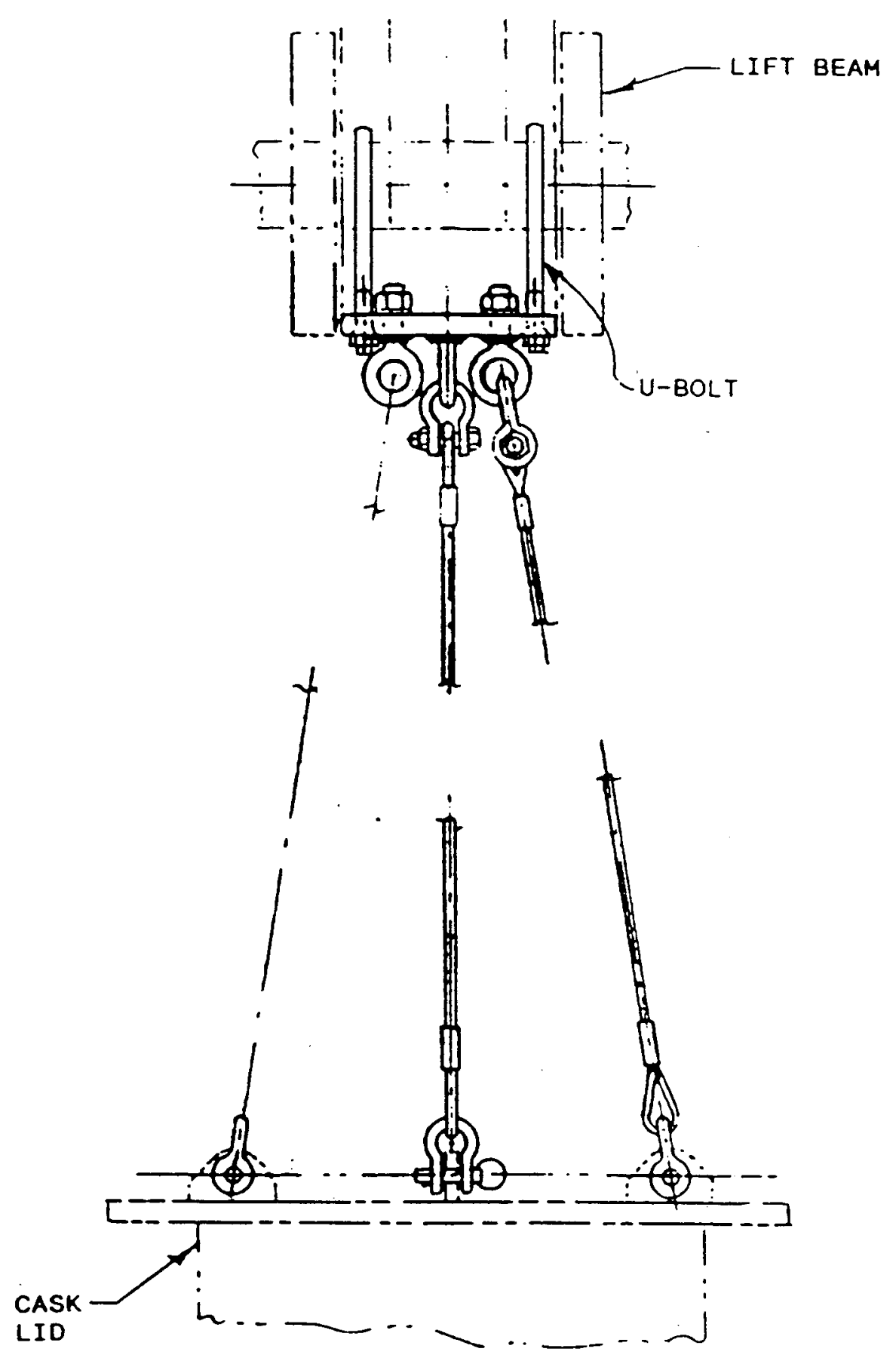

Figure 15 


\section{CASK BOTTOM PROTEOTIVE COVER}

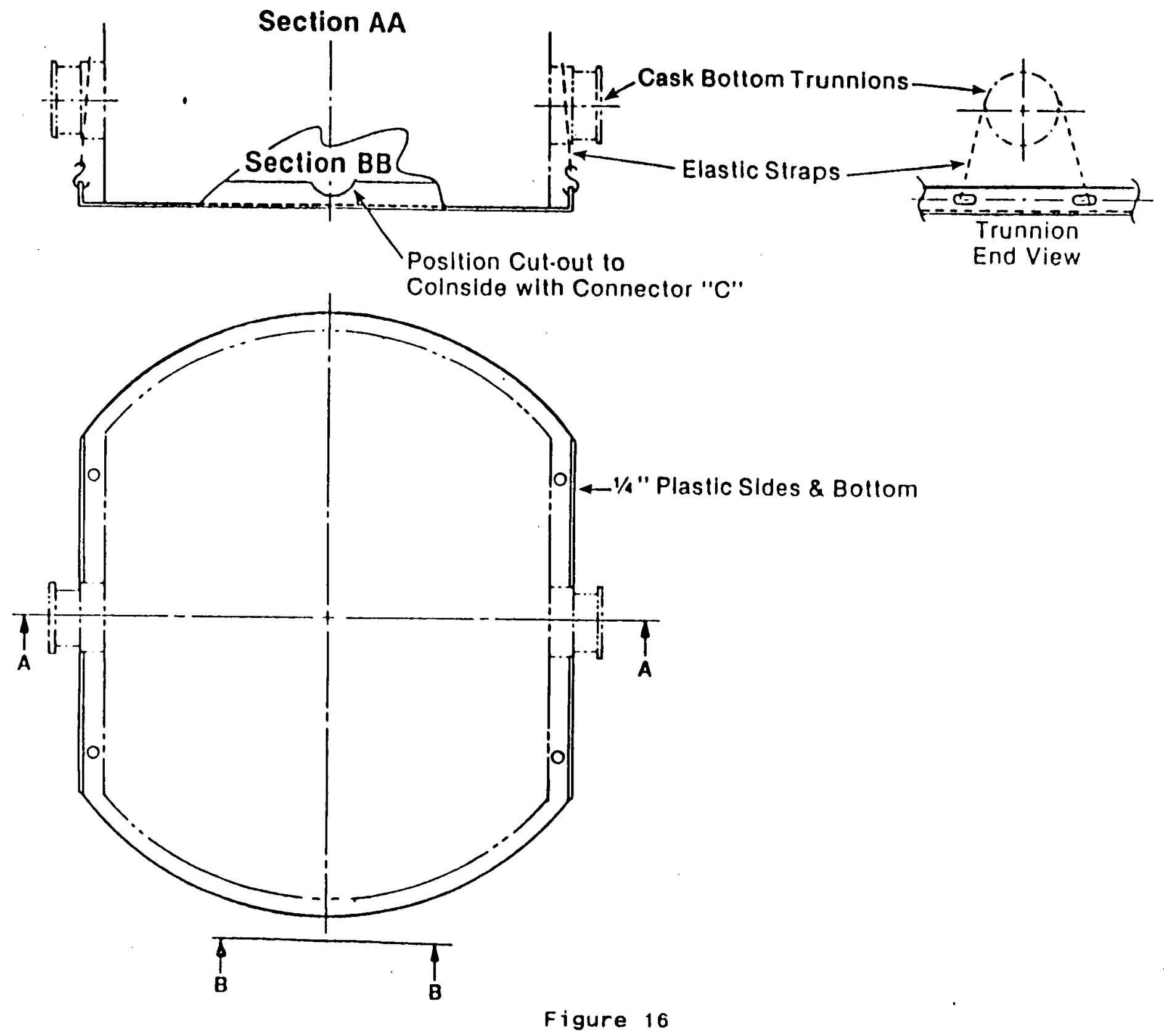


CASK TOP PROTEOTIVE COVER

\section{Sectlon AA}

오ํ

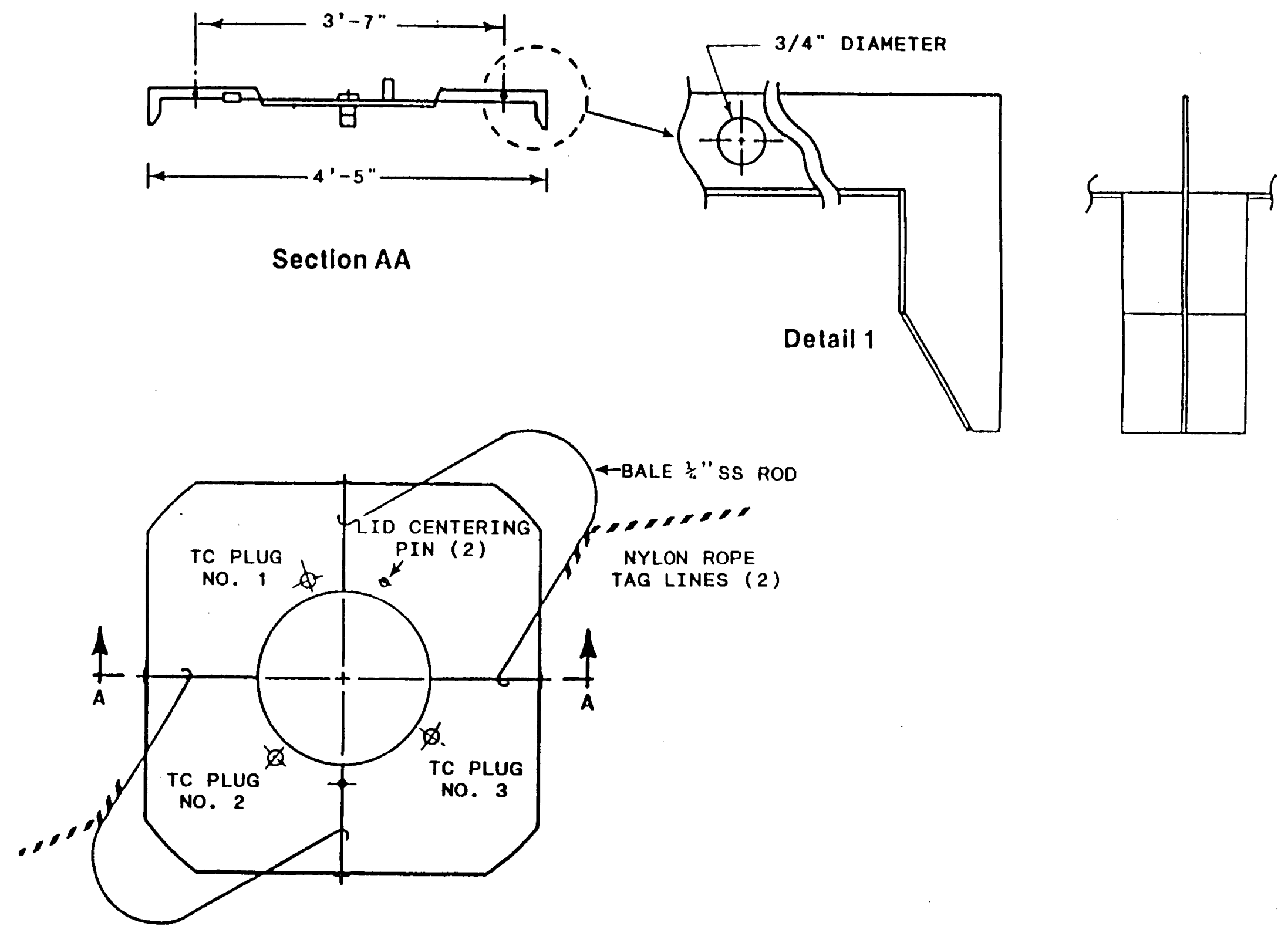


used repeatedly at several different sites, moving as LSA between sites or to or from Transnuclear's Aiken facility.

b. Special handling requirements

The items of special equipment mentioned above, with the exception of the fuel grapple, are handled manually. The seal surface protective cover is set into place using tag lines controlled by two operators and it is removed in the same manner. Lid lifting slings require manual attachment but this operation could readily be automated if difficulty of access warranted it. The bottom cover is attached to the lower trunnions of the cask by elastic straps after the cask has been lowered onto the cover in the work station.

c. Experience with wet/dry loading

The experience of Transnuclear personnel with loading operations extends we 11 beyond that of loading TN-8L and TN-9 casks in US commercial light-water reactors and hot cells. Personnel have had the opportunity to participate in both wet and dry loadings of casks in Europe and with wet loadings in Canada. Hands-on operations have been experienced with the following spent fuei casks:

$T N-8 L$

TN-9

NLI $-1 / 2$

$N L I-10 / 24$

NLI - MTR

NLI-AECL
GE-IF-300

FSV (wet and dry)

REA- 1023

Castor 1C (wet and dry)

NAC- 1 (NFS-4) 
A considerable amount of the time spent working with these casks was devoted to improving operating procedures and to improvements in their ancillary equipment, so the experience has included a great deal of depth and detail. It also has served as a good basis for optimizing the operations of the existing Transnuclear casks and for the development of new concepts for Transnuclear.

Wet loadings with the $T N-8 L$ and $T N-9$ have evolved to quite straightforward and routine operations. The preparations for loading include attaching the anticontamination skirt while filling the cask with water, disengaging the 1 id bolts, and attaching the 1 id lifting slings between the 1 id and the lifting beam. The skirt assembly is shown in Figure 18. A water inlet line for filling the skirt annulus is attached to the cask. While the skirt annulus is filling, the cask is lowered into the pool at a rate that permits a slight positive head of water to stand in the annulus. This assures that any leakage in the skirt system will be clean water leaking out rather than pool water leaking in. This arrangement is shown in Figure 19. The cask is placed onto the bottom of the pool, the lift beam is disengaged remotely and as the 1 ift beam is raised from the pool it brings the lid with it. A metal protective cover (Figure 17) is placed over the seal surfaces of the cask face and the cask is ready for loading with fuel.

The mechanics of the preparations for dry loadings are similar to those for wet loading except that the cask is not filled with water before being moved to the loading station and any protective skirt that may be used is 
just a loose-fitting cover rather than the type used for underwater loadings. The lid is handled in the same manner and a protective cover is placed over the sealing surfaces before fuel loading. The $T N-8 L$ has been used for dry, hot cell loadings and unloadings in this country (EMAD and TAN). Also, personnel now employed by Transnuclear have had the opportunity to work with dry, remote loadings of the Castor $1 \mathrm{c}$ in Europe. This work involved the use of a transfer cask and interface shield, rather than a hot cell. Still, the mechanics of the preparations for loading (although not the actual loading) were similar to those for wet loading or hot cell loading.

Dry operations in hot cells are initiated in much the same manner as are the preparations for wet operations. It is a hands-on operation until the point at which the cask would ordinarily go into the pool; i.e., the next step is lid removal. When this point is reached in a hot cell operation, all personnel leave the hot cell and operations from that time until the lid is back on the cask are conducted remotely from behind shielded windows. The primary difference between the two operations is that in a wet environment the operator is looking down on the cask while in a hot cell he or she is looking at it more from the side and so depends more on mirrors and closed-circuit television. As a rule, the amount of contamination picked up during wet loading is greater than during a dry loading. Also, the required operating time for dry operations is less than for similar operations done under water.

Dry operations that make use of transfer casks will usually include a transition piece between the transfer 
cask and the shipping cask. The transition piece must accommodate the removal and return of the 1 ids of both casks as well as provide radiation shielding to the area around the operation. These operations are observed remote1y. Because of the confined quarters, fiber optic viewing systems are especially adaptable to this purpose and do the job extremely well. The transition piece can be made a part of the transfer cask and thus eliminate one lid-handling operation, but this configuration is more cumbersome to handle and to decontaminate.

\section{d. Operating times}

A typical time for the preparation of the casks for loading is about one hour, but this can extend to several hours at some sites. Site specific HP practices, $Q A$ requirements and other such items over which the cask supplier has no control make the time somewhat unpredictable. These variations for each step are given in the tables of Attachment IV-2. As an example, some sites may assign health physics personnel full time to the cask handling operation, while others may send someone only after receiving a call for health physics services. Some site QA personnel institute more "QA hold points" than others, but QA personnel seldom remain at the cask handling location and their promptness in responding to calls can vary widely. Other factors affecting operational times include how the crew at the installation adheres to its break schedule. Some will not begin an operational step if it cannot be completed by "break time". 
e. Damage experience

There has been no recorded damage to any of the Transnuclear casks during this step of the operation. The nature of the operation is such that any possibility of damage is quite remote. Cask sealing surfaces are the most vulnerable to damage, especially those around the lid penetrations where the vacuum test covers (Figure 20) must be seated in the performance of leak tests. During the training program for cask users, Transnuclear personnel make special note of the possibility of damage to these surfaces if a connector is set down too hard or if the shielding plug is not carefully placed in its hole. If these surfaces were to be badly dented the surface around the opening would have to be re-machined. There has been some scratching of these surfaces, but no damage to the extent that some vacuum grease on the test cover o-ring could not compensate for it.

\section{f. Problems/recommendations}

The elimination of the need for cooling fins for most of the new generation casks will simplify the steps needed to control contamination of their outer surfaces. For those instances where the loading site makes use of a shelf in the pool and a lift beam extension, it would be desirable to develop a telescopic device that would remain at all times as an interface between the lift beam and the crane hook. Limited upward travel of crane hooks has been the main deterrent to a development of this type. 
Cask Test Fittings
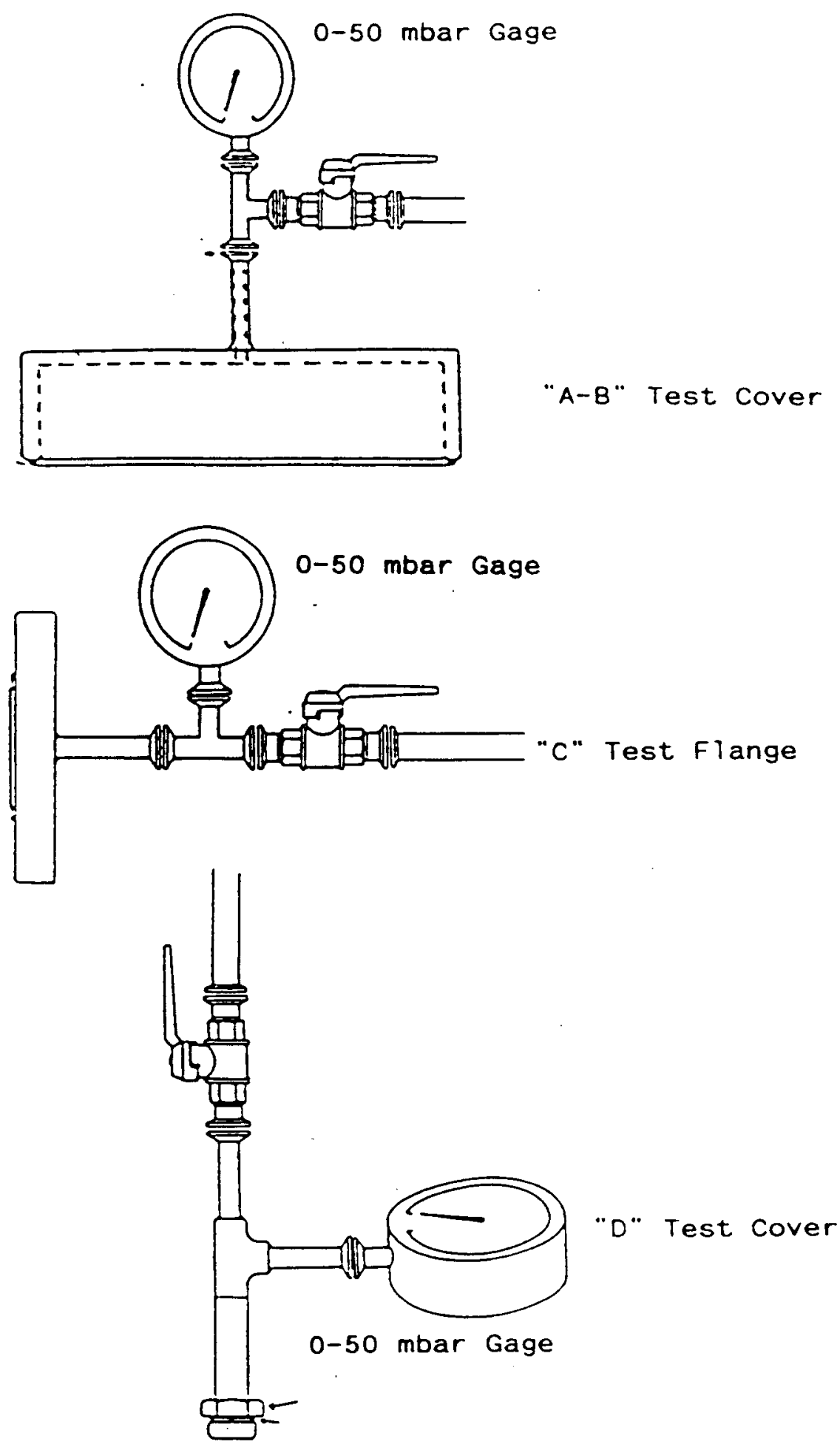

Figure 20 
7. Fuel Loading/Cask Sealing

a. Special equipment and tools

Fuel loading tools and equipment are specific to a given site and are not normally furnished by the cask supplier. After the lid is removed from the cask in preparation for loading fuel, the loading takes place using the fuel bridge crane and the fuel grappling equipment. special fuel grappling tools have been designed and supplied by Transnuclear to solve incompatibility problems in some cases.

To facilitate cask sealing after loading, a protective cover is placed over the cask face during fuel loading. The cover (Figure 17) protects the cask from inadvertent bumping of an assembly on the sealing surface. It also keeps any falling debris off the sealing surface. Tag lines are attached to the lifting bales of the cover. The cover may be lowered into place manually or with the use of the auxiliary crane. The cover will guide itself into place if the initiai contact with the cask is in reasonable proximity to the cask face. The cover is light enough in weight to be removed manually using the tag 1 ines.

b. Handiing requirements and procedures

Fuel is loaded into the cask in accordance with the site fuel handling procedures. Transnuclear's concern in this step of the operation is that the site operations in no way conflict with Transnuclear cask requirements (e.g., the fuel should clear the top of the cask 
sufficiently to avoid dragging the fuel over a sealing surface; the fuel rotational orientation capability of the site must permit reasonable alignment of the fuel with the cavity before insertion is attempted, etc.). Al1 cask handling operations including fuel loading and unloading are based on the operating procedure chapter in the NRC-approved Safety Analysis Report (SAR).

Transnuclear provides a generic procedure to the site, (Attachment IV-1) from which a complete, site-specific operating procedure is prepared. Transnuclear personnel review the site procedure to verify that it in no way conflicts with the SAR. After approval, the procedure is verified by a dry run and any necessary changes made.

\section{c. Fue 1 condition}

Prior to starting shipments, an evaluation is performed to verify that fuel in its then known or suspected condition will meet the minimum requirements for shipping. Failed fuel is defined by licensing authorities as any assembly having rod cladding defects greater than pin-holes or hairline cracks; exposed fuel pellet material; or severed, broken or grossly deformed fuel rods as determined by historical records or visual inspection prior to loading. Known or suspected failed fuel may be shipped only in NRC-approved failed fuel canisters. Transnuclear has designed and used such canisters. One such canister is shown in Figure 21. These canisters provide confinement (not "containment") of fuel, with flow ports covered by fine mesh screen, permitting free flow of 1 iquids and gasses across the canister boundary and the drying of canister contents prior to shipping. However, the fuel particles cannot 
Fuel Canister Lid Assembly

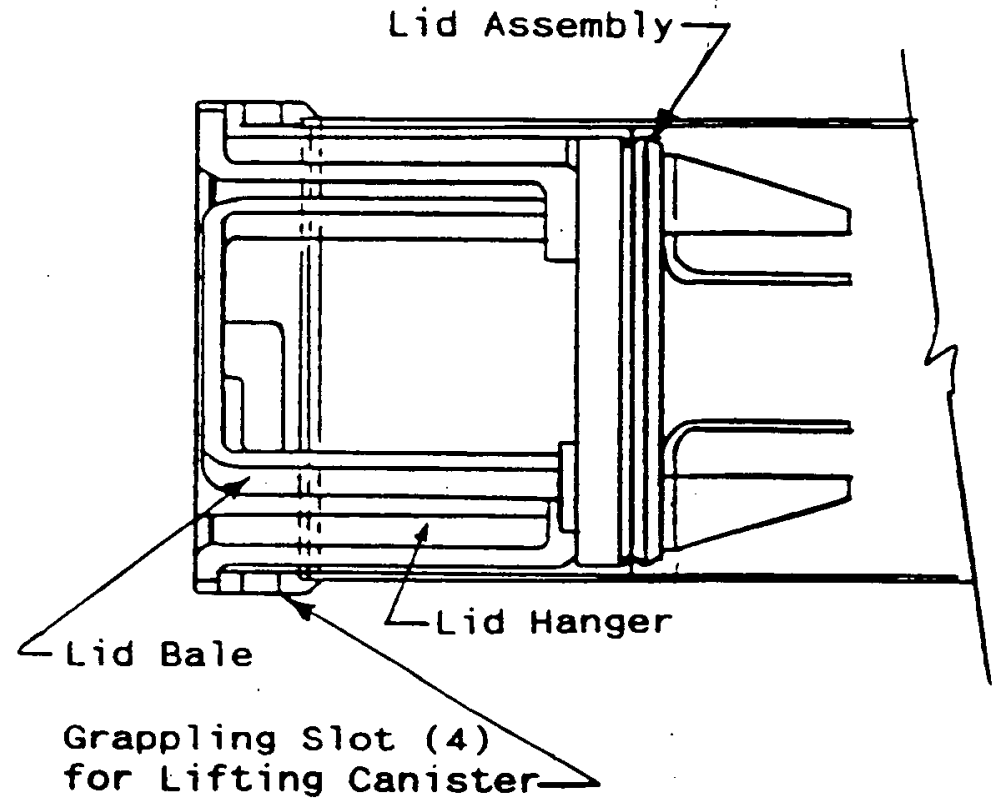

Serial No.

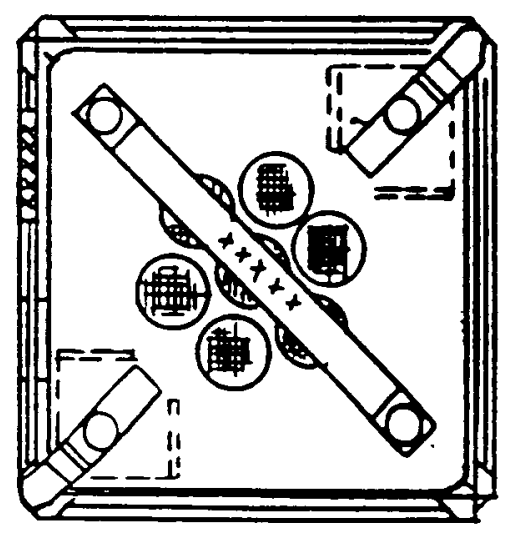

Top View
Fuel Canister

Bottom Plate

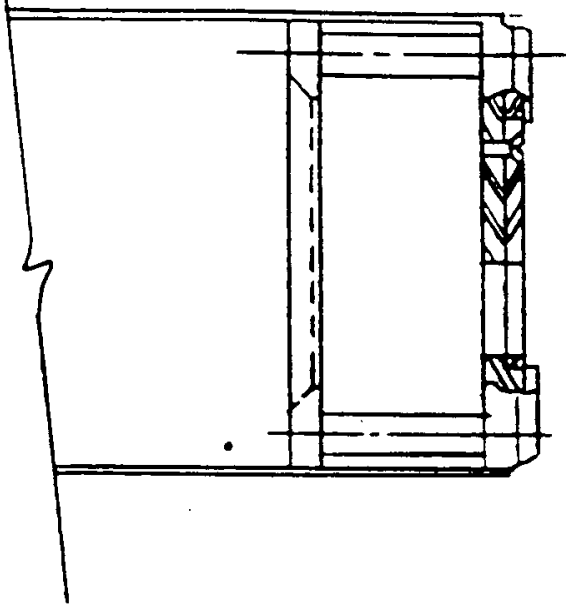

Scree

Suppo

Plate

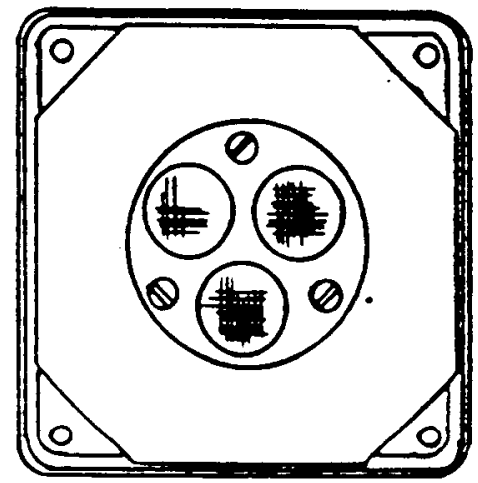

Bottom view

Figure 21 
escape through the wire mesh. The canisters have been shown to have no impact on cask containment capability, structural integrity, heat rejection capability, shielding effectiveness or criticality control.

The fuel compartments for the BWR cask (TN-9) are six inches square in cross section. The external dimensions of the canister are 5-7/8" square and the wall is $1 / 16^{\prime \prime}$ thick. BWR fuel is 5-1/2" square in cross section, leaving 1/8" clearance on all sides as fuel is inserted into the canister. This clearance has been adequate for all canister loadings to date. The canisters are placed in the fuel compartments before the fuel is loaded. When fuel is unloaded, a special grapple is used to engage the rim of the canister for removal and storage of the fuel. Any site that intends to further process canistered fuel should provide for restraining the canisters during fuel assembly removal and for processing the empty canisters.

It must be confirmed that the fuel to be shipped will fit within the length of the fuel compartments. Special lids have been designed and put into service to accommodate fuel or canisters that are too long for the normal cask cavity. The standard 1 id for al1 Transnuclear casks has a removable 1 " plate extending about 2" from the bottom of the 1 id. This provides flexibility in adapting to longer fuel assemblies or assemblies containing poison clusters. For shorter fuel, spacers are sometimes required to position the assemblies so that the bale is at the correct elevation for easy grappling, and to minimize fuel movement within the compartment during transit. 
Transnuclear has found that fuel that has become rather badly distorted (visibiy bowed or twisted when viewed under several feet of water) still can be loaded into a cask without excessive difficulty. Fuel assemblies are flexible and almost any bow or twist will respond to manipulation to assist insertion. Our experience has been that it is more difficult to insert an unusual fuel assembly than it is to remove it from the fuel compartment.

d. Damage experience

Damage experienced during or as a result of fuel loading has been non-existent to date, after over a hundred loadings and unloadings. This is attributed to the high quality of operator personnel and their training at the reactor sites.

e. Problems/recommendations

Transnuclear has avoided problems in this area by providing each operating crew with class room training, hands-on training during dry runs, and oversight of initial operations until satisfied that the user is completely qualified to operate the equiprient. classroom training is always conducted before the operators (and HP personnel, QA people and supervisors) have an opportunity for hands-on contact with the cask. This is augmented with the showing of over 100 color slides of the sequence of operations and the demonstration of some of the special connectors that are used with the system. A record is taken of the 
operators in attendance and only those people are permitted to work with the cask handing crew during the initial loadings. Training of individual replacements by the cask handling crew is permitted once the crew is experienced. The class time is especially useful in that ali attendees hear the questions being asked, which is not usually the case during operations. Transnuclear recommends that all cask users be prepared in the same manner.

Transnuclear has found that pneumatically operated grapples perform better than equipment that is manualiy operated. Such equipment is always designed so that the grapple cannot be opened when it is under load but will fail to the open position if the air supply is cut off and the grapple is not under load.

f. Radiological experience

Most spent fuel pools have a dose rate of about $2 \mathrm{mR} / \mathrm{hr}$. near the surface of the pool. The radiation exposure to the loading crew is generally proportional to the number of assemblies to be loaded; however, the greater the number of assemblies loaded in a given shipment, the less the dose per MTU for the total campaign. The use of Closed-Circuit Television (CCTV) during loading, with the camera sighting on the opening of the cask, can make a significant reduction in operator dose when compared to using binoculars to verify fuel numbers, fuel inspection, etc. It should be noted that the radiation doses estimated in Attachment IV-2 are from the cask only and do not include the contribution from the facility in which the cask is being used. The 
background radiation from the facility can vary from nearly zero to perhaps $5 \mathrm{mR} / \mathrm{hr}$.

Typical fuel pool contaminants are given in Table 1.

8. Preparation for Shipping/Receiving

a. Special equipment and tools

The primary item of special equipment required to prepare the loaded cask for shipment is the Vacuum Drying System (VDS). The VDS units, shown in Figure 22, are designed and assembled by Transnuclear and provide a method for rapid and efficient removal of all water from the cask cavity. A specific brand of vacuum fittings to connect the VDS to the cask is also supplied (Figure 23). The VDS also provides the vacuum used in leak testing penetration covers. The vacuum test covers and gages (Figure 20) also are considered to be special equipment.

b. Handing requirements and procedures

This part of the cask operation is very much caskspecific. The Transnuclear casks are raised from the pool at a rate that allows the skirt annulus to drain by gravity. Cask cavity drainage, lid securing, and seal testing are done in accordance with Transnuclear procedures. The site procedures may include specific paths to be followed when moving the cask from one location to another or may specify certain decontamination techniques, but the operations for cask preparation are dictated by the cask SAR. 


\section{VACUUM DRYING SYSTEM}

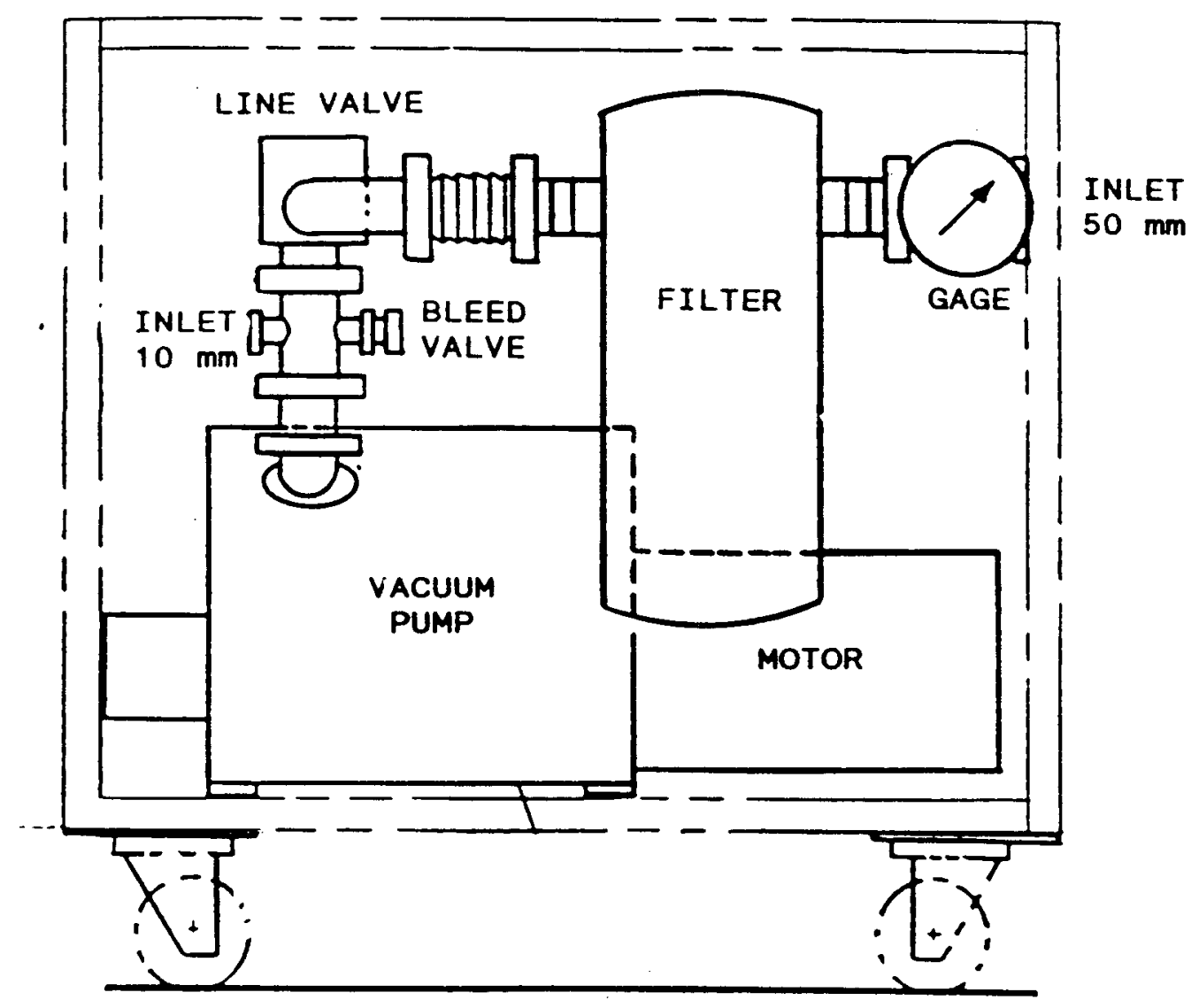




\section{VACUUM CONNECTIONS}
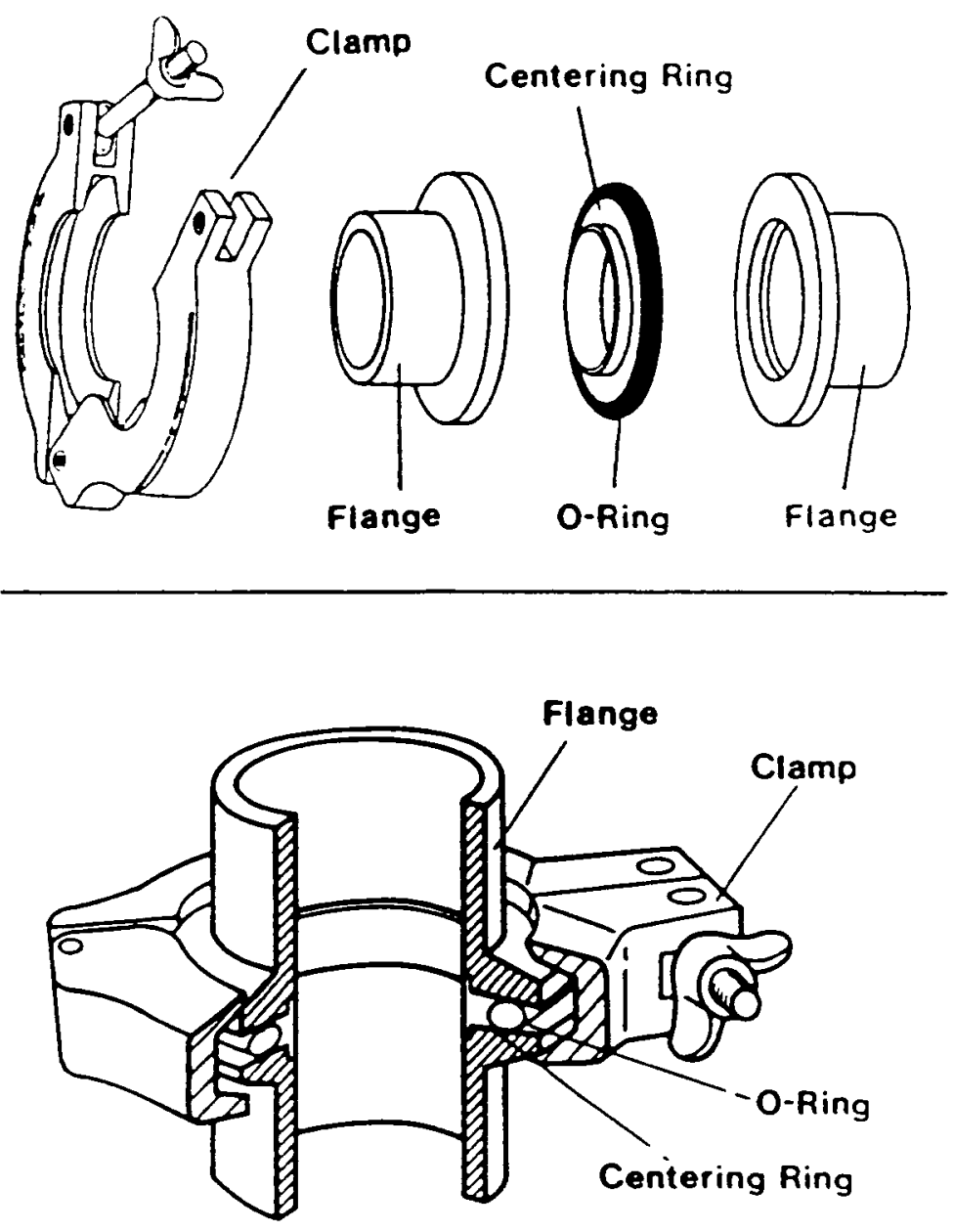

Figuré 23 


\section{c. Cleaning operations}

The cask does not become visibly dirty during loading or unloading operations. Cleaning becomes essentially a part of the decontamination step, which is discussed in Section 8.e., below.

\section{d. Drying operations}

The drying operation consists of two basic procedures: air flushing and vacuum drying. There are three "ports" (penetrations into the cask cavity) on the cask which are used in these operations. The ports are identified in Figure 1 as $A, B$ and $C$. The cask is normally in the vertical position during the drying operation.

After the cask is drained and sealed, a 2 "vacuum 1 ine is attached to the "A" port. A vacuum-tight bottle of about $2000 \mathrm{cc}$ volume is attached to the " $\mathrm{C}$ " port. The cavity pressure is reduced to less than 50 mbar, which results in the remaining moisture flashing to a fog. Air is then admitted through the "A" port, which flushes the vapor into the bottle where it will collect as 1iquid. The bottle is emptied and the process is repeated until no more free water is collected in the bottle. The performance of these flushings has two advantages over straightforward vacuum evaporation. First, it precludes the need to direct much of the water through the vacuum pump, a step that should be avoided if possible. Second it preserves much of the latent heat of the internal system, which is important to the efficiency of the vacuum drying step to follow. Tenyear-old fuel does not supply much heat to make up for the heat lost to vaporization, particularly in the vacuum environment of the drying step. 
For the second step, the bottle is removed from the " $\mathrm{C}$ " port and the port is sealed. Vacuum is applied to the cask cavity with the ballast valve of the vacuum pump in the open position, to assist condensable vapors in passing through the pump rather than remaining in the oi1. The pressure within the cavity will fall rather sharply at first, then stabilize at the vapor pressure corresponding to the temperature of the cask internals. Care must be taken not to pull the vacuum too quickly. The pressure should not be allowed to fall below 7 mbar, or free water in the system may turn to ice. If this happens it becomes difficult to ascertain whether the cask is dry or if the ice is subliming, in which case the pressure drop rate may be interpreted as that of a dry cask. The cavity is considered dry when the pressure drops rather rapidly through the level of the vapor pressure at the triple point of water and leak rate measurements become constant. This rapid drop is not induced in any way; it simply is the result of the lack of water to generate any vapor pressure. This is illustrated graphically in Figure 24. These criteria were developed by observing the cask internals through a special transparent $\mathrm{l}$ id and correlating observations with measurements, in keeping with vacuum theory. In practice, the criterion for dryness is a measure of pressure rise for the system over a unit of time. This is conservative as a determination of dryness but it is far more expeditious for use in the field. In addition to visual observations during tests, Transnuclear has the experience of dozens of shipments of non-fissile irradiated hardware, shipped in the TN-8LS from reactor sites to disposal facilities at Barnwel1, SC. and Hanford, WA. These shipments are dried in the same manner as spent fuel. Upon arrival at Barnwell, the cask is placed in a horizontal position in a trench for 


\section{CASK PRESSURE AS A FUNOTION OF TIME DURING THE DRYING PHASE}

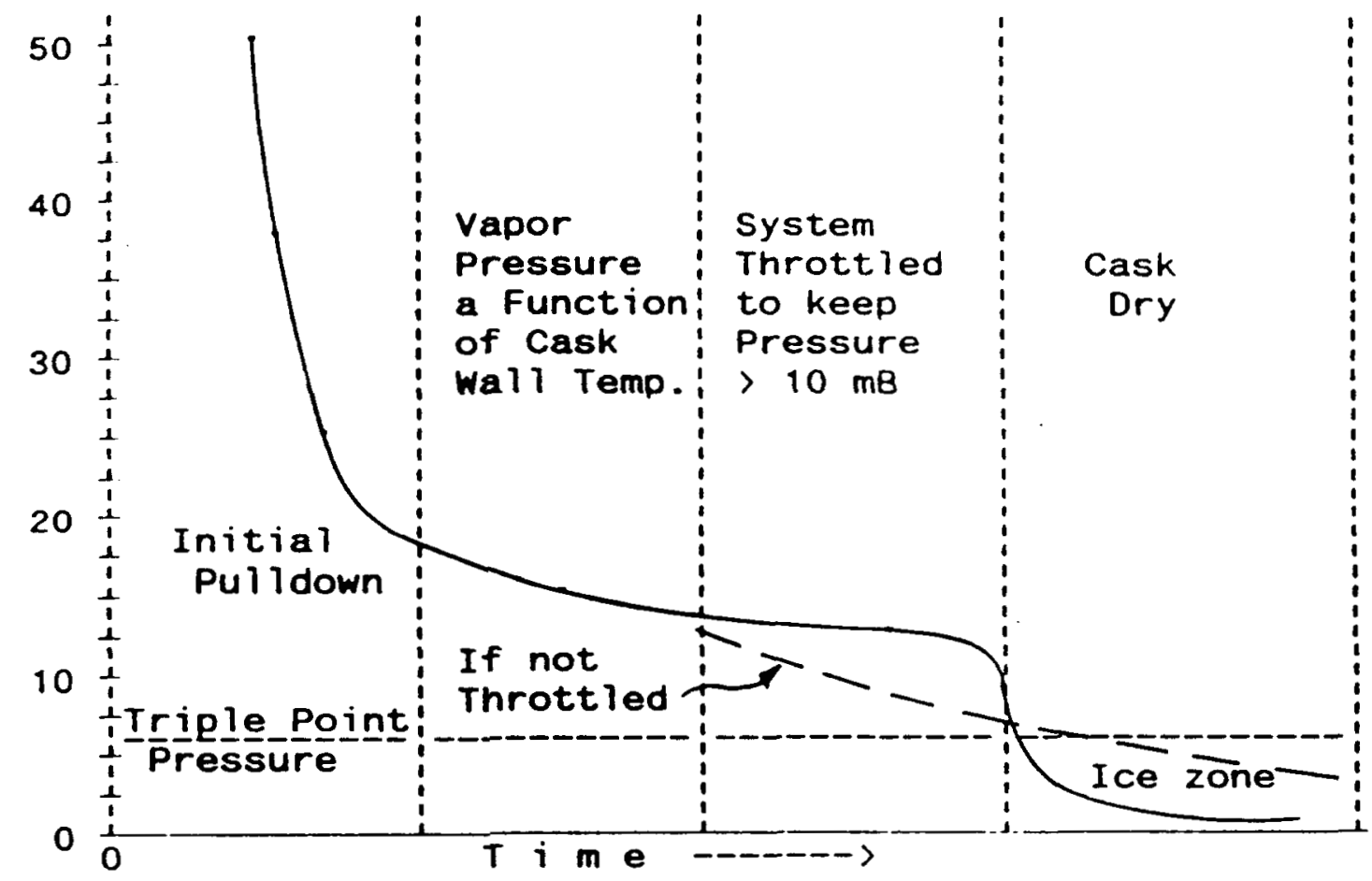

Figure 24 
dry unloading. The lid is removed remotely and the hardware canisters are pulled from the cask into a lower trench. Barnwell personnel and the state of South Carolina have very strict regulations about free water content in these shipments and they make a point of checking each unloading. To date they have detected no water from the Transnuclear casks. Fuel with the low decay heat generation of that typical of current shipments will make practically no contribution to the drying process. Any free water will settle to the bottom of the cask and, under vacuum, the only heat supplied by the fuel will be by radiation. Most of the radiation will be directed to the cavity walls. The bottom plate of the assembly will shield most of the downward thermal radiation. The bottom of the cask may cool quite rapidly but the relatively small heat gradient between the bottom and the walls will have little driving force to replace the heat, and stainiess steel is a rather poor conductor. Transnuclear has no correlation data between fuel decay heat and drying time. A significant correlation would not be expected with ten-year-old fuel because of the confounding contribution of other variables (fuel surface condition, end fitting configurations, etc.).

The cask must be dry to preclude overpressurization in the event of a fire accident. Any residual water may turn to steam and exert substantial pressures on the cask seals. This along with the presumed release of the pressurized gas from the fuel rods could cause a release of fission products. 


\section{e. Decontaminating operations}

The best way to deal with contamination is to avoid it as much as possible. Contaminated pool water is prevented from coming into contact with the thousands of cooling fins on the TN-8L and TN-9 casks by a skirt that provides an annulus of clean water around the fins (Figures 18 and 19). This system has worked well in preventing gross contamination of the fins. Contamination of a smooth cask surface without fins can be prevented by wrapping the cask with lightweight sheet plastic, held in place with adhesive tape while taking care that no air is trapped under the plastic. If air is trapped, it will accumulate under the top seal strip as the cask is being submerged and lift the seal from the cask.

There are some additional precautions which are recommended to minimize contamination. Before lowering a cask into the pool, al1 exposed surfaces should be thoroughly wetted with clean water and kept wet until submerged. Similarly, when a cask is brought out of a pool, all of the components should be thoroughly washed with clean water before they have had the opportunity to dry. During decontamination work, a soft absorbent material should be used and each surface of that material should make only one pass over the contaminated surface. Another preferred technique is to lightly spray the cleaning liquid onto the surface to be cleaned, then wipe it with a clean, dry absorbent material rather than wetting the absorbent material before use. 
Ancillary equipment will become contaminated during use but not to the extent that it presents a problem in preparing it for shipment as LSA RAM. Thorough rinsing of equipment used in the pool will preclude the requirement for storage isolation but such equipment will need to remain within a radiation controlled area under ordinary circumstances. Some equipment, as a matter of principal, is never "free released" because some internal surfaces are unavailable for obtaining a smear sample. An example of this would be any device powered by an electric motor. A fan will blow cooling air through the motor coils but the coils cannot be reached for smearing.

The decontamination solution used at Transnuclear's Aiken facility is Radiacwash, supplied by Atomic Products corp. It is described by the manufacturer as a liquid compound that combines a number of different chemicals and physical principles that cause it to act as a surface-wetting sequestering agent, chelater, carrier, ion-exchanger, emulsifier, solvent, complexer, peptizer and detergent. It contains no phosphates, chromates, silicates, enzymes, borates, aluminates, carbonates, halides or inert fillers. It is nonalkaline, non-corrosive, biodegradable, and germicidal. Cask user sites may use other decontamination solutions but these must be approved by Transnuclear before they can be used on the Transnuclear casks. 
Another important factor in contamination control is the preparation of the cask surface during fabrication to minimize its affinity for contamination. The surface should never be sand- or grit-blasted. A machined surface, no matter how smooth the finish is not recommended as the final finish. Glass or lead bead blasting will do a reasonably good job of sealing the microporosity of the surface. Probably the best surface for resisting contamination is an electroplated surface or an electroetched surface. These recommendations are the result of having worked with several casks of various manufacturers and observing their characteristics. They also confirm the characteristics that would be predicted from a study of the microporosity of surface finishes.

The phenomenon known as "weeping" seems to be associated with the combined effects of surface $f$ inish and the techniques of decontamination. A cask is said to "weep" when the level of smearable contamination increases as a function of time. This can be of concern during transport because, in severe cases, the cask may leave the consignor's station well within DOT limits but arrive at the consignee's at levels that are higher than permitted by the regulations. Some shipper-receiver measurements and differences are given in Table 2 .

Transnuclear is presently under contract with Sandia National Laboratories to investigate this phenomenon. The investigation includes compilation and analysis of historical data and an in-service monitoring campaign for ongoing shipments. Parameters include pool water chemistry and cleanliness, contamination prevention 
techniques, in-transport environmental conditions, decontamination methods, cask surface condition, preand post-transport surface contamination levels, and spent fuel payload characteristics.

f. Cask contaminants, amounts, types

Cask contaminants for the most part are "CRUD", an acronym for Chalk River Undefined Deposits. Crud is the scale and precipitants that accumulate on spent fuel in operation and storage and which may slough off after drying and during transport. The amount is difficult to measure because it is flushed away to some extent during cask draining and flushing. Residual crud is estimated not to exceed $10 \mathrm{Ci}$ but this is only an order-ofmagnitude estimate.

Typical dose rates at cask openings (without covers) are given in Figure 13.

g. Contaminant analysis

The radionuclides of typical contamination are about $80 \%$ cobalt-60, 10\% manganese-54, with the remainder being ces 1 um-137 and otrer isotopes. 
h. Testing requirements/experience

Routine testing prior to shipping consists of confirming that the cask cavity and contents are dry and that the leakage past penetration seals is within acceptable limits in accordance with the requirements of the SAR and the Certificate of Compliance and the guidelines of ANSI-N 14.5. Dryness is confirmed as discussed under Section 8.d. Seal leak testing is performed on the " $A$ " and " $B$ " ports of the $T N-8 L$ and $T N-9$ casks using a vacuum test cover (Figure 20) placed over the entire sealing flange. A pressure rise test is used after first evacuating the test cover to less than 20 mbar. For the " $C$ " connector, a similar test is made using a test flange with a vacuum fitting built into it. This test is actually that of the valved Hansen quick connect plug. These three tests require about 15 minutes each and may be done concurrently if desired. The test through the "D" port (a1so a pressure rise test) which checks the annulus between the two concentric o-rings in the lid, usually requires somewhat longer. Water is trapped in this annulus when the lid is set into place in the pool. Since the annulus includes a relatively large surface area with respect to its volume, it is slow to dry. Completion of this test may require onehalf to one hour. Other operations can take place during this operation so the total time is not added to the cask turnaround time.

The acceptance criteria for the leak tests is based on the maximum acceptable loss of fission products under normal and accident conditions. The value is half of the permissible leakage rate as calculated in the safety Analysis Report, in conformance with Paragraph 7.2 of 
ANSI N-14.5. The summation of all individual port tests is used to determine the actual leak rate; however, as an administrative control, a limit is placed on each test.

The formula for calculating leak rate is:

$$
L=\frac{A P \times V}{1013 \times T} \text { atm cc/sec }
$$

Where: $\triangle P$ is the measured pressure difference, mbar.

$$
V \text { is the volume in cc. }
$$

1013 is the conversion factor, atm. to mbar.

$T$ is the time in seconds.

The cask heat load is calculated by the cask user from reactor records and this value is accepted by Transnuclear. If the heat load is less than $25 \%$ of the design heat load, the requirement for periodic verification is waived by NRC.

\section{i. Damage experience}

To the best of our knowledge, there has been no serious damage to casks or ancillary equipment during these operations, beyond the normal wear that one would expect on parts that are removed and replaced repeatedly. The socket heads of flange bolts tend to round out if worn hex keys are used to torque them. Sometimes the cadmium plating of bolts or plugs will be damaged if the part is dropped. In one instance the stainless steel air tubing 
on a lift beam was damaged when the beam and its stand tipped over due to careless handing by site personnel. Three sections of tubing were replaced by Transnuclear personnel and the device was thoroughly tested but no other damage was evident. The lack of serious damage is due in part to well developed operating procedures that are generally followed without exception. It is also due in part to the simplicity and ruggedness of the cask and the ancillary equipment.

\section{j. Problems/recommendations}

Since turnaround times are of significant importance in establishing and maintaining cask shipping schedules, the coordination of the various groups that contribute to the shipment and recejpt of a cask can be a real concern. If health physics, quality assurance, security, maintenance, etc. coordinate their activities, the cask can be ready for use or transport within an hour after the last operational step; however, at some sites this may require up to 24 hours. If HP personnel are unfamiliar with the cask they may require a fairly detailed explanation of each step before permitting that step to be performed. That is why Transnuclear encourages HP and QA representation at training sessions and their active participation in the approval of site operating procedures. 
During vacuum drying operations it is recommended that a continuous recording be made of the pressure readings" as a function of time. This can assist in the resolution. of any errors that may enter into the interpretation of the drying procedure, and operators tend to be more diligent when a record of their activities is made.

k. Radiological experience

The highest dose to which operators may be exposed will occur around the top of the cask. This is due in part because the cask designs may include the shielding benefits of shock absorbing covers to meet regulatory requirements and these are not in place during work around the lid area. Operational steps that must be performed in this vicinity should be minimum in time and number. Extra, temporary shielding may prove worthwhile for some casks, especially new cask designs that may not be as heavily shielded as casks of the current generation. Lid lifting devices can be designed so that they snap into place or are removed by activating only one detent pin. Power tools can be provided to assist in bolt torquing (these should be counterweighted for easier use). Test equipment should be self supporting so that testing can continue without the need for an operator in the immediate vicinity. Lifting beam attachment and release should be completely remoteautomatic. There are numerous ways in which foresight in cask design and operational instructions can reduce radiation exposure to cask handling personnel. These might include:

- Standardize bolt sizes to reduce the number of tool changes required during operations. 
- Position penetrations for easiest access. For large casks place them near one another, not across a diameter of the cask.

- Provide surface finishes that are amenable to decontamination.

- Maintenance of the cask should not require manual access to any part of the cavity, such as basket locks to the inner wall.

- Cask bolting flanges should be thick enough to allow full torquing of bolts on one step (plus a confirmation round) rather than a series of incremental increases. Note, however, that bolts must be removed in a series of decreases in order not to overstress bolts adjacent to those being loosened.

9. Fuel Unloading

a. Special equipment and tools

Most of the foregoing discussion has been directed toward cask handling operations in spent fuel pools. For these facilities essentially the same equipment is used for wet unloading as that used for wet loading, except that cask drying and leak testing is not required for shipment of the empty cask. For wet unloading, there is an additional safety consideration. Even though current shipments contain fuel of very low decay heat, the fuel is always assumed to be hot enough to flash the cask fill water to steam. The water inlet line is provided with a check valve to prevent 
contaminated water from the cask from being blown back into the facility water supply, and a throttiing valve is used to control the rate of water flow into the cask. A relief valve set at 75 psig is located at the cask effluent connection. Pressure gages on both the inlet and effluent lines are monitored as water is admitted to the cask. If an increase in pressure is detected, the water inlet rate is reduced accordingly. The inlet flow rate is restricted to that amount of water that, when flashed to steam, can be accommodated by the effiuent 1 ines without exceeding 75 psig pressure in the system. As the fuel cools the water inlet rate can be increased and eventually the cask will be filled with liquid. The water flow would then continue until the temperature of the effluent stream is low enough (about $180^{\circ} \mathrm{F}$ ) to allow sufficient time to get the cask into the pool before the contained water starts to boi1. No steam generation has been experienced in any of the numerous unloadings in which Transnuclear has participated. The technique for steam control has been tested using dummy fuel in which a calrod heater was substituted for each fuel rod, permitting decay heat loads of up to $10 \mathrm{Kw}$ to be simulated. It should be noted that any facility that will load fuel under water should be equipped to unload the cask and control any steam generation while doing so.

For dry unloading in a hot cell that is not necessarily designed specifically for unloading casks, the equipment is essentially the same as for unloading in a dedicated hot cel1, but with the addition of manually operated gas sampling equipment to check the cask cavity for evidence of fuel pin leakage. A dedicated hot cell would handle this remotely and automatically. This requires a site approved sample bottle, valves, and hose connections 
that are attached to a standard cask connector for withdrawing the gas sample. The bottle is then analyzed spectrographically for radionuclide activity. If necessary, additional safety precautions are taken while unloading the cask, such as locating gaseous radwaste intake ducts near the top of the cask.

The lift beam is used to remove the cask from the trailer and to set it in the work station. In the nondedicated hot cell, the lid lifting sling is attached and the lid bolts are removed. Personnel then leave the ce 11. The lid is lifted from the cask and held suspended while the auxiliary crane removes the fuel to the storage racks. The 7 id is replaced and the crew returns to the cell to prepare the cask for shipment much as they would in a wet facility after the cask has been drained and dried. If the cask is unloaded dry but the fuel is to be stored in a pool (as is sometimes the case at INEL) the decay heat calculation should be confirmed by temperature measurements. Violent boiling could result if a hot assembly were placed into a pool, and considerable airborne contamination would be likely.

In a dedicated hot cel1, the entire unloading sequence can be done remotely, with personnel never entering the cel1.

b. Handing requirements and procedures

Handiing requirements and procedures for cask unloading follow the same philosophy as those for loading. 
c. Fuel condition

Transnuclear's experience is that any fuel assembly which can be loaded into a cask can be unloaded. Fuel condition is a concern only of the loading operation for all practical purposes. In Transnuclear's experience, a fuel assembly has never arrived at its destination in worse condition than when it was loaded. In only one instance has there been any indication of fuel $p$ in leakage, and that involved one of three assemblies that had been subjected to extensive handling in a laboratory rather than routine pool storage. In no instance have any fue $i$ assembly parts been left in the cask following unloading.

d. Casks contaminants, amounts, types

The accumulation of crud in a cask is at its greatest upon receipt at a site for unloading. In a wet operation most of this crud can be flushed out as the cask is drained, but this operation can also be a source of high dose rates if the drain lines are exposed; i.e., if 1 ines run across the floor from the cask to the pool. The configuration of the bottom of the fuel compartments and the convolutions of the drain lines (to preclude radiation streaming channels) can sometimes resist dislodging a buildup of crud. Casks with baskets may have additional holdup.

Maximum buildup experienced in the TN-8L and TN-9 casks has resulted in radiation doses rates out of the top of an empty cask (with the lid off and no water in the 
cavity) of about $40 \mathrm{R} / \mathrm{hr}$. Dose rates out of some other cask models under similar conditions have been reported as high as $200 \mathrm{R} / \mathrm{hr}$. Residual contamination in a cask has not been measured. It would not be practical to do so without tying up reactor site facilities for far longer than could be justified. Such a measurement should not be difficult to accomplish in a dedicated cask maintenance facility. This capability would be desirable in a situation where casks are routinely loaded in a wet commercial facility and unloaded in a dry government facility.

Whether or not the water drained from a cask should be diverted to a decontamination system rather than being directed to the spent fuel pool is a decision to be made by individual reactor operators. In most BWR systems, the drain hose is directed into the skimmer.

e. Contaminants analysis

The analysis of the contaminants is the same as those approximate values given in section 8.9 .

f. Damage experience

Transnuclear has had no damage experience related to cask unloading operations. 


\section{g. Problems/recommendations}

The greatest concern regarding fuel unloading is the residual contamination that might build up in the cask internals. Transnuclear has developed special proprietary equipment for use at reactor sites to control or to minimize this buildup. This equipment is now at one of the customer sites; however, they have not felt compelied to test it because the buildup has not been a probiem.

\section{h. Radiological experience}

The work in the vicinity of the top of the loaded cask is the area of greatest concern for radiation dose to operating personnel. It is not as great for fuel unloading preparations as it is for preparing a loaded cask for shipment because there are fewer operations involved. Temporary shielding and counterweighted power tools will help reduce accumulated dose.

\section{i. Decontamination/cleaning experience}

The requirements for the decontamination and cleaning of a cask after fuel unloading are identical to that of a loaded cask ready for release. Neither DOT nor NRC regulations differentiate between the two except for placarding and labeling. Comments on decontamination are given in Section $8 . e$. 


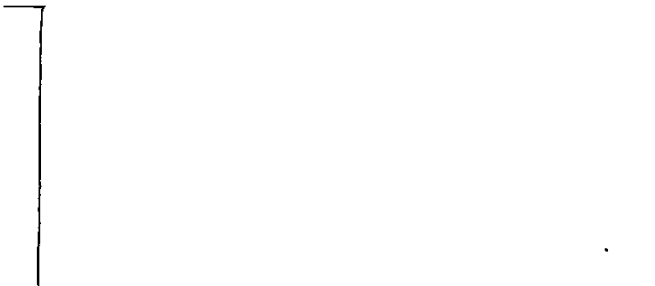

-

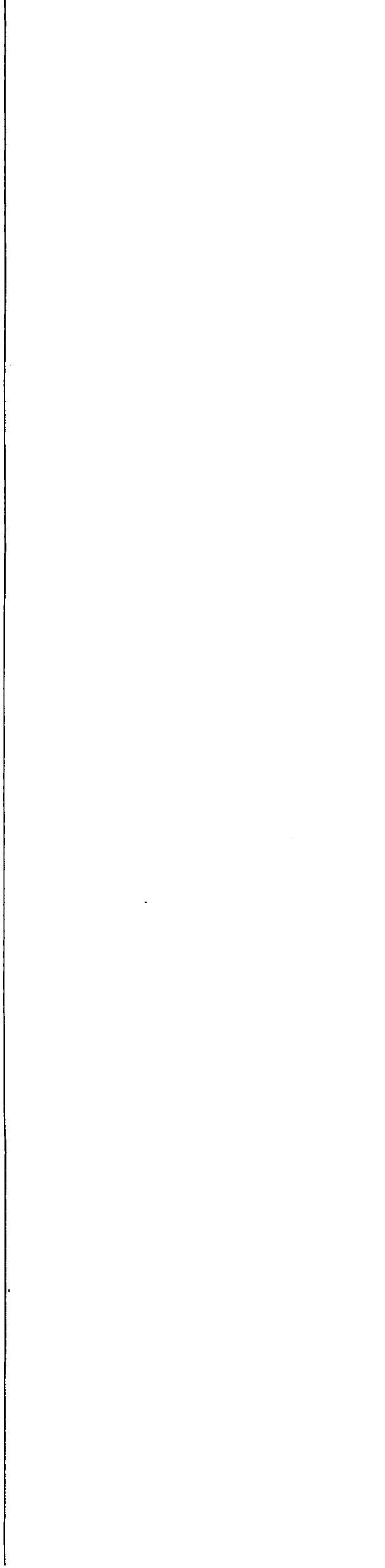

. 


\section{Part I I MAINTENANCE AND REPAIR OF CASK FLEET}

1. Hydrostatic Testing/Leak Testing/Thermal Testing/Other

1.1 Hydrostatic testing

a. Testing requirements and frequency.

This test is performed only one time for each cask as a part of the cask acceptance testing. It is performed after pickling and passivation of the stainiess steel surfaces. It consists of filling the packaging cavity (approximately 700 liters) with water, pressurizing to 11 bar absolute (other casks will have different test pressures) with a hydraulic pump and determining the pressure variation of the isolated pressurized cavity for six hours. The minimum test pressure for the $T N-8 / 9$, as determined from ASME Code, Sect. III para. NE.6221 is 9.85 bar gage or 10.85 bar absolute. The test is considered acceptable if there is no visible leakage at the orifice or at the lid closure and no loss of pressure beyond that attributable to changes in temperature.

This test is performed in conformance with the ASME Code, Section III - Article 6000 except for deviation from paragraph NE 6121 (exposure of joints) due to the fact that the requirements of paragraph NE 5221 are not (and need not be) fulfilled. 
b. Special equipment and tools.

It is required that the pressure gage sensitivity be $2 \%$ or better. A hydraulic pump and compatible fittings are the only additional required equipment.

c. Special handling requirements/operating time.

There are no special handling requirements for this test; it may be performed while the cask is either horizontal or vertical. The time required for the test is about eight hours. If a new lid is procured for an existing cask, e.g., the modified lid for the $T N-8 L$, that lid must also be hydro-tested.

d. Cask contaminants, amounts, types.

Since this is a one-time test for each new cask there are no contaminants introduced.

e. Contaminant analysis.

Contaminant analysis is not applicable to this test.

f. Damage experience.

There has been no damage experience resulting from these tests and conversely, since the test is for new casks only, there has been no testing of casks which have been damaged before testing. 
g. Radiological experience

Radiological experience is not applicable.

h. Problems, recommendations

This is a simple test. No problems have been encountered and there are no recommendations for doing the test any differently. Care should be taken during the performance of the test to prevent harm to personnel in the event of a high pressure leak or a cask containment failure.

i. Decontamination/cleaning experience.

The cask is exposed only to tap water so cleaning presents no problem. The last traces of moisture are removed as a part of the subsequent test (leak testing).

j. Handling equipment ( lift beam, hook adaptors)

If the cask needs to be moved before or after the test, tine standard 1 ift beam may be used.

1.2 Leak Testing

a. Testing requirements and frequency.

A pressure rise leak test is performed on a new cask before it is put into service, again after the third 
use of the cask and annually thereafter. The test is conducted in accordance with ANSI N-14.5. All of the pressure boundary $0-r i n g s$ are replaced prior to the start of the test.

The acceptance criteria for the test, derived from release 1 imitations given in 10 CFR 71 , are leak rates of less than $2.8 \times 10^{-4} \mathrm{~atm} \mathrm{cc} / \mathrm{sec}$ air through any cavity penetration and a total of $8 \times 10^{-4}$ for the system. This is one-half the leak rate that was calculated as being in compliance with paragraph 6.3 and 6.5 of ANSI $N-14.5$ for $L_{A}$ and $L_{N}$. The initial pressure for each test is of the order of magnitude of $10^{-3}$ mbar. There is no value of pressure differential as a function of time that can be used to characterize these tests in general because the leak rate is also a function of the volume being tested. The minimum allowable duration of a test is a function of the sensitivity of the test equipment. with highly sensitive gages this can calculate to less than a minute for some tests, but Transnuclear has set a minimum test time of two minutes. The cavity leak test will require nearly 20 minutes.

b. Special equipment and tools.

Transnuclear uses its Vacuum Drying system (VDS) vacuum pump for the initial pull-down of the cavity pressure. It is shown in Figure 22. A laboratory grade vacuum system, referred to as the Leak Test system (LTS), is then used for the actual testing. 
The LTS includes a liquid nitrogen cold trap. Pressure measurements are determined by Pirani gages and displayed on a digital readout device. Vacuum test covers are identical to those used in the routine leak testing of casks prior to each shipment (Figure 20). Vacuum 1 ines and fittings are off-thesheif quick-connecting components (Figure 23 ).

c. Special handling requirements/operating time.

The VDS is used not only for the initial pull-down of the pressure in the cask cavity but also to remove any moisture from the internals. The LTS is then used to pull down to about $10^{-2}$ mbar before introducing the liquid nitrogen to the cold trap. If the cask can be left overnight with the VDS in the drying mode for the initial pull-down, the leak tests can be completed in one operating shift.

d. Cask contaminants, amounts, types.

Equipment used during leak testing seldom becomes contaminated if used with reasonable care. The LTS is shipped as a "limited quantity shipment". It can not be shipped as an uncontaminated item because parts of the motor, etc., are nist accessible for taking smears for contamination measurements. The vacuum pump oil has not become contaminated during operations of Transnuclear's equipment. 
e. Contaminant analysis.

This is not applicable, because of the lack of contamination.

f. Damage experience.

Some shipping damage experience has been experienced but this would not be applicable to a dedicated facility. Careless handiing of the vacuum fittings can mar the aluminum sealing surfaces and undue flexing of the corrugated stainless steel vacuum tubing can result in fatigue cracks.

g. Radiological experience.

Radiological exposure is determined by the environment in which the testing is performed. All testing to date has been done at or near pool-side in reactor facilities and the operators may pick up about $2 \mathrm{mR} / \mathrm{hr}$ in such areas. In a dedicated facility, the exposure should be nearly zero.

h. Problems, recommendations.

Some of the problems encountered in uses to date, such as unstable scaffolding on which to rest the LTS, will not be a factor in a dedicated facility if adequate provision is made in the design of the facility. Casks with any appreciable amount of crud 
in the cavity or drain lines require extended outgassing which results in an extended test duration. The cask internals should be as clean as practical prior to the test.

i. Decontamination/cleaning experience.

There is no requirement for decontamination or cleaning of casks in order to perform these tests. It is prudent to clean surfaces on which test equipment will rest to prevent the spread of contamination.

j. Handling equipment

Except for using the crane and lift beam to move the cask to or from the test station, no special handling equipment is needed for these tests.

\subsection{Humidity Testing}

a. Testing requirements and frequency.

The humidity test is a determination of the dew point of the balsa wood filled compartments of the cask and its impact covers. The crush strength of the balsa is premised on a specific moisture content; this test is to verify that the amount of moisture neither increases nor decreases. The test consists of flowing a closed circuit of air through the component 
to be tested and determining the dew point with a condensation hygrometer. Each balsa wood filled compartment is tested every two years.

b. Special equipment and tools.

Thermometers are used for measuring both ambient and compartment wall temperatures. The hygrometer system consists of an air pump, an air flow rate meter, a gas drying chamber, a self-compensating condensation mirror and a digital control and readout. Ordinary tubing fittings are used to connect the components of the system. No special tools are required.

c. Special handling requirements/operating time.

A11 of the equipment can be carried in a suitcasesize container and is easily assembled for the testing. Operating time will vary depending on the stability of the ambient temperature. Once the temperature is stabilized, the test requires about an hour for each compartment to be tested.

d. Cask contaminants, amounts, types.

The compartments to be tested have no traces of contamination in them so it is relatively easy to keep the test equipment clean. 
e. Contaminant analysis.

Contamination analysis is not applicable to this test.

f. Damage experience.

There have been no incidents of damage related to these tests.

g. Radiological experience.

The drum sections of the casks are tested when there is no fuel in the cask so exposure to operators is i imited to that of the test environment. The impact covers can be removed from the fuel area for testing which minimizes exposure.

h. Problems, recommendations.

Transnuclear can identify no problems or recommendations regarding this test. This test is required only for casks which utilize wood in the impact 1 imiters.

i. Decontamination/cleaning experience.

The components are surveyed for contamination before testing and decontaminated if required. The cleaning of the components is the same as preparing a cask for shipment. 
j. Handling equipment ( 1 ift beam, hook adaptors).

No special handling is required, except that the impact covers must be removed from the cask. This is accomplished as a part of routine operations.

\subsection{Fusible Plug Leak Testing}

a. Testing requirements and frequency.

The balsa filled compartments of the cask and impact cushions have fusible plugs in the compartment walls. These plugs are designed to melt under fire accident conditions so that any steam formed in the compartment will escape rather than overpressurizing the compartment. The o-rings which provide the seal for the fusible plugs are routinely replaced once every six years. They also are replaced whenever a plug is removed for access to the compartment interior for humidity testing.

b. Special equipment and tools.

A special vacuum bel1, just large enough to fit over a fusible plug, is used to form a seal around the plug for leak testing. No other special equipment is required except that used in other leak testing.

c. Special handling requirements/operating time.

There are no special handling requirements. Each plug can be tested in about ten minutes (there are 30 
plugs on each cask and 8 plugs on each of the end covers, or 46 in al1).

d. Cask contaminants, amounts, types.

Routine decontamination procedures are all that is necessary to prepare the plugs for testing.

e. Contaminant analysis.

Contamination is minor. For a typical analysis

please refer to Part 1, Section 8.9.

f. Damage experience.

There has been no damage experience related to these tests. The plug ports usually are covered with tape when the cask is in a pool so they are protected from contamination.

9. Radiological experience.

Radiological exposure is that of the general environment in which the testing is being performed.

h. Problems, recommendations.

There are no problems or recommendations associated with this test. As noted above, the fusible plugs 
are only used on casks which require access to a normally sealed compartment.

i. Decontamination/cleaning experience.

Routine decontamination is all that is required for these tests.

j. Handling equipment ( 1 ift beam, hook adaptors).

The conditions of this test are closely related to those of the humidity test previously described.

\subsection{Load Testing}

a. Testing requirements and frequency.

Load testing requirements fall into two categories; one for devices for lifting 10,000 lbs or more and one for the lifting of less than 10,000 lbs. This discussion will deal only with the former except as specificaliy noted.

Lifting devices are typically designed to a yield point of three times the load to be carried or a tensile strength of five times the load. They are tested to 1.5 times the intended load at intervals of no more than one year. In some instances a liquid penetrant test may be used in lieu of actual load testing (see ANSI $\mathrm{N}-14.6$ ). 
Also required in addition to the physical testing are non-destructive pre- and post-test examination of the components and functional testing of the device before its return to service.

b. Special equipment and tools.

Testing equipment includes a hydraulic pump, a cylinder with a hydraulic driven piston, a pressure gage, hydraulic lines and fittings, and a test fixture especially designed for this purpose. The fixture is shown in Figure 25. In some instances, liquid penetrant testing materials are used. The cask itself may be substituted for the special fixture. This has the advantage of (1) testing the lifting trunnions as well as the lifting device and (2) only one-third the hydraulic load needs to be applied provided the cask is suspended about an inch above the deck during testing. For some casks, special provision will need to be made for the hydraulic cylinder load to be distributed uniformly over the head.

The lifting beam is assembled onto the fixture and the hydraulic cylinder is placed between the fixture and the lifting pin(s) of the lift beam. The cylinder is then loaded to the desired force (pressure $x$ piston area). 
LOAD TEST FIXTURE
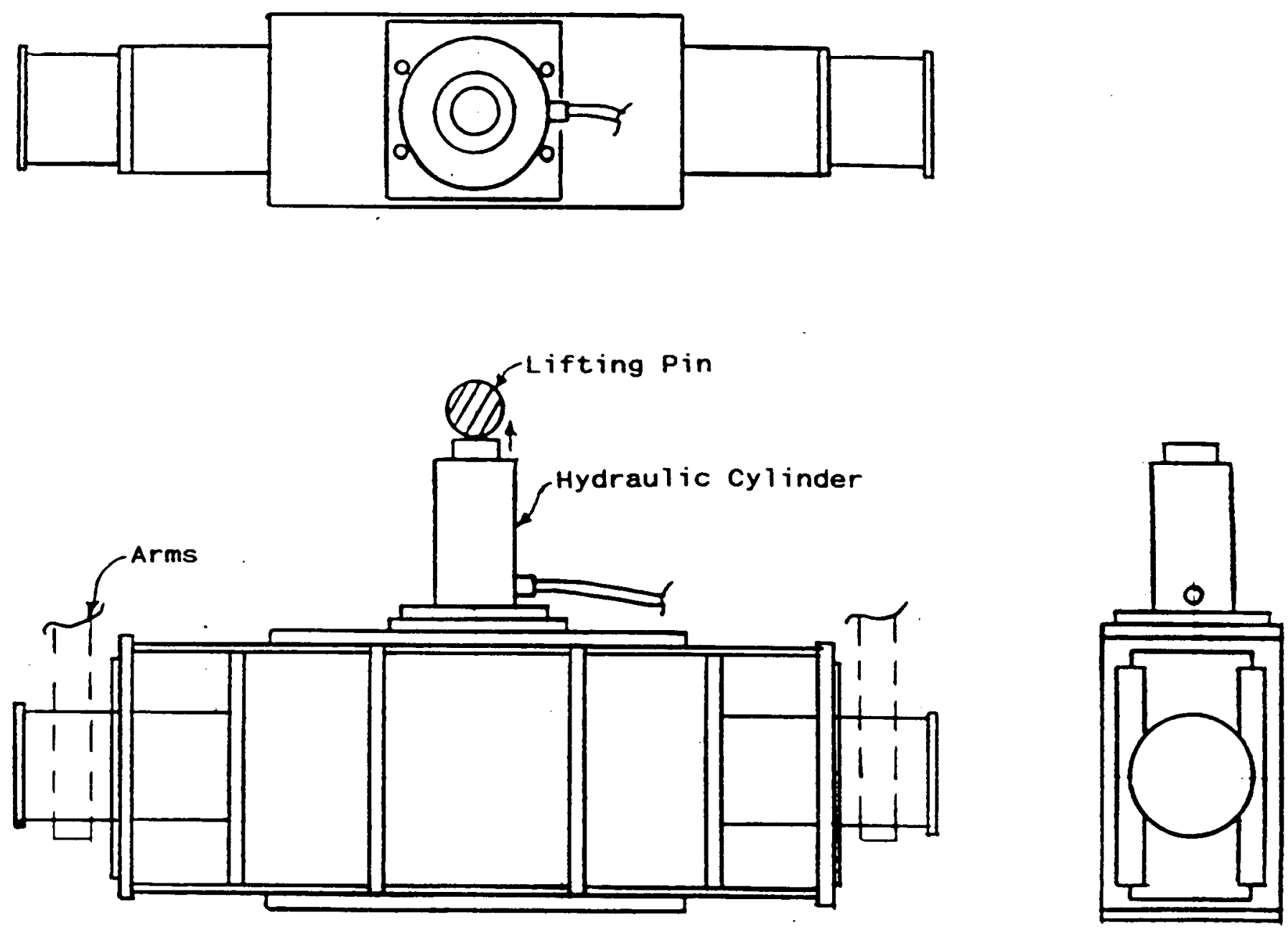

Figure 25 
c. Special handling requirements/operating time.

Prior to testing a lifting device it is visually examined and paint chips and other blemishes are marked. A crane is used to assist in assembling the lifting beam onto the test fixture and to provide a safety backup throughout the test in the event of tipping. After the load testing is completed, the load bearing components of the lifting beam are disassembled and inspected. Disassembly, inspection and reassembly of the heavy parts requires hands-on training of operators and strict following of procedures. Bearing surfaces are visually inspected. A comparison of the pre- and post inspections is recorded. A two-man team can perform a complete load test, do the inspection, and functionally test a lift beam in approximately eight hours.

Pairs of wire rope slings are usually used for lifting lighter loads. These slings can be tested by attaching the component normally lifted by the pair to one leg of the sling and suspending the load from the end of the other leg. The test load becomes twice that of the working load but still less than the design load.

d. Cask contaminants, amounts, types.

During the disassembly of the lifting beam, some surfaces are exposed that have been covered since the previous test. The beam will have been in and out of 
a pool several times without the benefit of decontamination of these surfaces. Therefore, caution must be exercised as these surfaces are exposed. Nearly all of the contamination will be tied up in the lubricant of the joint, so the possibility of airborne contamination is not great.

e. Contaminant analysis.

Please refer to Part 1 , Section 8.9 . for the anaiysis of the contaminants.

f. Damage experience.

A lift beam atop a test fixture is a top-heavy assembly and is easily tipped. The assembly should remain attached to the crane with moderate slack in the sling. Even with this precaution, we have had the experience of movement of the system sufficient to cause the cylinder to fall from the test fixture and damage a high-pressure fitting.

g. Radiological experience.

In one or two isolated incidents the health physics technician attending the test has required that the test operators wear respiratory equipment during the disassembiy of the beams. To the best of our knowledge, this was based on personal preference rather than high airborne contamination levels. 
During tests where Transnuclear health physics personnel were monitoring contamination levels, respiratory equipment has never been required.

h. Problems, recommendations.

A dedicated facility could be designed to handle load testing safely and expeditiously. With proper ventilation, any airborne contamination that is or might be present could easily be kept away from the test operators. A specific area with a permanent setup for load testing would provide a safe environment. In a dedicated facility for load testing lifting devices, the test area should be serviced by one five-ton capacity crane and at least two monorail jib cranes of one-ton minimum capacity each.

i. Decontamination/cleaning experience.

Decontamination of the disassembled components must proceed as the surfaces are exposed. For the most part this consists of wiping the lubricant from the component. Care must be taken if a solvent is to be used to assist in this because the resultant mixture may consist of a combinatiori of ha:ardous materials which may be almost impossible to dispose of properiy. 
j. Handling equipment ( 1 ift beam, hook adaptors).

Handling equipment consists only of a crane and a lifting sling, the latter preferably one of nylon webbing rather than wire rope.

\subsection{Radiation Shielding}

a. Testing Requirements and Frequency.

The radiation shielding test is performed with the cask loaded with fuel with a known source term. The test data are a record of beta, gamma and neutron radiation dose rates at predetermined locations over the surface of the cask. The locations shown in the test procedure are such that they can be reproduced for each test. The dose rate at each location is compared to that of previous tests to determine if there has been any change in shielding effectiveness. The shielding test is a commitment made in the safety Analysis Report (SAR) for the casks, which was submitted to NRC for approval. Subsequent to NRC's acceptance of the SAR it is automatically a requirement of the certificate of Compliance.

b. Special equipment and tools.

The test requires a neutron dose rate detector and a gamma dose rate detector, each with a range of $0-50$ or 0-100 mR/hr and a sensitivity of $5 \mathrm{mR} / \mathrm{hr}$. 
c. Special handling requirements/operating times.

The test procedure requires measurements to be made with the cask in both vertical and horizontal positions. The test can be performed at specific points in the normal operating procedure instead of requiring special handling. This test can be done in less than three hours, and can usually be performed concurrently with other cask handling steps.

d. Cask contaminants, amounts, types.

A prerequisite for this test is that it allows no smearable surface reading of greater than 220 dpm per $100 \mathrm{~cm}^{2}$ beta-gamma, averaged over five $300 \mathrm{~cm}^{2}$ smears. The concern for contamination is removed before the test is started.

e. Contaminant analysis.

Contaminant analyses are given in Part 1 , section 8.9.

f. Damage experience.

Transnuclear has had no damage experience associated with this test. 
g. Radiological experience.

Even though the cask is filled with fuel when this test is done, the age of the fuel has been such that the radiation levels are quite low. In addition, the time required to take a reading is only a few seconds, so overall exposure can be held to a low level if reasonable caution is exercised.

h. Problems, recommendations.

There are no problems associated with this test. A crane with a powered, rotating hook can significantly speed up the taking of the readings.

i. Decontamination/cleaning experience.

Any decontamination associated with this test is of a routine nature.

j. Handling equipment ( 1 ift beam, hook adaptors).

The handling of the cask for this test is a part of the standard operating procedure.

\subsection{Packaging $K_{\text {eff }}$ Testing}

a. Test Requirements and Frequency.

This test is performed with fuel in the cask. One set of readings is taken with water in the cask and a 
second set with the cavity dry. A formula is then used to calculate $K_{\text {eff }}$ as:

(Avg. count, wet) $-0.301 \times$ (Avg. count, dry)

(Avg. count, wet)

The result is not as accurate as a neutron multiplication test, but it provides an adequate margin of safety with a limit of acceptance of 0.916 for this calculation vs. an SAR limit of 0.95 . This test is performed on each cask at least once every two years if the cask is in service.

b. Other considerations.

Please refer to items b through $j$ of section 1.6 of this Part.

\subsection{Thermal Testing}

a. Test Requirements and Frequency.

The initial license for the Transnuclear casks specified that every two years the temperature of the fins and the cask cavity walls be measured after the cask reaches thermal equilibrium. After compensating for differences in fuel decay heat load the temperatures would be compared with earlier tests to ascertain whether there had been a change in heat dissipation efficiency. After circumstances indicated that the casks would seldom if ever be used at their design heat load capacity, NRC agreed to 
waive this test unless the fuel to be shipped had a heat load that exceeded $25 \%$ of the design heat load. For all practical purposes this decision has eliminated the requirement for thermal testing of the present Transnuclear fleet. If at some time the $25 \%$ heat load were to be exceeded we would be required to perform the test. Casks of new designs with less excess heat dissipating capability may need to be tested on a routine basis.

b. Other considerations.

The other considerations related to this test are covered throughout section 1 of Part II.

2. Repair Operations

a. Repair experience (i.e., nature and frequency).

The need to repair casks is negligible. They do, however, have some vulnerable features that require special care in order to avoid the need for repairs. As examples:

- All o-ring sealing surfaces can be marred to the extent of affecting their effectiveness. The lid sealing surface is protected by a metallic shield at any time the cask is being loaded or unloaded.

Sealing flanges must be handled with reasonable care while removed from the cask. The surfaces that these flanges seal against are susceptible to being dented by connecting devices and careless replacement of the flange. 
- Cask trunnions and the surfaces against which they rub, such as during cask rotation to and from the venicle, may experience galling if insufficient or inadequate lubricant is used.

b. Special equipment and tools.

The repair of a sealing surface can be a difficult and time consuming operation. The repair may require machining a thin layer of material uniformly from the entire surface. Sealing surfaces that have been badly dented may require a weld bead over the defect before the machining step. It should be noted that any repair must be performed in accordance with the original design and fabrication criteria of the cask, and recertification testing must be done on all components affected by the repair.

c. Special handling requirements/operating time.

It is conceivable that the same handiing equipment could be required for major repairs that was used in the fabrication of the cask. It should be assumed that the area in which repairs are made as well as the equipment that is used will become contaminated. Operating time is difficult to estimate but it is probable that far more time and effort will be spent in preparing procedures, etc., for the repair and certifying the result than will be spent accommplishing the repair. The machine set-up time will be the major part of the repair effort for a lid sealing surface. 
d. Cask contaminants, amounts, types.

Cask repairs in the vicinity of drain 1 ines could dislodge accumulated internal contamination which could be quite "hot" even in small quantities. The planning phase of the repair should take such possibilities into account. The amount involved could range up to several curies and the type would be typical of crud.

e. Contaminant analysis.

The analysis of contaminants exposed through repair work would be similar to that given in Part I, Section $8 . \mathrm{g}$.

f. Damage experience.

Transnuclear has had insufficient experience with damaged casks, or repairs to casks, to cite any specific repair history.

9. Radiological experience.

The lack of repair experience does not permit us to draw any conclusions about radiological effects.

h. Problems, recommendations.

The obvious recommendation is to keep casks free of damage through diligent planning and training and 
careful operation in accordance with the approved Quality Assurance program. A cask maintenance facility should be equipped with good welding facilities, seal surface machining and honing equipment, and good ventilation for controlling airborne contamination. Facilities for painting, ultrasonic decontamination, electroetching and electroplating should also be included.

i. Decontamination/cleaning experience.

No conclusions can be drawn because of the lack of repair experience.

\section{Basket Removal}

Transnuclear's TN-8L and TN-9 casks do not have removable baskets. The fuel assembly compartments are fixed within the lead gamma shielding which was poured directly around the compartments during cask fabrication. Therefore, we cannot offer any direct experience on this topic. Larger casks designed and manufactured recently by Transnuclear do have removable baskets, but no operating experience that includes basket replacement has been accumulated.

Our estimate of the requirements for a cask fleet indicates that dedication of a group of casks to BWR's and another group to PWR's would probably be the most efficient way to operate. Although this would preclude the necessity for frequent basket changes, the cask maintenance facility should have the capability to remove and repair baskets. 


\section{Maintenance Quality Assurance Requirements.}

What recommendations for:

a. Cask moving.

The design of a cask maintenance facility should provide the capability for the movement of casks through all areas by overhead crane. The movement and placement of casks can be accomplished more quickly and safely by crane than by dollies. Dollies could be used only if the maintenance facility were collocated with an overhead hot cell unloading facility such that dollies would be required to place the cask under the unloading ce11. Even then, dollies are recommended for that movement only with all other moves being by crane.

b. Cask testing and cleaning.

Individual stalls are recommended for cleaning and testing stations. Separate facilities are recommended for cleaning baskets as opposed to casks because the cleaning techniques are different. Consideration should be given to setting up a dedicated test station for each specific type of test rather than attempting to use all stations for all purposes. The work scaffolding within a station should be very sturdy, should function as an elevator to access all levels of the cask and should be able to carry loads greater than just personnel. Each station should have its assigned set of tools. Heavier tools should be mounted on jibs and counterweighted for easier, faster operation. If the decision is made that the cask maintenance facility is not to be collocated 
with a cask loading or unloading facility, consideration should be given to performing many of the routine tests while the cask remains on the vehicle.

c. Basket testing and cleaning.

Baskets will be highly contaminated, therefore, the basket testing and cleaning area should be enclosed and separate from the other work stations and be almost entirely remotely operated. The capability for inspecting baskets by closed circuit television should be included. A controlled area should be assigned for the storage of spare baskets after they have been cleaned and tested. Testing will include load testing of the basket lifting lugs, inspection of the basket's structural components, and the effectiveness of the neutron poison materials.

d. Special equipment, facilities, utilities for cleaning and testing areas.

Special equipment might include:

- High volume vacuum pumps

- Low volume, very low pressure vacuum pumps

- Liquid nitrogen availability

- An inventory of special vacuum fittings

- Equipment for cleaning and drying cold traps (involves flammable solvents) 
- A vacuum pump maintenance capability

- Vacuum and pressure gage maintenance and calibration capability.

- Powered and manually operated torque wrenches

- Torque wrench calibration capability

- Radio controlled cask and auxiliary cranes.

- Air supply, demineralized water, electrical outlets at each station, including three phase power for higher horsepower motors.

- A spare parts control program with all of the necessary additional controls for parts important to safety (traceability to origin, acceptance data, storage environment record, shelf life control, etc.)

- Computerized flagging of every item subject to recertification testing, listing items by specific identity and the specific test(s) due by a given date.

- The capability of tracing the history of every test including the validity of the procedures used, the certification of the test equipment used, the certification of replacement parts, the qualifications of the test operators, the review and verification of results, and the prompt and accurate logging of the test information. 
e. Office area requirements.

The amount of office space required will be a function of not only the number of management personnel associated directly with operations of the facility, but also the number of support personnel (accounting, human resources, etc.) required. Collocation with another facility under the same ownership or control would reduce the number of support personnel required.

f. Vehicle maintenance requirements.

The maintenance requirements for highway trailers could best be determined by visiting any Fruehauf trailer maintenance facility and duplicating the buildings, equipment, and procedures.

The maintenance of rail cars should include an inspection passage between and beneath the rails for visual inspection by a qualified rai $i$ car mechanic. The mechanic's work would be limited to changing out brake shoes, replacing air valves, etc. Major maintenance of rail cars should be handled by a car shop on a contract basis. 
g. Facility staffing for one shift operation.

$\begin{array}{lc}\text { Personnel required for } & \text { Add the following for } \\ \text { a colLOCATED site } & \text { an INDEPENDENT site } \\ \text { Facility manager } & \text { HP manager } \\ \text { Test area supervisor } & \text { QA manager } \\ \text { Test operators } & \text { Rail car mechanic } \\ \text { HP technicians } & \text { Heavy equip. oper. } \\ \text { QA technicians } & \text { Calibration tech. } \\ \text { NDT technician } & \text { Security staff } \\ \text { Test engineer } & \text { Building maint. staff } \\ \text { Support clerical } & \text { Draftsperson }\end{array}$

h. Projected cost for cask service (overall and annually per cask).

Projected costs estimated for specific programs in which a maintenance facility was assumed, but was not amortized as a part of the maintenance cost, were of the order of magnitude of $\$ 20,000$ per year. 

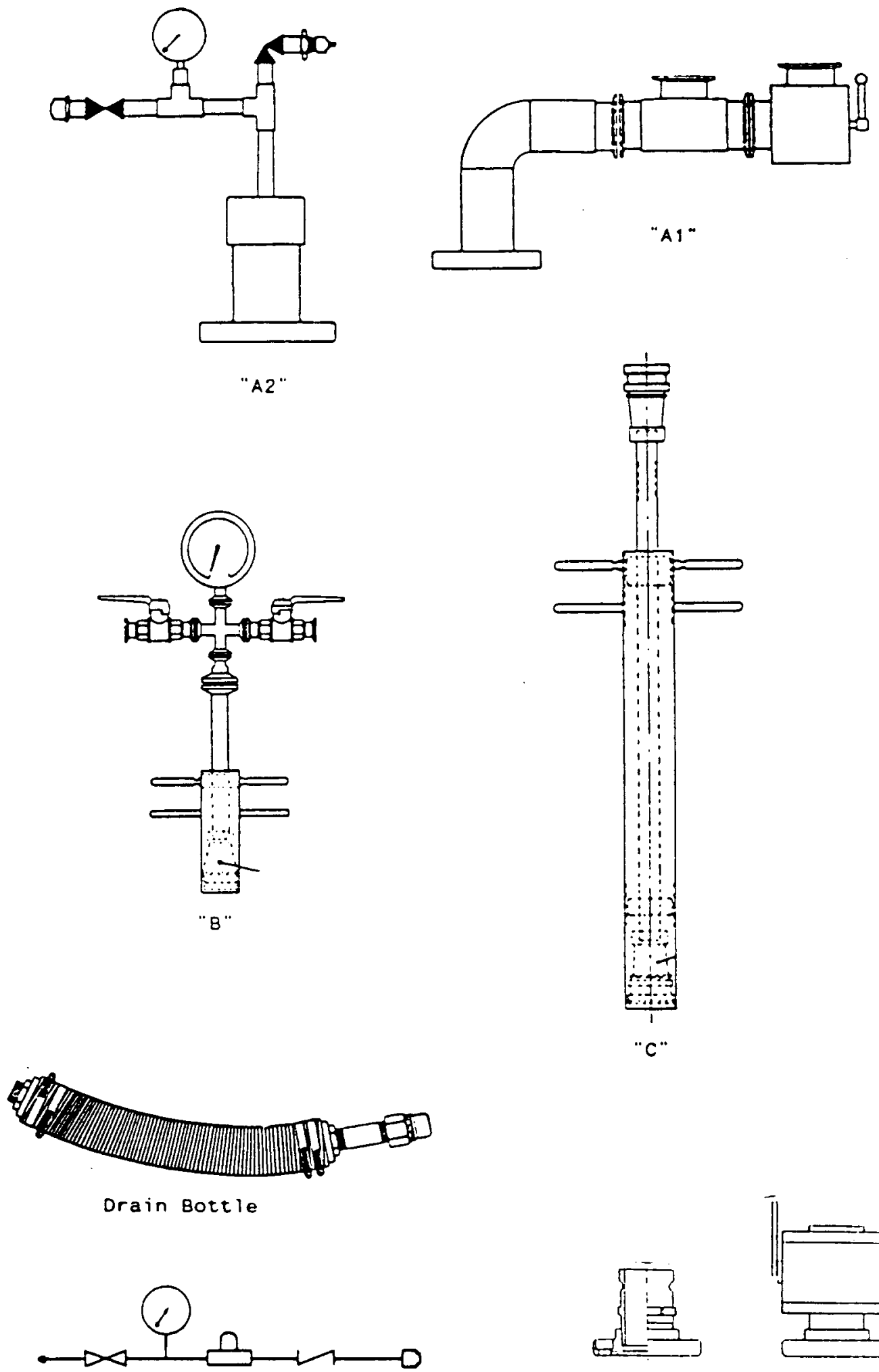

Cooldown system (CDS)

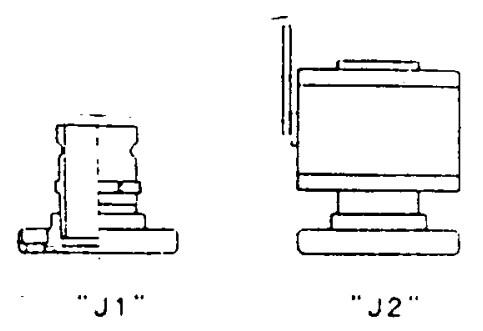


1. CERTIFICATE NYYYOTFY

IENABLE

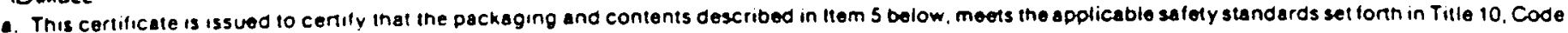
of Federal Regulations. Part 71. Packaging and Transponation of Radioactive Material."

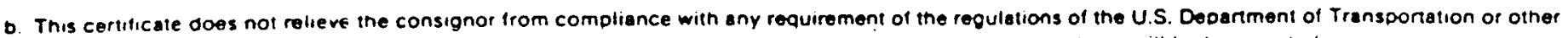
applicabie regulatory agencies. Including the government of any country inrough or into which the package will be transported

THIS CERTIFICATE IS ISSUED ON THE BASIS OF A SAFETY ANALYSIS REPOAT OF THE PACKAGE OESIGN OA APPITCATION

- ISSUED TO INeme and AdAres'

b. TITLE ANO IOENTIFICATION OF REPOAT OA APPLICATION

Transnuclear, Inc. One North Broadway White Plains, NY 10601
Transnuclear, Inc. application dated

October 16, 1985, as supplemented.

C. DOCKET NUMEER $71-9015$

(a) Packaging

(1) Model Nos.: TN-8 and TN-8L

(2) Description

Lead, steel and resin shielded irradiated fuel shipping casks. The casks approximates a right circular cylinder 1,718 $\mathrm{mm}$ in diameter and $5,516 \mathrm{~mm}$ long. The cavity consists of three (3) stainless steel square pressure vessels welaed to an end plate and a circular stepped top flange, separated by a T-shaped copper plate anc surrounded with $B 4 C+C u$ plates. Each cavity is $230 \times 230 \mathrm{~mm}$ and $4,280 \mathrm{~mm}$ long. The main shielding consists of $135 \mathrm{~mm}$ of lead, $26 \mathrm{~mm}$ of steel and $150 \mathrm{~mm}$ of resin. A wet cement layer is located between the lead and the outer shell. Radial copper fins are welded to the outer shell and ccver the surface of the cask between each end drum. The Modei No. TN -8 has 150 rows of firs and the Model No. TN-8L has 104 rows of fins.

The lid is a welded stainless steel shell containing lead and resin shields. The pressure vessels are closed and sealed by sixteen, 11/4-inch diameter bolts arid two silicone rubber or Viton 0-rings located within recessed grooves on the top flange. Each extremity of the cask is surrounded by circular stainless steel drums reinforced by radial gusset plates end filled with balsa wccc. A disk shaped impact limiter, corstructed of carbon steei and balsa wood is fastened to each drum with four, 1-1/4-inch bolts. The vent ard drain lines which penetrate the inner cavity are eouipped with positive closures. In addition, all access ports are protected by the impact limiters.

The lid of the casks may be replaced with a modified lid which increases the cavity length to $4,362 \mathrm{~mm}$ or to $4,394 \mathrm{~mm}$ with the lid plate removed. This arrangement will be referred to as "Configuration $X . "$ 
Page 2 - Certificate No. 9015 - Revision No. 14 - Docket No. 71-o015

5. (a) Packaging (continued)

(c) Description (continued)

Trunnions are used for liftirg and tie-dcwn of the package. The packäges weigh approximately $36,000 \mathrm{~kg}$.

(3) Drawings

The Model No. TN-8 packaging is constructed in accordance with Transnuclear Drawing No. 9317.01, F.ev. J. The Model No. TN-8L is constructed in accordance with Transnuclear Drawing No. 9317.138, Rev. A. The materials of construction and welds shall be in accordance with Annex A, B, ard C to Chapter II of the Application.

The lid for Configuration $X$ is constructed in accordarce with Trarisnuclear Drawing Nos. 9040-500-1, Pev. 1, 9040-500-2, Rev. I and 9040-500-3, Rev. 0.

(b) Contents

(1) Type and form of material

(i) Irradiated PWR uranium oxide fuel assemblies of the following specifications:

Fuel form

Cladding material

Maximum initial U content/assembly, $\mathrm{kg}$

Maximum average initial U-235

enrichment with $\mathrm{Zr}$ cladding, w/o $\$ .2$

Maximum average initial $11-235$ enrichment with SS cladding, w/o 4.0

May.imum bundle cross section, in

Maximum active fuel length, in

Minimum cooling time, day

Maximum weight/fuel assembly, $\mathrm{kg}$

Group I fuel assemblies

Initial fuel pin pressure at $100^{\circ} \mathrm{F}$, psig

Maximum average burnup, MWD/MTU

Group II fuel assemblies

Maximum average burnup, MWU/MTU

$36,0 \mathrm{CCO}$

Clad UC Fellets Zr or $5 \hat{S}$

469

4.0
8.5

146

150

733 ; ànd

250

38,500 ; or

For the casks in Configuration $y$, the minimum cooling time of the fuel assemblies shall be 1,460 days with the lid plate installed and 2,190 days with the lid plate removed. 
Page $\mathbf{3}$-Certificate No. 9015 - Revision No. 14 - Docket Ho. 71-9015

5. (t) Conterits (continued)

(ii) Solid non-fissile irradicted hardware. As needed, appropriate component spacers must be used when loading irradiated hardware into the cask cavity to limit movement of the contents during accident conditions of transport.

(iii) Intact Bh'R and PWR fuel rods; failed or damaged BWR or PWR fuel rods encapsulated in welded, stainless steel tubes; or combinations of such fuel rods. Encapsulation tubes shall te fabricated in accordance with Battelle Urawing No. BCD-WJ-001, Revision 1. Rods shall be constrained ty a basket or grid structure; initial li-235 content shall be less than $15.0 \mathrm{~kg}$ per rod bundle; cross sectional area of the rods, tubes, and full length structural material shall not be less than 29.6 square inches; and the bundle cross section shall not be greater than 8.5 irches. Maximum weight per bundle shall not exceed $733 \mathrm{~kg}$. The group I and Group II burnup limits of paragraph $5 .(b)(1)(i)$ apply.

(2) Maximum quantity of material per package

(i) For the contents described in Item 5.(b)(1)(i), Group I fuel assemblies:

Three PWR assemblies. The maximum decay heat load is nct to exceed 35.5 kilowatts per package and 12 kilowitts per assembly for the Model No. TN-8 packaging and 23.7 kilowatts per packäge and 7.9 kilowatts per assembly for the Model No. TN-8L packaging.

(ii) For the cortents described in Item 5.(b)(1)(i), Group II fuel assemblies:

Three Ph'R assemblies. The maximum decay heat load and the maximum free gas volume are rict to exceed the limits listed in the table below:

Maximum Free Gas

Decay Heat per)
Shipment, $k \mathbf{k}^{\prime}$

1.5

3.0

9.0

15.0

21.0

27.0

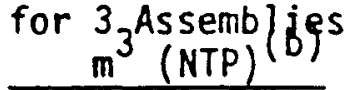

0.558

0.543

0.483

0.441

0.408

C. .384
Configuration $X$

Maximum Free Gas

for ${ }_{m}^{3} \begin{aligned} & \text { As semplies } \\ & \text { (NTP) }\end{aligned}$

0.601

0.585

0.520

0.475

0.439

0.413

Notes: (a) Decay heat load per assembly must not exceed 7.9 kilowatts for Model No. Tii-8L packaging.

(b) NTP conditions are $25^{\circ} \mathrm{C}$ and one (1) bar. 
Pace 4 - Certificate No. 9015 - Revision lio. 14 - Docket No. 71-9015

5. (b)(2) (continued)

(iii) For the contents described in ltem 5.(b)(1)(iii): Three (3) rod bunules. The maximum decay heat load and riaximum free gas volume are not to exceed the limits listed in Paragraph $5 .(b)(2)(i i)$.

(c) Fissile Class

Maximum number of packages per shipment
III

One (1)

6. Group I and Group II fuel assemblies, either Zr or SS clad, and bundles of PWR. and/or BWR fuel rods that individually meet all the appropriate specifications of 5.(b)(1)(i), 5.(b)(2)(i), 5.(b)(1)(iii), and 5.(b)(2)(iii) above may be packaged in any combination.

7. PWR assemblies may be shipped either with or without burnable poison rod, thimble plug, or coritrol rod assemblies.

8. As needed, appropriate component spacers may be used in the cask cavity to properly position the fuel assemblies.

9. The maximum weight of the contents (fuel assemblies, component spacers, inserts, irródiated harcivare, etc.) must not exceed $2,200 \mathrm{~kg}$.

10. The cask cavity must be dry (no free water) when delivered to a carrier for transport. For the contents described in I tem 5.(b)(i)(i) and $5 .(b)(1)(i i i)$, residial moisture must be promptly removed from the cask cavity by the methods described in Annex I to Chapter VIII of the Application and the cavity must be promptly backfilled with $1.0 \mathrm{~atm}$ of helium, nitrogen, or argon gas.

11. Known or suspected failed fuel assemblies (rods) and fuel vith cladding defects greater than pin holes and hairline cracks are not authorized except as provided in $5 .(b)(1)(i i i)$.

12. Prior to each shipment, the package must meet the tests and criteria specified for each shipnent (operction) in Chapter VIII of the Application.

13. The package contents must be sc limited that under normal conditions of transport the total ciose rates must not exceed $17 \mathrm{mrem} / \mathrm{hr}$ at one meter from the surface of the package.

14. Any system used for cooling down the package must be provided with a pressure relief device set so that the maximum pressure in the containment vessel cannct exceed 7 atmospheres during the cool-down process.

15. The systems and components of each packaging must meet the pericdic tests and criteria specified in Chapter VIII of the Application. Each packaging that fails to meet these criteria must be withdrawn from service untii corrective action has been completed.

16. Repair and maintenance of the packaging must be as described in Chapter VIII of the Application. 
Page 5-Certfficate No. 9015 - Kevision No. 14 - Docket Ho. 71-9015

17. All valves, fittings, seals and relief devices must be of the type, size, model and manufacture as indicated on the design drawings. The resin material nust be of the specifications stated in Annex A to Chapter II of the Application.

18. Prior to first use, each packaging must meet the acceptance tests and criteria specified in Chapter VIII of the Application.

19. In accordance with Annex $L$ to Chapter VIII, at periodic intervals not to exceed two years, the thermal performance of the cask must be arialyzed to verify that the cask operation has not degraded below that which is licensed*. Following the initial acceptance tests, the heat source may be that provided by the decay heat from the loading of the package, provided that the heat source is equal to at least 25\% of the design heat load for the package. Each cask that fails to meet the thermal acceptance criteria given in Annex L of the Application must be withdrawn from service until corrective action can be completed or the license amended to linit the package to a lower heat load.

ऋ The thermal performance test is not required at pericdic intervals when the maximum decay heat load per package does not exceed $25 \%$ of the design heat load.

20. Use of Configuration $X$ lid shall require modification of Chapter VIII of the application in accordance with page 28 (9.0 PACKAGING ACCEPTANCE, OPERATIONS AND MAINTENANCE PROGRAMS) of the April 30, 1986 supplement.

21. The package authorized by this certificate is hereby approved for use under the ceneral license provisions of $10 \mathrm{CFR} \$ 71.12$.

22. Expiration date: January 31, 1991.

\section{REFERENCES}

Transnuclear, Inc. afplication dated 0ctoher 16, 1985.

Supplements dated: December 27, 1985; March 11 and 14, Apri1 30, and Cctober 29, 1986; and February 27 and May 15, 198.7.

FCR THE U.S. MUCLEAR REGULATORY COMMISSION

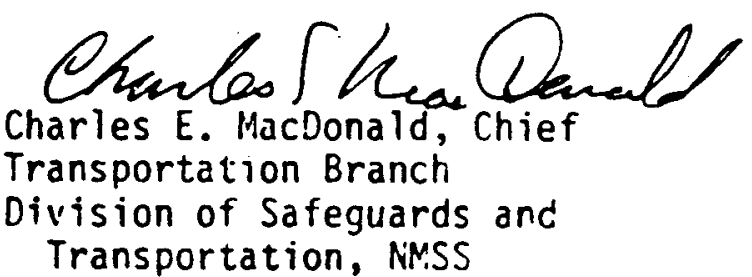

Dated: HOV 271897 


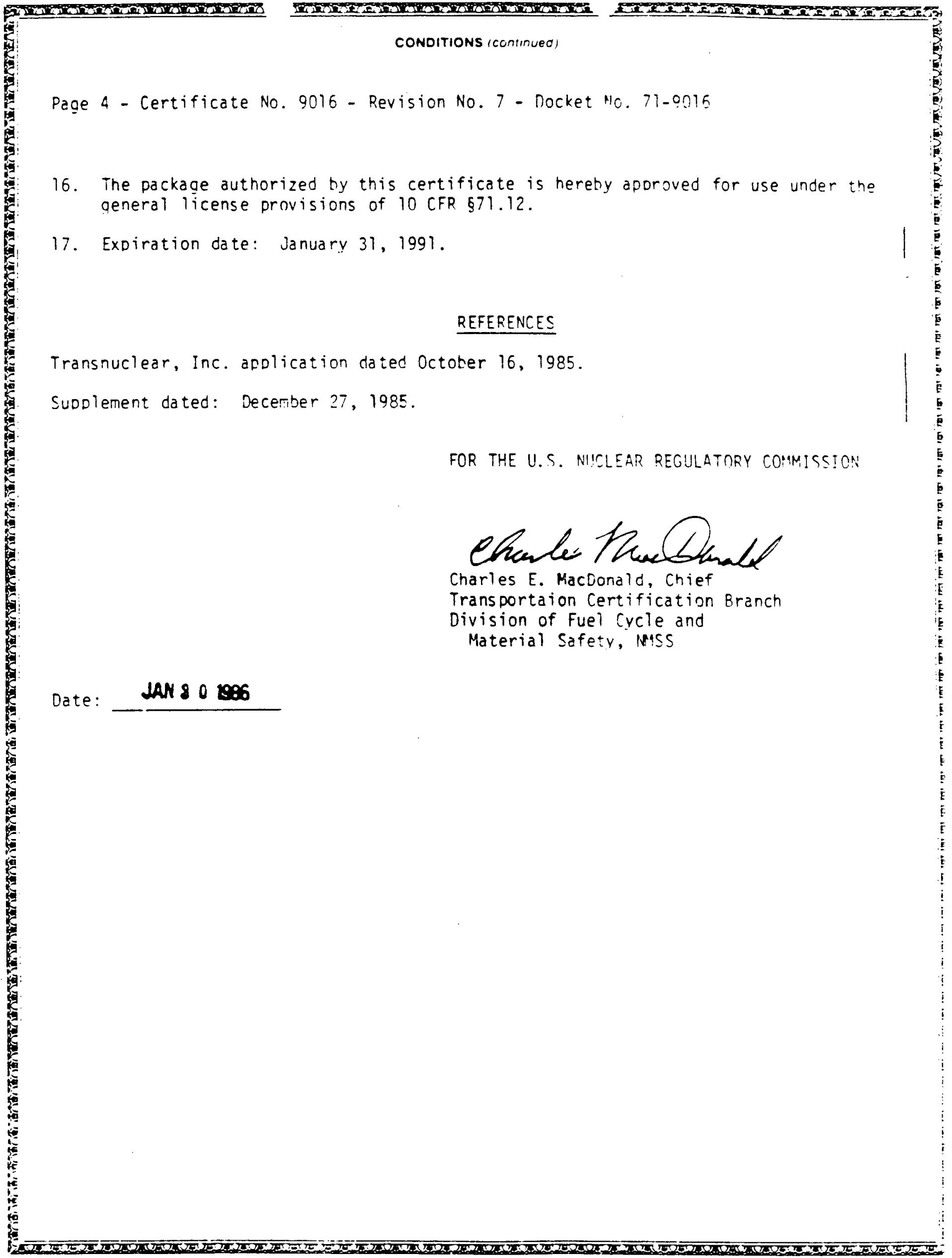


ATTACHMENT 1 |

TRAILER DATA

MAINTENANCE LOG

CASK CARRIER \#TN-500

DATE MILEAGE

$1 / 18 / 85$

$2 / 06 / 85$

$2 / 14 / 85$

$4 / 02 / 85$

$5 / 03 / 85$

$5 / 10 / 85$

$6 / 01 / 85$

$8 / 11 / 85$

$12 / 10 / 85$

$12 / 27 / 85$

$4 / 21 / 86$

$5 / 02 / 86$

$5 / 13 / 86$

$5 / 19 / 86$

$6 / 03 / 86$

$6 / 17 / 86$

$6 / 19 / 86$

$7 / 30 / 86$

$9 / 15 / 86$

$10 / 27 / 86$

$1 / 19 / 87$

$2 / 09 / 87$

$3 / 02 / 87$

$3 / 23 / 87$
3,900

5,100

6,800

11,000

14,300

15,974

17,312

39,651

60,575

65,707

77,210

78,042

79,774

81,280

82,591

86,364

86,450

89,226

91,150

93,780

96,180

97,800

99,006

100,211
DESCRIPTION OF WORK PERFORMED

King Pin housing rewelded.

Crack in first crossmember repaired. Weld repair, LR trunnion support.

Crack in first crossmember repaired.

Left front shock replaced. Chassis

lubricated. Deck support rewelded.

Deck supports rewelded.

crossmember weld repairs.

TSI (Mfgr) repairs on main beam weld. New tarpaulin.

Replaced 4 tires, all wheel seals, dismantied and inspected brakes.

Replaced wheel seal.

New tarpaulin. Deck supports

rewe lded.

Replaced air-ride leveler valves.

Reinforcing plates installed first

five crossmembers and first axle

crossmember.

stop-drilled cracks in three crossmembers. Weld repair on crossmember. Brake service on three wheels.

stop-drilled crack in fifth crossmember. Replaced air-ride leveler valves.

Repair welds at deck hatch support.

Repaired crack in second air bag support.

Replaced two rear shocks. Weld repair on rear pylon. Weld repair on deck support.

Air bag support welded. Weld repair in crossmemter.

Repaired deck plate supports.

Weld repairs; deck hatch, air vents.

Replaced one landing leg.

Weld repair at deck plate support.

Repaired break at deck plate support. 
$E-8306$

Revision 1

August 8,1986

Page 1 of 4

\section{TN-8/9 TRANSPORT TRAILER \\ INSPECTION CHECKLIST \\ PROJECT 1020}

\subsection{Identification:}

Tractor Identification No.

Trailer Identification No.

Hub odometer Reading:

miles.

Location:

Date:

Note: Record any findings in the Remarks section of this checklist. If a nonconformance is found, the inspector shall place an asterisk (*) on the line associated with the finding. A description of the nonconformance shall be recorded in the Remarks section and reported to Transnuclear.

\subsection{Tires:}

2.1 Check tires for adequate air pressure (between 100 psi and 105 psi on each tire):

2.2 Check tire tread wear (3/32 inch minimum tread on each tire and no uneven wear):

2.3 Verify that valve caps are present on each tire:

Note: Replacement tires to be Michelin XZZ, or XZAT, $10.00 \times 22.5$, $14 \mathrm{PR}$. 
3.0 Air suspension system:

3.1 Check all air bags for cracks and general condition:

3.2 Check all air bags for equal firmness:

3.3 Verify that system is operational:

3.4 Verify that trailer sits level (side to side):

3.5 Check for air system leaks:

Note: Adjustments to the Neway Air Suspension system to be performed in accordance with Neway Maintenance Manual, Form 468-B-7-85. All replacements to be Neway components.

4.0 Brakes:

4.1 Verify slack adjuster is within proper range (between 1 and $1-1 / 4$ inches).

4.2 Verify that the brake snoe lining is greater than $3 / 8$ inches:

4.3 Check for excessive wear in brake drums:

4. 4 Verify brake fittings are properly greased:

4.5 Check cam bushings on slack adjuster for excessive wear and general condition:

4.6 Check all brake pads for cracks and general condition:

4.7 Verify that there is sufficient service brake application when service pedal is depressed:

4.8 Check system for audible air leakage:

4.9 Verify brake chamber brackets are securely installed:

4.10 Check airline glad-hand connections for cracks and general condition: 
5.0 Wheels:

5.1 Verify all lug nuts are installed and torqued:

5.2 Check aluminum rims for cracks or other obvious defects:

5.3 Check oil level in wheel hubs:

5.4 Check oil seals for general condition and signs of leakage:

6.0 Shock Absorbers:

6.1 Check shock absorbers for signs of fluid leakage and general bushing condition. Verify bolts are torqued to $150 \mathrm{ft}-1 \mathrm{~b}$ : -

6.2 Check shock absorbers for damage and general condition:

Note: Replace shock absorbers in pairs. Do not replace only one shock absorber. Use Neway shock absorbers (ID No. 90044001 )

7.0 Other:

7.1 Check tarpaulin for tears and proper fit:

7.2 Verify all lights are operational:

7.3 Check kingpin and kingpin housings for cracks and general condition:

7.4 Verify all deck plate bolts are installed and tightened:

7.5 Verify that current trailer registration is in registration holder (located on enclosure front wall) and that license plate and registration sticker are present and in good condition: 
8.0 Weld Inspection:

8.1 Verify weld inspection has been completed and attach the signed checklist to this inspection checklist:

Note: Perform weld inspection per TN Procedure No. 1020-I-002.

9.0 Closeout:

9.1 Verify that all items have been inspected and that all required information has been recorded on this checklist:

10.0 Remarks:

11.0 SIGNATURES:

Inspector:

Date:

Maintenance Supervisor:

Date:

Observer:

Date:

$0141 \mathrm{~L}$ 
$1020-I-002-A 1, \operatorname{Rev} \cdot 1$

TN-8/9 Trailer

Weld and Structural Component Inspection

Check List

Date:

Shipment No:

Cask Model No.:

Location:

Trailer VIN:

1.0 PRIMARY MEMBERS

1.1 Main Beam Welds: Describe defects or indications/identify any attached photographs and/or sketches:

1.2 Front and Rear Cask Tie-Downs and supports: Describe defects or indications (identify any attached photographs and/or sketches):

1.3 Structural Components: Describe defects below:

2.0 SECONDARY MEMBERS

2.1 Cross-members to main beam welds: Describe defects or indications (identify any attached photographs and/or sketches): 
$1020-I-002-A 1$, ReV. 1

2.2 Axle support Attachments: Describe defects or indications (identify any attached photographs and/or sketches):

2.3 Structural Components: Describe defects:

4.0 TERTIARY MEMBERS

4.1 Describe weld defects or indications (identify any attached photographs and/or sketches):

4.2 Structural Components: Describe defects noted below:

5.0 SIGNATURES

5.1 Inspections Completed

Inspector:

Date:

Observer:

Date:

5.2 Repairs Completed

Inspector:

Date:

Observer:

Date:

$0635 \mathrm{C}$ 

Division of State Pollce Hozordous Motorlols Section Compllance Check Number
RADIOACTIVE MATZRIALS VRICIE DSPECTION

DATA SHDET
Offlce Use Only:

Dlsirlet

Yeor \& Soquentlol Number:

\section{VEBICLE INFORMATION}

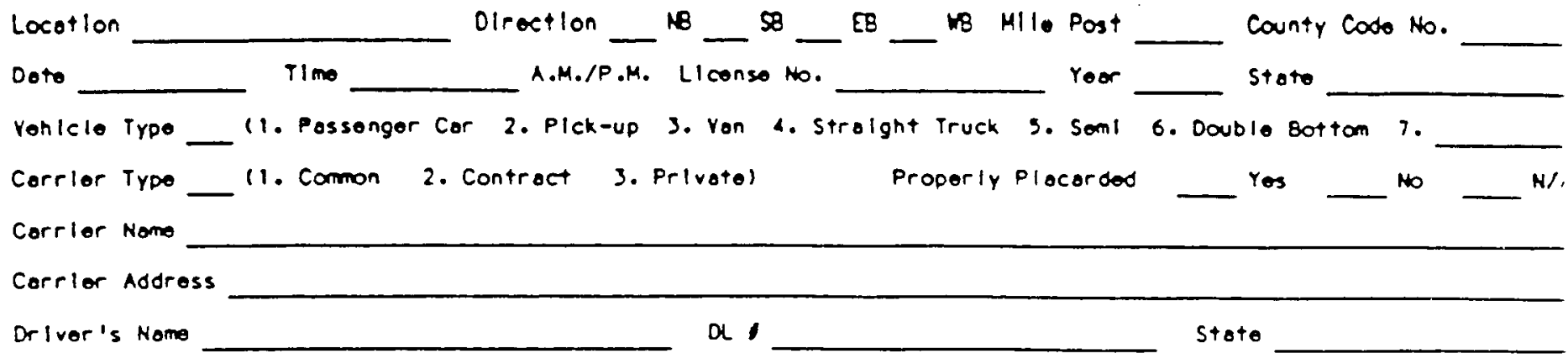

\section{SHIPPING DOCUMENTS}

Shlppling Popers __ Yes __ No Shlpping Nomo

Hozerd Class UN/NA Isotope(s)

Total Quantity

(1. Curlos (Cl) 2. Mllilicurlos (mcl) 3. Mlerocurles ( Cl) 4. Kllograms 5.

Pockoge Type (1. A 2.8 3. Strong 4. Other

Pockoge Spec. No.

Spect ol form No Normol Form (1. Gos 2. Llauld 3. Sollio or Porder Chemicol Form Tronsportation Index (Total for Vehlele)

Lobels (1. No Lobel Requirod 2. Whito 1 3. Yollow 11 4. Yellow 111 5. Other

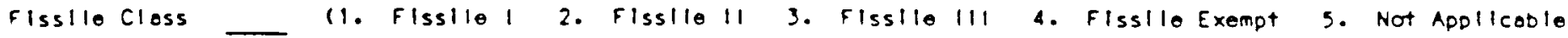

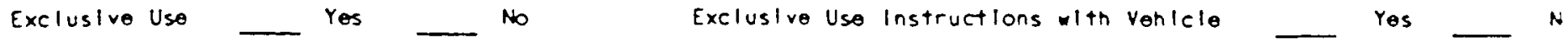
Shlppor Nome

Shlpper Aodress

Consignoe Name

Conslgnes Address

\section{VERICLE SURVEY}

Rodiation Levels

- MR/RR Cob Seat (Exclusive use limit is $2 \mathrm{mR} / \mathrm{hr}$ (Privote corrler exempt wien monltored))

- mR/hr Outside Surloco (hIghest rooding)

- Mritr Tro Moters From Outside Surface (Exclusive uso only)

Pockoge Plocement 11. Possengar Car 2. Plck-up 3. Von 4. Stralght Truck 5. Seml 6. Double Bottom 7. Pockoge seporotion in feet from neorest occupled oreo

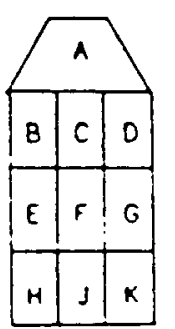

1.

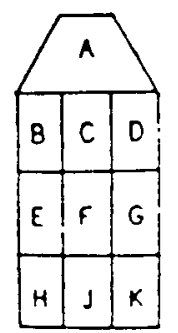

2.

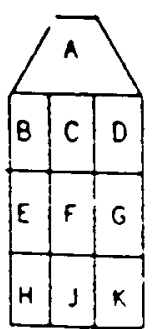

3.

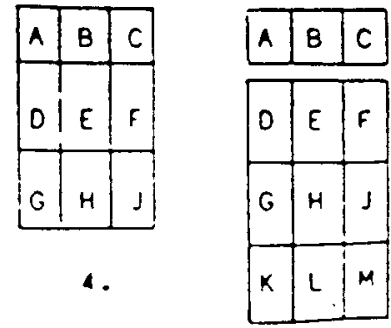

3.

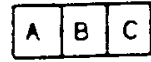

\begin{tabular}{|l|l|l|}
\hline$O$ & $E$ & $F$ \\
\hline$G$ & $H$ & $J$ \\
\hline$K$ & $L$ & $M$ \\
\hline$N$ & $P$ & $O$ \\
\hline$P$ & $S$ & $T$ \\
\hline$U$ & $V$ & $H$ \\
\hline
\end{tabular}


IV. OTHER RAZARDOUS MATERIALS ON VEHICLE

Yos No

Shlpping Nemes

Hozord Closs

Quant $14 y(s)$

\section{v. INSPECTION RESULTS}

MV :

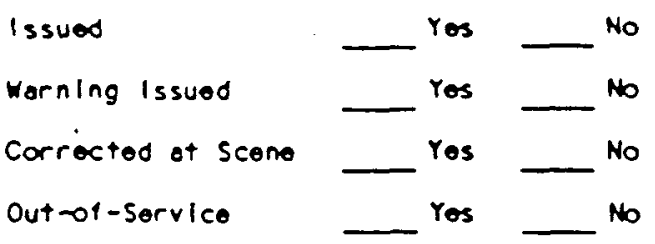

Troller sealed, unoble to Inspect pockago
MCS :

Inspection

violotion

Complaint Clitation

Qut-ot-Sorvice

Yes

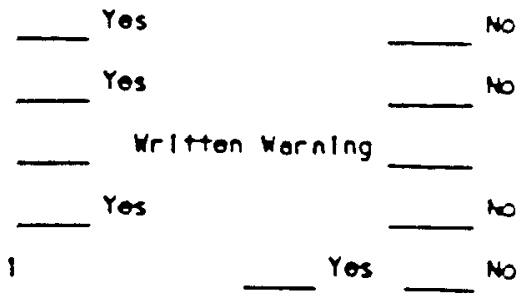

vI. PACKAGE INPORMATION

Total Pockoges in Shlpmont

Number of Pockages Inspoctod

Pockogo Labelod for Addltional Hazard

_ Yos _. Na Ra Romovoble Contamination

L.S.A. Pockages Marked or Stenclled (Rodlooctive - LSA) _ Yos _ No _ NA

To be obtalned then obvlous discreponcles ore present 11.0. , radiation roodings in excess of rogulatory 11 imits. indication of rodlooctive materlal on board and shippling popers ore missing or shor no radioective materlal on board and shippling papers do not provide requlrad Information and such informetion is ossentlol to proper onforcemont oction).

\begin{tabular}{|c|c|c|c|c|c|c|c|c|c|c|}
\hline Pock & $\begin{array}{l}\text { Pock } \\
\text { Type }\end{array}$ & $\begin{array}{l}\text { Pock } \\
\text { Spec. }\end{array}$ & $\begin{array}{l}\text { Pock } \\
\text { Sool }\end{array}$ & Lobel & I sotopo & Quantity & $\begin{array}{l}\text { Surfoco } \\
\text { Reading }\end{array}$ & $\begin{array}{c}T 1 \\
\text { Label }\end{array}$ & $\begin{array}{l}\text { Ti Inst. } \\
\text { Roodling }\end{array}$ & $\begin{array}{l}\text { Gross } \\
\text { welght }\end{array}$ \\
\hline 1. & & & & & & & $\dot{.}$ & 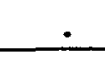 &. & \\
\hline 2. & & & & & & & $\dot{.}$ & $\cdot$ & $\cdot$ & \\
\hline 3. & & & & & & & . & $\cdot$ & $\therefore$ & \\
\hline 4. & & & & & & & - & - & - & \\
\hline 5. & & & & & & & - & · & - & \\
\hline 6. & & & & & & & - & $\dot{-}$ & - & \\
\hline 7. & & & & & & & $\cdot$ & $\therefore$ & 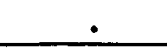 & \\
\hline 8. & & & & & & & $\cdot$ & $\dot{-}$ & . & \\
\hline 9. & & & & & & & $\cdot$ & $\dot{-}$ & $\dot{.}$ & \\
\hline 10. & & & & & & & $\cdot$ & - & $\cdot$ & \\
\hline 11. & & & & & & & $\cdot$ & $\dot{-}$ & - & \\
\hline 12. & & & & & & & $\dot{-}$ & $\therefore$ & - & \\
\hline
\end{tabular}

Comments: 
ILLINOIS OEPNETMEAT OF NUCLEAF SATE' SPENT FUE SHIPAENT IKSPECTIOA FOF

Truck

A. Shlowint Roure:

Shlpont Rof. 1:

Ra11

SAlpper:

Cerrler:

Cost mode :

Troetor Unit :

Cask Sorlol i:

irellor Unlt i:

\begin{tabular}{|c|c|c|}
\hline Cosk Rodiution Levels & Eoto/Gomme (nR/hr) & Noutron IIndicoto Unlt \\
\hline (Mox Inum) & (1.0.N.S.: Shloper) & (1.D.N.S.: Shloper) \\
\hline D. Suttoco $(\cos k)$ & $:$ & $:$ \\
\hline 0. I Motor (Fron Cosk - TI) & $:$ & $:$ \\
\hline c. Surlece (vonicle) & $:$ & $:$ \\
\hline 0. 2 metors (from vehicle) & $:$ & $:$ \\
\hline e. Coo (ventele) & : & : \\
\hline
\end{tabular}

\begin{tabular}{|c|c|c|}
\hline$\frac{\text { Contominetion Levels }}{\text { (Romoroble/100 cel') }}$ & $\begin{array}{l}\text { Moximum }(\infty) M) \\
\text { (1.O.R.S.: Shlpoer) }\end{array}$ & $\begin{array}{l}\text { Averoge }(D P M) \\
(1.0 . \text { N.S. : Shlpoor) }\end{array}$ \\
\hline c. Geto/Genmo & : & : \\
\hline D. Alono & : & : \\
\hline
\end{tabular}

D. Cosk LasellngMorking:
a. Tronsport Inoox (TI)
c. Roclonvellos
- Proser shipding nomo

E. Placercing:

•. TrDo

b. Curlo Contont

o. Lodel tyoe 6 (1)

1. UN

f. Snlpoing paders:
c. Comillection
D. Pysical/tror forr
c. Metches Smlpping iodol
o. Nototions for Flssile lil \& Hey Controlloo

G. Orivers:
- Orlver Nome
c. Troining Dotes

b. Higtrer Routo Plan

H. Insdections on, Testing ronducted (Inelcato Indridual's namo):

a hotor Corrlor sototy D. Modl Le Phone/ce

c. Ho:orous Metoriols Roclation Survar

d. IONS - NRC

1. Socurlty Soels: (1) Cosk (2) Brocing

1. Comments (DOT rlolotlons, escort trolning. MCS violetlons, otc.): 
Truat

A. Shippent Fouste:

Shipwent Ref. H:

RAI

Snipper:

Carrier:

Cask Serial ":

Cast. Model:

Tractor Unit : Trafler Unit $4:$

B. Cast Radiation Levels

Eeta/Gama (mi/hr) i Neutron (Indicate Unit

(Maximsti) (I.D.N.S.: Shipper) । (I.D.N.S.: Shipper)

a. Surfaxe (Cast) (1000 minr)

b. 1 Meter (Fran Cast - TI)

c. Surfaxe (Vehicle) (200 mR/hr)

d. 2 Meters (From Vehicle) (10 mR/hr)

e. Cab (Vericle) (2 mp/ $\mathrm{mr}$ )

C. Contamination Levels

Neximum (DPY:)

(I.D.N.S.: Shipper)

(Removable/100 cric)

a. Beta/Gamp (2200 dp:)

b. Plphe $(220 \mathrm{dad})$

D. Cask Labeling Marking:
a. Iransport Index (TI)
c. Radionuclides
e. Proper Sripping liame

b. Qurie Content

d. Label Type \& (\#)

f. Uif

E. Placarding:

a. Type

b. 4 Sides

F. Sripping Papers:

a. Certificetion

b. Physical/Chem Form

c. Matches Snipping Label d. Notations for Fissile III \& thy Controlled

C. Drivers:
a. Driver Niame
c. Training Dates b. Hijginay Route Plan d. Emergency Procedures Available

fi. Inspections anj Testing Conducted (Indicate Individual's name):
a. Motor Carrier Safety
b. Mobile Phone/Cs
c. Hazardous Meterials Radiation Survey
d. IDS
e. $\mathrm{NRC}$
f. Security Seals: (1) Cask
(2) Eracing

End: 
LOADING OPERATIONS

This attachment describes the loading operations of the TN- $8 \mathrm{~L}$ cask. Instructions, procedures, forms and report out 1 ines are provided for the guidance of the facilities' staff in preparing the necessary administrative, operational and test procedures that are required to document, control and verify cask loading operations.

Sections 1.0 through 7.0 provide the step-by-step sequence to be followed in the receipt, loading, testing and shipment of the cask plus additional information, procedures, forms and report outlines for implementing various steps in the "Loading Procedure".

Procedural steps in the "Loading Procedure", Sections 1.0 through 7.0 marked by an asterisk $(*)$, indicate information is required to be entered on the referenced form or report.

Section 8.0 provides an example of a Cask Loading Report which wili be filled out for each loading operation and is included with the shipping documentation and is also retained as a permanent record. Section 9.0 provides the procedures to be utilized for performing vacuum drying, dryness verifications and closure leaktightness tests.

Tools, accessories and system interfaces that are required during cask operations are identified as they are required. 


\section{LOADING PROCEDURE}

1.0

CASK ARRIVAL

1.1* Inquire for any special precautions, the driver's report and shipping documentation from the driver. Verify documentation.

1.2* Review all shipping documentation and note any comments provided by the shipper. Verify documentation.

1.3 slide back the trailer protective enclosure per the following instructions:

1.3.1 Release the tarpaulin tie-down along the sides of the trailer by pulling the elastic tie-downs from the trailer tie-down hooks.

1.3.2 Release the trailer rear tarpaulin section by unbuckling the straps along each side of the tarpaulin.

1.3.3 Roll-up the rear tarpaulin section and secure it in this position by placing the straps around the tarpaulin and buckling the straps to the tarpaulin roof section.

1.3.4 Slide the enclosure forward by releasing the lock pin on each side of the rear track bar and having one person at ground level on each side of the trailer. Grasp the side section of the tarpaulin 
and pull it towards the front of the trailer (this will result in sliding the roller mechanism forward). Slide the enclosure until the tarpaulin is drawn as far as possible against the front of the enclosure. A rope and pulley are also located on the inside of the trailer front wall to assist in pulling the tarpaulin forward. The mechanism can then be locked in place by the pin locks on the tarpaulin track.

1.3.5 If it is desirable to limit the cask or cover lift height during removal from the trailer, the lengths of the slide mechanism roller tracks may be removed between the track support posts. This removal is done by retracting the spring loaded pins from the ends of the track and removing the track section.

1.4* Perform cask and trajler contamination and radiation surveys, as applicable, per the instructions below and record results on Form 1, Cask Receipt Radiation Survey, Form 2, Trailer Receipt Radiation Survey, and on Form 5 , Cask Loading Report located at the end of this chapter, for locations not accessible with cask on trailer, these contamination swipes shal1 be performed when they become accessible. (Section 7.0 of this chapter.)

1.4.1 Upon receipt of an unloaded TN-8L cask at a facility, the cask and trailer external surfaces shall be surveyed for radioactive contamination. 
1.4.2 If removable radioactive contamination in excess of 22,000 beta/gamma disintegrations per minute (dpm) per 100 square centimeters or 2200 alpha $\mathrm{dpm} / 100 \mathrm{~cm}^{2}$ of package surface is found, refer to Section 3.0 of Reporting Requirements (Chapter IX) for NRC notification requirements.

1.4.3 Complete the survey forms and retain for documentation requirements.

1.5 If contamination levels are acceptable, excessive road dirt, if present, can be removed at the site's discretion using low pressure water spray with TN approved detergent.

1.6* Perform cask receipt inspection and record results on the Cask Loading Report and verify that:

1.6.1 Cask and trailer appear to be in good physical condition (i.e., no large deformations, cracks, paint removed from large areas, surface cleanliness is acceptable and no signs of mishap during transport).

1.6.2 Cask tie-down is acceptable (i.e., no loosening of bolts and collars are correctly positioned on trunnion inside shoulder).

1.6.3* Security seals are installed on the shock absorbing covers and show no signs of tampering and have the same number as shown on the cask receipt shipping papers. Record the numbers on the Cask Loading Report. 
1.6.4* The regulatory labels of the cask and vehicle are installed and are correct. Verify by initials.

1.6.5 The impact limiters and the shock absorbing covers are correctly installed.

1.6.6 Inspect the cask for any abnormal presence of water or contamination or any other indication that might suggest that the cask containment may have been compromised.

1.7 Position trailer under the unloading crane.

1.8 Remove the trunnion impact 1 imiters as follows:

Note: This step may be done simultaneously with step 1.9 to the extent practicable.

Note: The lower vertical redundant impact limiter should not be removed until after the front shock absorbing cover is removed.

Required Equipment

- Ratchet

$-13 / 16^{\prime \prime}$ socket

-Ratchet drive extension

1.8.1 Remove the limiter $9 / 16^{\circ}$ bolt. 
Note: As bolt is removed, manually restrain the trunnion impact 7 imiter (approximate weight of a trunnion impact limiter is 45 1 bs. ).

1.8 .2 When the bolt is removed, remove the trunnion impact limiter from the trunnion.

1.8.3 Inspect the threads of the $9 / 16 "$ bolt and the trunnion hole. Apply two layers of waterproof tape over the bolt hole.

1.8.4 Store the bolt and trunnion impact limiter in a clean, protected storage area.

Note: If storage is made in a contaminated area, the bolts and trunnion impact 1 imiters should be covered with a sheet of plastic or similar covering to prevent contamination.

1.9 Remove the shock absorbing covers (Figure 25) per the instructions below.

\section{Required Equipment}

$-1 / 2$ ton min. capacity chain hoist

-Two-legged sling equipped with appropriate connections for attachment to the chain hoist and to shackles on the shock absorbing cover 1 ift lugs 
-Dynamometer (0-1000 1b. min.)

-Two connecting shackles

-Ratchet

-Ratchet drive extension

$-1-7 / 8^{\prime \prime}$ socket

-Plastic or tarpaul in cover

(if necessary, see step 1.9.8)

1.9.1 Attach the shackles to the lifting lugs of the shock absorbing cover then attach one leg of the sling to each shackle.

Note: Either cover may be removed first.

1.9.2 Center the crane hook directly over the shock absorbing cover to be handled. Attach the chainfall then the dynamometer to the crane hook.

1.9.3 Lower the crane hook to permit attachment of the two-legged sling lifting bale to the dynamometer.

1.9.4 Slowly raise the crane hook to take slack out of the sling legs.

1.9.5 Using the chain hoist, lift up on the sling until a reading of 850 pounds is indicated on the dynamometer. Further adjustment, using the chain hoist only, may be made as necessary to assist in the removal of the shock absorbing cushion, step 1.9.7. 
1.9.6 Remove the four shock absorbing cover bolts. The two top bolts should be removed before the two bottom bolts. Store the bolts in a clean, protective container.

Note: Due to the angle of the covers from the vertical, care should be taken when removing these bolts as the bottom of the rear cover could swing out from the cask when its bolts are removed.

1.9.7 Gently move the shock absorbing cover away from the cask until the cover centering pins are clear of the cask. Lift the shock absorbing cover using the crane.

1.9.8 Move the shock absorbing cover to its designated storage area and disconnect the shackles from the shock absorbing cover lifting lugs.

Note: If the storage area is dirty or contaminated, the covers shall be stored on a sheet of plastic or a tarpaulin and covered. Care should be exercised in handling and storing cover bolts to prevent thread damage. 
1.9.9 Transfer the crane hook and two-legged sing to the other shock absorbing cover.

1.9.10 Repeat Steps 1.9 .1 through 1.9 .8 for the other shock absorbing cover.

1.9.11 Remove the two-legged sling from the crane hook.

1.9.12 Apply two layers of waterproof tape over holes in the cask rear face.

1.10 Release front trunnion tie-down and rear trunnion tie-down per the instructions below:

\section{Required Equipment}

- Ratchet

$-3 / 4$ " socket (for trunnion guide assembly bolts)

$-1-1 / 4$ " socket (for rear trunnion bolts)

$-1-1 / 4$ " open end wrench

1.10.1 Front Trunnions

1.10.1.1 Release the load binder handle restraint chain.

1.10.1.2 Release tension from the front trunnion restraint by lifting up on the binder hand le.

CAUTION: The handle may rise up suddenty. 
1.10.1.3 Remove the binder attachment hook from beneath the trunnion tie-down support ip.

1.10.1.4 Swing the binder assembly free of the cask trunnion by pivoting around the tie-down rod pivot pin. Lay the binder assembly on trailer deck.

1.10.1.5 Repeat Steps 1.10 .1 .1 through 1.10 .1 .4 for the second front trunnion tie-down.

1.10.2 Rear Trunnions

1.10.2.1 Remove the two $3 / 4^{\prime \prime}$ bolts and their lock washers from the rear trunnion tiedown.

1.10.2.2 Lift the rear trunnion tie-down collar free of the cask rear trunnion. Store the bolts, lock washers, and tie-down collars in a clean, protected area.

1.10.2.3 Repeat Steps 1.10.2.1 and 1.10.2.2 for the second rear trunnion tie-down.

1.11 Remove trunnion guide assembly as follows: 


\section{Required Equipment}

-Ratchet

$-3 / 4 "$ socket

1.11.1 Swing back the front cradle dust cover plate from the underside of the trailer.

1.11.2 Remove the two $1 / 2$ " hex head bolts and their lock washers.

1.11.3 Remove the trunnion guide assembly from the trailer (this frees the lower redundant trunnion and allows cask removal from the trailer). Store the bolts, lock washers and the guide assembly in a clean, protected area.

1.12 Attach the primary (or secondary) lift beam assembly to the cask front trunnions per the instructions below. The lift beams and air controller are shown on Figures $2 a, 2 b$, $2 c$ and 3 .

Note 1: Visually inspect the major load-carrying welds and critical areas of each cask 1 ift beam for indications of damage or deformation prior to each use.

Note 2: The major load-carrying welds and critical areas of each lift beam shall be visually inspected by maintenance or non-operating personnel at intervals not to exceed three months in length, for indications of damage or deformation. 
Note 3: If the bearing surface of the crane hook will result in a point loading of the lift beam pin, or a line load of less than 4-3/4", a lift beam pin sleeve adaptor will be provided by TN to reinforce the pin.

Note 4: If redundant lifting will be used for movement of the cask within the facility, use of the primary lift beam is preferred for removing the cask from the trailer.

1.12.1 Remove the center (four-inch) pin and/or the two three-inch lifting pins from the lift beam (depending on the site and crane hook, either the primary or secondary beam may be used).

1.12.2 Lower the crane hook between the cross member plates of the lift beam. Align the four-inch hole in the crane hook lift palm with the holes in the lift beam.

1.12.3 Insert the pin(s) and install the keeper plate(s).

Note: Some stations using the whiting redundant crane system sister hook may use the two three-inch diameter pins of the primary lift beam rather than the four-inch center pin. 
CAUTION: The operator is to promptly notify his supervisor of any malfunctions in the equipment.

1.12.4 Connect the air controller to an air supply of $75-$ 125 psig.

1.12.5 Estimate the maximum distance that the air controller will be from the beam during the intended operation.

1.12.6 Attach as many fifty foot long sections of flexible hose to the three quick connectors on the air controller as needed to achieve the distance estimated. The hoses and quick connectors are color coded to assure proper connection.

Note: It may be necessary to disconnect the flexible hose from the lift beam during certain out-ofpool operations.

1.12.7 Connect the three hoses to the fittings on the right hand side of the beam as one faces the side with the piping. The hoses, piping and air controller are color coded.

Note: Be certain the hose connections are fully seated. A distinct click can be heard when the quick-connectors are properly engaged. 
1.12.8 Verify that the bypass toggle valves located on the beams are in the closed position.

1.12.9 Observe whether the lifting arms are in the release or engage position. Set the arm control lever on the air controller to the same position.

1.12.10 Set the red handle of the locking cylinder valve to the "lock" position.

1.12.11 Depress the black handled toggle valve (labeled "Flow Reset") on the air controller until a pressure of at least $50 \mathrm{psig}$ is indicated on the pressure gage. Release the toggle to close this valve and activate the automatic cut-off valve in the air controller.

Note: The valve is designed to cut off air supply to the system if a leak develops in the hoses, piping or connections.

1.12.12 The system is now operational and shall be operated in the following sequence:

1.12.12.1 Set the red handled locking cylinder valve to "unlock".

1.12.12.2 Move the arm positioning lever to the desired position. 
1.12.12.3 visually verify that the arms have moved fully to the desired position.

1.12.12.4 Set the red handled locking cylinder valve to "lock".

CAUTION: Do not attempt to move the arms when the red handle is on "lock". However, if this should happen, return the arm positioning lever to the position corresponding with the current position of the arms on the beam before moving the red handled locking cylinder valve to "un 1ock".

1.12 .13 When the system is in the "lock" position, visual confirmation is provided by smail metal flags which are mounted on one side of the lift beam. The flags extend horizontally over the lock pins when the pins are fully extended through the lock plate. They can be seen from the surface of the pool when the cask is under water. The lift beam must be oriented on the cask before the cask goes into the pool so that the flags can be observed by. the operator.

1.12 .14 When changing the lift arm position, wait until the pressure gage indicates 1 ine pressure after 
moving the red handled valve to the "unlock" position. Then reposition the arms to the desired position.

Note: The arm repositioning will take longer if the air lines are especially long, air pressure is on the low side, or the system is in the redundant configuration.

1.13 Apply Nuclear Grade Never-Seez lubricant to outer shoulder of front horizontal trunnions and to engagement surface of lifting arms. Engage the lift beam to the trunnions as follows.

1.13.1 With the lift arms locked in the release position, align the lift beam over the cask trunnions.

1.13.2 Lower the lift beam so that the guide arms rest lightly on the trunnion inner tie-down shoulders.

1.13.3 Unlock the lift arms and move the arm positioning lever on the air controller to the "engage" position. Verify that the lift arms are positioned properly on the lifting shoulders and there are no interferences with the trunnion lips or tie-down shoulders. Verify that there is no binding.

1.13.4 Lock the lift arms in the engage position on the cask trunnions. Lift the cask slowly, 
approximately one inch and observe the crane/lift beam for unusual noises, deformation or indication of improper function.

1.13.5 If no problems are noted, proceed to make the actual cask lift in accordance with approved facility procedures and the instructions below.

CAUTION: If the trailer must be moved during off-loading of the cask, the tractor driver shall be in the cab. If not, the trailer wheels shall be blocked from the front and rear on at least one axle, on both sides and the tractor and trailer brakes shall be set.

1.14 Maintain crane and cables in a vertical position over lifting trunnions as cask is tilted to the vertical position as shown on figure 26.

1.15 Lift the cask off the trailer and remove the trailer from the area. If site procedures require redundant lifting, perform the following (if not required, proceed to step $1.16)$.

1.15.1 Lower cask to a height of about six inches above a level floor area which has been determined to be capable of supporting the cask load.

1.15.2 Place a protective cover under the cask and iower to the floor. 
Note: A protective cover may consist of layers of Herculite or plywood or any other site approved material suitable to prevent damage to the cask rear face.

1.15.3 Release the lift beam from the cask and move it to the lift beam stand.

1.15.4 Rotate the crane hook redundant lifting eye block so that the axis is perpendicular to the axes of the lift pins of the primary lift beam.

1.15.5 Raise the primary lift beam so that the lifting arms clear the top of the secondary lift beam. Rotate the primary lift beam and/or the secondary lift beam on the lift beam stand, so that the axes of the lift beams are perpendicular.

1.15.6 Lower the primary lift beam so the redundant eye block is aligned with the 4" diameter pin of the secondary lift beam. Insert the 4 " diameter pin and install the keeper plate.

1.15.7 Attach the three six-foot hoses for the air system from the primary beam to either side of secondary beam.

1.15.8 Repeat Steps 1.13 .1 through 1.13 .5 to attach the 1 ift beams (now consisting of both primary and secondary lift beams) to the cask top trunnions and redundant trunnions. 
1.16 Transfer the cask to the decontamination pad and insta 11 the bottom protective cover (Figure 18) as the cask is lowered to the pad per the instructions below.

1.16.1 Prior to lowering the cask onto the decontamination pad, place the bottom protective cover onto the decontamination pad.

1.16.2 Lower the cask until its bottom region is approximately six inches above the bottom cover. verify that the cut-out for the " $\mathrm{C}$ " port on the bottom protective cover is aligned with the " $C$ " port on the cask.

1.16.3 Manually lift the bottom cover and fit it onto the cask rear face (approximate weight 30 1bs.).

1.16.4 Attach the cover to the cask by looping the cover attachment elastic straps over the lower cask trunnions and securing them to their attachment point on the bottom cover.

1.16.5 Slowly lower the cask onto the decontamination pad.

1.17 Disengage the lift beam and move it from the operations area.

1.18 Remove lubricant from all trunnions. 
1.19 Apply two layers of waterproof tape over all shock absorbing cover bolt and alignment pin holes of the cask front face.

1.20 Install the top face plastic protective cover.

2.0 CASK PREPARATIONS FOR LOADING

2.1 Install the cask protective skirt around the finned length of the cask per the instructions in step 2.1 .2 below and as shown on Figures 20 through 24 .

2.1.1 Skirt Operation Precautions

2.1.1.1 Utilize a reinforced translucent hose for the skirt water $f i l l$ and vent 1 ines to provide a visible water level indication.

2.1.1.2 Ensure that lighting in the operations area is adequate to allow easy observation of the water level in the skirt and skirt hose.

2.1.1.3 Keep the skirt fill hose as short as possible. Excessive lengths may result in interference problems. The hose should be allowed to hang freely but 
not allowed to become entangled, kinked or bent. Tag lines may be helpful in this regard.

2.1.1.4 Plan thoroughiy prior to lowering the cask into the pool to ensure that immersion times are minimized. The shorter the immersion time, the less severe the contamination problems incurred and associated decontamination efforts.

2.1.1.5* Check the skirt condition prior to installation. Holes, cracks, tears or other leaks shall be patched using a reinforced plastic patch or two layers of waterproof tape on the inside (cask side).

2.1.1.6 The skirt surface should be thoroughly rinsed prior to immersion in the spent fuel pool. This will reduce skirt decontamination requirements.

2.1.2 Skirt Installation

Required Equipment

-Allen wrench - 3/8"

-Never-Seez lubricant, or site approved equivalent 
-Waterproof tape

-Scokets - 3/4" (2)

-Ratchet drives for sockets (2)

2.1.2.1 Remove the skirt from storage. Unroll it and inspect it to ensure that condition is acceptable (i.e., no holes, acceptable contamination levels, etc.). Check condition of skirt accessories, water hoses, connectors " $J 1$ " and "J2", cables, cable tensioners and screws. Lubricate screw threads if necessary.

Note: Refer to Figures 20 through 24 of the manual. Item numbers in brackets in this section are shown in these figures.

2.1.2.2 Insert the two pins (4) of the inner bar into the cask skirt lugs (11) and manually wrap the skirt around the cask utilizing the handles (5) of the outer bar for support.

2.1.2.3 Insert the two pins (3) of the outer bar into the corresponding holes of the skirt inner bar (2). Install the thirteen screws (22) to close the skirt. Torque the screws to approximately $5 \mathrm{ft}-1 \mathrm{~b}$ (slightly more than finger-tight). 
2.1.2.4 Locate the upper skirt lateral guide (8a) in the cask front drum groove:

2.1.2.5 Insert one free end of cable into the hole (15) in the right hand rotating drum (14) of the tensioning device. Lock the cable into place by tightening the cable securing screws (16) to hand tight, then tighten an additional $1 / 4$ turn. Use a socket and ratchet wrench on the cable tensioning nut (19) to rotate the drum in the direction indicated by the arrow in section AA of Figure 23. Turn the right hand rotating drum two revolutions to take up excess cable.

2.1.2.6 Position the cable as shown in Figure 20, Detail 1. The cable is wrapped between the lateral guide and the cask center. Wrap the cable once around the cask as shown in Figure 20 .

2.1.2.7 Insert the cable under the outer bar (1) and into the drum groove (insert cable in groove shown in Figure 20 , Detail 1 and Figure 24, Detail 1) and wrap the cable around the cask a second 
time, while carefulty positioning the cable in the cask drum groove, inside the lateral guide (towards the center of the cask) as shown in Figure 20 , Detail 1. The cable should not cross itself at any point around the cask.

2.1.2.8 Pull the cable taut and check that the cable is correctly positioned in the drum groove.

2.1.2.9 Repeat Step 2.1.2.5 for the other cable end and rotating drum. Turn the rotating drum to take up slack in the cable and check that the cable is still correctly positioned.

Note: There should be approximately the same amount of cable on both rotating drums to prevent uneven loading. It may be necessary to loosen the cable and reposition it on the drums.

2.1.2.10 Place a socket and a ratchet wrench on each of the cable tensioning nuts (19) and turn both drums simultaneously in the direction indicated until the cable is under tension. Push the locking handles (17) down firmly against the rotating drums (14). Do not over tighten. 
2.1.2.11 Locate the lower lateral guide (8b) in the cask rear drum groove.

2.1.2.12 Repeat Steps 2.1.2.4 through 2.1.2.10 for the lower skirt cable tensioner (6) (the cable is placed between the lateral guide and the center of the cask).

2.1.2.13 Install a layer of waterproof tape along the upper and lower edges of the skirt as shown on Figure 20, Detail 1. Tape can also be instalied over the upper bar after the screws have been installed. This reduces skirt water supply requirements for keeping the skirt full while it is in the pool.

2.2 Refer to Figure 27 for skirt fill configuration. Remove the blind flanges from " $J 1$ " and " $J 2$ " openings, and install connectors "J1" and "J2" (Figure 17). Torque the three lubricated bolts in each flange to $35 \mathrm{ft}-1 \mathrm{~b}$ proceeding clockwise from the first bolt, then repeat the torquing in a counterclockwise direction.

2.3* Remove the blind flange from opening " $B$ " and measure the radiation level of opening " $B$ " (beta/gamma at contact). Record measurement in the Cask Loading Report. Record the identifying code of the flange. 
2.4 Install connector " $B$ " to the cask in vent mode as shown in Figure $9 B$. Do not connect $V-3$ to the gaseous radwaste system at this time. Make sure that valves $V-1, V-2$ and $V-3$ are closed.

Note: Some " $B$ " connectors are equipped with an attachment for a two inch vacuum hose. This attachment should be blanked off for all operations involving this connector. The referenced figures show the " $B$ " connector with a two-inch vacuum hose connection.

2.4.1 The " $B$ " and " $C$ " connectors are installed by squeezing the handles together and firmly pushing the connector into its corresponding opening. The connector shall seat itself when the innermost handles are released. A cursory check is performed by giving a slight tug on the outermost handies only. If the connector is properly installed the connector will not release.

2.5* Measure the cask internal pressure by opening valve $v-2$ and reading the pressure on gage $G-1$. Record the measured pressure on the Cask Loading Report. Close valve V-2. If the measured pressure is greater than atmospheric, connect valve $v-3$ to the gaseous radwaste system and open $v-3$. 
Close valve $V-3$ when the cask is at atmospheric pressure. If the measured pressure is less than atmospheric, simply open valve $v-3$ to admit ambient air into the cavity until equilibrium pressure is attained. Remove connector " $B$ " by squeezing the handles together and pulling upward.

2.6* Remove the blind flange from opening " $\mathrm{C}$ " and measure the radiation level at the flange surface of opening " $C$ " (beta/gamma at contact). Record measurement in the Cask Loading Report. Note the identifying code of the flange to ensure proper replacement.

2.7 Remove the shield plug from opening "A". Avoid contact with the plug end as it is likely to have surface contamination present.

2.8* Visually inspect the gaskets of blind flanges " $B$ " and " $C$ " and shield plug "A". Gaskets shall be visually inspected to ensure they are free of cuts, grooves, gouges or cracks. Particular attention should be given to observe "feathering" at the edges. An indication of normal conditions will be that the seating surface appears as a somewhat flattened area. If the inspection indicates a gasket defect, the gasket should be replaced in accordance with Step 2.8.1. Gasket inspection shall be noted in the cask Loading Report. Gasket installation and replacement shall be detajled and recorded on the Cask Loading Report under "Remarks". 


\subsubsection{Gasket Replacement Instructions}

2.8.1.1 Remove old gasket from the gasket groove using an o-ring removal tool (care should be taken not to damage the gasket seating surfaces).

2.8.1.2 Clean gasket groove with alcohol (Note: do not use acetone), wipe dry with a clean cloth and visually inspect the gasket groove to ensure that the surfaces are clean and that no fragments of the old gasket remain. Break the old gasket to ensure that it does not get reused.

2.8.1.3 Visually inspect the new gasket to ensure it is in good condition.

2.8.1.4 Position the gasket in the groove.

2.8.1.5* Install the gasket by pushing the gasket into the groove at four diametrically opposite points using the thumb (this "tacking" minimizes the gasket's tendency to stretch during installation). Continue pushing the gasket into its groove at diametricalily opposite points until the entire gasket is installed (e.g. no bulging). Record this activity in the Cask Loading Report. 


\subsubsection{Attach the green tag from the gasket package to TN's copy of the Cask Loading Report.}

2.9 Prepare the Cooldown system (CDS) for the cask filling mode per Figure 10, including connector " $\mathrm{C}$ " and connector "A2" and torque per the following procedure. Note that valve $v-9$ is open and valve $v-10$ is closed.

\section{Required Equipment}

-Torque wrench suitable for setting torques of $35 \mathrm{ft}$-ib $-3 / 8$ " hex head socket
2.9.1 Install the three bolts for the flange of con- nector "A2", torque the bolts to $35 \mathrm{ft}-1 \mathrm{~b}$ in a clockwise direction from the first bolt.

2.9.2 Repeat the torquing of the bolts to $35 \mathrm{ft}-10$ in a counterclockwise direction.

2.10 Set the clean water pressure regulator valve, PR-1, to approximately 25 psig.

2.11 Open valve $V-10$ and fill the cask cavity through connector "C" while venting the cask cavity through connector "A2". 
2.12 When water begins flowing from the vent hose, stop water supply by closing valve $v-10$. Per site requirements, an analysis of the activity of the cooldown water can be performed.

2.13 Orain any water from the overflow hoses and remove the hoses.

2.14 Remove connector " $C$ " from the cask and disconnect fill I ine from the connector. Reconnect connector " $C$ " with a hose and allow about one gallon of water to drain from the cask.

2.15 Remove connector " $C$ ", thereby disconnecting the CDS. Install the blind flanges on openings " $B$ " and " $C$ " and torque the three bolts of each flange to $35 \mathrm{ft}-\mathrm{ib}$ in a clockwise sequence from the first bolt and repeat in a counterclockwise sequence.

2.16 Remove connector "A2" by removing the three cap screws. Replace shield plug into opening " $A$ " but do not install bolts.

2.17 Loosen and remove all lid bolts per the procedure below.

Note: Some facilities may require that some hand tight bolts remain in place until the cask is lowered into the pool.

2.17.1 Select one bolt and loosen $1 / 4$ turn. 
2.17.2 Continue loosening al1 remaining bolts by $1 / 4$ turn following the sequence as shown on Figure $25(\mathrm{a})$.

2.17.3 Repeat the loosening of the lid bolts by another $1 / 4$ turn by repeating the sequence in step 2.17 .2 .

2.17.4 Upon completion of both $1 / 4$ turn cycles, all the bolts may then be removed.

2.18 Remove plug from port "D". Verify shield plug "A" is installed without bolts.

2.19 Remove the top face plastic protective cover.

2.20 Attach the lid lifting assembly per the following.

Note: Sites may require alternate assembly designs and instructions.

2.20.1 Place the two " $U$ " bolts over the four inch lifting pin, one on either side of the crane hook inboard of the two crossmembers.

2.20.2 Attach the support plate to the " $U$ " bolts, using the nuts and jam nuts provided.

2.20.3 Verify that the support plate hangs level. 
2.20.4 Attach a single-legged sling to each of the shoulder eye bolts in the support plate. If slings are identified with orientation markings, be sure to observe their proper location.

\subsection{CASK LOADING}

3.1 Position the beam over the lifting trunnions and engage the beam to the outer lifting shoulders of these trunnions following instructions in step 1.12 .

3.2 Attach the lid lifting system slings to the cask lid lifting lugs. Verify that the two inch plastic ball valve $V-3$ (Figure 27) on connector " $J 2$ " is open. Lift the cask off the decontamination pad and transfer to the pool.

Note: Continue to refer to Figure 27 for skirt fil1.

3.3 Attach the fill hose to "Jl" when cask is in position over pool. Connect the clean water supply for skirt filling (connection "A"). Verify valve $V-1$ is open and valve $V-2$ is closed.

3.4 Lower the cask into the pool while filling the skirt volume with clean water such that the skirt internal water level is maintained approximately six to eighteen inches above the pool water surface. As the cask is lowered slowly feed the fill hose into the pool and continue to spray the surfaces with clean water. 
3.5. Reduce crane speed and water flow rate as skirt water level approaches the top of the skirt.

3.5.1 Reduce the water supply, if necessary, so that the remainder of the skirt cavity fills slowly to displace the air still contained therein. As the skirt water level disappears from sight, reduce the water pressure by throttling valve $V-1$. It may be necessary to lower the cask in small increments to try and maintain the skirt water level within six to eighteen inches above the pool water level.

3.5.2 When the "J2" connector is within six inches to one foot from the pool water surface, stop lowering the cask until water is observed flowing from the "J2" connector.

3.5.3 Slowly feed the remaining fill hose into the pool such that the water level in the hose is slightly above the pool level. This will assure that no air gets trapped in the hose. Open valve $V-2$ then lower the reservoir until the bottom of the tank is about twelve inches above the pool water leve 1 .

3.5.4 Disconnect the water supply from the skirt filling line and reconnect it to the static pressure line (connection " $B$ "). 


\subsection{5 close valve $v-3$}

3.6 Continue to lower the cask. Maintain approximately six to eighteen inches of water head over-pressure inside the skirt above pool water level by adjusting valve $v-1$ to maintain an adequate water level in the water reservoir.

3.7 As the cask front face approaches pool surface leve1, remove any remaining 1 id bolts and store them properly.

3.8 Continue lowering the cask to the bottom of the pool at normal crane speed while continuing to maintain the six to eighteen inches of water over-pressurization in the level/reservoir box.

3.9 Gently place the cask on the bottom of the pool.

3.10 Remove the cask lid as follows:

3.10.1, Lower the lift beam unti 1 the guide arms are resting on the lifting trunnions. Release the lifting arms from the trunnions.

3.10.2* slowly raise the $1 \mathrm{ift}$ beam. As the slack is taken out of the lid lifting slings, visually verify that the top surface of the lid is level as it is lifted from the cask cavity. Gently lift the lid out of the cask cavity. 
Note: If the lid shows signs of binding, lower the crane hook until the cable is slack and carefully check the crane hook vertical alignment over the lid center and adjust as necessary. Repeat steps 3.10 .1 and 3.10 .2 as needed. Record any findings in the Remarks section of the Cask Loading Report.

3.10.3 Once the lid is free, continue lifting in normal speed until it has been lifted approximately four feet. This provides clearance for lid removal.

3.10.4 Remove the lid from the operations area.

3.10.5 Move the lid to its storage area. If the lid is to be removed from the pool, spray all crane cables, the crane hook, lift beam and lid with clean water as they surface.

Note: Lid should be stored on a support cradle so that there is no damage to gasket R6, the lid barrier gasket or the sealing gaskets R1A and R1B.

3.10.6 Position the crane as needed for further cask operations.

3.10.7 Inspect the lid O-rings per Steps 2.8 .

3.11 Install the front face protective cover per the instructions below (see figure 19).

3.11.1 Attach a tag line to each cover bale. 
3.11.2 Orient the cover over the lid recess area such that the two lid centering pins are in alignment with the bosses of the cover.

3.11.3 Lower the cover onto the cask until it is fully down (i.e., slack cable). The cover is designed such that the edges of the cover will center it correctiy.

3.11.4 Visually verify that cover is correctly installed (i.e., lying flat on the front face and correctly oriented).

3.11.5 If the cover position is not correct, slowly lift the cover clear using the tag lines, adjust its position as needed by rotating and repeat steps 3.11 .3 and 3.11 .4 .

3.11.6 Using the tag lines, position the bales such that they hang along the side of the cask and are out of the way of fuel loading operations.

3.12* Load the fuel assemblies into the cask fuel compartments per the instructions below. Record loading position of each fuel assembly by its identification number in the Cask Loading Report.

Note 1: If operating problems occur such that the binding procedure in section 3.13 is utilized, information on the problem should be provided in the Cask Loading Report under Remarks. 
Note 2: It is recommended that reference height indications be marked on the fuel handling equipment so they can be used to assist in determining fuel assembly elevations.

Note 3: During al1 fuel transfer operations performed in the pool, ensure that the fuel assemblies are free of all obstacles throughout transfer.

\section{Required Equipment}

-Fuel handing tool to be supplied by the site. -Crane facilities to be supplied by the site. Crane hook should be able to be rotated.

3.12.1 Attach the fuel handling tool to the crane hook.

3.12.2 Engage the fuel assembly to be loaded using the fuel handing tool and transfer it to a point directly over the cask fuel compartment into which it is to be loaded.

3.12.3 Lower the fuel assembly until its bottom nozzle is about three feet above the cask front face.

3.12.4 Verify that the fuel assembly is centered over the desired fuel compartment and oriented properly. If it is not, adjust its lateral position or rotate the assembly as needed.

3.12.5 When alignment is satisfactory, slowly begin lowering the assembly into the fuel compartment. 
3.12.6 As the fuel assembly bottom nozzle begins to enter the cask fuel compartment, begin closely monitoring for binding indications. If binding occurs, go to section 3.13 .

3.12.7 Continue slowly lowering the fuel assembly until a slack cable indication shows that the fue 1 assembly is fully down.

3.12.8* Visually verify that the fuel assembly is proper 1 y seated.

3.12.9 If the fuel assembly is not fully seated, raise the fuel assembly as needed per section 3.13 and reload it per the steps of 3.12 .1 through 3.12 .13 of this section, as required.

3.12.10 A fuel assembly that sits too deep in the fuel compartment could indicate that a fuel spacer is missing. If this is the case, contact the Transnuclear representative for further instructions.

3.12.11 If the fuel assembly is properly seated, disengage the fuel handling tool from the fuel assembly.

3.12.12 Slowly remove the fuel handling tool from the cask. 
Note: Ensure that tool is free from all obstacles during removal and that assembly is disengaged.

3.12.13* Record placement of each fuel assembly in cask by identification number and location in the Cask Loading Report.

3.12.14* Repeat Steps 3.12.2 through 3.12 .13 for each fuel assembly until the cask is loaded. Record time at completion of loading in the cask Loading Report.

3.12.15 Store the fuel handling tool in its storage area and disconnect it from the crane hook.

3.12.16 Remove the crane from the operations area.

\subsection{Binding Indication Instructions}

3.13.1 Stop lowering the fuel assembly. If slack has formed in the fuel handling crane cable, remove this slack by raising the crane hook in the jog mode.

3.13.2 If assembly is then not binding and free to be removed, remove the fuel assembly in the jog mode unti: the buttom nozzle of the assembly is clear of the cask front face.

3.13.3 If assembly is binding and cannot be removed, carefully move the fuel handing tool slightly back and forth (laterally) in a "rocking" 
motion. Perform this step in combination with removal of the assembly in the jog mode until the fuel assembly is clear of the cask front face.

3.13.4 Verify that the fuel assembly is not damaged (i.e., excessive bowing, etc.). If the assembly seems acceptable, the problem was probably due to improper alignment and loading operations may be repeated, starting at step 3.12.4. If binding is again experienced during the performance of steps 3.12.4 through 3.12.11, the fuel assembly should be carefully inspected for damage prior to further loading operations.

3.14 Check and lubricate (using Never-Seez) the threads of all removed cask bolts and screws as necessary.

3.15 Upon completion of cask loading, remove the front face protective cover by manually pulling both tag lines. The front face protective cover may be stored in the pool. If it is to be removed from the pool, spray with demineralized water as it reaches the surface.

3.16 Replace the cask lid onto the cask per the following instructions:

3.16.1 If the cask 1 id and/or lift beam have been removed from the crane hook, reconnect them. verify that lid lifting slings are attached in 
the proper orientation. Verify that the beam and lid are in proper orientation for positioning the lid onto the cask.

3.16.2 Transfer the lid to a position directly over the cask cavity lid seating surface. Establish correct lid orientation using the orientation marks and lower the lid to a height of about four feet above the cask front face. Adjust the vertical alignment and orientation as needed.

Note: This alignment is critical and should be done carefully. Angular orientation shall be established by lining up the cask and lid orientation marks prior to installing the lid. The lift beam should be rotated as needed to orient the lid.

3.16.3 Slowly lower the lid into the lid recess.

Note: Lateral and rotational adjustments of the lid may be made as the lid nears the cask front face but no lateral movement of the crane should be made once the lid has entered the lid recess. If further lid position adjustments are needed, the lid should be lifted until it is free of the lid recess and above the cask.

3.16.4 If the lid indicates significant binding during crane descent, slowly raise the lid in the jog mode until it is again free of binding and raise the lid out of the lid recess. Check the lid a) ignment and repeat steps 3.16 .2 and 3.16 .3 . 
3.16.5 As the lid nears its full down position, ensure that the two centering pins are protruding through their respective lid flange holes.

3.16.6 If they do not protrude, stop crane descent. slowly raise the lid a few inches.

3.16.7 Twist the crane hook in whichever direction is needed by referencing the 1 id orientation marks. Return to step 3.16 .3 and continue 1 id installation.

3.16.8 Continue lowering until the lid is fully down as indicated by slack cable in the sling cables. visually verify the lid for proper installation. The alignment pins should protrude from the lid plate.

3.17 Continue lowering the 1 ift beam until the guide arms contact the trunnions.

3.18 Attach the lift beam to the cask front trunnions (see step $1.13 .1)$.

3.19 Raise the cask to the pool surface and check that the lid is properly seated by surveying the lid seating area for radiation streaming. Wash down any exposed cask and 1 ift beam surfaces using a clean water spray. 
3.20 Remove water from the bolt holes using an aspirator and install four or more lid bolts to hand tight, as required by the facility.

3.21 Slowly remove the cask from the pooi while thoroughly washing down the top, skirt and base of the cask with a clean water spray to remove particulate and soluble contaminants.

3.22* As the cask is removed from the pool, the water inlet flow should be reduced and finally stopped as the top of the skirt surfaces from the pool. Open valve $v-3$ on connection "J2" when it reaches the surface. Once the inlet flow has been stopped, the fill hose is disconnected from the reservoir at the coupling between valve $V-2$ and the tee. The line is then used as a drain hose. Immediately begin raising the cask. Control the upward crane speed to maintain one to two foot skirt overpressure. Spray all component surfaces as they emerge from the pool, using clean water. Record total time in the pool.

3.23 When the cask and skirt are acceptably dry, disconnect hose connection "JI" at the fill line and transfer the cask to the decontamination pad. Dry all surfaces with clean rags.

Note: Do not remove the skirt until all required exter.lal cask decontamination operations are complete. Removal of the skirt prior to the completion of these, risks contamination of the cask fins. 
3.24 Skirt Operation Precautions

3.24.1 The skirt surface should be thoroughly rinsed as the cask is removed from the pool. If this is done, extensive skirt decontamination is not normaliy required.

3.24.2 The skirt should not be left installed for extended periods of time after a loaded cask has been removed from the pool. The skirt decreases the fin heat dissipation capacity. If loaded with the maximum $23.5 \mathrm{~kW}$ decay heat load, a time limit of eight hours shall be imposed for this condition. For cases of fuel with lower residual heat, this time period may be extended if cask cavity temperatures are monitored. Excessive temperatures may necessitate skirt removal.

3.25 Disconnect the lid lifting system from the cask 1 id.

3.26 Disengage the lift beam and move it out of the operations area (see step 1.15.3).

4.0 CASK LEAKAGE RATE AND DRYING VERIFICATIONS

4.1 Install the plastic protective cover on top of the cask.

4.2 Remove shield plug "A". Attach connector " $C$ " with drain hose in cask draining mode (Figure 11b). Drain approximately ten gallons. 
4.3 Turn on the vacuum pump with the gas ballast open. Pump requires approximately thirty minutes warm-up time before drying and/or testing can begin.

4.4 Verify that port plug " $D$ " is removed. Remove water from bolt holes using an aspirator and install remaining id bolts and tighten all lid bolts to the specified torque per the instructions below.

\section{Required Equipment}

- Torque wrench(es) suitable for setting torques of 40 and $290 \mathrm{ft}-1 \mathrm{~b}$, equipped with a $1-7 / 8$ " socket.

4.4.1 Install all bolts and tighten to hand tight.

4.4.2 Tighten bolts to $40 \mathrm{ft}$-lb following the numerical sequence as shown in Figure $25(\mathrm{a})$.

4.4.3* Tighten all id bolts to the final required torque of $290+10,-0 \mathrm{ft}-1 \mathrm{~b}$ by following the numerical sequence used in Step 4.4.2. Repeat torquing to ensure proper tightness. Record final torque values.

4.5 Install the Vacuum Drying System (VDS) in the lid tightness testing mode as shown on figure 8 with valve $v-13$ closed. Perform lid leak test in accordance with procedures of section 9.0 of this chapter. 
4.6 Upon successful completion of the lid tightness test, disconnect the VDS and assemble the cask in draining mode as shown on Figure 118. Install and torque the three bolts of connector " $\mathrm{A} 1$ " to $35 \mathrm{ft}-1 \mathrm{~b}$ per the procedure of Steps 2.9.1 and 2.9.2.

4.6.1 Drain the cask to the liquid radwaste drain or the spent fuel pool.

4.6.2* Remove the thermocouple well port plugs. Install test thermocouples into thermocouple wells " $F 1$ " (shortest), "F2" and "F3" (longest) and measure the temperatures of the cask cavity wall. Record temperature and time readings in the Cask Loading Report (Section 8.0). Check temperature rise from completion of cask draining until just prior to removal of cask from decontamination pad. Temperature rise should be below curve of figure 28. Record temperatures and times.

4.6.3* Upon completion of cask draining, record the time on the Cask Loading Report.

4.7 Replace the " $D$ " port plug and tighten to a torque of $35 \mathrm{ft}$ $1 b$. 
Note: Whenever performing operations around shield plug "A" or when shield plug "A" is removed, care should be taken as radiation streaming may be present.

4.8 Disconnect the " $C$ " connector. Connect the VDS to the cask in the cask vacuum drying mode as shown on Figure 6 . Ensure that valves $v-3$ and $v-4$ are closed.

4.9* Dry the cask cavity per the procedure provided in section 9.0 until the cask dryness test is satisfied. Record the total pressure rise.

4.10* Upon completion of cask drying, unbolt and remove connector "Al" and reinstall shieid plug " $A$ " and tighten bolts per the procedure of Steps 2.10 .1 and 2.10 .2 . Record final torque.

4.11 Remove the tape from the front face shock absorbing cover bolt holes. Remove any water from bolt holes.

4.12 If required for the specific shipment, obtain a gas sample from the cask cavity. Install the VDS in the sampling mode as shown on Figure $9 A$ but do not attach "B" connector to the cask at this time. Note that the two inch vacuum hose connection is blanked off at connector "B" (if equipped ).

4.12.1 Open valves $V-1, V-2$ and $V-3$ and evacuate the " $B$ " connector and sample bottle using the vacuum pump until a pressure of less than $10 \mathrm{mbar}$ is indicated on gage $G-1$. Close valve $V-3$.

4.12.2 Connect the " $B$ " connector to the top of the cask. 
4.12.3* After fifteen seconds, close valve $V-1$. Remove the " $B$ " connector from the cask and with the vacuum pump running, open valve $v-3$ until gage $\mathrm{G}-1$ reads 10 mbar. Close valve $V-3$. Remove the $3 / 8$ " vacuum hose, open valve $V-3$ and allow " $B$ " connector to return to atmospheric pressure. close the valve on the sample cylinder (not shown in Figure 9A). Remove the sample cylinder and measure the gaseous activity. Record measured gaseous activity on the Cask Loading Report.

4.13* Install the 3/8" vacuum hose between the connector " $B$ " and the backfill gas as shown on Figure 29. Set the backfill gas supply to a pressure of no more than 30 psig (excessive pressure will result in severe damage to the gage). Open valve $V-2$ in order to read the cask cavity pressure. Backfill the cask cavity with nitrogen to one atmosphere (ambient pressure). Record final pressure on the Cask Loading Report.

4.14* Replace $b 1$ ind flange for " $B$ " and tighten bolts to $35 \mathrm{ft}-1 \mathrm{~b}$ per the procedures of Steps 2.10 .1 and 2.10.2. Verify that this is not a " $J$ " opening flange.

4.15 Reconnect the VDS in the leak testing mode as shown in Figures $7 A$ and $7 B$. Verify separately the leakage rates of openings "A", "B" and " $C$ ". Perform leak tests in accordance with the procedures of step 9.5.2. 
4.16* Verify that the sum of the pressure rise for each opening tested is less than the allowable total pressure rise of 11 mbar. Record the total actual pressure rise on the Cask Loading Report.

4.17 Remove remaining VDS components from the cask.

4.18* Replace blind flange for " $C$ " and torque bolts to $35 \mathrm{ft}-1 \mathrm{~b}$ per the procedure of steps 2.9 .1 and 2.9.2. Verify that this is not a " $J$ " opening flange.

5.0 PREPARATION OF THE CASK FOR SHIPMENT

5.1 Check the external contamination levels of a 11 exposed cask surfaces and decontaminate as required. (See Chapter VI . )

Note: Do not permit water spray to enter the thermocouple ports.

5.2 Remove the protective plastic skirt as follows:

5.2.1 Check the skirt contamination leve1. Decontaminate if necessary to acceptable levels. Normally, washing the skirt with clean water and a soft cloth is sufficient to decontaminate the skirt.

Note: Do not remove the skirt until all required external cask decontamination operations are 
complete. Removal of the skirt prior to the completion of these steps risks contamination of the cask fins.

5.2.2* Remove connectors " $J 1$ " and "J2" and replace blind flanges for both openings. Verify that these were the flanges that were removed from the " $J$ " openings. Torque to $35 \mathrm{ft}$-ibs per the procedure Steps 2.9.1 and 2.9.2. Record final torque values.

5.2.3 Remove any remaining tape from the upper and lower skirt edges and unwrap the tensioning cables, freeing the skirt from the drum grooves.

5.2.4 Remove the thirteen screws from the upper and lower skirt bars. (Note: Remove the bolts from bottom to top.)

5.2.5 Remove the skirt from the cask using the skirt handies.

5.2.6 When the skirt surface is dry, fold it so that the outer surface never comes in contact with the inner surface. Store it in its storage area.

Note: The skirt should be stored in a clean area to avoid contamination or damage.

5.3 Check the contamination levels of the cask areas which were exposed by removal of the skirt and decontaminate as required. 
5.4 Visually inspect the thermocouple plugs and threads and lubricate plugs with a small amount of Never-Seez, if required.

5.5 Visually inspect the thermocouple plug gaskets to ensure they are free of cuts, grooves or cracks (see step 2.8).

5.6* Record final temperature readings and record on the Cask Loading Report. Determine total time between temperature measurements performed following training. Determine temperature difference $\mathrm{F} 2-\mathrm{t}$ amb from the final temperature measurements and for the time between temperature measurements verify that the difference is below the curve of Figure 28 .

5.7* Remove the test thermocouples and reinstall plugs into "F1", "F2" and "F3" and torque plugs to $35 \mathrm{ft}-1 \mathrm{~b}$.

Note*: Record a 11 cask parts replaced on the Cask Loading Report.

5.8 Apply Never-Seez to the engagement surfaces of the 1 ift beam arms, outer front trunnion shoulders (except redundant lift components) and rear trunnion inner shoulders.

5.9 Engage the lift beam to the front trunnions (see step 1.13.1). Lift the cask off the decontamination pad and remove the bottcm protective cover per the instructions below and remove the tape covering the bolt and alignment pin holes.

5.9.1 Disconnect the bottom cover attachment straps from the cask trunnions and fold them to the side of the cover so they are not in the way. 
5.9.2 slowly lift the cask off the decontamination pad. As the cask is lifted, remove the bottom cover from the cask.

5.9.3 Transfer the cover to its storage area.

5.10 Survey for removable contamination and decontaminate the rear cask face as required.

5.11 Transfer the cask from the decontamination pad to the floor in the vehicle area. Protect the cask rear face. Remove any debris, etc. from floor.

5.12 If redundant lifting was used, remove the secondary lift beam assembly from the crane leaving the primary 1 ift beam assembly attached to the top trunnions.

5.13 Lubricate rear trailer trunnion supports with Never-Seez. Install a set of shims to the rear trunnion supports and apply a layer of lubricant to the surface.

5.14 Lift the cask off the floor and lower the cask bottom trunnions onto the trailer rear trunnion supports. Cask should be lowered on trailer such that drain " $C$ " faces upward, after tilting into a horizontal position.

5.15 Tilt the cask from the vertical to the horizontal position as shown on Figure 26. Maintain crane and crane cables in a vertical position over lifting trunnions as cask is rotated to the horizontal position.

5.16 When cask is properly positioned on trailer, disengage the lift beam and remove from the area. 
5.17 Perform rear trunnion tie-down as follows:

5.17.1 Place the trunnion tie-down collars over the rear trunnions.

Note: Ensure that the bolt threads have been lubricated. Ensure that the bolt lock washers are installed.

5.17.2 Install the two $3 / 4$ " bolts (with their lock washers) to hand tight.

5.17.3 Tighten each bolt to a torque of $125 \mathrm{ft}-1 \mathrm{~b}$ using a torque wrench equipped with a 1-3/4" socket and extension. Repeat for second rear trunnion support.

5.18 Perform contamination survey required by Step 6.1 on cask surfaces not accessible after shock absorbing cover and impact limiter installation and record on appropriate forms.

5.19 Perform front trunnion and trunnion guide assembly tiedown operations per the following instructions:

Required Equipment

-Ratchet

$-13 / 16^{\prime \prime}$ socket

$-3 / 4$ " socket (for trunnion guide assembly bolts) 
-Torque wrench (suitable for setting torques of $30 \mathrm{ft}-1 \mathrm{~b}$ )

$-1-1 / 4$ " open end wrench

-Ratchet drive extension

5.19.1 Front Trunnions

5.19.1.1 Swing the binder assembly over the cask trunnion.

5.19.1.2 Verify that the collar is correctly positioned on the trunnion inside shoulder. The position of the collar should be such that it restrains the top half of the trunnion shoulder. If necessary, adjust the collar position by performing step 5.19.3.

5.19.1.3 With the binder handle in the up position, engage the binder attachment hook under the trunnion tie-down support lip.

5.19.1.4 Push the binder handle down to the full down position. Verify that the collar is tight against the cask trunnion. If it is not, adjust the tie-down assembly by performing step 5.19.3.

5.19.1.5 Lock the load binder handle to its down position and install the safety chain. 
5.19.1.6 Repeat Steps 5.19.1.1 through 5.19.1.5 for the second front trunnion.

5.19.2 Trunnion Guide Assembly Installation

5.19.2.1 Swing back the trailer front cradle dust cover plate.

5.19.2.2 Install the trunnion guide assembly around the cask bottom trunnion.

Note: It may be necessary to transfer some shim plates from one side of the trunnion guide assembly to the other side so that the guide assembly fits easily and snugly around the trunnion. Do not leave any shims out.

5.19.2.3 Install the two $1 / 2$ " bolts with their lock washers.

Note: Lubricate the bolt threads as needed prior to installation.

5.19.2.4 Torque the two $1 / 2$ " bolts to a torque of $30 \mathrm{ft}-1 \mathrm{~b}$.

5.19.3 Front Trunnion Tie-Down Adjustment

If necessary adjust the tie-down collar tension in accordance with the following: 
5.19.3.1 Using a 1-1/8" open end wrench, loosen the two jam nuts above and below the turnbuckle.

5.19.3.2 Release the load binder handle and rotate the turnbuckle to adjust the tie-down collar tension as needed.

5.19.3.3 Position the tie-down assembly over the trunnion and verify that the adjustment is correct.

5.19.3.4 Lock the load binder handle and attach the safety chain.

5.19.3.5 Tighten the jam nuts wrench tight against the turnbuckle.

5.20 Remove tape from bolt holes in trunnions and replace the trunnion impact limiters as follows:

\section{Required Equipment}

-Ratchet

$-13 / 16^{\prime \prime}$ socket

-Torque wrench suitable for setting torques of $30 \mathrm{ft}-1 \mathrm{~b}$

-Ratchet drive extension

5.20.1 Manually position the trunnion impact 1 imiter on its respective trunnion (see Figure 5 ). 
Note: The trunnion impact limiter without gussets must be installed on the downward facing (in relation to trailer) redundant trunnion (Figure 1).

5.20.2 Install the $9 / 16^{\prime \prime}$ bolt to hand tight.

5.20 .3 Tighten the $9 / 16^{\prime \prime}$ bolt to a torque of $30 \mathrm{ft}-1 \mathrm{~b}$.

5.20.4 Repeat Steps 5.20.1 through 5.20.3 for the remaining impact 1 imiters to be installed.

5.21 Install the shock absorbing covers per the following instructions. The weight of each cover is approximately 870 pounds.

\section{Required Equipment}

- Two-legged sling equipped with connections to allow attachment to the lifting crane hook (bale) and to the cover connecting shackles (loops, etc.).

-2 connecting shackles

-Ratchet

-Ratchet arive extension

$-1-7 / 8$ " socket

-Torque wrench(es) suitable for setting torques of 40 and $290 \mathrm{ft}-1 \mathrm{~b}$

-Chain hoist, $1 / 2$ ton capacity, minimum

5.21.1 Attach the two-legged sling to the two lifting lugs of the shock absorbing cover by means of the two connecting shackles. 
5.21.2 Attach the chain hoist to the crane hook. Center the crane hook directly over the shock absorbing cover to be handled. There is no preference in the shock absorbing cover installation sequence; either may be installed first. Lower the chain hoist hook to a height of approximately two feet above the cover.

5.21.3 Attach the two-legged sling lifting bale to the chain hoist hook.

5.21.4 Slowly raise the crane until the sling legs are taut.

5.21.5 Transfer the shock absorbing cover to its respective end of the cask.

Note: The shock absorbing covers are not interchangeable.

5.21.6 Lower the shock absorbing cover such that its centering pins are in alignment with the cask drum alignment pin holes.

5.21.7 Install the cover by slowly moving the cover toward the cask face. Care should be taken to ensure that the alignment pins are aligned correctiy and the covers are kept vertical during installation. Once the alignment pins are started into the holes all vertical height adjustment shall be by manual operation of the chain hoist only. 
5.21.8 Install the four shock absorbing cover bolts and torque them as follows:

5.21.8.1 Tighten to hand tight.

5.21.8.2 Tighten all bolts to $40 \mathrm{ft}-1 \mathrm{~b}$ following the numerical sequence shown in Figure $25(b)$.

5.21.8.3 Repeat the cycle until all bolts are torqued to $40 \mathrm{ft}-1 \mathrm{~b}$.

5.21.8.4 Tighten all bolts to the final required torque of $290 \mathrm{ft}-1 \mathrm{~b}$ in the same numerical sequence followed in step 5.21.8.2.

5.21.9 Lower the crane hook until the two-legged sling cables are slack.

5.21.10 Remove the shackles from the shock absorbing cover and transfer the crane hook and two-legged sling to the other cover.

5.21.11 Repeat Steps 5.21.1 through 5.21.9 for the other shock absorbing cover.

5.21.12 Disconnect and store the two-legged sling, connecting shackles and hand tools. 
6.0 CASK DEPARTURE

6. 1* Perform a cask and trailer contamination survey, recording the readings on Form 3, Cask Transport Radiation Survey, and Form 4, Trailer Departure Radiation Survey and record maximum values on the Cask Loading Report. See Section 7.0. Decontaminate as required to meet allowable levels for transport.

Note: DOT considers a contamination level significant if, when averaged over 300 square centimeters of any part of the package surface, the level exceeds $2200 \mathrm{dpm} / 100 \mathrm{~cm}^{2}$ for beta/gamma or $220 \mathrm{dpm} / 100 \mathrm{~cm}^{2}$ for alpha (49CFR173.443).

6.2* Using a hand held pyrometer, measure the cask surface temperature near the base of a centraliy-located $f$ in and record on the Cask Loading Report.

6.3* Install the security seals to the shock absorbing covers per the instructions below and record the numbers on the Cask Loading Report.

\section{Required Equipment}

-(2) security seals (type E seals or equivalent) and corresponding wire

-Pliers

6.3.1 Install the security seal wire through the two holes of the shock absorbing cover bolt boss and through the top section of the security seal. 
6.3.2 Pull the wire taut, tie it in a secure knot and twist the wire. The wire thus seals the bolt boss.

Note: The wire should be taut to ensure that the shock absorbing cover bolt cannot be removed without breaking the security seal.

6.3.3 Trim the twisted ends of the wire and place them in the bottom section. Install the security seal top section onto its bottom section.

6.3.4 Squeeze the security seal top and bottom sections such that the security seal is locked. The shock absorbing cover bolt hole is now sealed and the bolt cannot be removed without breaking the security seal wire.

6.3.5 Repeat Steps 6.3.1 through 6.3.4 for the other shock absorbing cover.

6.4* Attach the required regulatory labels to the cask as detailed below and verify on the Cask Loading Report.

The requirements for package labeling as detailed in 49CFR172.403 are as follows:

6.4.1 Affix two "Radioactive Yellow-III" labels to opposite sides of the package with one placed on or near the package closure. (Recommend applying 
one label to each shock absorbing cover on opposite sides.)

Note: Do not place labels on cask drums.

6.4.2 Enter the following information in the blank spaces on the label by printing with a durable, weather resistant means of marking:
(a) Contents: "Mixed Fission Products"
(b) Number of Curies:
(c) Transport Index:

6.5* Perform a final cask inspection. Verify and record findings on the Cask Loading Report.

6.5.1 The cask appears to be in good condition.

6.5.2 All tie-downs are secure (i.e., no loosening of bolts/tie-downs).

6.5.3 There is no water leakage or bubbling that could indicate a failure of the cask containment system.

6.5.4 The impact limiters and shock absorbing covers are correctly installed and the bolts are torqued properly.

6.6 Install the trailer protective enclosure as follows:
6.6.1 Install any roller track sections that were removed to position the cask or cover onto the trailer.


6.6.2 Install the trailer protective enclosure by sliding the enclosure rearward by having one person on each side of the trailer grasp the side section of the tarpaulin and pull it towards the rear of the trailer. Slide the enclosure until the tarpaulin is fully extended. Insert the locking pins.

6.6.3 Release the back section of the tarpaulin by unbuckling the straps which fasten it to the tarpaulin roof section. Allow it to unroll.

6.6.4 Fasten the rear tarpaulin section to the enclosure sides by buckling the straps along both sides of the rear tarpaulin section.

6.6.5 Secure the side tarpaulin walls of the protective enclosure by pulling the elastic tie-downs over the trailer tie-down hooks. Ensure that the tiedowns are taut and firmly restraining the tarpaulin at all tie-down points.

Note: Metal " $S$ " hooks should not be attached to the " $D$ " rings on the canvas enclosure. Hooks are provided under the lip of the trailer for the purpose of attachment to the metal " $\mathrm{s}$ " hooks.

6.6.ij Ve-ify that all side vents of the protective enclosure are not obstructed by snow, ice, dirt or debris. 
6.7* Verify that placards installed on trailer are correct for the type of shipment. Record on the Cask Loading Report.

6.8 Complete and sign the Cask Loading Report.

Note: The TN-8L trailers are equipped with flip-type placards located in four placard holders.

6.9 Provide all required shipping documents as detailed in Step 6.10 and a copy of the Cask Loading Report to the carrier.

Note: The regulatory requirements listed in this section are applicable to each individual offering the package for transport and to each carrier who transports the package by road. The specific DOT regulatory requirements are noted in parenthesis after each section below and are based upon 49CFR Parts 172 and 173 .

\subsection{Requirements for Shipping Papers}

Each person who offers spent fuel assemblies for transport shall describe it on the shipping papers with the following information (See Attachment 1, "Shippers certification For Radioactive Material", for example format).

6.10.1 The proper shipping name: "Radioactive Material, Fissile, N.O.S." - Further description can be provided by the phrase "Irradiated Fuel Assemblies" in parenthesis following the proper shipping name. (Section 172.202 (a) (1) ) 
6.10.2 The class prescribed for the material: "Radioactive Material". (Section 172.202 (a) (2) )

6.10.3 The total quantity of material to be shipped by weight (of the fuel assemblies) (Section 172.202 (a) (4) )

6.10.4 The term "Mixed Fission Products" (Section 172.203 (d) (i) )

6.10.5 Description of the physical and chemical form of the material; "Irradiated Fuel Assemblies" (Section 172.203 (d) (i i) )

6.10.6 The activity contained in the package expressed in Curies. (Section 172.203 (d) (iii) )

6.10.7 The category of label applied to the package in the shipment: "Radioactive Yellow-III" (Section 172.304 (d) (iv) )

6.10.8 The transport index assigned to the package (Section 172.203 (d) (v) )

6.10.9 The fissile class of the package, "Fissile class III", and the following additional notation:

"Warnirg-Fissile Cliss III Shipment. Do not load more than one (1) package per vehicle. In 
loading or storage areas, keep at least 20 feet ( 6 meters) from other packages bearing radioactive labels". (Section 172.203 (d) (vi) (B) \& (c).)

6.10.10 The package identification marking as prescribed in the USNRC Certificate of Compliance. (Section 172.203 (d) ( $v i i)$ )

6.10.11 The statement of shipper's certification shall be printed on the shipping papers and shall be as follows: (Section 172.204(a)) "This is to certify that the above materials are properly classified, described, packaged, marked and labeled and are in proper condition for transportation according to the applicable regulations of the Department of Transportation".

6.10.12 The shipper's signature.

6.10.13 Due to the internal contamination of the TN-8L cask, an empty cask shall be transported as Radioactive Material. The proper label to affix to the cask is based on the radiation level at the surface of the cask and the transport index. (Section 172.403 (c) ).

Note: Radioactive White-I and Radioactive Yellow-II shipments do not require placarding.

6.11 Release the package for transport. 
7.0 RADIATION SURVEY REQUIREMENTS

7.1 Purpose

This section has been prepared to provide guidance to facilities radiation protection staff personnel for the performance and documentation of surface contamination and radiation surveys of the $\mathrm{TN}-8 \mathrm{~L}$ cask and trailer upon receipt and before departure so as to comply with the requirements of Titie 10CFR Part 20 and Title 49CFR Part 173.

Utilizing the guidance provided below, users of the $\mathrm{TN}-8 \mathrm{~L}$ cask shall prepare suitable procedures incorporating the appropriate requirements for performing radiation surveys of the cask and trailer.

7.2 Unloaded Cask Receipt Monitoring Procedure

7.2.1 Upon receipt of the unloaded cask at a facility, cask and trailer external surfaces shall be monitored for possible radioactive contamination.

7.2.2 Record measured radiation levels and contamination readings on Form 1, Cask Receipt Radiation Survey form and Form 2, Trailer Receipt Radiation survey form, as applicable.

7.2.3 Complete and retain the forms for documentation requirements. 
7.3 Loaded Cask Departure Monitoring Procedure

7.3.1 Upon completion of loading operations and removal of the cask from the pool, the exterior surfaces should be decontaminated as detailed in the Decontamination Section (Section 6.0).

7.3.2 Perform radiation and contamination surveys of the cask and trailer and record measured radiation levels and surface contamination readings on Form 3 "Cask Transport Radiation Survey Form", and on Form 4, "Trailer Departure Radiation Survey Form", as applicable.

7.3.3 Record the following measurements on Form 5, Cask Loading Report:

a) Maximum beta/gamma and neutron at cask surface. Note locations.

b) Maximum dose rate at three (3) feet from the cask surface: both beta/gamma and neutron. Note locations.

c) Maximum dose rate at vehicle outer surface, both beta/gamma and neutron. Note locations.

d) Maximum dose rate at six (6) feet from vehicle, both beta/gamma and neutron. Note locations. 
e) Maximum dose rate in any normally occupied position of the trailer/cab.

f) Maximum removable surface contamination measured.

7.3.4 The regulatory limitations for transport for the above measurements are as follows:

a) The radiation dose rate must not exceed 200 millirem per hour at any point on the external surface of the package,

b) The radiation dose rate must not exceed ten millirem per hour at any point six (6) feet from the vertical planes projected from the outer edges of the vehicle.

c) The radiation dose rate must not exceed two millirem per hour in any normally occupied position in the trailer/cab (this provision does not apply to private motor carriers).

d) Surface contamination shall not exceed those levels specified in the Note of step 6.1 .

7.3.5 Certificate of Compliance No. 9015 states that the package contents shall be so limited that under normal conditions of transport, the total 
dose rates shall not exceed $17 \mathrm{mR} / \mathrm{hr}$ at three feet from the surface of the package.

7.3.6 Complete and retain the survey forms for documentation purposes. A copy shall be attached to the Cask Loading Report.

8.0 CASK LOADING REPORT

\subsection{Purpose}

The purpose of the Cask Loading Report is to record certain observations and inspections which are made while the cask is at a facility to be loaded with fuel. In particular, the report covers measurements which are mandatory upon arrival of the cask at a facility and prior to its departure. The report identifies the fuel assemblies and their characteristics which are actualiy loaded into the cask, and records the observations and measurements which are taken to assure safety during transport. An example format is provided on Form 5, the TN-8L Cask Loading Report.

\subsection{Instructions}

8.2.1 The Cask Loading Report shall contain information on radiation, temperature and pressure measurements, visual observations and other data as indicated on the report form. 
8.2.2 The corresponding procedural steps of the Loading Procedure (Section 1.0 through 6.0 of this chapter) are provided in parenthesis for convenience.

8.2.3 Any negative or non-conforming response to an inspection or data point shall be recorded in the Remarks section of the example form. If additional explanatory or informational comments are necessary for any procedural step of this report, they should also be noted in the Remarks section. All remarks shall be provided with the applicable referenced procedural step of this report.

8.2.4 The person(s) responsible for recording the information on this report and for performing inspections shall date and sign the report upon completion of the loading operations. If several individuals are responsible for data recording, all should sign the report indicating what steps they witnessed or recorded.

8.2.5 The radiation and contamination forms (Forms 1-4) are to be attached to the Cask Loading Report.

8.2.6 The completed Cask Loading Report shall be forwarded to the responsible personnel in the facility's organization for any required reviews and record retention, as dictated by site operating procedures. 
8.2.7 Copies of the Cask Loading Report shall be transmitted with the shipment to the receiving facility.

8.2.8 A complete copy of each Cask Loading Report shall be transmitted to Transnuclear, Inc. within five working days of each shipment. The mailing address is 310 Woodward Drive, Aiken, South Carolina 29801, Attention: Cask Operations Manager.

\subsection{VACUUM DRYING AND LEAKAGE RATE TESTING}

\subsection{Introduction}

The purpose of this section is to provide the procedures for performing the cask drying and dryness verification, and the cask tightness testing required to be performed following the loading (see chapter IV) of the TN-8L package as required by the Certificate of Compliance.

\subsection{Cask Leakage Rate Testing}

\subsubsection{Loading Operations}

The cask leakage rate testing is performed in two steps following removal of the cask from the fuel storage pool. Prior to draining of the cask cavity, a lid tightness test is performed to verify the proper functioning of the two lid gaskets. 
Following successful completion of this test, the cask cavity is drained and then dried by use of the vacuum pump. Any residual moisture in the cavity is removed at this time and a cask cavity dryness verification test is performed.

At this point the cask cavity pressure is established for transport.

Once the cavity has been verified dried, the remaining cask openings (shield plug at " $A$ ", blind flange at " $B$ ", and Hansen coupling plug at " $C^{\prime \prime}$ ) are individualiy tested to verify that the leaktightness criteria for transport have been met. The acceptance criteria given in this section, is valid only for the specific test system described. If a different leakage test system is utilized, a different set of acceptance criteria must be established. Appendix $B$ and $C$ outline the methods needed to determine the new set of acceptance criteria. The results of the tests are recorded on Form 6, the Cask Loading Leakage Rate Testing Data Sheet.

9.2.2 Following removal of the TN-8L cask from the fuel storage pool after removal of the spent fuel assemblies, it is necessary to drain the cask cavity. As no fuel is present in the cask cavity, it is not necessary to perform the cask leakage rate testing required of a loaded package. 


\subsection{Lid Gasket Tightness Testing}

\subsubsection{Introduction}

This section provides the procedure to be utilized for verifying the lid gasket tightness by subjecting the interspace between the inner and outer lid gaskets to a pressure rise test using the VDS installed through the lid gasket port and connector " $D$ " as shown on Figure 8 .

\subsubsection{Lid Leakage Rate Test Procedure}

9.3.2.1 Following torquing of the lid bolts, remove residual water from 1 id gasket port opening " $D$ " with an absorbent material.

9.3.2.2 Connect the VDS in the lid tightness testing mode as shown on Figure 8 with valves $V-13, V-5$ and $V-7$ closed.

9.3.2.3 With the vacuum pump running and the gas ballast open, open valve $v-13$ and begin vacuum drying of the lid gasket interspace by throttling valve $v-6$ to obtain a vacuum reading of approximately 10-25 mbar on gage G-3. Gage G-3 will normally be 0-50 mbar dial gage. 
9.3.2.4 When leak testing the "A", "B", " $C$ " and "D" openings there will be some water present in each cavity that must be evaporated (dried) before the leak rate can be determined. During the drying phase, do not permit the pressure on G-3 to fall below 10 mbars. A cursory check for dryness is performed by closing valve $V-13$ and observing how rapidly the pressure increases. If the increase is relatively rapid it probably indicates the presence of water vapor. Open $v-13$ and continue pumping at $10-25$ mbars. If the pressure rise during the cursory check is quite slow, open valve $v-13$ to bring the pressure down to 10 mbars and perform the leak test.

9.3.2.5* When the specified vacuum is reached, close valve $V-13$ and wait five or ten seconds until pressure is stabilized and the indicator is in line with a gage mark. Record pressure as measured on gage $G-3$ and the test start time on the data sheet.

9.3.2.6* After twelve minutes(*), record the observed pressure from gage $G-3$ and time on the data sheet. If gage reading is between increments, read the next higher increment. 
9.3.2.7* Calculate the pressure rise $(\Delta P)$ by subtracting the starting pressure from the final pressure and record on the data sheet.

9.3.2.8 QA observe leak test and verify that the pressure $r i s e$ is less than 5 mbar(*). If the actual leakage rate meets the above criteria, the lid leakage is within acceptable limits and the test is complete. Cask operations may now continue per the Cask Loading Procedure, Step 4.6 .

(*) Based on a total test volume of 300 cc. If this volume should change, the time or acceptable $\Delta P$ must change accordingly. The test volume can be verified by the Transnuclear representative.

9.3.2.9 If the pressure rise is greater than 5 mbar, the test is unacceptable and Steps 9.3.2.3 through 9.3.2.8 may be repeated several times. If the results are still unacceptable, proceed to Section 9.6 for instructions on corrective actions and retesting. 
9.4 Cask Drying and Dryness Verification

9.4.1 Introduction

This section provides the procedure for performing vacuum drying at the cask cavity following draining and for performing the cask dryness verification test.

9.4.2 Cask Cavity Drying

9.4.2.1 Upon completion of cask draining operations per Step 4.6 of the Loading Procedure the cask cavity shall be vacuum-dried in accordance with this procedure.

9.4.2.2 Connect the VDS to the cask cavity through shield plug opening " $A$ " as shown on Figure 6 . Ensure valves $V-3$, $V-4, V-5$ and $V-7$ are closed. Install drain bottle in connector " $C$ ". The use of the " $B$ " connector is optional if $\mathrm{G}-2$ has a valid calibration sticker.

Note: To facilitate operations, it is recommended that a curve be plotted of cask internal pressure (mbar) versus pumping time during cask drying.

$9.4 .2 .3 *$ Open valve $v-6$ and start the vacuum pump with the gas ballast valve open. 
Observe the cask cavity pressure using gage $G-3$ (if using " $B$ " connector) or G-2 using valve $V-6$ to throttle the vacuum pump suction, if necessary. Record initial start time and minimum cold wall temperature as measured by thermocouple "F1", "F2" or "F3" on the data sheet.

Note: The cask cavity pressure will normally show an initial steep pressure decrease until a pressure corresponding to the vapor pressure of the residual liquid in the cavity is reached. At this point, the cask cavity pressure will remain nearly constant showing a plateau region. This plateau will be observed to be at a pressure equal to the vapor pressure corresponding to the temperature of the cold wall of the cask cavity (anticipated pressure: 14 mbar - 35 mbar). Refer to Figure 30 for vapor pressure corresponding to the cavity wall temperature.

9.4.2.4 When the vacuum reaches approximately 40 mbar, close valve $V-6$ and open valve $v-4$. This step is intended to accelerate drying by forcing remaining water out through the drain lines into the drain bottle installed on connector "C". Disconnect and drain the water in 
the drain bottle, then reconnect it. close valve $V-4$ and open valve $V-6$ and continue pumping until the pressure is back down to approximately 40 mbar. Continue to repeat this step as long as additional water is observed entering the drain bottle.

9.4.2.5 When no significant amount of water is collected in the drain bottle, repeat Step 9.4.2.4 one more time, then disconnect connector " $C$ " from the cask. Continue vacuum pumping using valve $v-6$ to limit the cavity pressure to a minimum of 10 mbar. At some point in time it will be necessary to close $v-6$ to prevent the pressure from falling below 10 mbar.

9.4.2.6* To test the dryness, close valve $v-6$. Allow for stabilization of system pressure for about one minute. Read the pressure using gage G-2 or G-3. It is recommended that this reading be performed when the gage indicator is aligned with a mark on the dial: If the indicator is between two dial marks, the next lower mbar shall be used as the first pressure reading. 
Record time and pressure on the data sheet. After ten minutes read the pressure on the same gage G-2 or G-3. If the gage indicator is between two dial marks, the next higher mbar shall be used as the second pressure reading. Record pressure in the data sheet. If the pressure increase does not exceed 3 mbar, the cask is considered to be dry. Proceed to step 4.11. Otherwise continue with step 9.4 .2 .7 .

9.4.2.7 If the pressure increase exceeds 3 mbar, open valve $v-6$ and reduce the cask pressure to 10 mbar. Close valve $v-6$ and repeat the dryness test as described in step 9.4.2.6. Record test data on the data sheet. If the observed pressure rise for successive tests is slightly less each time, drying appears to be taking place. Repeat this step until the dryness test results indicate that the cask is dry. Proceed to Step 4.11 .

If the observed pressure rise remains constant or increases from drying cycle to drying cycle, there may be a physical leak in the system. Proceed to Step 9.4.2.8. 
9.4.2.8 If a leak in the system is suspected:

a) Check that all connections between the cask and the VDS are properly made up and proper closure of the valves required to be closed $(V-4, V-5, V-7)$. Open valve $V-6$ and reduce the cask pressure to 10 mbar as observed on G-3. Repeat the dryness test as described in Step 9.4.2.6.

b) If the dryness test still indicates a pressure rise in excess of 3 mbar, remove connector " $B$ ". Open valve $V-6$ and reduce the cask pressure to $10 \mathrm{mbar}$ as observed on $\mathrm{G}-3$. Perform a dryness test as described in step 9.4.2.6.

c) If still not successful, install connector "B", disconnect the hose section at connector " $A 1$ " and reconnect valve $V$ 4 directly on the outlet of connector "A1". Connect the vacuum hose to $V-4$. Open $v-4$ and $v-6$. Reduce the cask pressure to 10 mbar as indicated on gage G-2. Close $V-4$ and perform a dryness test (using pressure reacings from gage G-3).

d) If there is still evidence of leakage, notify the Transnuclear representative. 


\subsection{Cask Openings Leakage Rate Testing}

\subsubsection{Introduction}

This section provides the procedure to be utilized for verifying that the leakage rate of cask openings other than the 1 id is satisfactory and meets the requirements of the certificate of compliance. The test is performed by the use of a test cover for checking the gaskets of the blind flange at the vent opening " $B$ " and shield plug " $A$ ", and a test flange to check the Hansen coupling plug at drain opening " $C$ ". (Refer to Figures 7A and 7B.)

\subsubsection{Cask Openings Leakage Rate Test Procedure}

9.5.2.1 Close valves $V-11$ and $V-6$. Use a clean wipe to remove foreign matter from the o-ring of the test cover and the seating surface on shield plug " $A$ ". If may be necessary to apply a thin layer of vacuum grease to the o-ring of the test cover before installing the cover over shield plug "A".

9.5.2.2 Open valve $V-11$, thereby evacuating the volumes between the test cover and the shield plug.

9.5.2.3 Continue vacuum pumping until a vacuum of less than 10 mbar (but not less than 7 mbar) is indicated on pressure gage $\mathrm{G}-3$. 
9.5.2.4 When the vacuum is stabilized at about 10 mbar, close valve $v-11$. Record initial pressure and time on the data sheet.

9.5.2.5* Test for twelve minutes. Record final pressure, test stop time and total elapsed number of seconds.

9.5.2.6 Verify leak rate of shield plug "A".

9.5.2.6.1* Calculate $\Delta P$ by subracting the pressure recorded in Step 9.5.2.4 from the pressure recorded in step 9.5.2.5.

9.5.2.6.2 The leak rate is acceptable if the pressure rise during the twelve minute test period does not exceed 2 mbars.

9.5.2.6.3* QA observe leak test and verify shield plug "A" leakage rate test pressure rise is acceptable.

9.5.2.7 Wipe a 11 excess water from recess at opening " $\mathrm{C}$ ". Install the test flange and VDS on drain opening " $C$ " as shown in Figure 7B using the " $C$ " flange 
bolts, and torque each bolt to $35+5-0$ ft-lb sequentially in a clockwise direction. Repeat torquing sequentially in a counterclockwise direction. No grease is required for the " $C$ " flange.

9.5.2.8* Repeat Steps 9.5.2.2 through 9.5.2.5 for the leak rate data ( $\Delta$ time and $\Delta P$ ) for the " $C$ " Hansen plug leak test.

9.5.2.9 Verification of leak rate of " $\mathrm{C}$ " fitting.

9.5.2.9.1* Calculate $\Delta P$ by subtracting initial pressure from final pressure recorded in Step 9.5.2.8 for fitting " $\mathrm{C}$ ".

9.5.2.9.2 The leak rate is acceptable if the pressure rise during the thirteen minute test period does not exceed 2 mbar.

9.5.2.9.3* QA observe leak test and verify Hansen Plug " $C$ " fitting leakage rate test pressure rise is acceptable. 
9.5.2.10 Remove the " $C$ " test flange and attach the " $C$ " blind flange with bolts torqued to $35+5,-0 \mathrm{ft}-1 \mathrm{~b}$. Verify bolts torqued to $35+5,-0 \mathrm{ft}-1 \mathrm{~b}$.

9.5.2.11* Connect the VDS in the leak testing mode as shown in Figure $7 \mathrm{~A}$ and verify the leakage rate of the " $B$ " flange. Wipe excess water from recess opening "B".

9.5.2.12* Repeat Steps 9.5.2.1 through 9.5.2.5 checking flange " $B$ " in the same manner as shield plug "A".

9.5.2.13* Verification of leak rate of " $B$ " flange.

9.5.2.13.1 Calculate $\Delta P$ by subtracting the initial pressure from the final pressure recorded.

9.5.2.13.2 The leak rate is acceptable if the pressure rise during the twelve minute test period does not exceed 2 mbar.

9.5.2.13.3* QA observe leak test and verify " $B$ " flange leakage rate test pressure is acceptable. 


\subsection{Corrective Action Procedures}

\subsubsection{Introduction}

This section provides the methods to be used when leakage testing acceptance criteria are not met, i.e., the pressure rise for the measured test time exceeds the maximum allowable. In all tests, except for the " $A$ " and " $B$ " opening, the most likely cause is excessive moisture in the cask opening. Prior to assembly of the test system to the cask opening, dry all accessible cask surfaces.

\subsubsection{Lid Leakage Rate Test}

9.6.2.1 Verify that all lid bolts are torqued to $290+5,-0 \mathrm{ft}-1 \mathrm{~b}$.

9.6.2.2 Verify that connector " $D$ " is torqued to $35+5,-0 \mathrm{ft}-1 \mathrm{~b}$.

9.6.2.3 Check vacuum fitting connections on Connector "D" for tightness.

9.6.2.4 Repeat the lid leakage rate test. If results are still unacceptable, the cask must be returned to the pool and the lid removed for 1 id gasket inspection and/or replacement. Proceed from Step 2.8 of the Loading Procedure. 
9.6.3 Opening " $A$ " and " $B$ " Leakage Rate Test

9.6.3.1 Remove test cover from the affected opening and inspect gasket. Replace as necessary.

9.6.3.2 Verify cleanliness of gasket and on machined seating surface around the flange. Clean as necessary.

9.6.3.3 Verify torque of blind flange bolts is $35+5,-0 \mathrm{ft}-1 \mathrm{~b}$.

9.6.3.4 Repeat the test. If the results are still unacceptable, remove the flange for "B" or the shield plug and inspect the gasket. Replace as necessary. Inspect gasket seating surface of the opening. Clean as necessary.

9.6.3.5 If the cask lid surface on which the test cover seats, is badly marred, contact the Transnuclear representative.

9.6.3.6 Repeat the test. If results are still unacceptable, replace flange or shield plug with spare.

9.6.4 "C" Hansen Coupling Leakage Rate Test 
9.6.4.1 Remove the flange cover and check gasket and seating surface. Replace gasket if necessary.

9.6.4.2 Install " $C$ " connector and cycle the Hansen plug several times to get better seating of the plug.

9.6.4.3 Reinstall flange cover and torque bolts to $35+5,-0 \mathrm{ft}-1 \mathrm{~b}$.

9.6.4.4 Repeat the test. If the test is still unacceptable remove test flange and replace Hansen coupling plug in accordance with section 3.0 of Chapter VII. 
FORM 5

IN-8L CASK LOADING REPORT

Facility:

Package Identification:

Loading Identification Number:

Date:

Carrier:

1.0 CASK RECEIPT

1.1 (1.1) Verify all shipper's documentation transmitted by the carrier has been turned over to the appropriate receivers:

1.2 (1.2) Verify that all appropriate shipper's documentation has been reviewed and that a 11 comments have been noted:

$1.3(1.4)$ Complete Forms 1 and 2

1.3.1 Maximum dose rate at cask surface:

Beta/gamma : $\mathrm{mR} / \mathrm{hr}$

location:

1.3.2 Maximum dose rate at $2 \mathrm{~m}\left(6^{\prime}\right)$ from cask surface:

Beta/gamma: $\mathrm{mR} / \mathrm{hr}$

locatior:

1.3.3 Maximum dose rate at trailer surface:

Beta/gamma: $\mathrm{mR} / \mathrm{hr}$

location: 
1.3.4 Maximum removable contamination of the cask:

Beta/gamma: $\mathrm{dpm} / 100 \mathrm{~cm}^{2}$

location:

1.3.5 Maximum removable surface contamination of the trailer:

Beta/gamma: $\mathrm{dpm} / 100 \mathrm{~cm}^{2}$

location:

Alpha: $\mathrm{dpm} / 100 \mathrm{~cm}^{2}$

Beta/gamma: $\mathrm{dpm} / 100 \mathrm{~cm}^{2}$ location:

1.3 .5 .1 Attach Radiation and Contamination Forms 1 and 2 to the Report:

1.4 (1.6) Visualiy inspect cask and trailer to check for damage or other irregularities. Record any deficiencies in the Remarks section.

1.4.1 Verify cask tie-down is acceptable

1.4.2 Record the type: and number: of the regulatory labels on the cask.

1.4.3 Inspect the cask for any abnormal presence of water, bubbling or high levels of contamination: 
1.4.4 (1.6) Verify that all Impact Limiters and Shock Absorbing covers are properly installed

1.4.5 Cask and trailer appear to be in good condition:

1.5 (1.6.3) Record the two Security Seal Numbers and verify that they have not been tampered with. Verify that the numbers agree with the shipping papers.

1.5.1 Front:

1.5 .2 Rear:

$1.6 \quad(1.6 .4)$ Verify regulatory labels are installed and are correct

2.0 CASK PREPARATION

2.1 (2.1.1.5) Inspect the protective skirt and skirt assembly. Record any abnormalities or irregularities of operation in the Remarks section.

2.2 (2.3) Measure radiation level at the surface of opening "B" recess (beta/gamma at contact):

$\mathrm{mR} / \mathrm{hr}$

2.3 (2.3) Identification code of blind flange " $B$ " 
2.4 (2.5) Measure and record Cask Cavity Pressure: mbar

2.5 (2.6) Measure radiation level at the surface of drain opening " $\mathrm{C}$ " recess (beta/gamma at contact): $\mathrm{mR} / \mathrm{hr}$

2.6 (2.6) Identification code of blind flange " $C$ "

2.7 (2.8) Verify inspection of gaskets of:

2.7 .1 Blind flange " $B$ "

2.7 .2 Blind flange " $\mathrm{C}$ "

2.7 .3 Shield plug "A"

Note 1: Indicate in the Remarks section if there was any difficulty when removing any of the blind flanges.

2.8 (2.8.1.5) Record any gasket replacement in the Remarks section.

3.0 FUEL LOADING

3.1 (3.10.2) Indicate any difficulties in lid removal in the Remarks section.

3.2 (3.12.8) Verify that al1 fuel compartment spacers and removable lid plate are present in the cask. N/A if not applicable 
$3.3(3.12 .13)$ Record fuel data as 1 isted on the Fuel Information sheet.

3.4 (3.12.14) Record time at completion of loading:

3.5 (3.22) Record the total in-pool time of the cask:

3.6 (4.4.3) Record the final torque values for the cask. Lid $f t-1 b$

3.7 (4.8) Record the final torque values for the "D" plug $f t-1 b$

4.0 PREPARATION OF CASK FOR TRANSPORT

4.1 (4.6.2) Record the temperatures measured by the three thermocouples inserted into the thermocouple wells "Ft", "F2" and "F3", and the ambient air cemperature following the completion of cask draining:

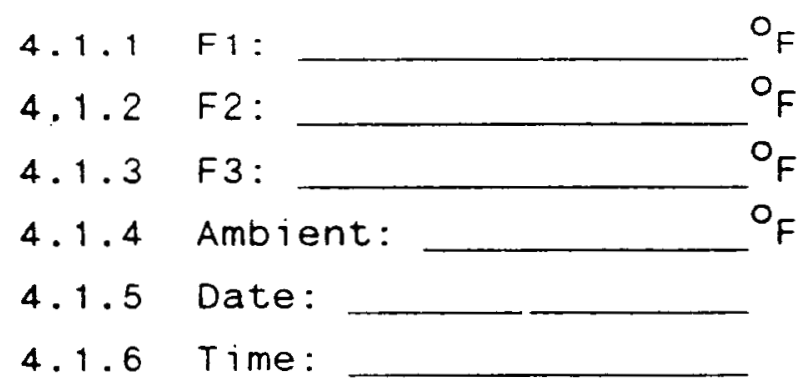

4.2 (4.6.3) Record time at completion of cavity draining: 
4.3 (4.9) Record the total pressure rise ( $\Delta P$ ) determined during the Cask Dryness Testing. (Must be less than 3 mbar in 10 minutes.)

4.3.1 $\triangle P=$ mbar

4.4 (4.12.3) Record the internal cavity gas activity measured: $\mathrm{uCi} / \mathrm{ml}$

4.5 (4.13) Record the final internal cavity pressure prior to transport: mbar

4.6 (4.19) Record the sum of the pressure rises for each opening tested ("A", "B", "C" and "D")

4.6.1 $\triangle P=$ mbar

4.7 Record the final torque values for:

Blind Flanges: $(4.10)$ " $A$ " $f t-1 b$

$$
\begin{aligned}
& (4.14) \text { "B" } \\
& (4.18) \text { "C" }
\end{aligned}
$$
$f t-1 b$ $f t-1 b$

4.8 (5.6) Upon completion of cask operations, record final temperatures as measured by thermocouples installed in "F1", "F2", "F3" and the ambient air temperature:

$\begin{array}{ll}4.8 .1 & \mathrm{~F} 1: \\ 4.8 .2 & \mathrm{~F} 2:= \\ 4.8 .3 & \mathrm{F3}: \\ 4.8 .4 & \text { Ambient: } \\ 4.8 .5 & \text { Date: } \\ 4.8 .6 & { }^{\circ} \mathrm{O} F \\ \end{array}$


4.9 (4.14) Determine total time between temperature measurements performed following draining (from 4.2 above ): hours.

4.10 (4.14) Determine temperature difference of $F 2-t_{a m b}$ of final temperature measurements: ${ }^{\circ} F$ and verify that the difference is below the curve of figure 28:

4.11 Record the final torque values for the cask.
4.11 .1
Blind Flanges:
(5.2.1) "J1" $f t-1 b$
$(5.2 .1)$ "J2" $f t-1 b$

4.11.2 Plugs:

$$
\begin{aligned}
& (5.7) " F 1 " \\
& (5.7) \text { "F2" } \\
& (5.7) \text { "F3" }
\end{aligned}
$$
$f t-i b$$$
f t-1 b
$$
$f t-1 b$

4.12 (5.17) List all cask parts replaced by spares in the Remarks section.

\subsection{CASK DEPARTURE}

5.1 (6.1) Record the dose rates measured as detailed below:

5.1.1 Maximum dose rate at cask surface:

$$
\text { 5.1.1.1 beta/gamma: }
$$
$\mathrm{mR} / \mathrm{hr}$ location:

5.1.1.2 neutron: $m R / h r$ location: 
5.1.2 Maximum dose rate at 3 feet from cask surface:

5.1.2.1 beta/gamma: $\mathrm{mR} / \mathrm{hr}$ location:

5.1.2.2 neutron: $\mathrm{mR} / \mathrm{hr}$ location:

5.1.3 Maximum dose rate at vehicie outer surface:

5.1.3.1 beta/gamma: $\mathrm{mR} / \mathrm{hr}$ location:

5.1 .3 .2 neutron: $\mathrm{mR} / \mathrm{hr}$ location:

5.1.4 Maximum dose rate at 6 feet from venicle:

5.1.4.1 beta/gamma: $m R / h r$ location:

5.1 .4 .2 neutron: $\mathrm{mR} / \mathrm{hr}$ location:

5.1.5 Maximum dose rate in any normally occupied position of the trailer/cab: $\mathrm{mR} / \mathrm{hr}$

5.1.5.1 Verify that Radiation and Containment Forms 3 and 4 are attached to the report 
5.2 (6.1) Record the maximum removable surface contamination measured on the cask:

Beta/gamma: $\mathrm{dpm} / 100 \mathrm{~cm}^{2}$

location:

5.3 (6.2) Record the maximum cask surface temperature measured with the hand held pyrometer:

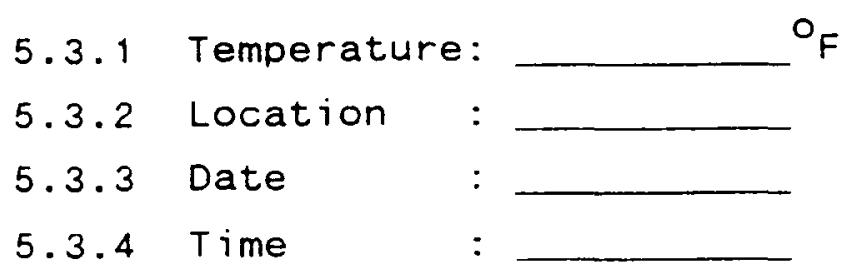

5.4 (6.3) Record the numbers of the security seals after their installation on the shock absorbing covers:

5.4.1 Front:

5.4 .2 Rear :

5.5 (6.4) Verify all necessary regulatory labels required for transport are properly installed (refer to section 6.4 and $6.7)$ :

5.6 (6.5) Visually inspect the cask on the trailer for irregularities in the fins and resin section. Record any findings in the Remarks section:

5.7 (6.5) Inspect the cask surfaces for dents, rust and general condition. Record any findings in the Remarks section: 
5.10 (6.7) Verify that the Regulatory placards are present and are readable. Record any findings in the Remarks section:

5.8 (6.5) Visually inspect the cask on the trailer and verify that all impact limiters are installed correctly (i.e., gussets on horizontal and top redundant trunnions only, proper torquing of bolts). Record any findings in the Remarks section:

5.9 (6.5) Visually inspect all cask surfaces for bubbles or water or high contamination levels: 
6.0 REMARKS

Inspector:

Data Recorder:

Date of Departure:

Time of Departure:

Responsible supervisor: 
FORM 6

CASK LOADING LEAKAGE RATE TESTING DATA SHEET

1.0 Lid Gaskets Leakage Rate Testing

1. 1 Initial pressure: mbar

Time:

1.2 Final pressure: mbar

Time:

1.3 Test $\Delta P_{\text {id }}$ : mbar

Test $t$ : seconds

1.4 Verify $\Delta P_{1 j d}$ over twelve minutes is less than 5 mbar and test is acceptable:

2.0 Cavity Drying and Dryness Verification

2.1 Vacuum Drying Operations

2.1.1 Time: at start of vacuum drying operations.

2.1.2 Minimum cold wall temperature ( $t$ ) as measured by thermocouple "F1", "F2" or "F3":

Location:

Temperature: $o_{F}$

2.1.3 Water vapor pressure (P) in equilibrium with cold wall temperature, ( $t$ ): (See Figure 30) vapor pressure: mbar 
2.2 Cavity Dryness Verification

2.2.1 Cavity pressure at beginning of dryness verification:

Pressure: mbar

Time:

2.2.2 Cavity pressure at end of dryness verification:

Pressure: mbar

Time:

2.2.3 Verify cavity gas pressure rise is no greater than 3 mbar for a ten minute test period:

$\triangle P$ : mbar

i : seconds

Test is acceptable:

3.0 Cask Opening Tightness Testing

3.1 Shield Plug "A" Test

3.1.1 Initial pressure: mbar

Time:

3.1.2 Final pressure: mbar

Time:

3.1 .3 Test $\Delta P_{A}$ : mbar Test $t$ : seconds 
3.1.4 Calculated pressure rise (must be less than 2 mbar for a twelve minute test period)

$\Delta P$.A": mbar

Test is acceptable:

3.2 " $C$ " Hansen Coupling Plug Test

3.2.1 Initial pressure: mbar

Time:

3.2.2 Final pressure: mbar

Time:

3.2 .3 Test $\Delta P_{C}:$ mbar

Test

$t:$ seconds

3.2.4 Calculated pressure rise (must be less than 2 mbar for a thirteen minute test period):

$\Delta P . \mathrm{C}$. : mbar

Test is acceptable:

3.3 Blind Flange " $B$ " Test

3.3.1 Initial pressure: mbar

Time:

3.3.2 Final pressure: mbar

Time: 
3.3 .3 Test $\Delta \mathrm{P}_{\mathrm{B}}$

Test $t$ :

3.3.4 Pressure rise (must be less than 2 mbar per a twe lve minute test period):

$\Delta P_{\text {"B. : }}$ mbar

Test is acceptable:

4.0 Total Actual Leakage Rate

4.1 $\Delta P_{\text {Total }}=P_{1 i d}+P_{A}+P_{B}+P_{C}$

$\Delta \mathrm{P}_{\text {Total }}$

4.2 Test is acceptable if:

$\Delta P_{\text {Total }}<11$ mbar

Test is acceptable 


\title{
OPERATIONAL TIMES AND PERSONNEL EXPOSURE ESTIMATES
}

\author{
BWR LOADING
}

ACTIVITY

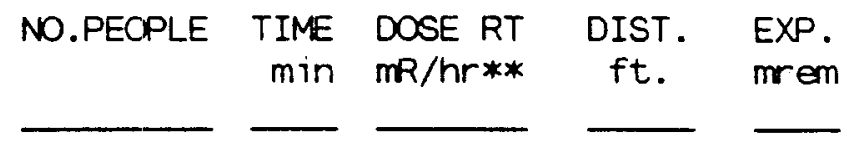

Cask Receiving

SECURITY INSPECTION

INOOMING HP SURVEY

WAIT FOR HP RESULTS

$\begin{array}{lllll}2 & 45 & 0.11 & 8 & 0.17 \\ 1 & 30 & 0.31 & 3 & 0.15 \\ 0 & 30 & 0.00 & 0 & 0.00\end{array}$

Cask to Work Area

MOVE CASK TO TRAILER BAY

ROLL BACK TARPAULIN

HP SURVEY

WAIT FOR HP SURVEY RESULTS

REMOVE SHOOK ABSORBERS

SURVEY CASK ENDS

REMOVE IMPACT LIMITERS

REMOVE TRAILER TIE-DOWNS

ATTACH LIFT BEAM TO CRANE HOOK

ENGAGE LIFT BEAM TO CASK

REMOVE CASK FROM TRAILER

ATTACH REDUNDANT LIFT BEAM

TRANSFER CASK TO WORK STATION

\begin{tabular}{|c|c|c|c|c|}
\hline 2 & 10 & 0.11 & 8 & 0.04 \\
\hline 2 & 10 & 0.23 & 4 & 0.08 \\
\hline 1 & 30 & 0.31 & 3 & 0.15 \\
\hline 0 & 30 & 0.00 & 0 & 0.00 \\
\hline 2 & 25 & 0.23 & 4 & 0.19 \\
\hline 1 & 15 & 0.46 & 2 & 0.11 \\
\hline 1 & 10 & 0.46 & 2 & 0.08 \\
\hline 1 & 5 & 0.23 & 4 & 0.02 \\
\hline 2 & 10 & 0.09 & 10 & 0.03 \\
\hline 2 & 15 & 0.09 & 10 & 0.05 \\
\hline 2 & 5 & 0.09 & 10 & 0.02 \\
\hline 2 & 10 & 0.09 & 10 & 0.03 \\
\hline 1 & 20 & 0.04 & 25 & 0.01 \\
\hline
\end{tabular}

Cask Preparation for Loading

INSTALL SKIRT

MEASURE INTERNAL PRESSURE \& VENT (HP)

FILL CASK WITH WATER

REMOVE LID BOLTS

ATTACH LID LIFTING SLINGS

ENGAGE LIFT BEAM

$\begin{array}{rrrrrr} & 3 & 35 & 0.46 & 2 & 0.80 \\ * \quad 2 & 20 & 0.46 & 2 & 0.31 \\ * \quad 1 & 30 & 0.09 & 10 & 0.05 \\ & 2 & 10 & 0.46 & 2 & 0.15 \\ & 1 & 10 & 22.00 & 0 & 3.67 \\ & 2 & 3 & 0.09 & 10 & 0.01\end{array}$

Fuel Loading

SUBMERGE CASK/FILL SKIRT

PLACE CASK ON POOL BOTTOM

DISENGAGE LIFT BEAM

REMOVE LID/LIFT BEAM/ CRANE FROM AREA

INSTALL TOP PROTECTIVE COVER

INSTALL 7 BWR ASSEMBLIES

REMOVE TOP PROTECTIVE COVER

INSTALL LIO

ENGAGE LIFT BEAM

REMOVE CASK FROM POOL/DRAIN SKIRT

$\begin{array}{rr}2 & 20 \\ 2 & 10 \\ 2 & 3 \\ 2 & 10 \\ 2 & 10 \\ 2 & 90 \\ 2 & 5 \\ 2 & 10 \\ 2 & 5 \\ 2 & 30\end{array}$

0.08

12

0.05

0.00

40

0.00

0.00

0.00

0.00

0.00

0.00

0.00

0.00

30

0.00

40

40

40

0.00

0.00

40

0.00

40

0.17

12

0.17 
Cask Preparation for Shipping

MOVE CASK TO DECON STALL

RELEASE LID LIFTING SLINGS

DISENGAGE LIFT BEAM

INSTALL \& TORQUE LID BOLTS

LID TIGHTNESS TEST (D)

DRAIN CASK

CASK DRYING

LEAK TEST A B C

BACKFILL CASK

DECONTAMINATE CASK

HP SURVEY

WAIT FOR HP SURVEY RESULTS

REMOVE SKIRT

$\begin{array}{rrrrr}2 & 5 & 0.10 & 20 & 0.02 \\ 1 & 10 & 48.00 & 0 & 8.00 \\ 2 & 3 & 0.20 & 10 & 0.02 \\ 2 & 20 & 1.00 & 2 & 0.67 \\ 1 & 45 & 0.33 & 6 & 0.25 \\ 1 & 25 & 0.20 & 10 & 0.08 \\ 2 & 60 & 0.33 & 6 & 0.67 \\ 1 & 45 & 0.33 & 6 & 0.25 \\ 2 & 15 & 0.20 & 10 & 0.10 \\ 2 & 45 & 1.00 & 2 & 1.50 \\ 1 & 30 & 0.67 & 3 & 0.33 \\ 0 & 30 & 0.00 & 0 & 0.00 \\ 3 & 20 & 1.00 & 2 & 1.00\end{array}$

Return Cask to Trailer

ENGAGE LIFT BEAM

MOVE CASK TO TRAILER BAY

REMOVE REDUNDANT LIFT BEAM

POSITION CASK ON TRAILER

DISENGAGE LIFT BEAM

INSTALL TRAILER TIE-DOWNS

INSTALL IMPACT LIMITERS

INSTALL SHOCK ABSORBERS

$\begin{array}{rrrrrr} & 2 & 3 & 0.20 & 10 & 0.02 \\ & 1 & 25 & 0.10 & 20 & 0.04 \\ & 2 & 10 & 0.20 & 10 & 0.07 \\ & 2 & 5 & 0.20 & 10 & 0.03 \\ & 2 & 3 & 0.20 & 10 & 0.02 \\ * & 1 & 5 & 0.50 & 4 & 0.04 \\ * & 1 & 10 & 2.00 & 1 & 0.33 \\ & 2 & 35 & 0.50 & 4 & 0.58\end{array}$

\section{Cask Release}

CASK \& TRAILER SURVEY

WAIT FOR SURVEY RESULTS

ATTACH REGULATORY LABELS

CLOSE TARPAULIN

PLACARDS

$\begin{array}{rrrrr}1 & 45 & 0.67 & 3 & 0.50 \\ 0 & 30 & 0.00 & 0 & 0.00 \\ 1 & 5 & 0.50 & 4 & 0.04 \\ 2 & 20 & 0.50 & 4 & 0.33 \\ 2 & 10 & 0.20 & 10 & 0.07\end{array}$

TOTAL EXPOSURE $=21.30 \mathrm{mrem}$

TOTAL. MANHOURS a 29.0

TOTAL ELAPSED TIME $=17.8 \mathrm{hrs}$.

* activity PERFormed SiMUL TANEOUSLY WITH aNOTHER STEP.

NOT INCLUDEO IN TOTAL ELAPSED TIME

** DOSE RATE IS DUE to CASK oONTRIBUTION ONLY 
OPERATIONAL TIMES AND PERSONNEL EXPOSURE ESTIMATES

PWR LOADING

ACTIVITY

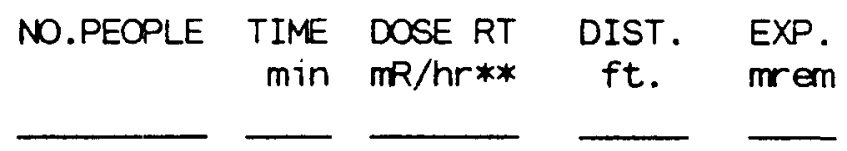

Cask Receiving

SECURITY INSPECTION

INOOMING HP SURVEY

WAIT FOR HP SURVEY RESULTS

$\begin{array}{lllll}2 & 45 & 0.11 & 8 & 0.17 \\ 1 & 30 & 0.31 & 3 & 0.15 \\ 0 & 30 & 0.00 & 0 & 0.00\end{array}$

Cask to Work Area

MOVE CASK TO TRAILER BAY

ROLL BACK TARPAULIN

HP SURVEY

WAIT FOR HP SURVEY RESULTS

REMOVE SHOCK ABSORBERS

SURVEY CASK ENDS

REMOVE IMPACT LIMITERS

REMOVE TRAILER TIE-DOWNS

ATTACH LIFT BEAM TO CRANE HOOK

ENGAGE LIFT BEAM TO CASK

REMOVE CASK FROM TRAILER

TRANSFER CASK TO WORK STATION

\begin{tabular}{|c|c|c|c|c|c|}
\hline & 2 & 10 & 0.11 & 8 & 0.04 \\
\hline & 2 & 10 & 0.23 & 4 & 0.08 \\
\hline & 1 & 30 & 0.31 & 3 & 0.15 \\
\hline & 0 & 30 & 0.00 & 0 & 0.00 \\
\hline & 2 & 20 & 0.23 & 4 & 0.15 \\
\hline & 1 & 15 & 0.46 & 2 & 0.11 \\
\hline * & 1 & 10 & 0.46 & 2 & 0.08 \\
\hline * & 1 & 5 & 0.23 & 4 & 0.02 \\
\hline * & 2 & 10 & 0.09 & 10 & 0.03 \\
\hline & 2 & 15 & 0.09 & 10 & 0.05 \\
\hline & 2 & 5 & 0.09 & 10 & 0.02 \\
\hline & 1 & 15 & 0.04 & 25 & 0.01 \\
\hline
\end{tabular}

Cask Preparation for Loading

$\begin{array}{lrrrrrr}\text { INSTALL SKIRT } & & 3 & 35 & 0.46 & 2 & 0.80 \\ \text { MEASURE INTERNAL PRESSURE \& VENT (HP) } & * & 2 & 20 & 0.46 & 2 & 0.31 \\ \text { FILL CASK WITH WATER } & * & 1 & 30 & 0.09 & 10 & 0.05 \\ \text { REMOVE LID BOLTS } & & 2 & 10 & 0.46 & 2 & 0.15 \\ \text { ATTACH LID LIFTING SLINGS } & & 1 & 10 & 22.00 & 0 & 3.67 \\ \text { ENGAGE LIFT BEAM } & & 2 & 3 & 0.09 & 10 & 0.01\end{array}$

Fuel Loading

SUBMERGE CASK/FILL SKIRT

PLACE CASK ON POOL BOTTOM

DISENGAGE LIFT BEAM

REMOVE LID/LIFT BEAM/CRANE FROM AREA

INSTALL TOP PROTECTIVE OOVER

LOAD 3 PWR ASSEMBLIES

REMOVE TOP PROTECTIVE OOVER

INSTALL LID

ENGAGE LIFT BEAM

REMOVE CASK FROM POOL/DRAIN SKIRT

$\begin{array}{rrrrr}2 & 20 & 0.08 & 12 & 0.05 \\ 2 & 10 & 0.00 & 40 & 0.00 \\ 2 & 3 & 0.00 & 40 & 0.00 \\ 2 & 10 & 0.00 & 40 & 0.00 \\ 2 & 10 & 0.00 & 40 & 0.00 \\ 2 & 45 & 0.00 & 40 & 0.00 \\ 2 & 5 & 0.00 & 40 & 0.00 \\ 2 & 10 & 0.00 & 40 & 0.00 \\ 2 & 5 & 0.00 & 40 & 0.00 \\ 2 & 30 & 0.17 & 12 & 0.17\end{array}$


Cask Preparation for Shipping

MOVE CASK TO WORK STATION

RELEASE LID LIFTING SLINGS

DISENGAGE LIFT BEAM

INSTALL \& TORQUE LID BOLTS

LID TIGHTNESS TEST (D)

DRAIN CASK

CASK DRYING

LEAK TEST A B C

BACKFILL CASK

DECONTAMINATE CASK

HP SURVEY

WAIT FOR HP SURVEY RESULTS

REMOVE SKIRT

$\begin{array}{rrrrr}2 & 5 & 0.10 & 20 & 0.02 \\ 1 & 10 & 48.00 & 0 & 8.00 \\ 2 & 3 & 0.20 & 10 & 0.02 \\ 2 & 20 & 1.00 & 2 & 0.67 \\ 1 & 45 & 0.33 & 6 & 0.25 \\ 1 & 25 & 0.20 & 10 & 0.08 \\ 2 & 60 & 0.33 & 6 & 0.67 \\ 1 & 45 & 0.33 & 6 & 0.25 \\ 2 & 15 & 0.20 & 10 & 0.10 \\ 2 & 45 & 1.00 & 2 & 1.50 \\ 1 & 30 & 0.67 & 3 & 0.33 \\ 0 & 30 & 0.00 & 0 & 0.00 \\ 3 & 20 & 1.00 & 2 & 1.00\end{array}$

Return Cask to Trailer

ENGAGE LIFT BEAM

MOVE CASK TO TRAILER BAY

POSITION CASK ON TRAILER

DISENGAGE LIFT BEAM

INSTALL TRAILER TIE-DOWNS

INSTALL IMPACT LIMITERS

INSTALL SHOCK ABSORBERS

Cask Release

CASK \& TRAILER SURVEY

WAIT FOR SURVEY RESULTS

ATTACH REGULATORY LABELS

CLOSE TARPAULIN

PLACARDS

$\begin{array}{rrrrr}1 & 45 & 0.67 & 3 & 0.50 \\ 0 & 30 & 0.00 & 0 & 0.00 \\ 1 & 5 & 0.50 & 4 & 0.04 \\ 2 & 20 & 0.50 & 4 & 0.33 \\ 2 & 10 & 0.20 & 10 & 0.07\end{array}$

TOTAL EXPOSURE a $21.16 \mathrm{mrem}$

TOTAL MANHOURS $=26.6$

TOTAL ELAPSED TIME $=16.6 \mathrm{hrs}$.

* activity PERFormed simul tANEOUSLy with aNOTHER STEP. NOT INCLUDED IN TOTAL ELAPSED TIME

** DOSE RATE IS DUE tO CASK OONTRIBUTION ONLY 
RESTRICTED AREA ENTRANCE VEHICLE BAY I CASK WORK

IN-POOL

CASK WORK STATION

1
1

VEHICLE BAY
RESTRICTED AREA EXIT

ANCILLARY EQUIPMENT

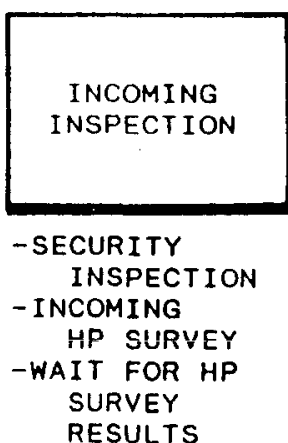

$-$$$
\text { - MOVE CASK TO }
$$
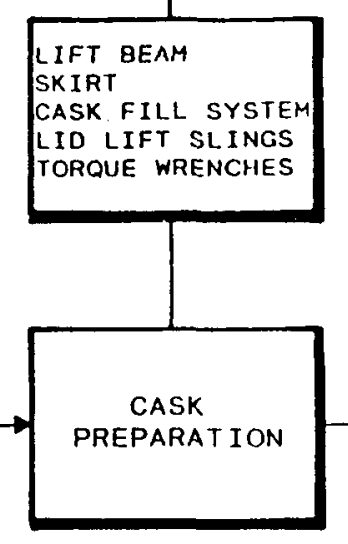

-INSTALL SKIRT -MEASURE

INTERNAL PRESSURE \& VENT (HP)

-FILL CASK WITH WATER

-REMOVE LID BOLTS

-ATTACH LID LIFT ING SLINGS

-ENGAGE LIFT BEAM
BEAM EXTENSION TOP PROT. COVER BOT. PROT.

SKIRT FILL SYS.

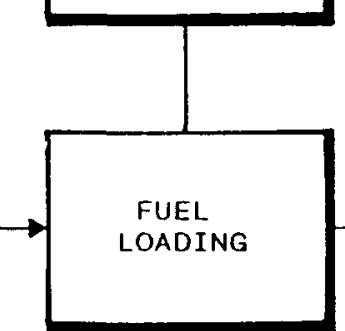

-SUBMERGE CASK/FILL SKIRT

-PLACE CASK ON POOL BOTTOM

-DISENGAGE LIFT BEAM

-REMOVE LIDLIFT BEAM CRANE FROM AREA - INSTALL TOP PROTECTIVE COVER

- LOAD 3 PWR ASSEMBLIES -REMOVE TOP PROTECTIVE COVER

- INSTALL LID -ENGAGE LIFT BEAM

-REMOVE CASK FROM POOL DRAIN SKIRT
LIFT BEAM VACUUM SYSTEM VAC. TEST EQUIP. CASK DRAIN

TORQUE WRENCHES

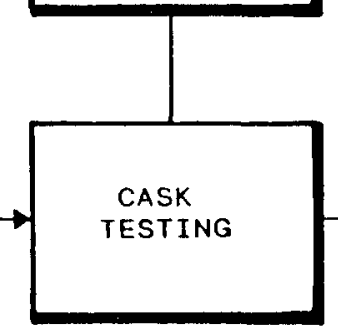

-MOVE CASK TO WORK STATION -RELEASE LID LIFTING SLINGS

-DISENGAGE LIFT BEAM

-INSTALL \&

TORQUE

LID BOLTS

-LID TIGHTNESS

TEST (D)

-DRAIN CASK

- CASK DRYING

- LEAK TEST ABC

-BACKFILL CASK

- DECONTAMINATE CASK

-HP SURVEY

-WAIT FOR HP

SURVEY

RESULTS

-REMOVE SKIRT
LIFT BEAM

TORQUE WRENCHES

SLINGS

CHAINFALL.

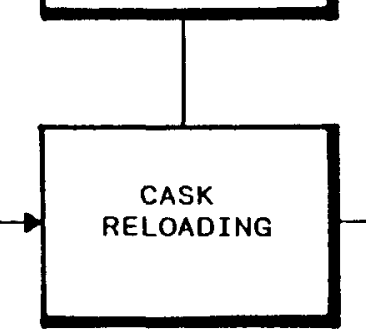

-ENGAGE LIFT BEAM

- MOVE CASK TO

TRAILER BAY

-POSITION CASK

ON TRAILER

-DISENGAGE

LIFT BEAM

- INSTALL TRAILER

TIE-DOWNS

-INSTALL IMPACT

LIMITERS

- INSTALL SHOCK

ABSORBERS
OUT-GOING

INSPECTION

-CASK \&RAILER

SURVEY

-ATTACH

REGULATORY

LABELS

- CLLSE TARPAULIN

-PLACARDS

STATION

T




\section{OPERATIONAL TIMES AND PERSONNEL EXPOSURE ESTIMATES}

PWR DRY UNLOADING

ACTIVITY

\begin{tabular}{lrlcl} 
NO.PEOPLE & $\begin{array}{r}\text { TIME } \\
\mathrm{min}\end{array}$ & $\begin{array}{c}\text { DOSE RT } \\
\mathrm{mR} / \mathrm{hr} * *\end{array}$ & $\begin{array}{c}\text { DIST. } \\
\mathrm{ft} .\end{array}$ & $\begin{array}{c}\text { EXP. } \\
\mathrm{mrem}\end{array}$ \\
\hline
\end{tabular}

Cask Receiving

SECURITY INSPECTION

INCOMING HP SURVEY

WAIT FOR HP SURVEY RESULTS

$\begin{array}{lllll}2 & 45 & 0.25 & 8 & 0.38 \\ 1 & 30 & 0.67 & 3 & 0.33 \\ 0 & 30 & 0.00 & 0 & 0.00\end{array}$

Cask to Work Area

MOVE CASK TO TRAILER BAY

ROLL BACK TARPAULIN

HP SURVEY

WAIT FOR HP SURVEY RESULTS

REMOVE SHOCK ABSORBERS

SURVEY CASK ENDS

REMOVE IMPACT LIMITERS

REMOVE TRAILER TIE-DOWNS

ATTACH LIFT BEAM TO CRANE HOOK

ENGAGE LIFT BEAM TO CASK

REMOVE CASK FROM TRAILER

TRANSFER CASK TO WORK STATION

DISENGAGE LIFT BEAM

\begin{tabular}{|c|c|c|c|c|}
\hline 2 & 10 & 0.25 & 8 & 0.08 \\
\hline 2 & 10 & 0.50 & 4 & 0.17 \\
\hline 1 & 30 & 0.67 & 3 & 0.33 \\
\hline 0 & 30 & 0.00 & 0 & 0.00 \\
\hline 2 & 25 & 0.50 & 4 & 0.42 \\
\hline 1 & 15 & 1.00 & 2 & 0.25 \\
\hline 1 & 10 & 1.00 & 2 & 0.17 \\
\hline 1 & 5 & 0.50 & 4 & 0.04 \\
\hline 2 & 10 & 0.20 & 10 & 0.07 \\
\hline 2 & 15 & 0.20 & 10 & 0.10 \\
\hline 2 & 5 & 0.20 & 10 & 0.03 \\
\hline 1 & 20 & 0.08 & 25 & 0.03 \\
\hline 2 & 3 & 0.20 & 10 & 0.02 \\
\hline
\end{tabular}

Cask Preparation for Unloading

MEASURE INTERNAL PRESSURE \& VENT (HP) *

REMOVE LID BOLTS

ATTACH LID LIFTING BRACKET

$\begin{array}{rrrr}15 & 1.00 & 2 & 0.50 \\ 20 & 0.46 & 2 & 0.31 \\ 10 & 0.46 & 2 & 0.15 \\ 10 & 48.00 & 0 & 8.00\end{array}$

Fuel Unloading

REMOVE LID

INSTALL TOP PROTECTIVE OOVER

UNLOAD 3 PWR ASSEMBLIES

REMOVE TOP PROTECTIVE COVER

INSTALL LID

$\begin{array}{rrrrr}1 & 10 & 0.00 & 100 & 0.00 \\ 1 & 10 & 0.00 & 100 & 0.00 \\ 1 & 45 & 0.00 & 100 & 0.00 \\ 1 & 5 & 0.00 & 100 & 0.00 \\ 1 & 10 & 0.00 & 100 & 0.00\end{array}$


Cask Preparation for Shipping

REMOVE LID LIFTING BRACKET

INSTALL \& TORQUE LID BOLTS

DECONTAMINATE CASK

HP SURVEY

WAIT FOR HP SURVEY RESULTS

REMOVE PLASTIC COVER

$\begin{array}{rrrrr}1 & 10 & 22.00 & 0 & 3.67 \\ 2 & 20 & 0.46 & 2 & 0.31 \\ 2 & 30 & 0.46 & 2 & 0.46 \\ 1 & 30 & 0.31 & 3 & 0.15 \\ 0 & 30 & 0.00 & 0 & 0.00 \\ 2 & 10 & 0.46 & 2 & 0.15\end{array}$

Return Cask to Trailer

ENGAGE LIFT BEAM

MOVE CASK TO TRAILER BAY

POSITION CASK ON TRAILER

DISENGAGE LIFT BEAM

INSTALL TRAILER TIE-DOWNS

INSTALL IMPACT LIMITERS

INSTALL SHOCK ABSORBERS

$\begin{array}{rrrrrr} & 2 & 3 & 0.09 & 10 & 0.01 \\ & 1 & 15 & 0.05 & 20 & 0.01 \\ & 2 & 5 & 0.09 & 10 & 0.02 \\ & 2 & 3 & 0.09 & 10 & 0.01 \\ * & 1 & 5 & 0.23 & 4 & 0.02 \\ * & 1 & 10 & 0.92 & 1 & 0.15 \\ & 2 & 20 & 0.23 & 4 & 0.15\end{array}$

Cask Release

CASK \& TRAILER SURVEY

WAIT FOR SURVEY RESULTS

ATTACH REGULATORY LABELS

CLOSE TARPAULIN

PLACARDS

$\begin{array}{rrrrr}1 & 30 & 0.31 & 3 & 0.15 \\ 0 & 30 & 0.00 & 0 & 0.00 \\ 1 & 5 & 0.23 & 4 & 0.02 \\ 2 & 20 & 0.23 & 4 & 0.15 \\ 2 & 10 & 0.09 & 10 & 0.03 \\ & & & & \\ & \text { TOTAL EXPOSURE }= & 16.84 & \mathrm{mrem} \\ & \text { TOTAL MANHOURS }= & 14.7 & \\ \text { TOTAL ELAPSED TIME }= & 10.9 \mathrm{hrs} .\end{array}$

* activity PERFormed SiMul taneOusly WITH aNOTHER STEP. NOT INCLUDED IN TOTAL ELAPSED TIME

** DOSE RATE IS DUE TO CASK OONTRIBUTION ONLY 
GENERIC DRY UNLOADING FACILITY

(w/ow1 $w$ coated Cask Maintemance Facil ity)

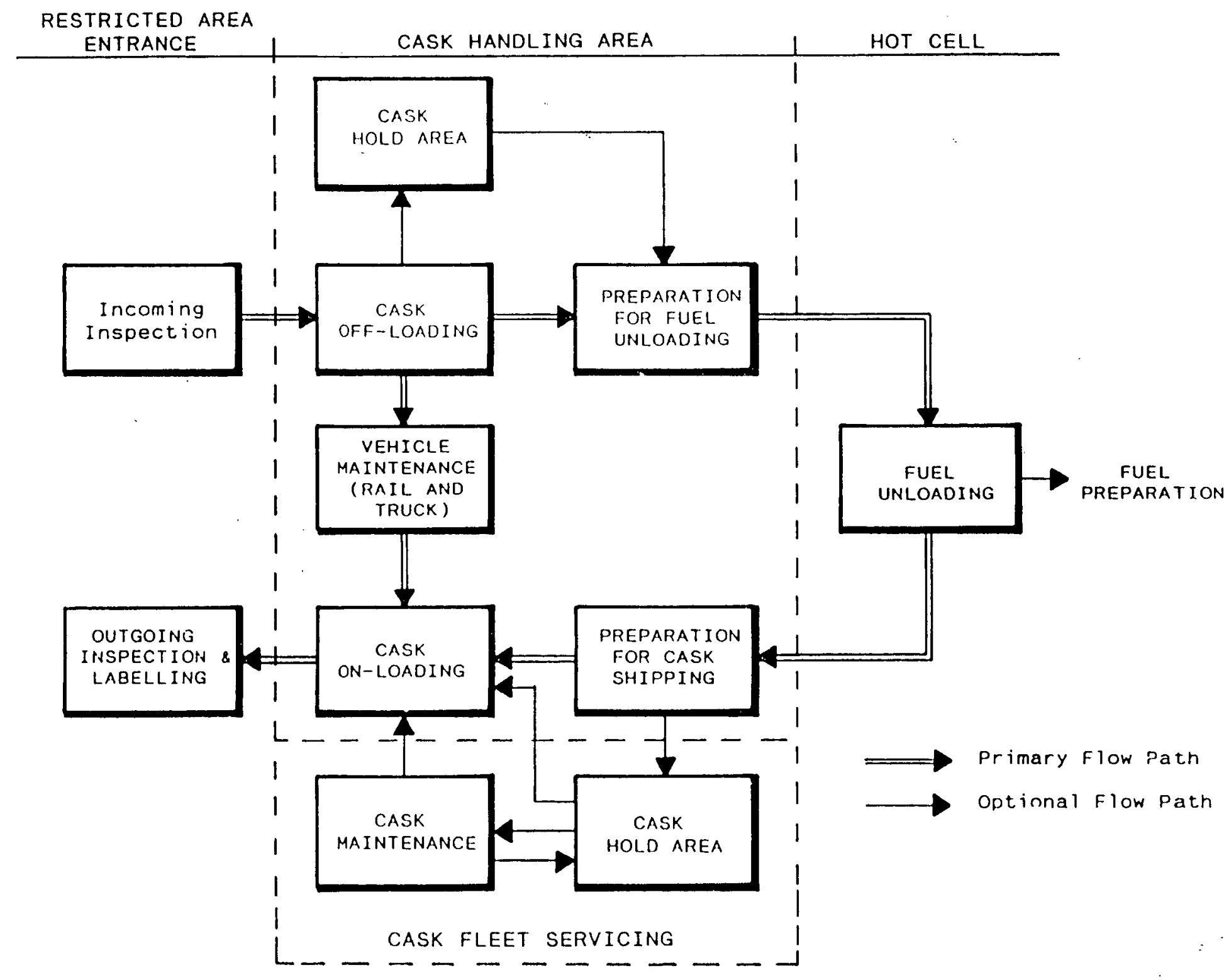


TRANSNUCLEAR SUPPLIED EQUIPMENT

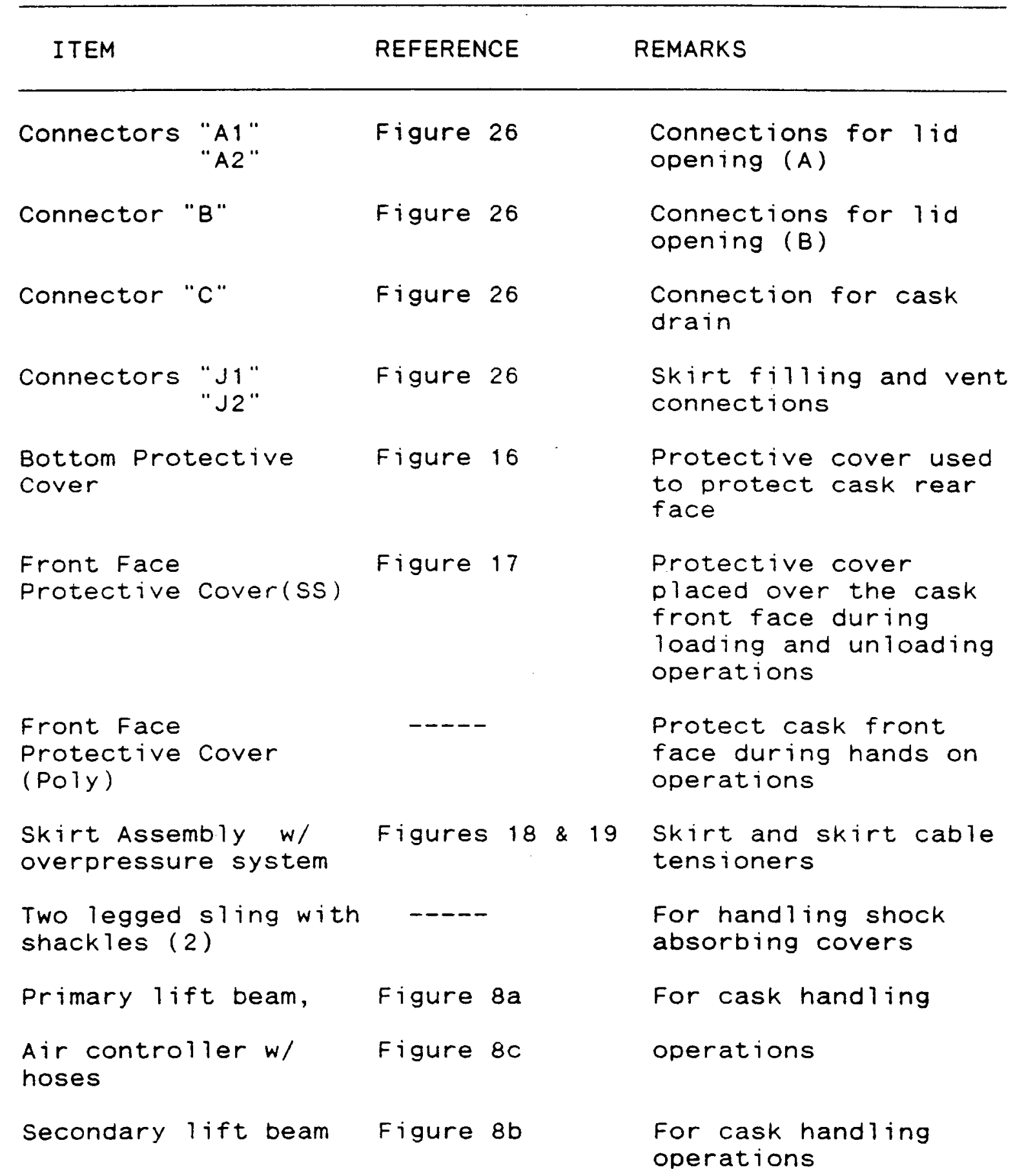




\begin{tabular}{|c|c|c|}
\hline ITEM & REFERENCE & REMARKS \\
\hline $\begin{array}{l}\text { Sleeve Adapter } \\
\text { ( if required) }\end{array}$ & ----- & $\begin{array}{l}\text { Prevent point loading } \\
\text { of } 4 \text { " lift pin }\end{array}$ \\
\hline $\begin{array}{l}\text { Four legged sling } \\
\text { w/ shackles (4) }\end{array}$ & Figure 15 & $\begin{array}{l}\text { For } 1 \text { id handling } \\
\text { operations }\end{array}$ \\
\hline Cooldown system & Figure 26 & $\begin{array}{l}\text { Filling, flushing and } \\
\text { draining }\end{array}$ \\
\hline Vacuum Drying System & Figure 22 & $\begin{array}{l}\text { For leakage testing, } \\
\text { gas sampling, and } \\
\text { drying }\end{array}$ \\
\hline Security seals & ----- & $\begin{array}{l}\text { Seals installed on } \\
\text { cask shock absorbing } \\
\text { covers for tamper } \\
\text { protection }\end{array}$ \\
\hline "A-B" Test Cover & Figure 20 & $\begin{array}{l}\text { For leak testing } \\
\text { ports "A" and "B" }\end{array}$ \\
\hline "C" Test Flange & Figure 20 & $\begin{array}{l}\text { For leak testing } \\
\text { "C" port }\end{array}$ \\
\hline "D" Test Connector & Figure 20 & For lid seal test \\
\hline Drain Bottie & Figure 26 & $\begin{array}{l}\text { For blowdown of } \\
\text { residual water }\end{array}$ \\
\hline $\begin{array}{l}\text { Temperature read- } \\
\text { out and thermocouples }\end{array}$ & ---- & $\begin{array}{l}\text { For measurement of } \\
\text { cask internal cavity } \\
\text { wall temperatures }\end{array}$ \\
\hline
\end{tabular}


TRANSNUCLEAR SUPPLIED SPARE PARTS

ITEM

QUANTITY

1. Blind Flange Bolts

2

2. Lid/Shock Absorber Bolts 2

3. Trunnion Impact Limiter Bolts 2

4. O-Ring, Inner Lid 1

5. O-Ring, Outer Lid 1

6. O-Ring, Blind Flange 2

7. O-Ring, "D"/ "TC" Ports 2

8. O-Ring, Skirt Tentioner 1

9. O-Ring, "A-B" Test Cover 1

10. Connector, Male, Bulkhead 1

11. Connector, Female, Bulkhead 1

12. Connector, Male, 1/4" FNPT 1

13. Connector, Female, $1 / 4 "$ FNPT 1

14. Rubber Straps 4 
$17 / 8$ " socket ratchet (s)

drive extension(s)

dynamometer, 0-1000 ib min.

$3 / 8$ " allen wrench

$13 / 8$ " socket

$13 / 16^{\prime \prime}$ socket

$3 / 4$ open end wrench

torque wrench(s)

$17 / 8$ " socket

$3 / 8$ " Hex set screw socket

$13 / 16$ " socket

$3 / 4$ " socket

$11 / 4$ socket

$11 / 4$ open end wrench

screw driver

tool box
Removal of shock absorbing

cover and lid bolts

Removal of blind flange and shield plug screws.

Removal of thermocouple and 1 id gasket port plugs.

Removal of trunnion impact limiter bolts.

For skirt installation and removal.

Used for setting specified torques for cask bolts, screws and plugs.

Trunnion guide and rear trunnion tie-down.

* Note: The intent of this listing is to show what tools are necessary for these steps. Accordingly, some tools listed may be the same tool (i.e. sockets, etc.), according to the site requirements. 
TNB SPENT FUEL CASK

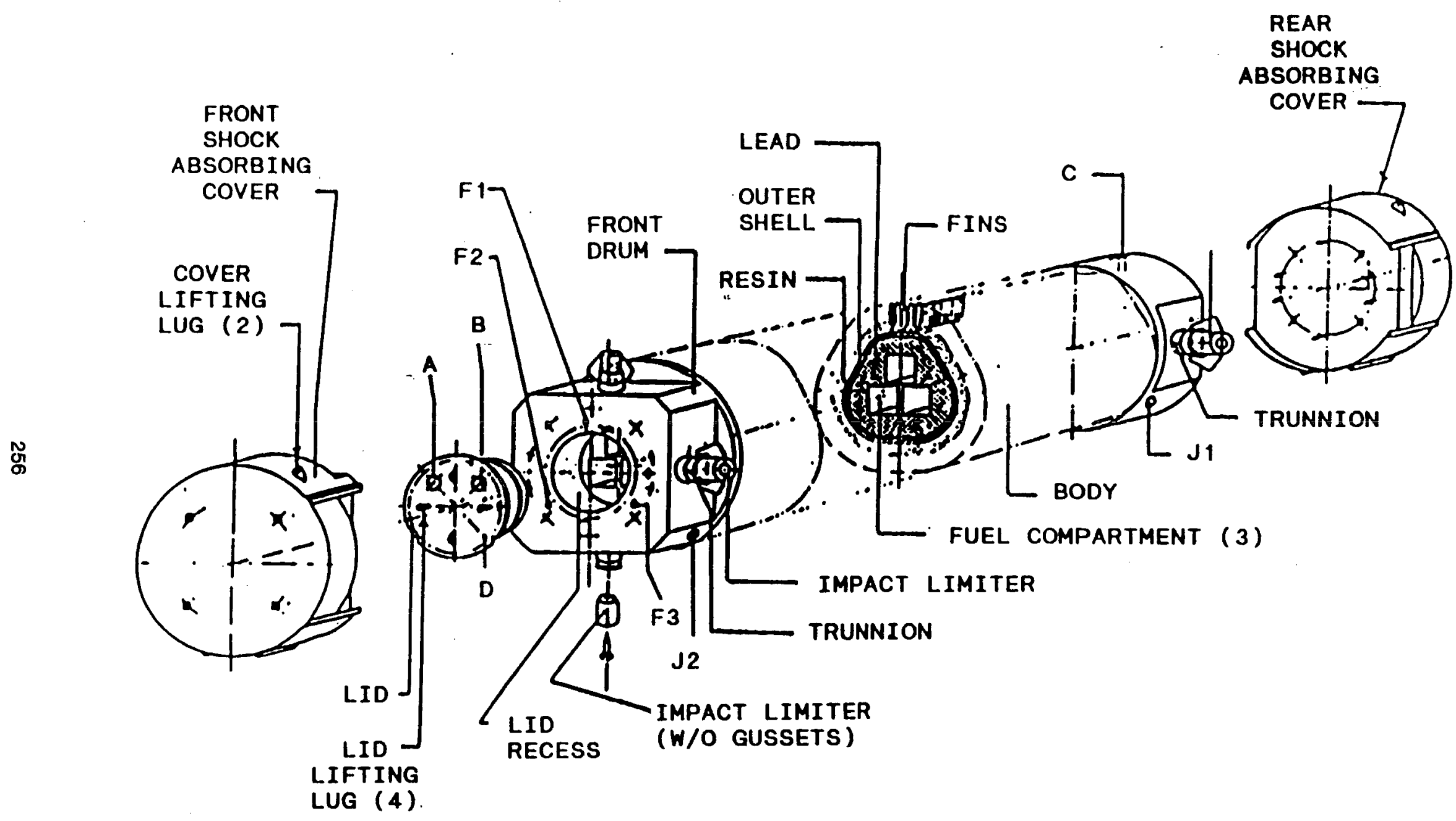


PRIMARY LIFT BEAM ASSEMBLY

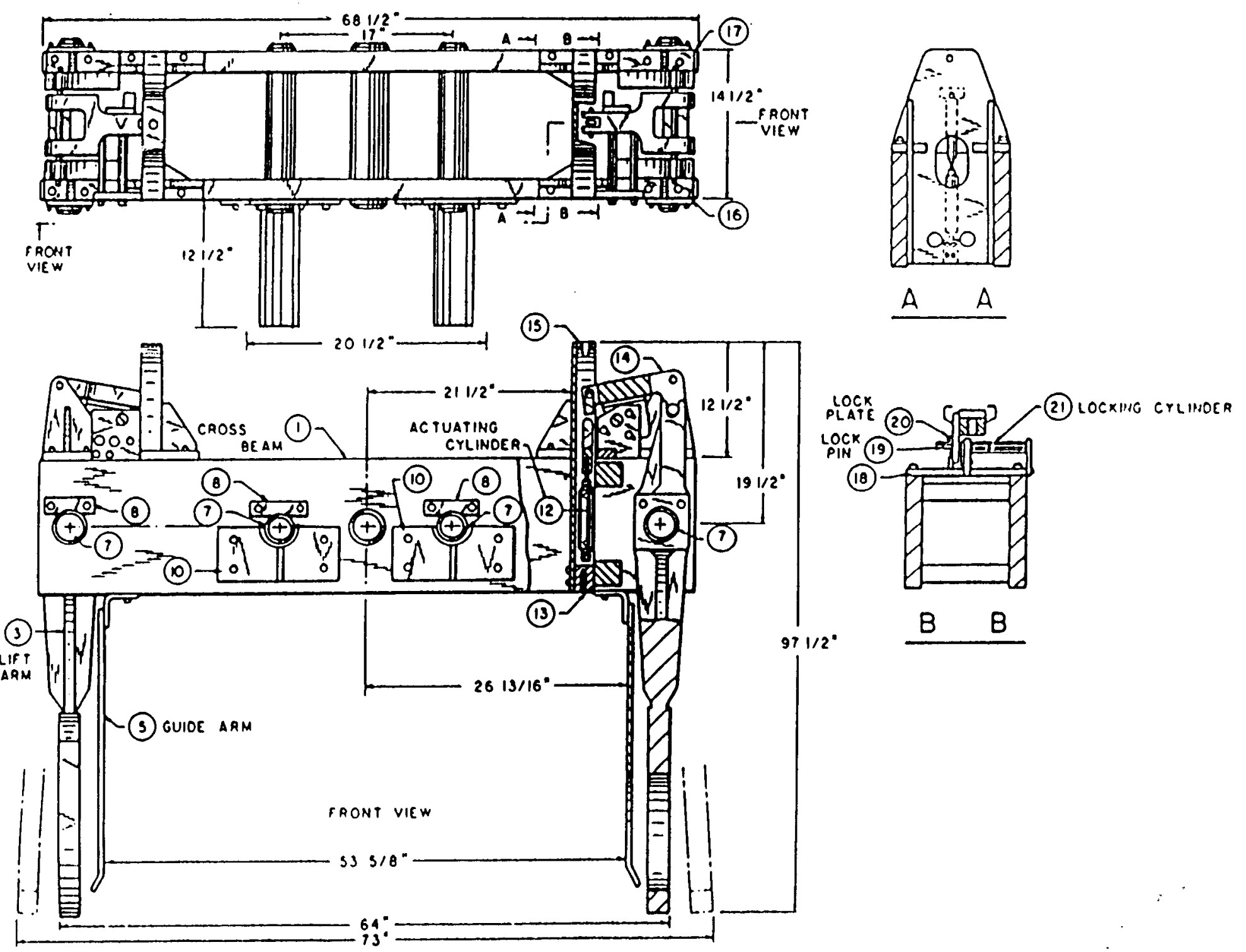




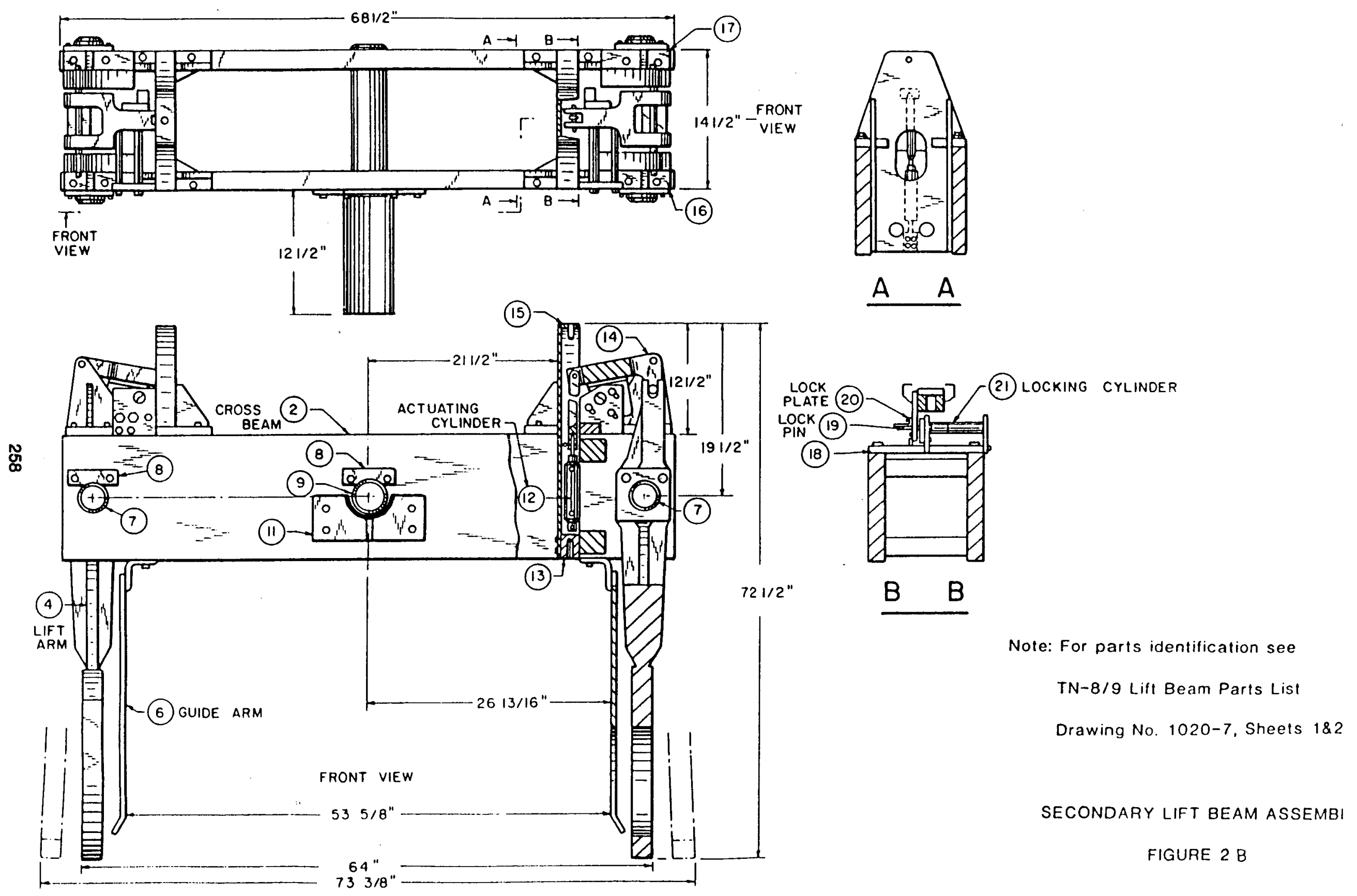




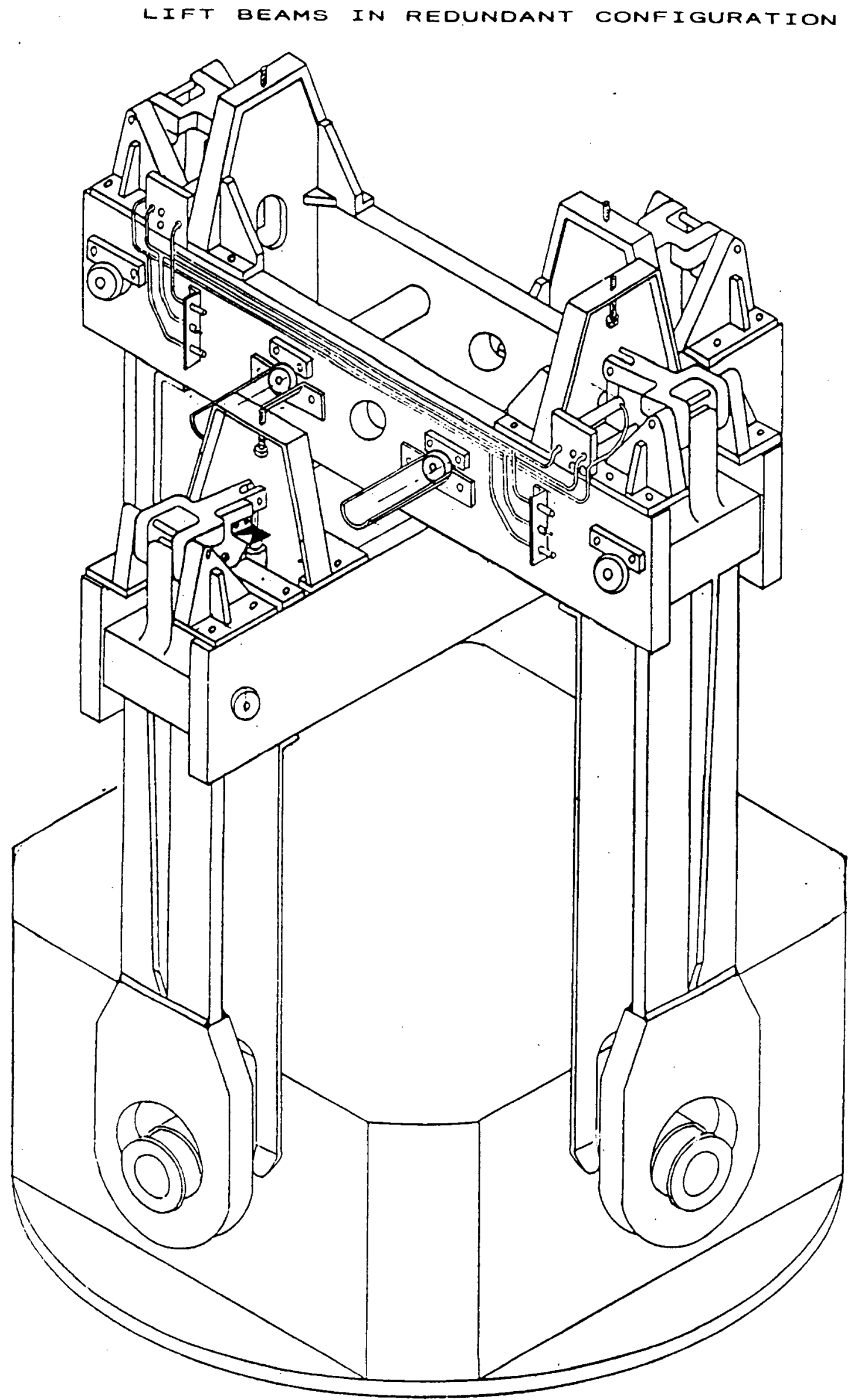

Figure 2c 
LIFT BEAM PNEUMATIC CONTROL SYSTEM

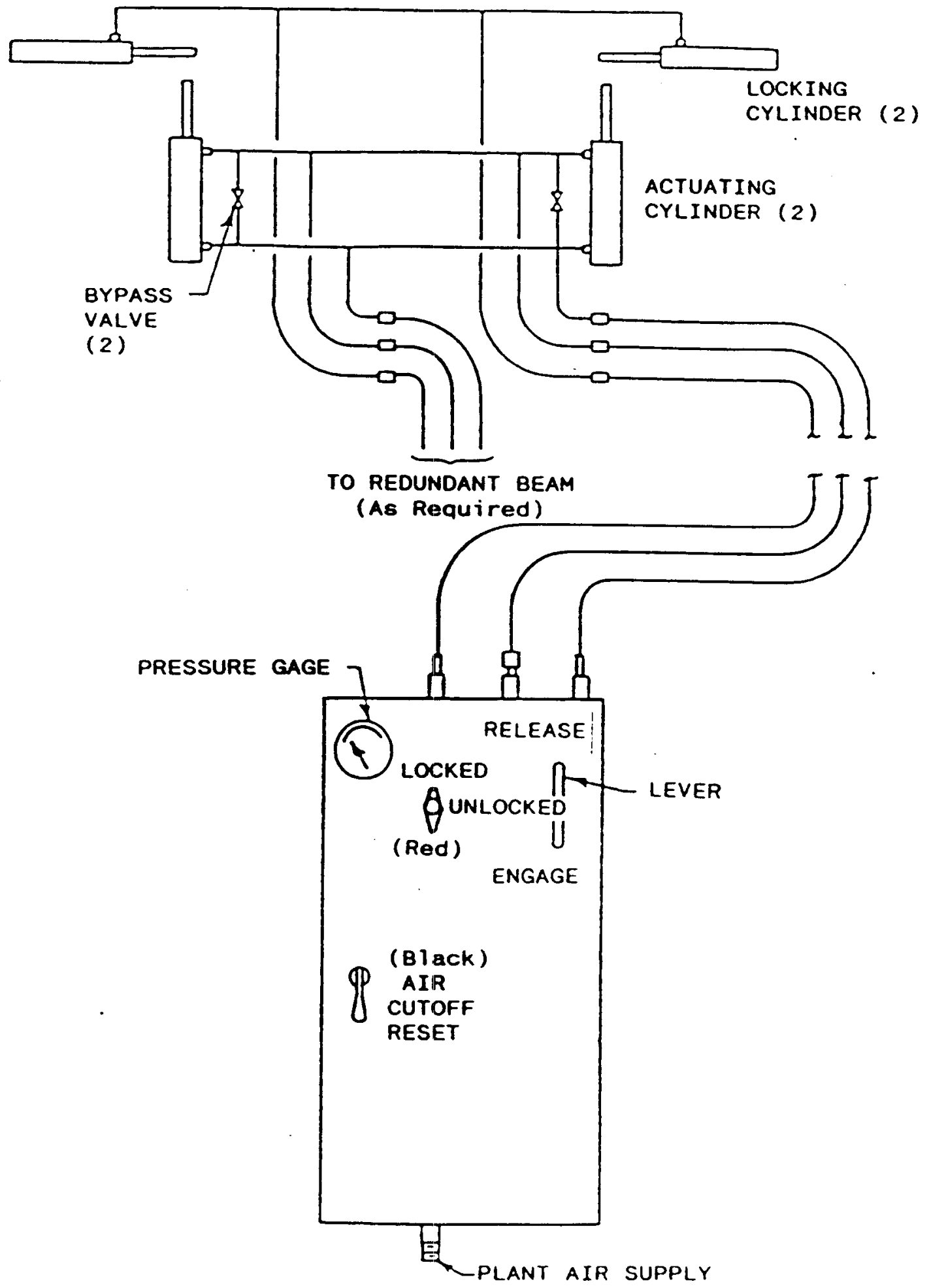

Figure 3 


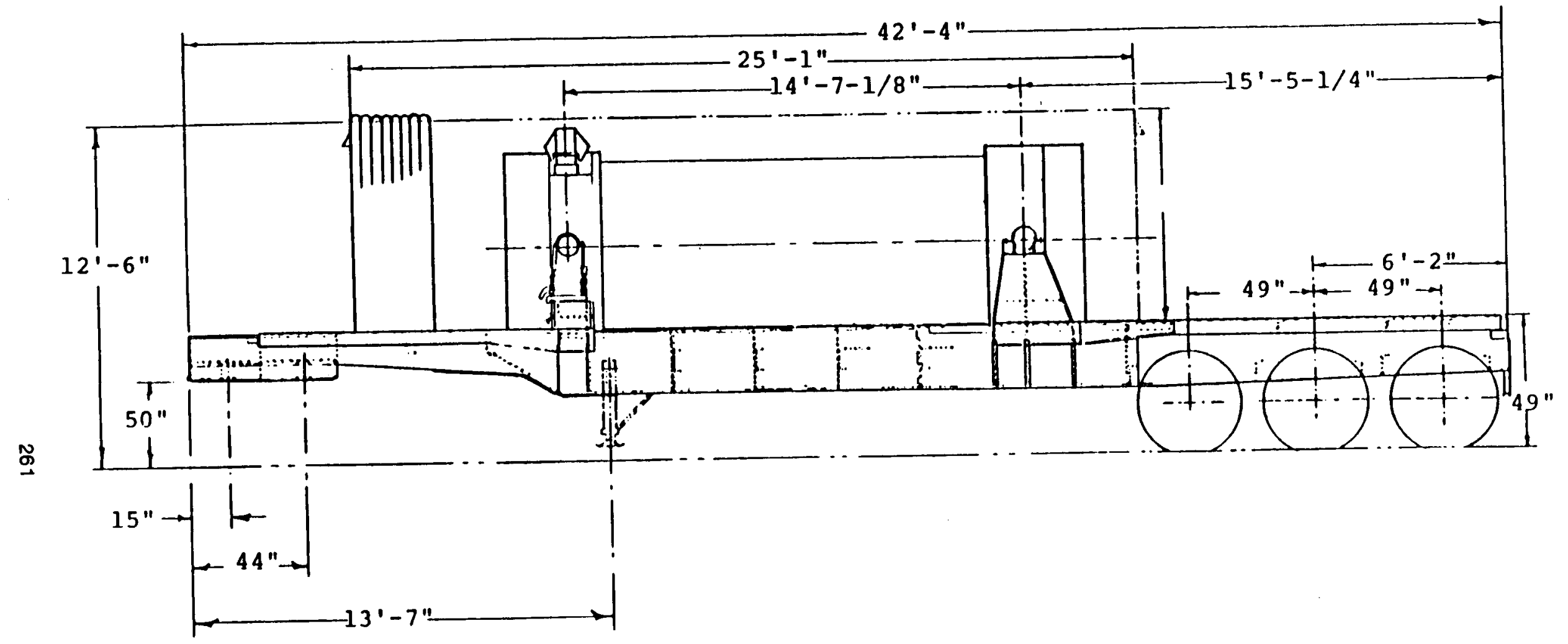

Trailer Arrangement

Figure 4 


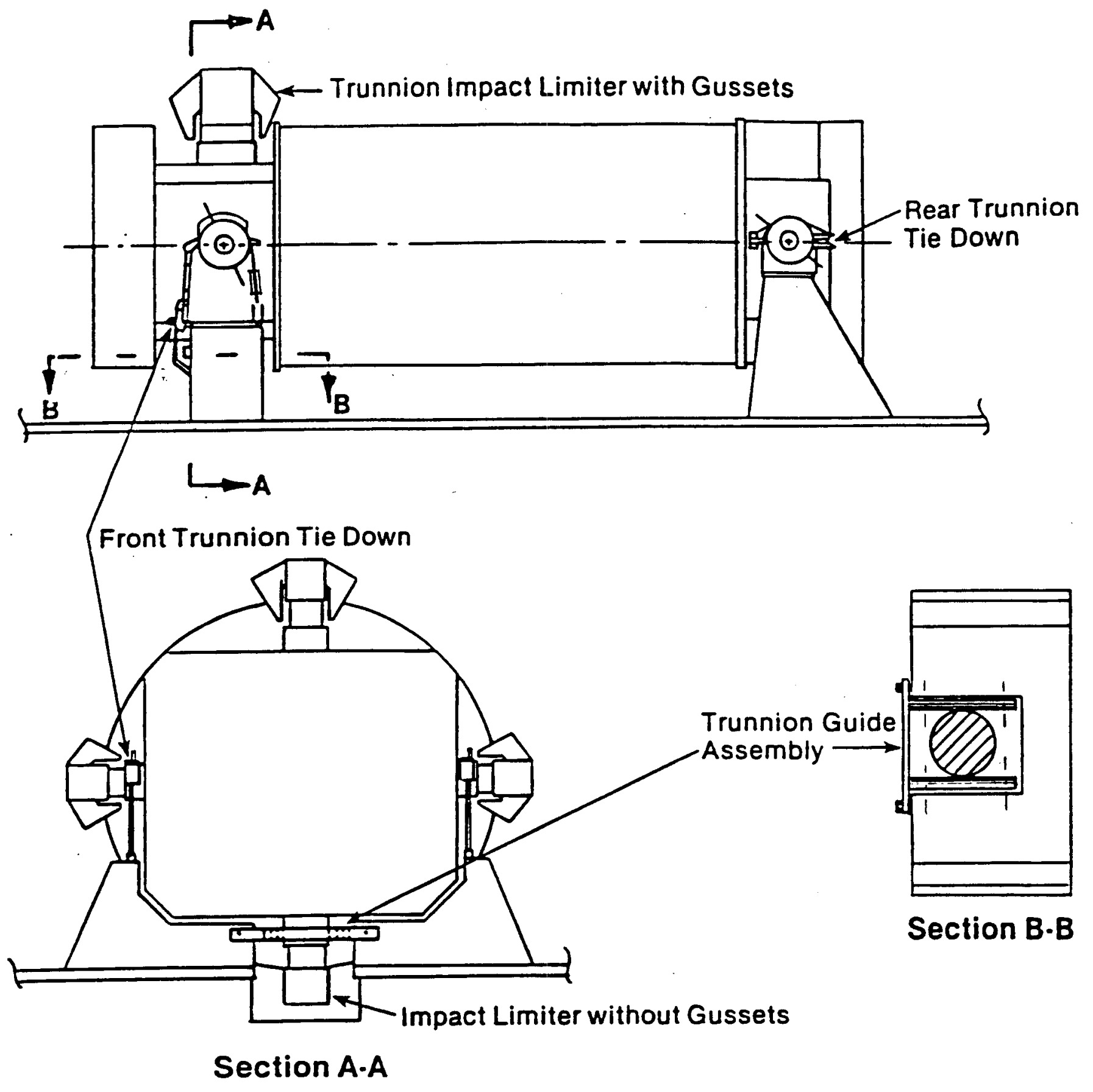

Cask Transport Arrangement

Figure 5 


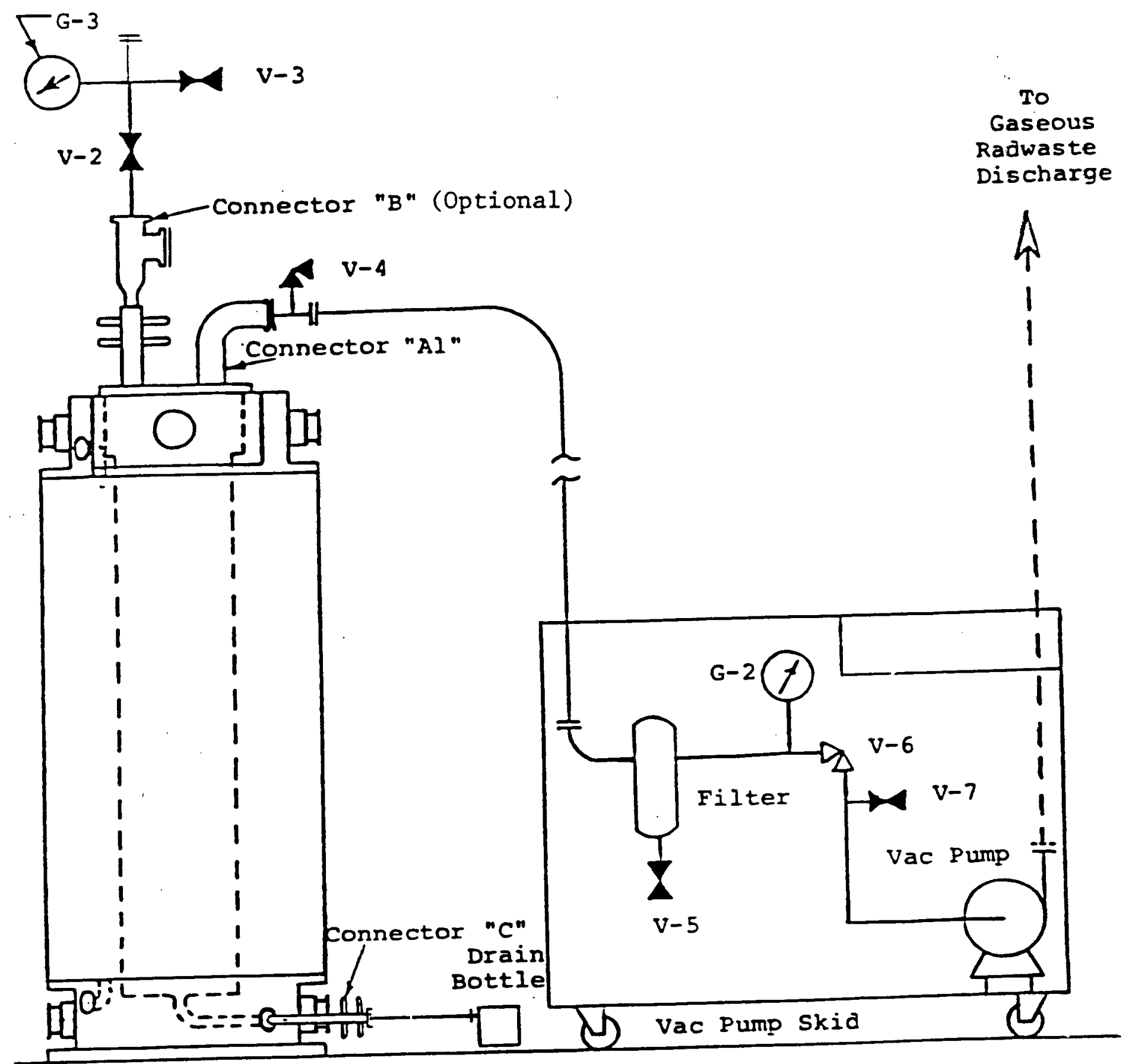

vDS in Vacuum Drying Mode

Figure 6 


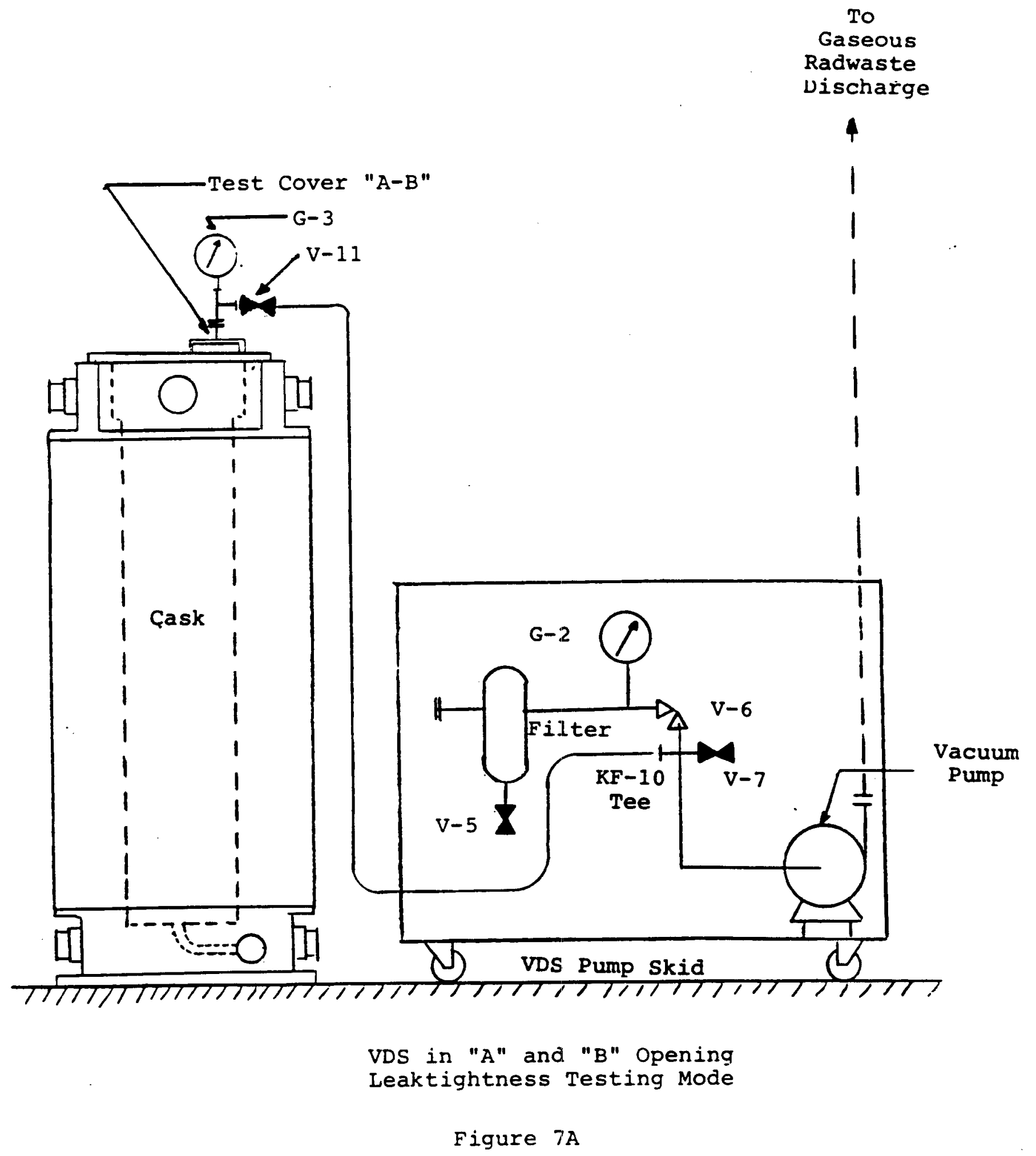


To

Gaseous

Radwaste

vischarge

4

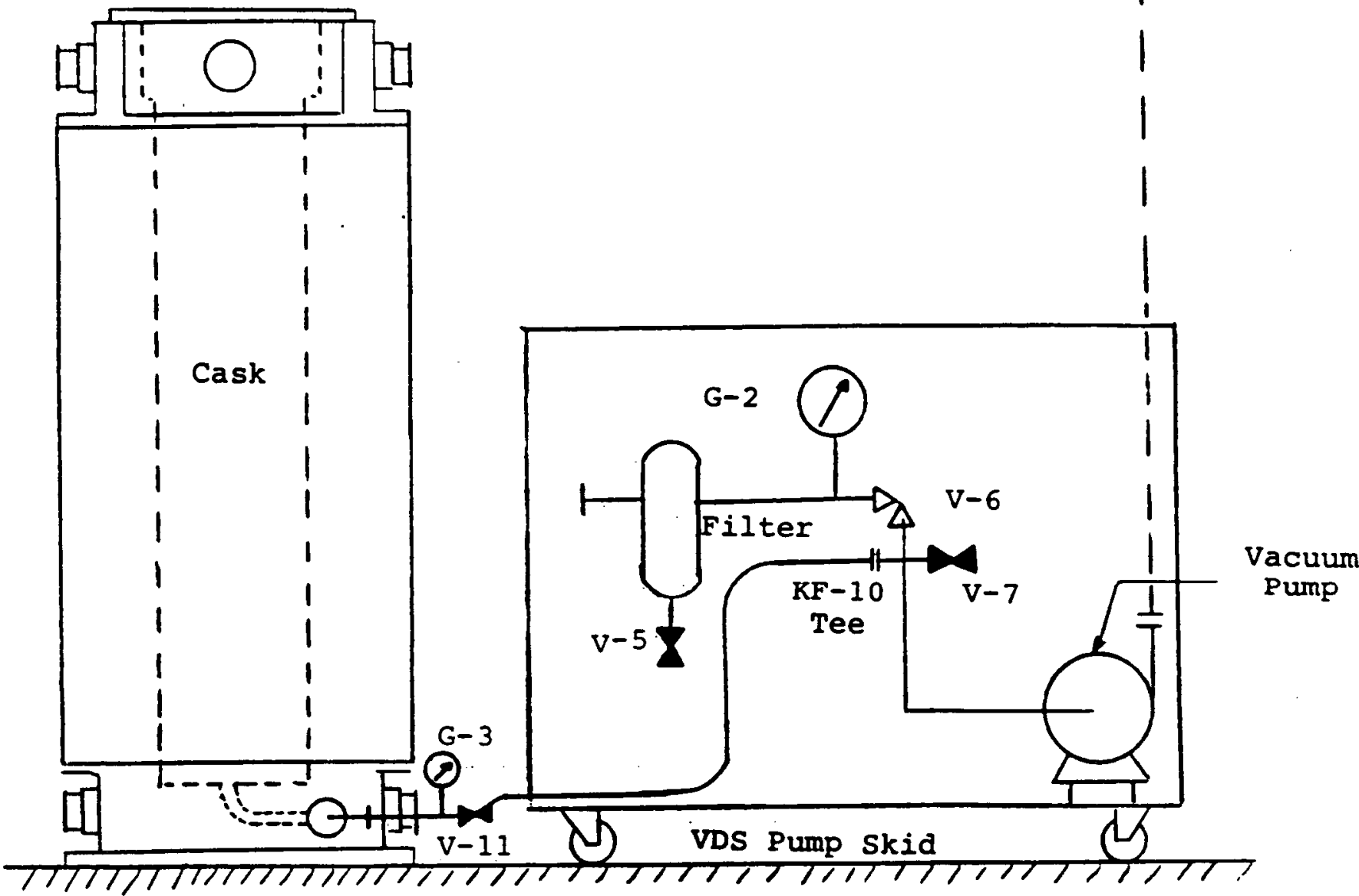

Test Flange "C"

VDS in "C" Opening Leaktightness

Testing Mode

Figure 7B 


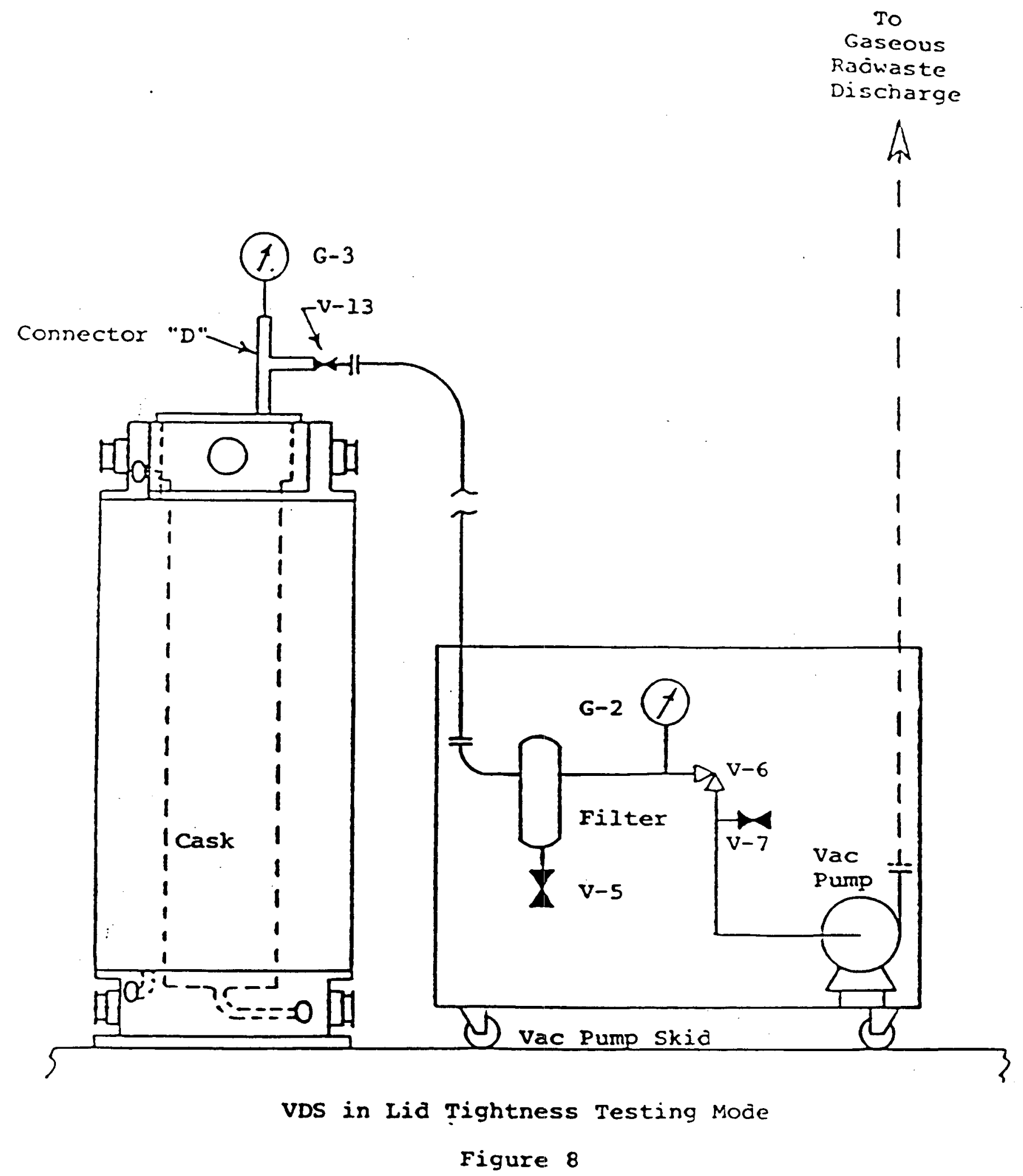




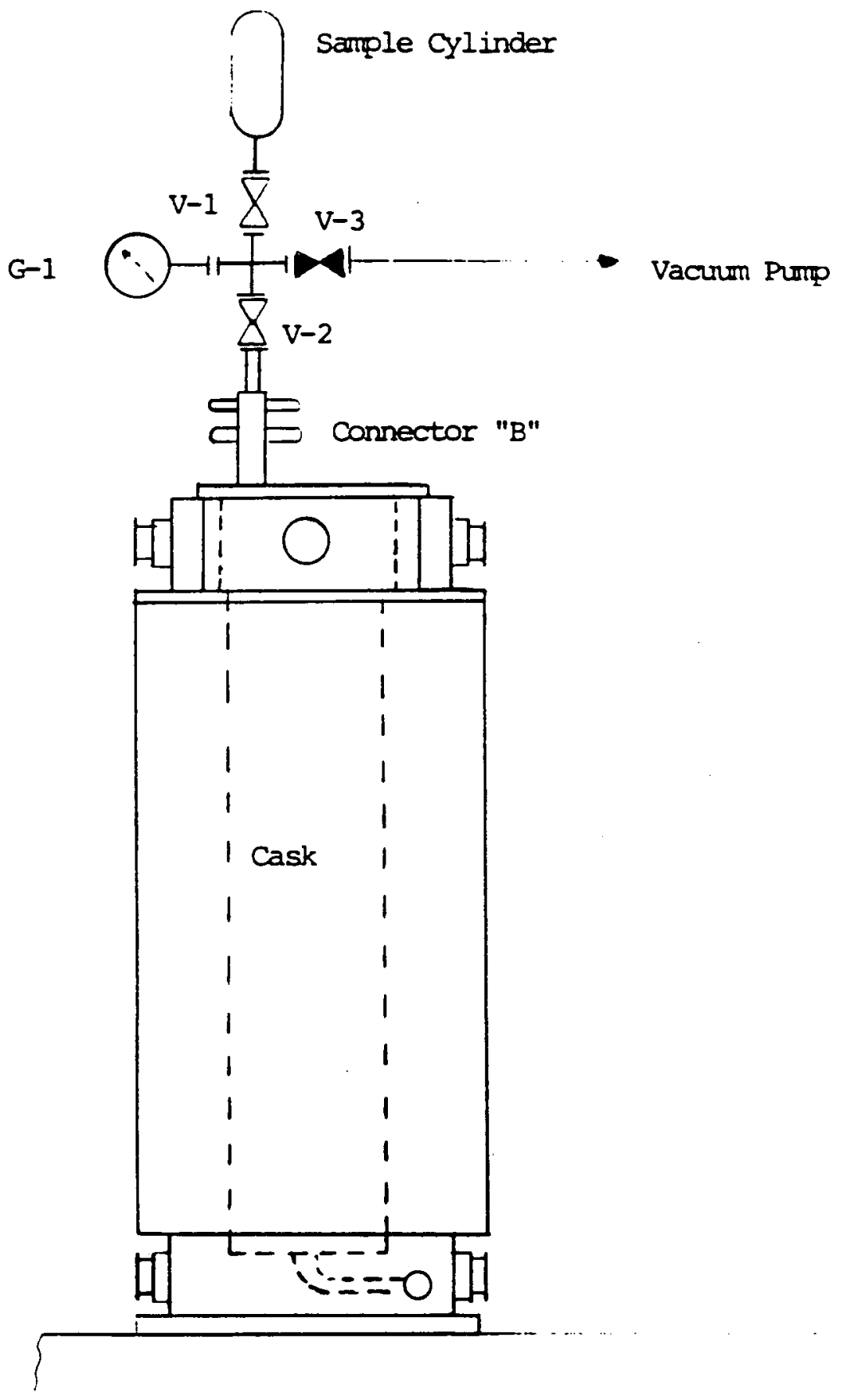

Cask in Sampling Mode

Figure 9A 


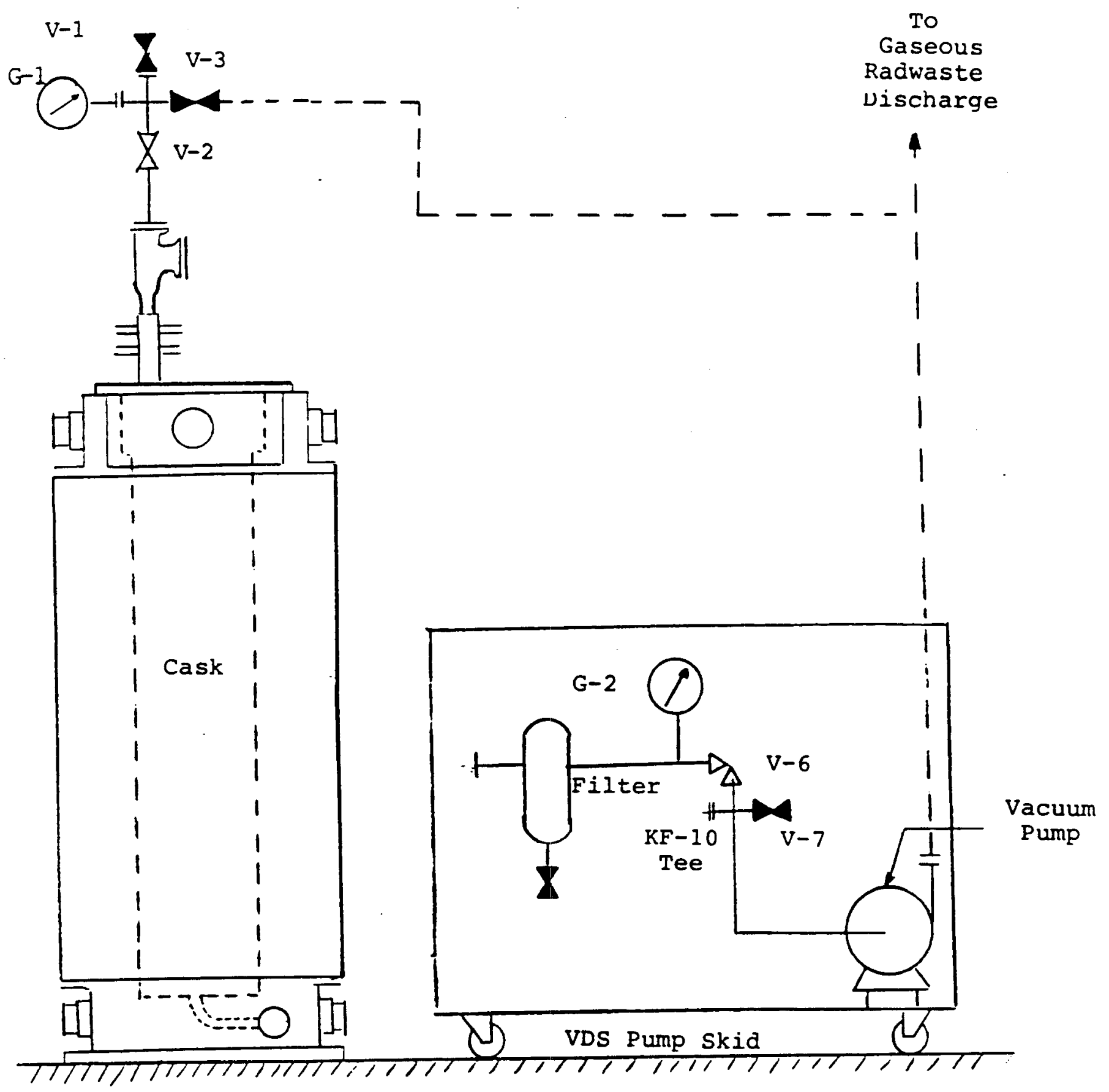

Cask in Vent Mode

Figure 9B 


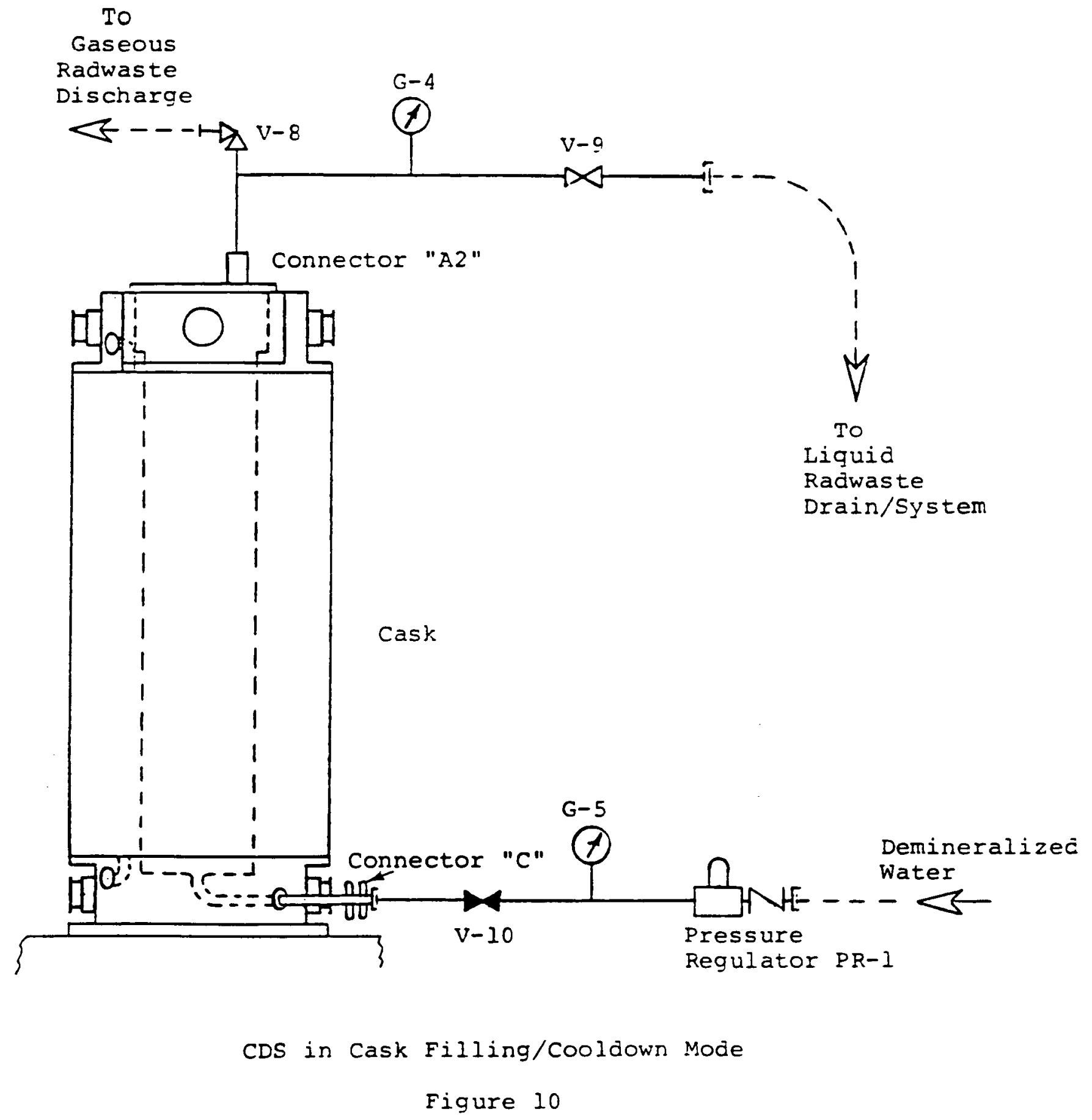




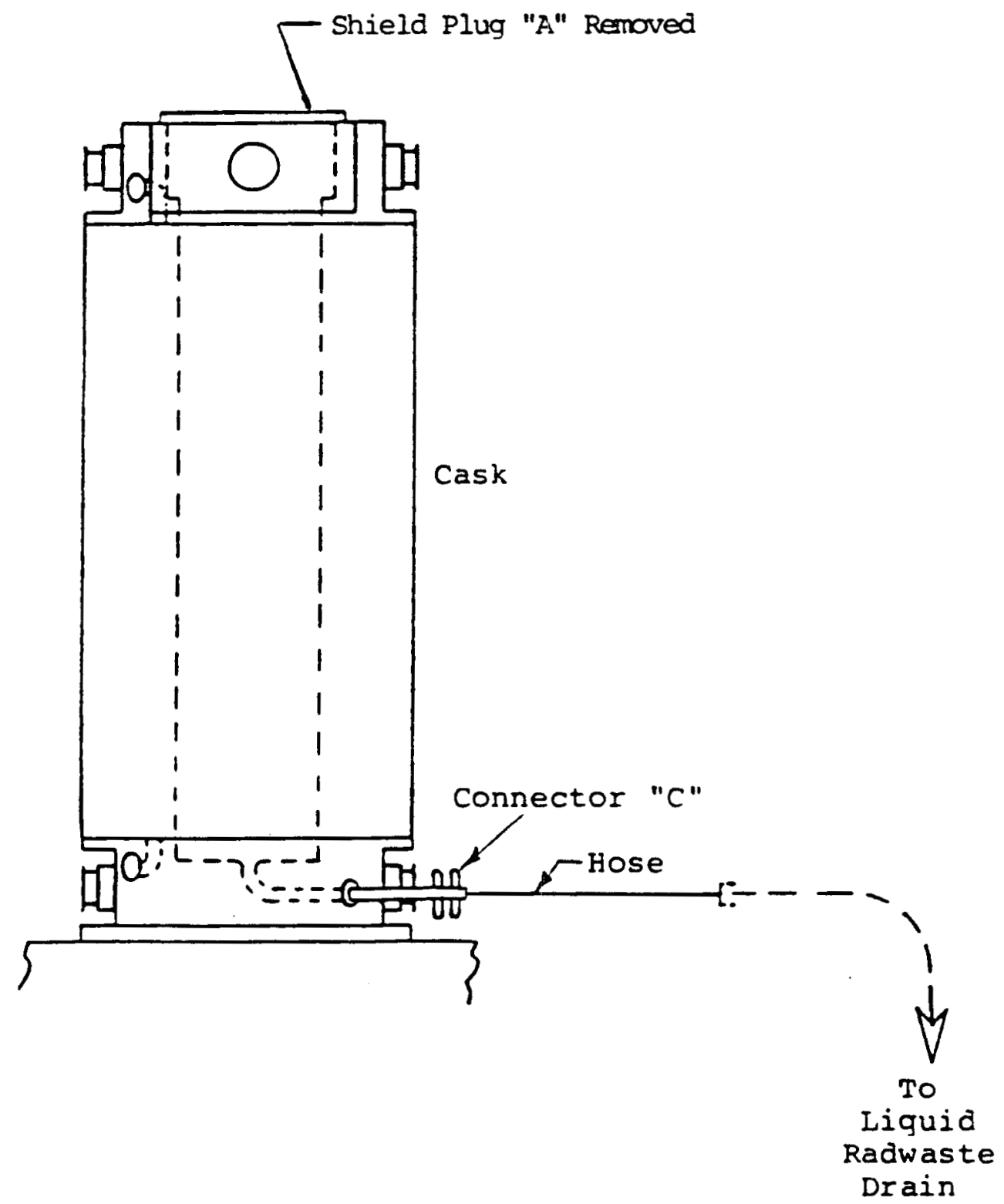

Unloaded Cask in Draining Mode

Figure IIA 


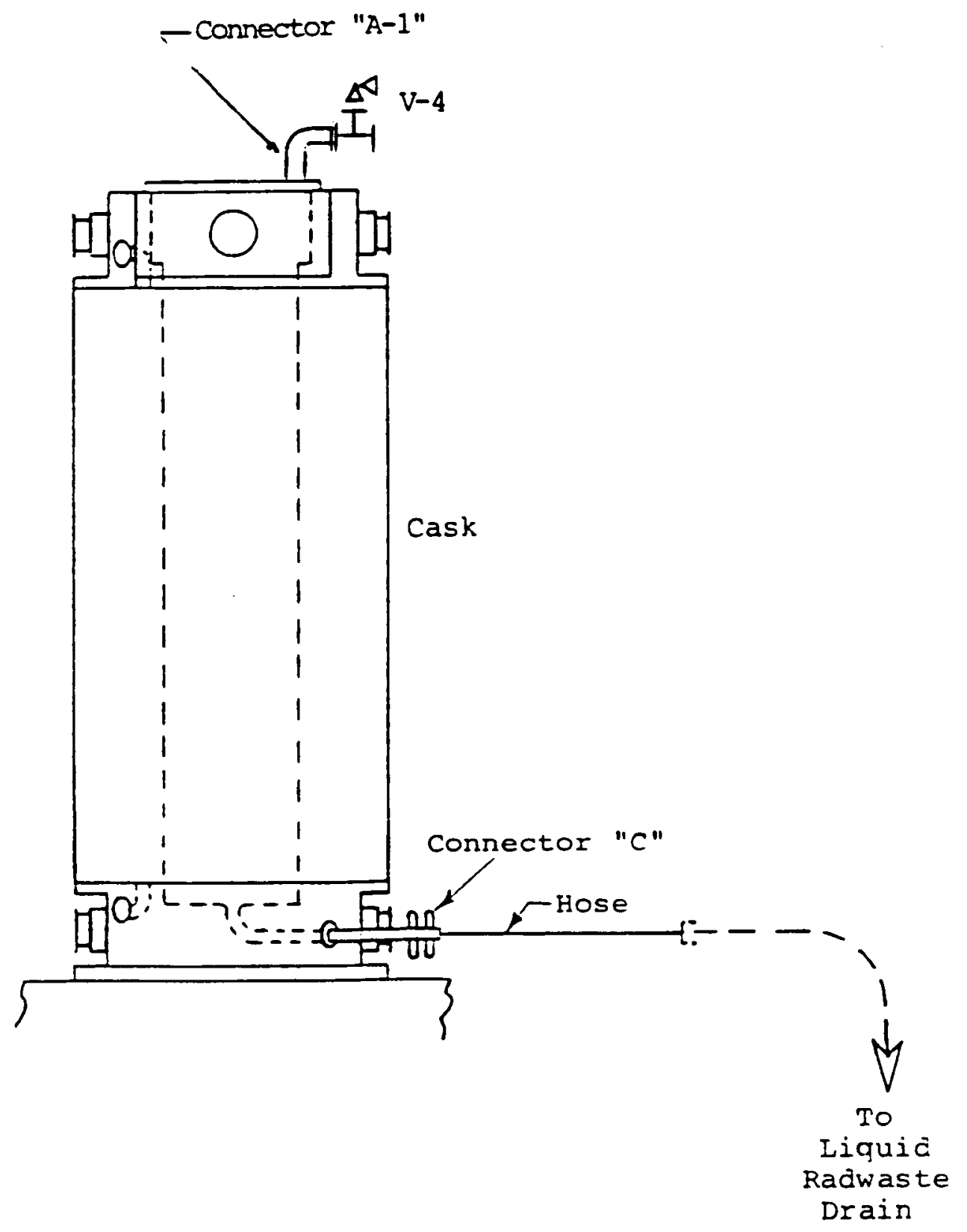

Loaded Cask in Draining Mode

Figure $11 \mathrm{~B}$ 


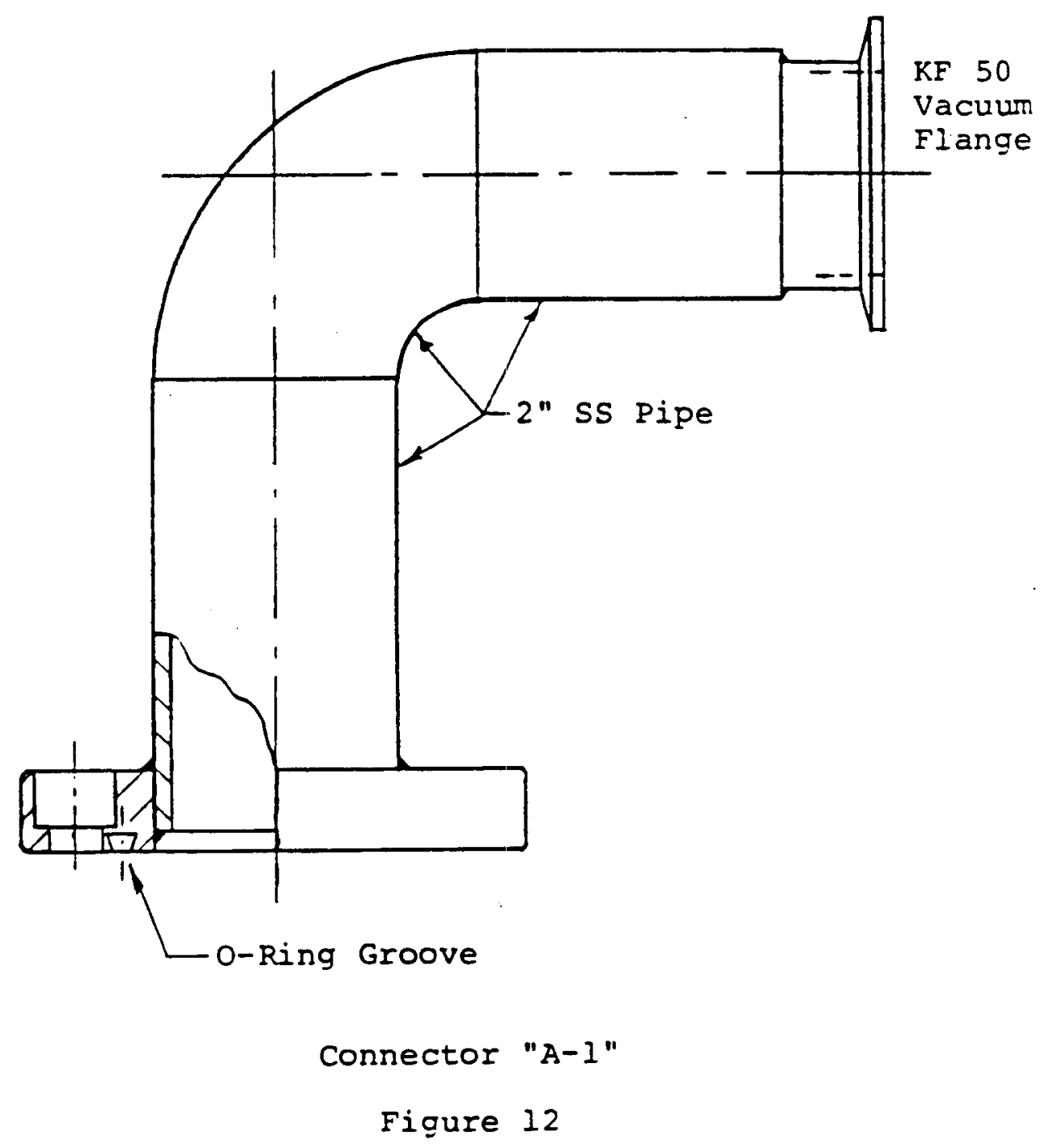




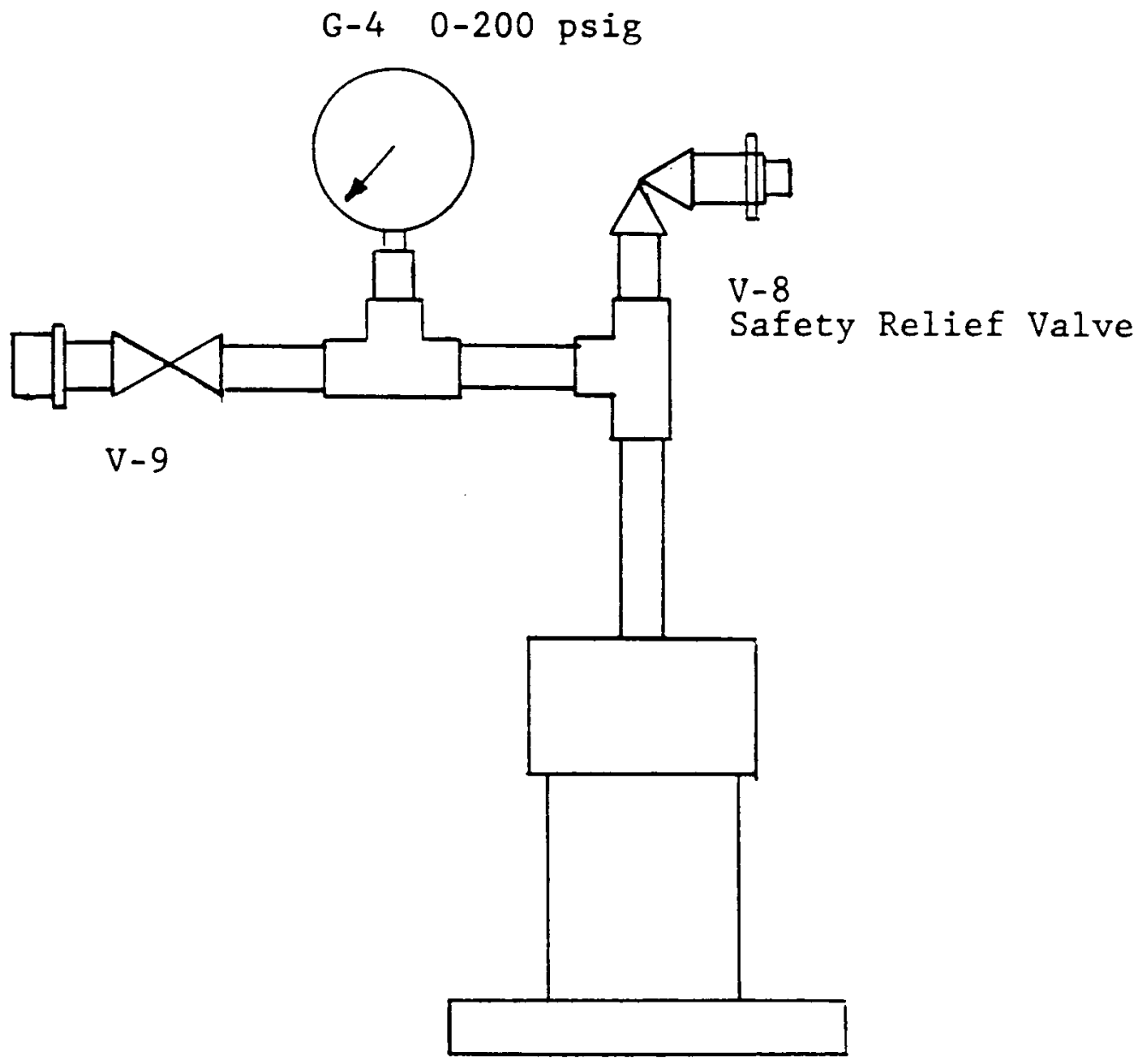

Connector "A-2" with

Valves and Gage

Figure 13 


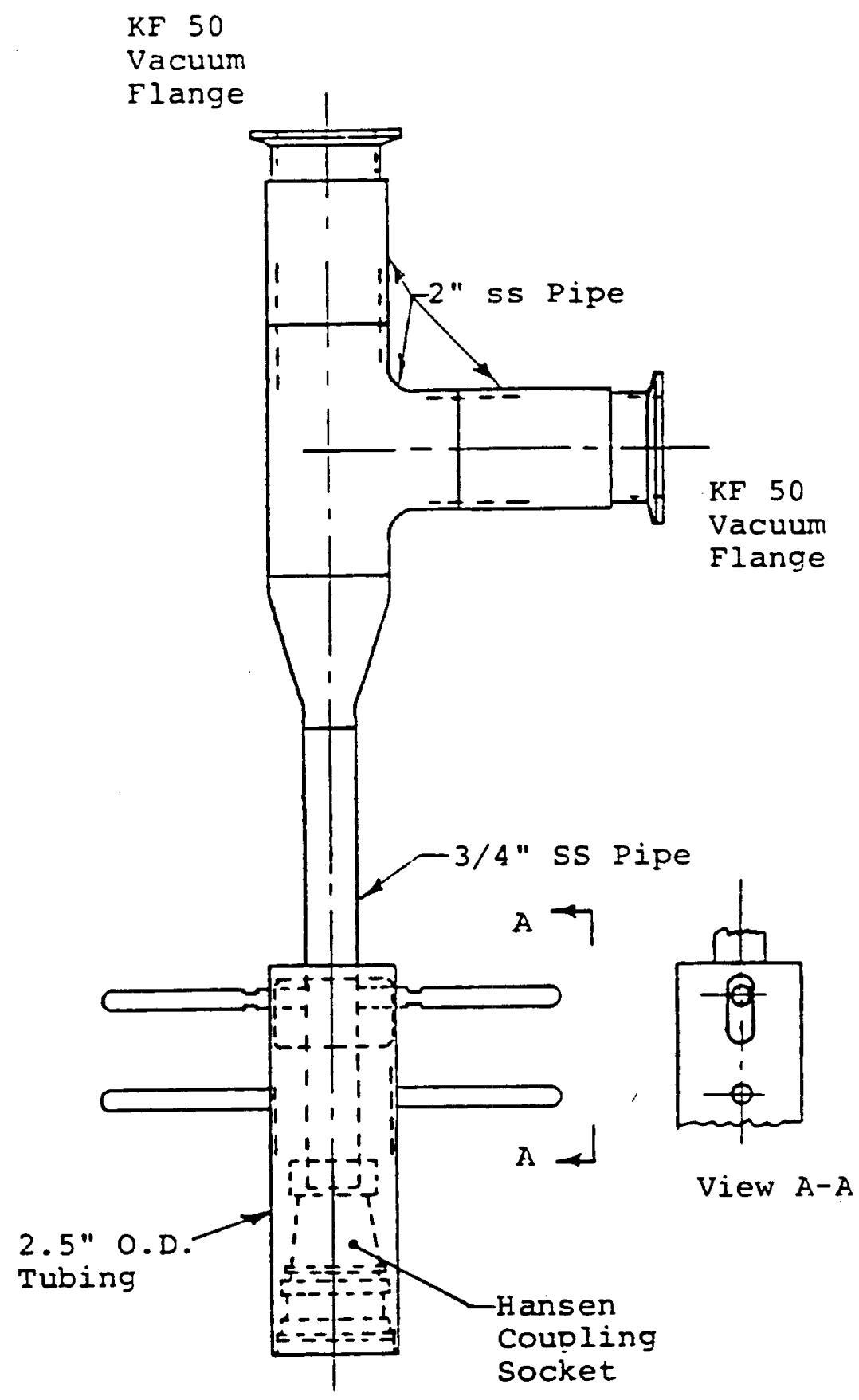

Connector "B" Equiped with

2 inch Vacunm Hose Flange

Figure 14A 


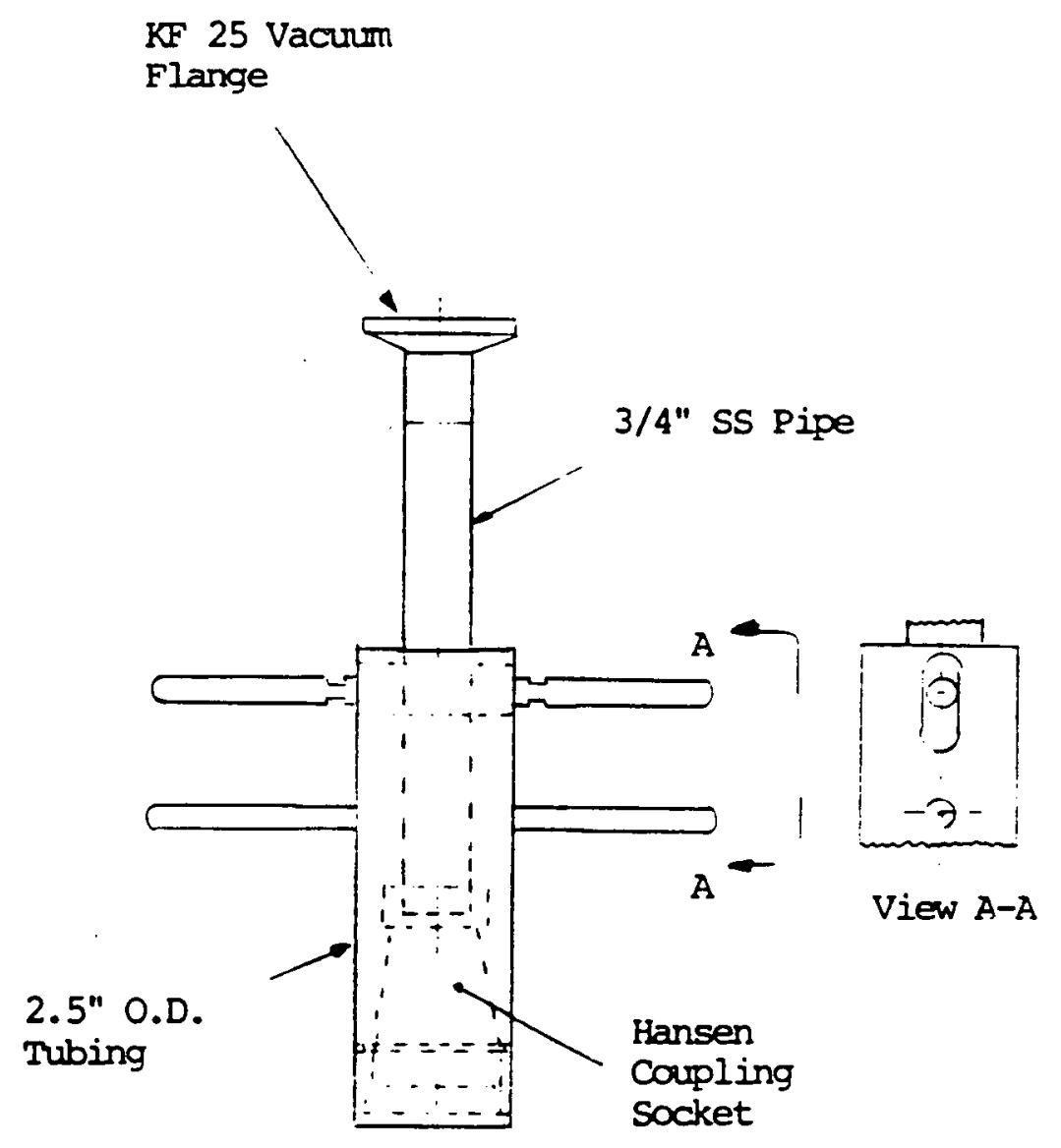

Connector "B" Equiped With

KF 25 Vacuum Hose Flange

Figure 14B 


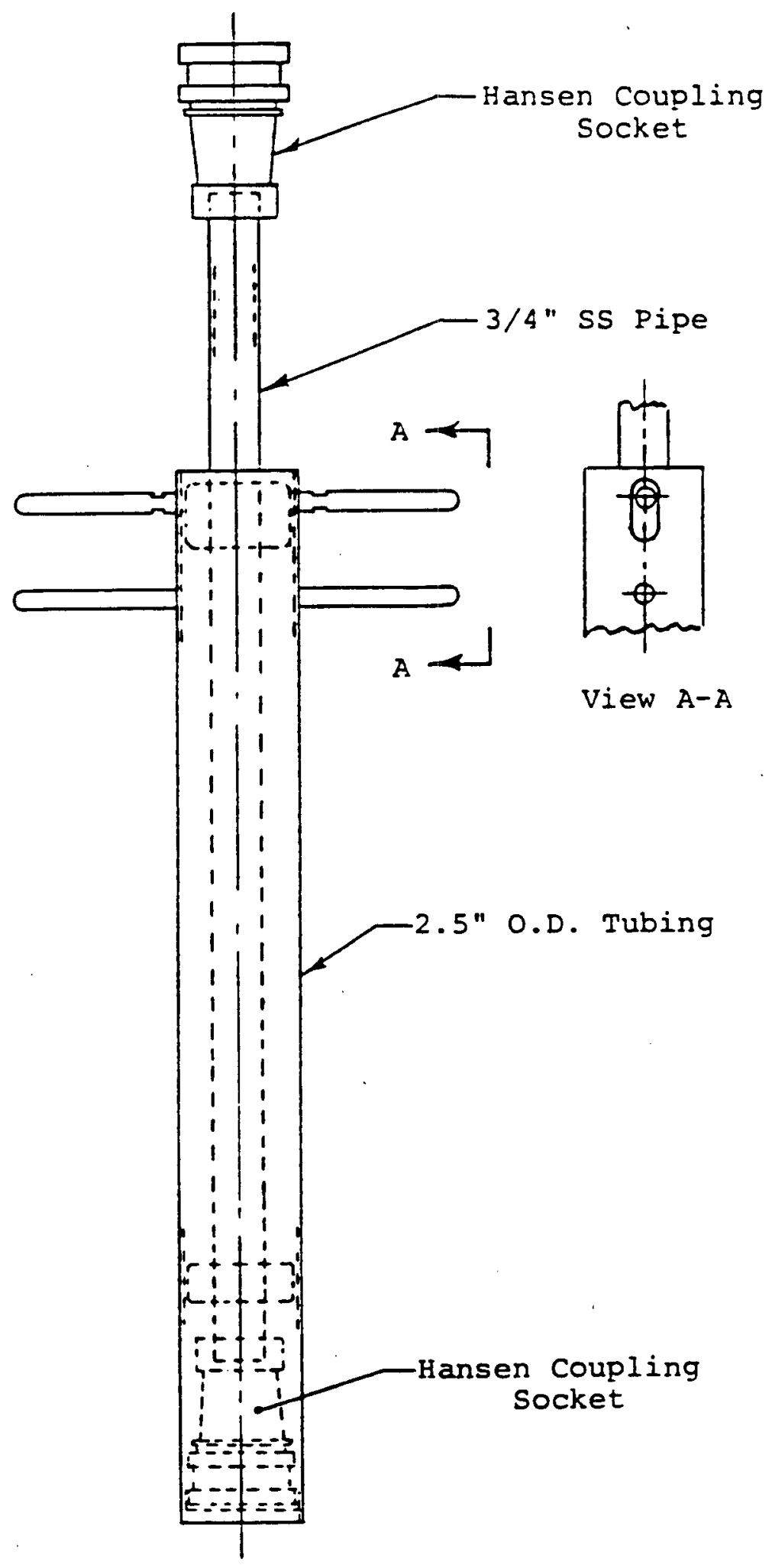

Connector "C"

Figure 15 


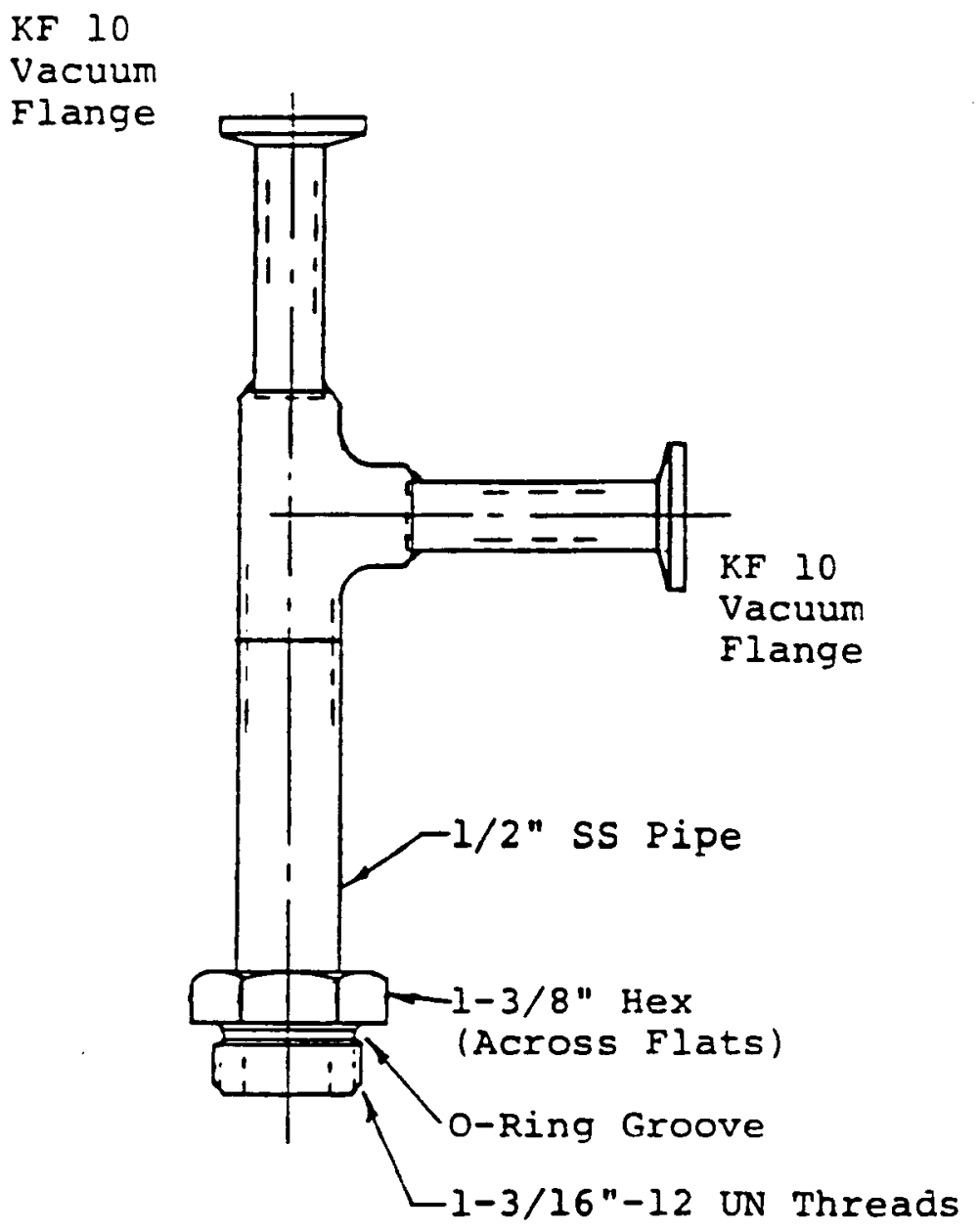

Connector " $D$ "

Figure 16 

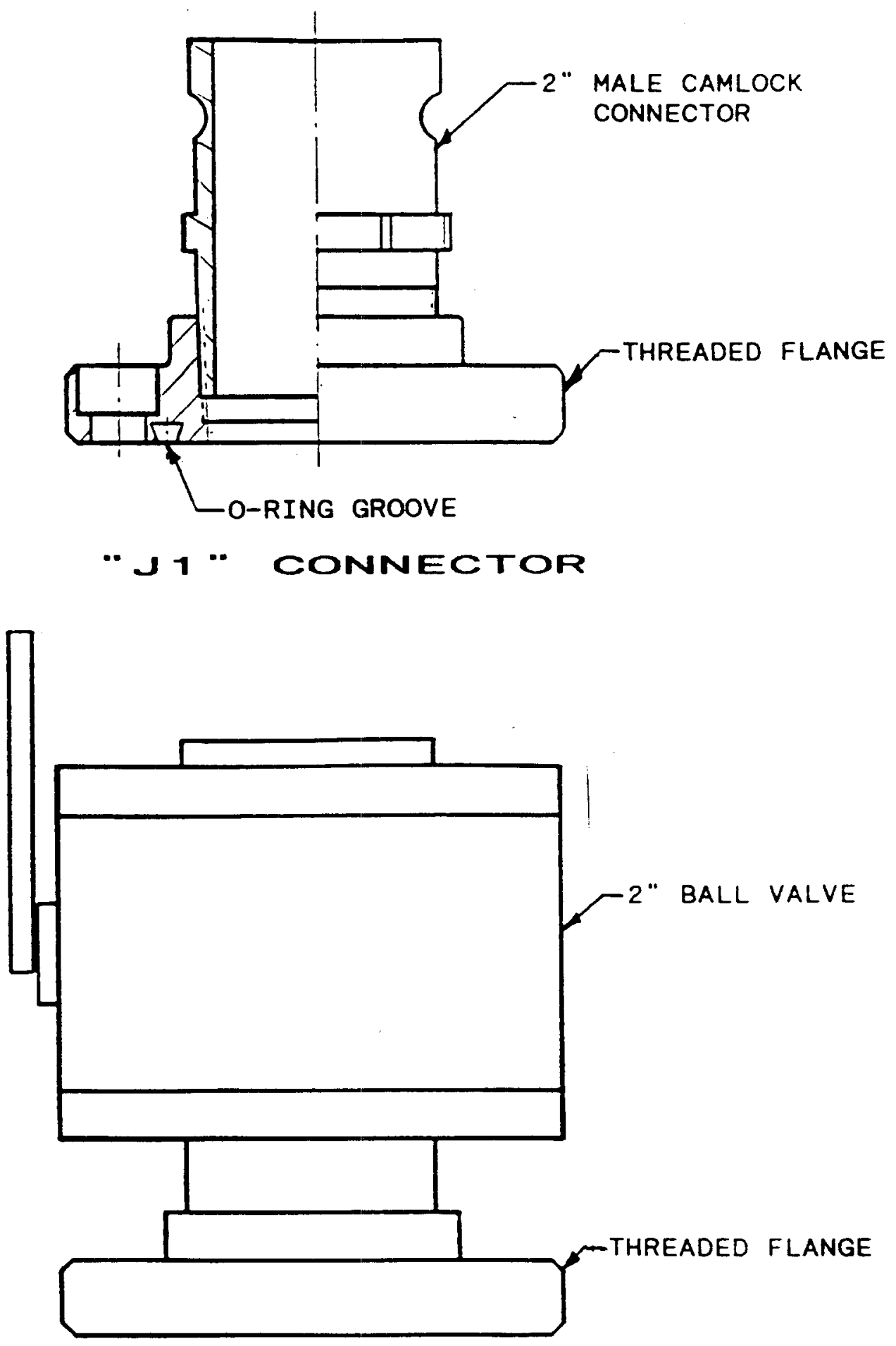

". 2 ". CONNECTOR

Figure $\quad 17 \quad 278$ 
CASK BOTTOM PROTEOTIVE COVER

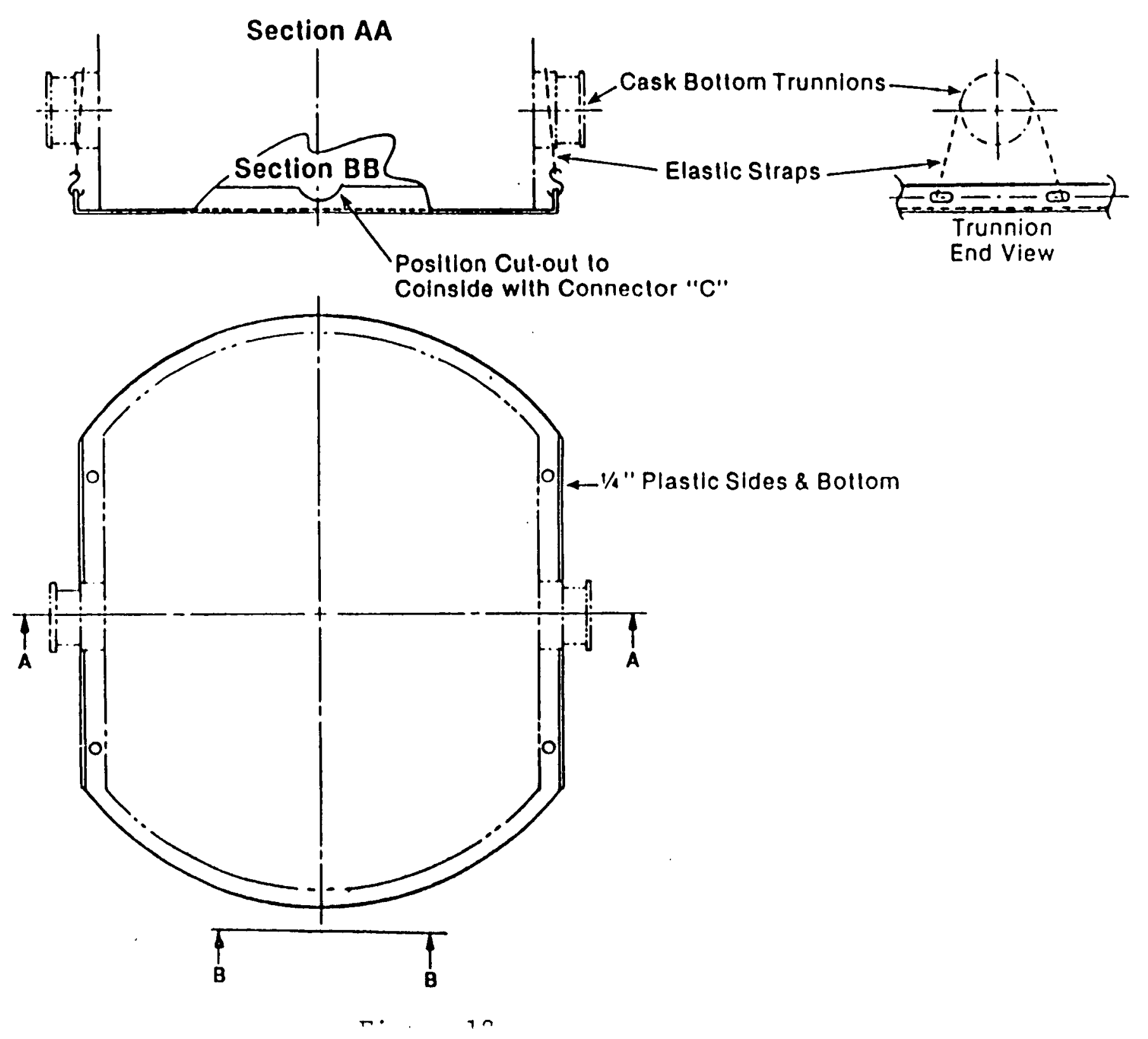


OASK TOP PROTEOTIVE COVER

Secllon AA

$\tilde{\mathrm{g}}$

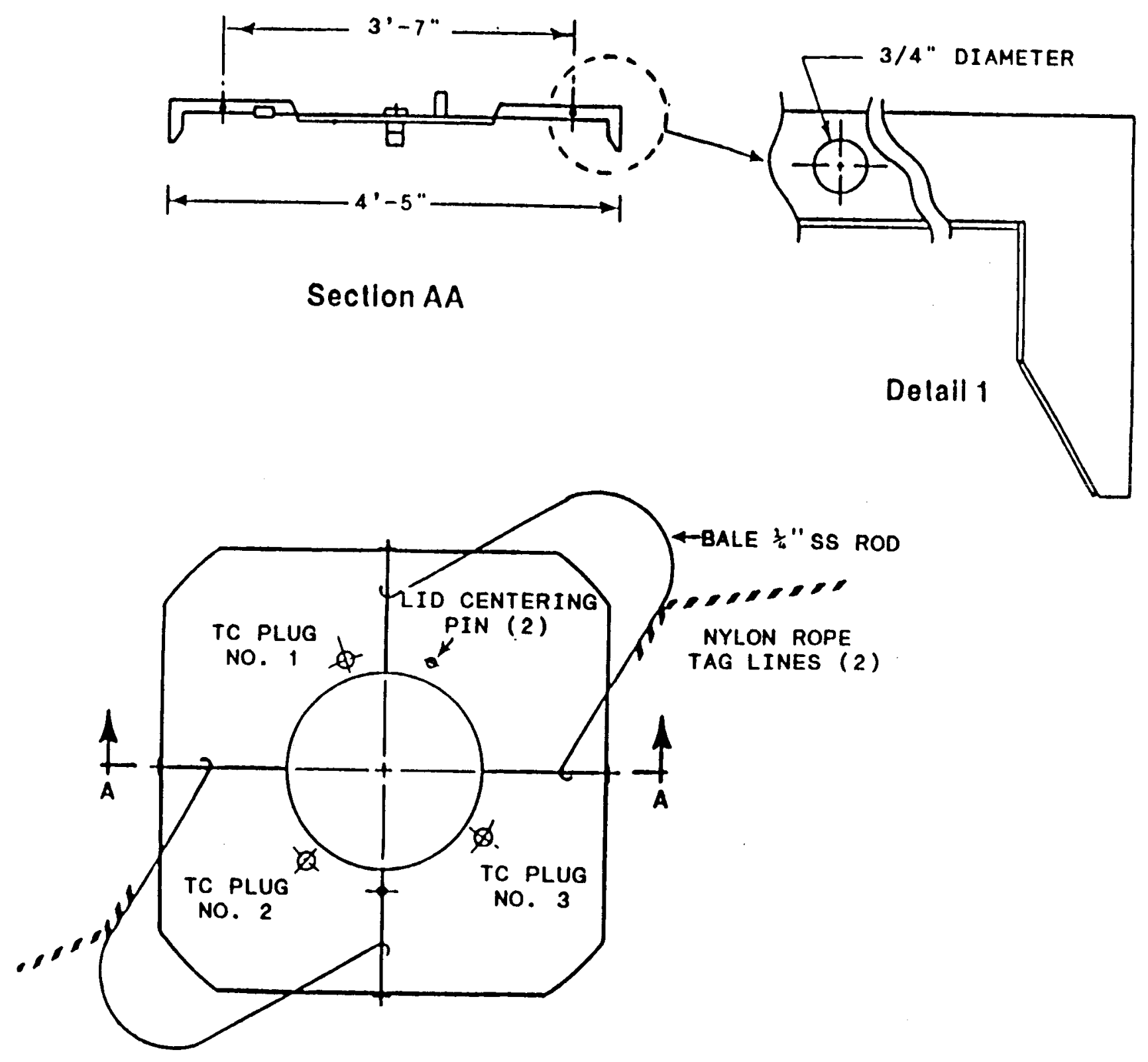




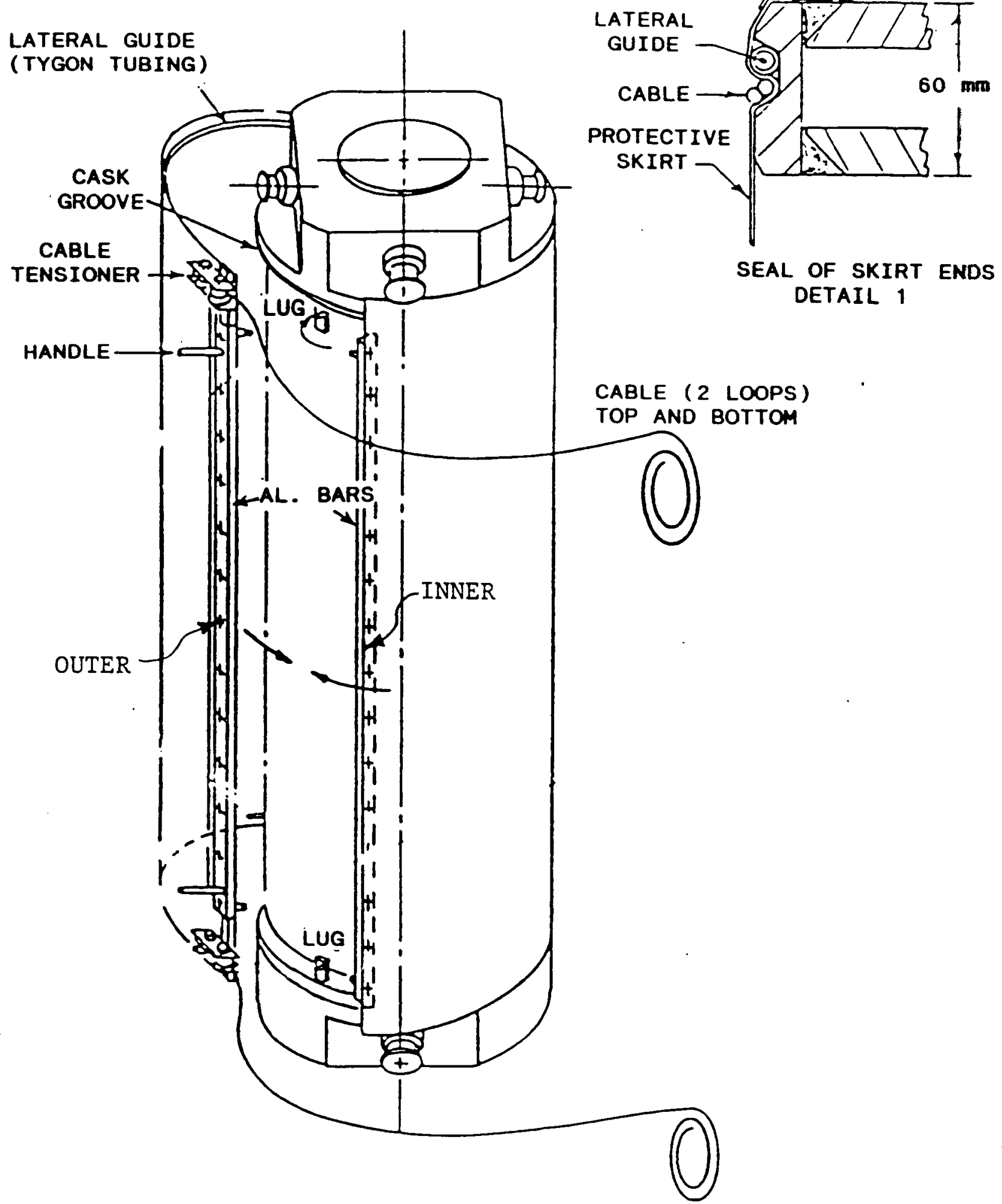




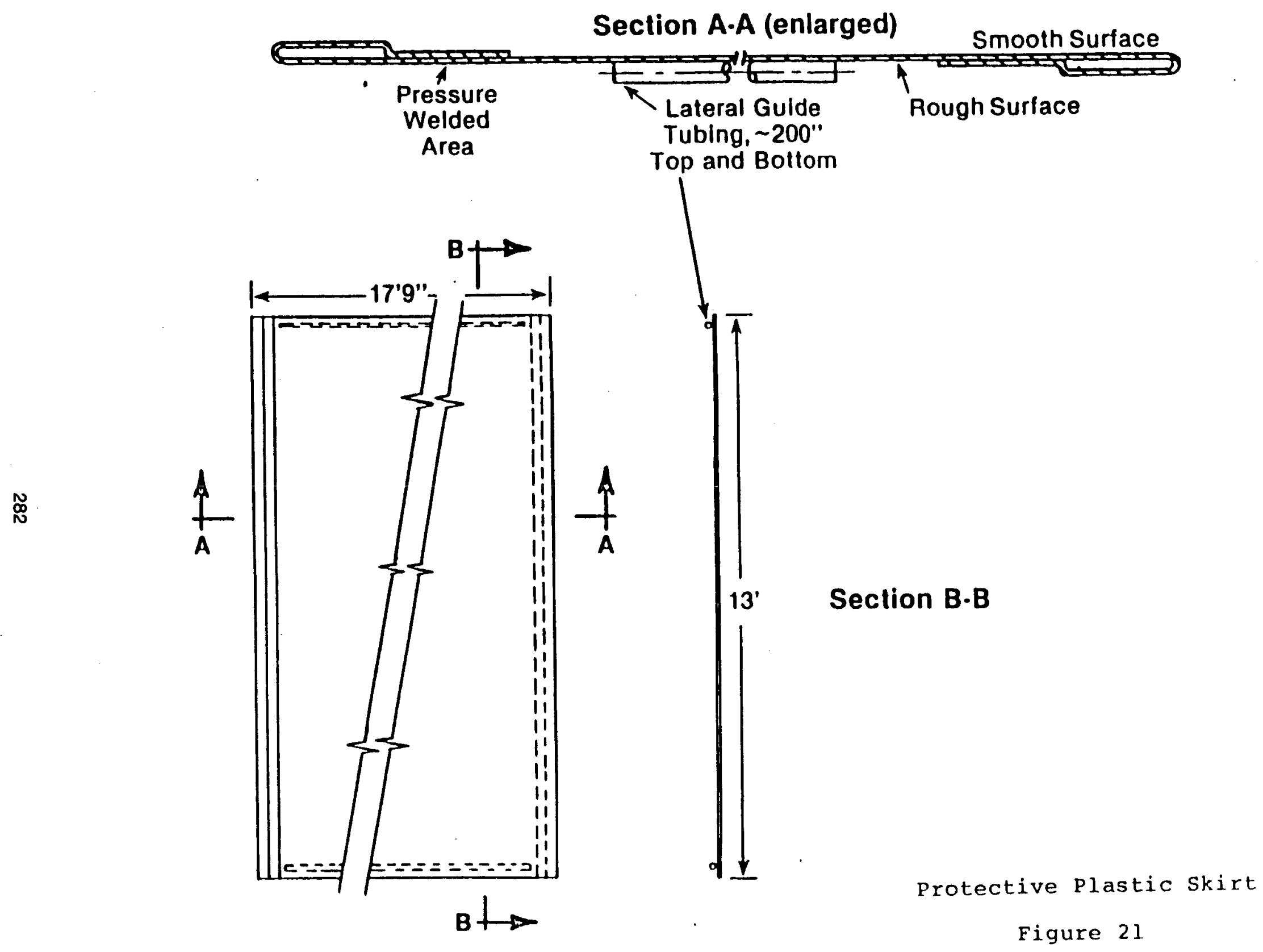




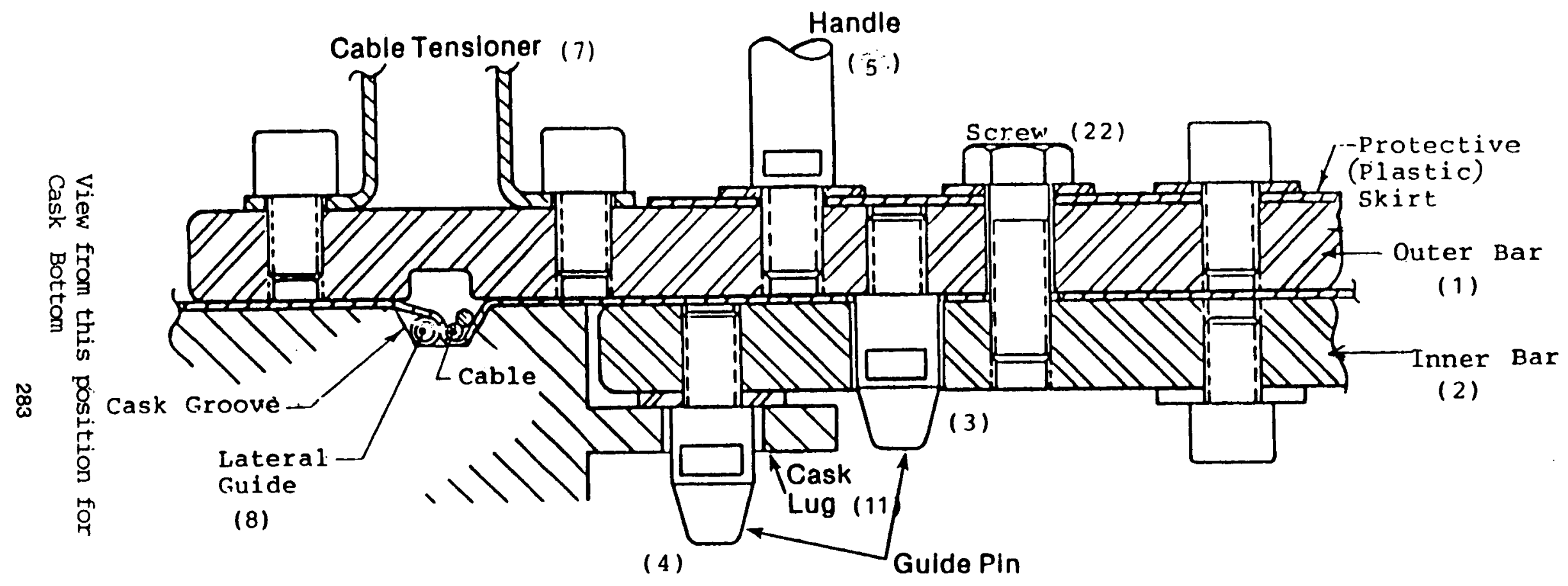




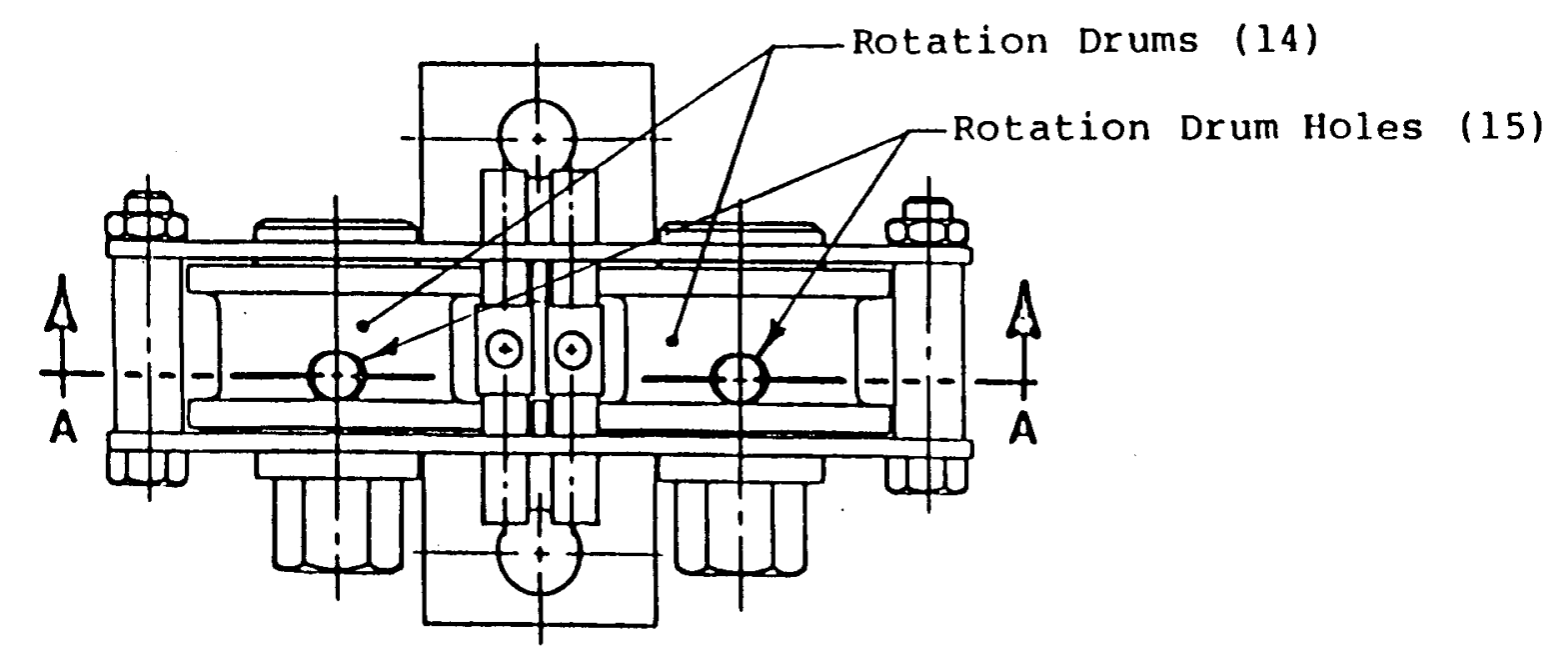

⿷
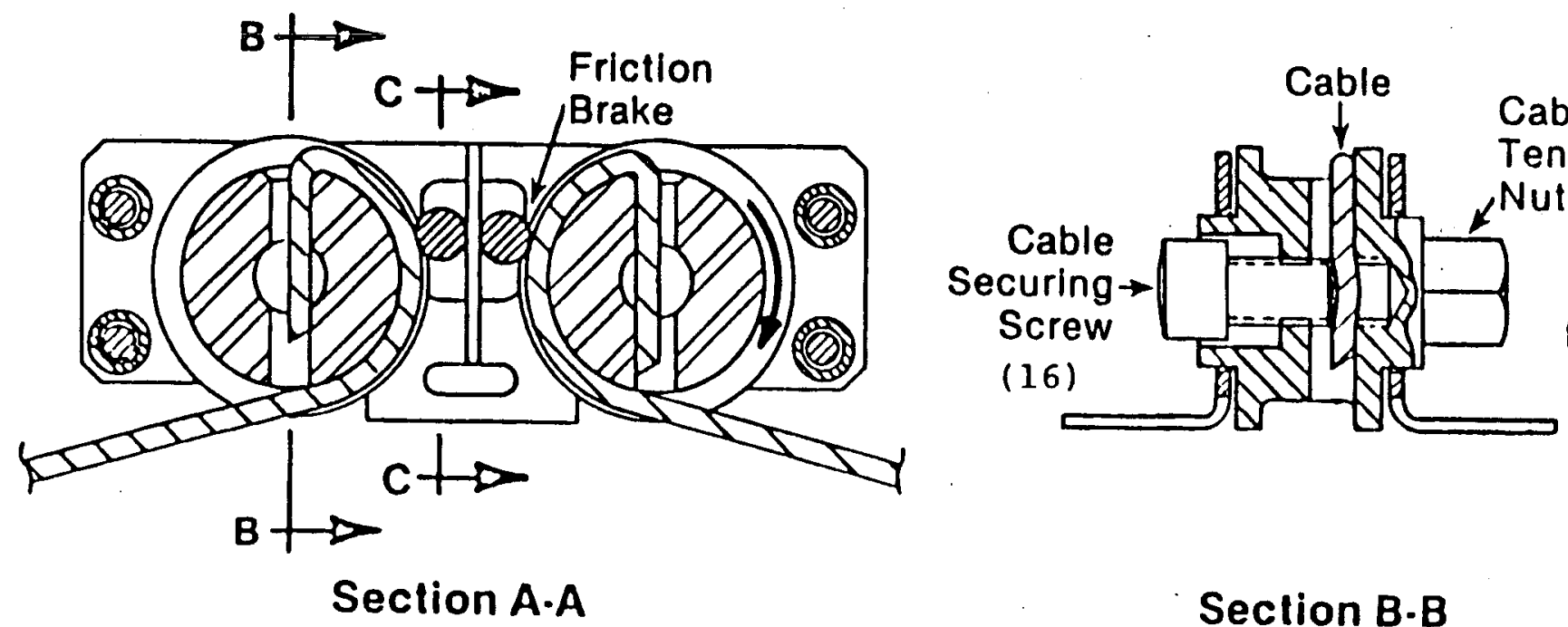

Cable

Tensioning

Nut (19)

"O" Ring for Spring $\rightarrow$ Tension (18)

Section B-B

Section C.C

Skirt Cable Tensioner

Figure 23 


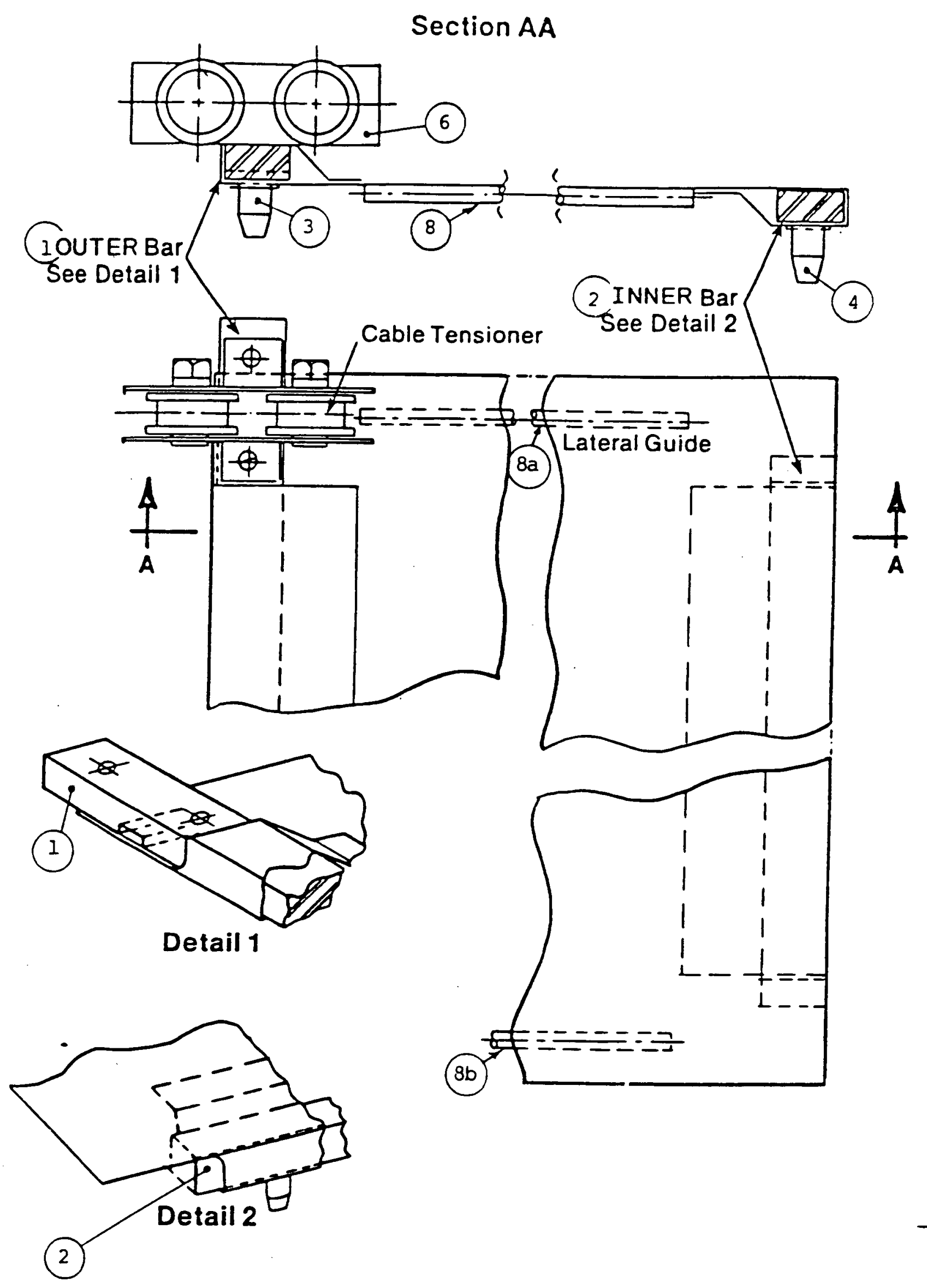

Protective Skirt Assembly

Figure 24 


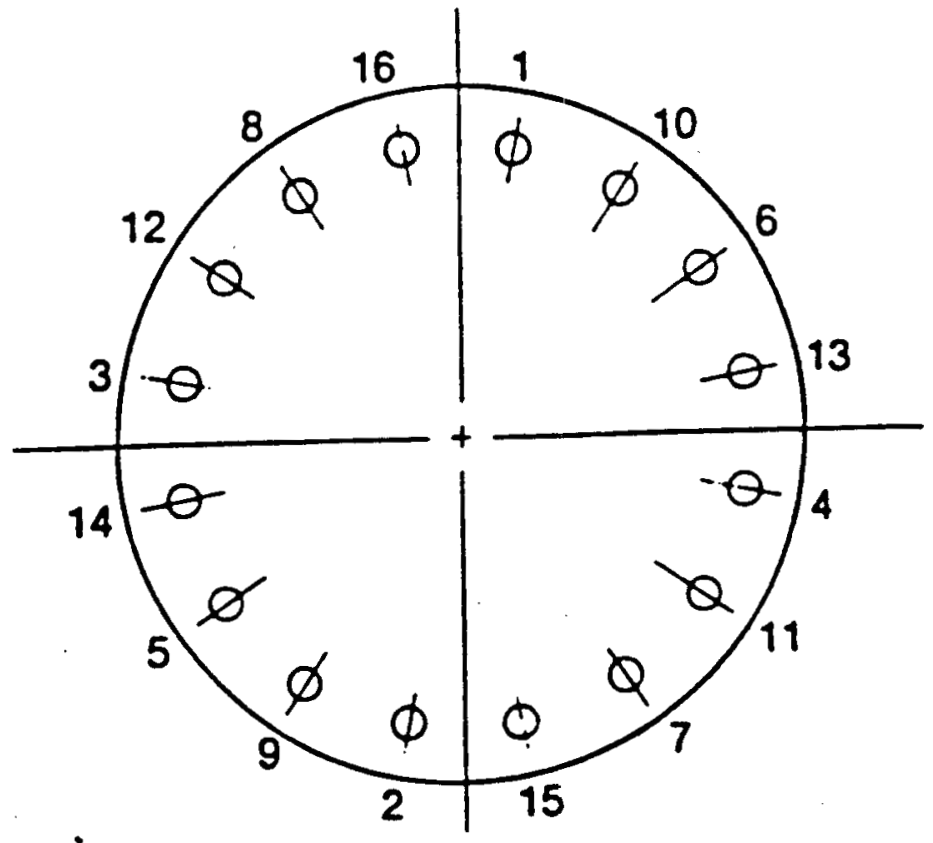

(a) Lid

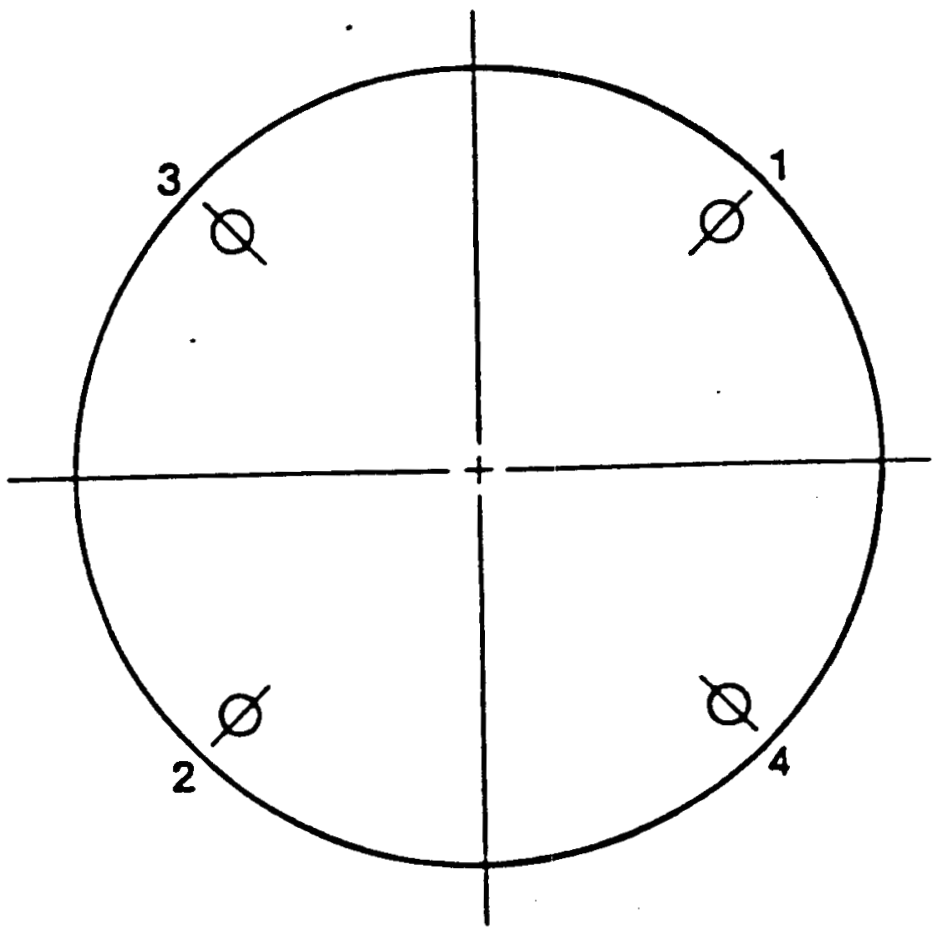

(b) Shock Absorbing Covers

Lid and Cover Bolt Tightening Sequence

Figure 25 


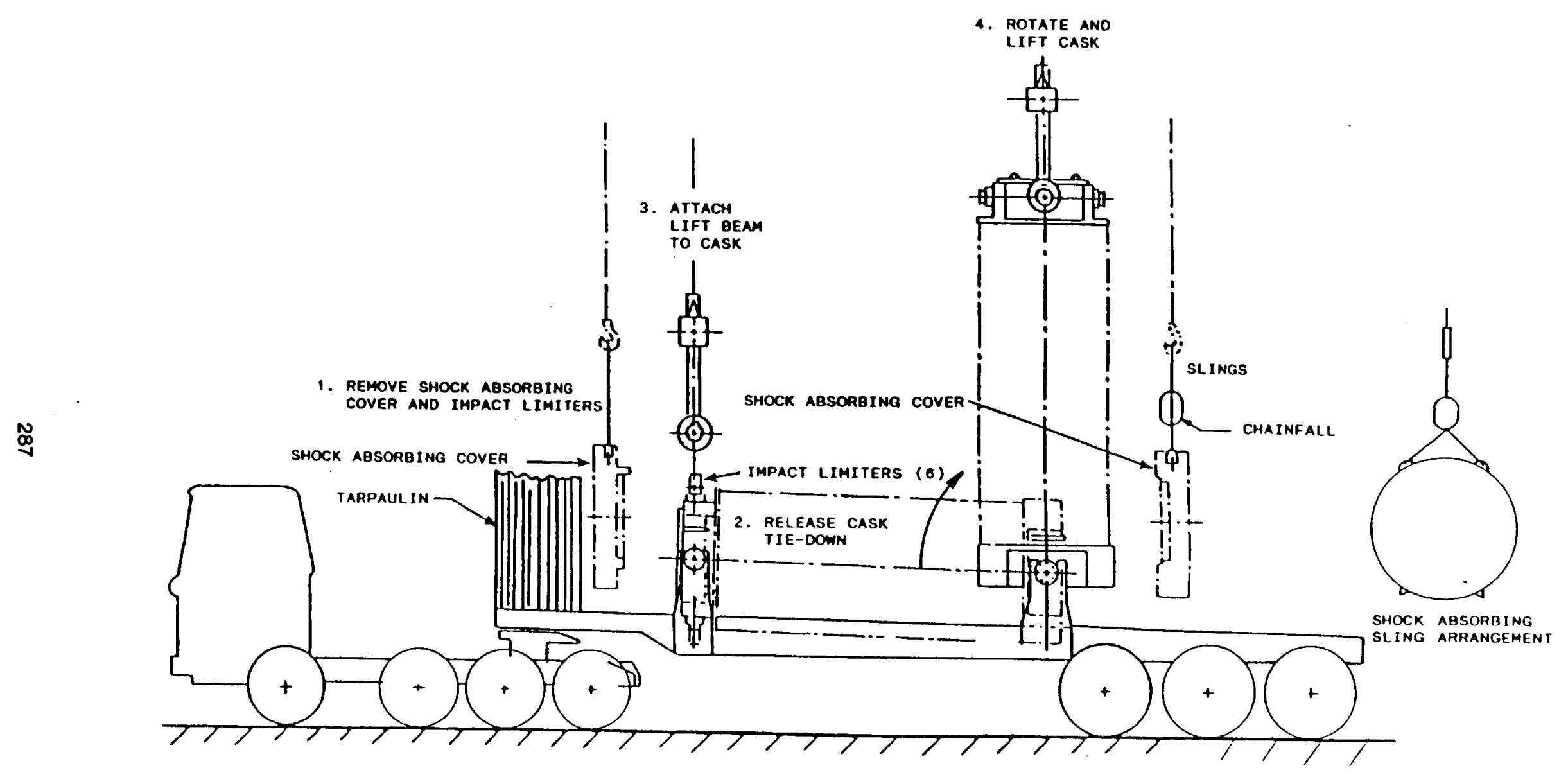

Figure 26 
SKIRT FILL STSTEM

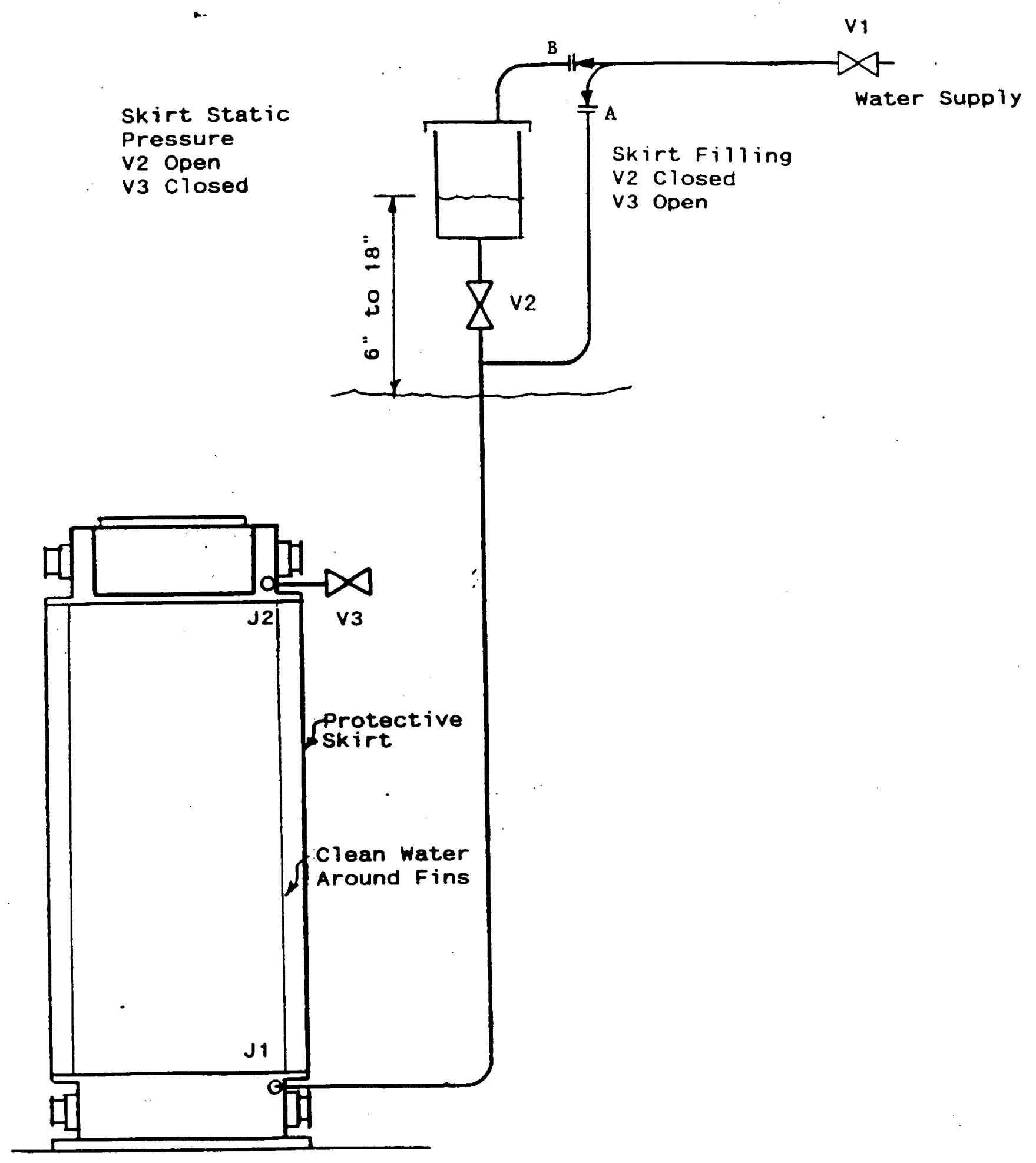

Figure 27 


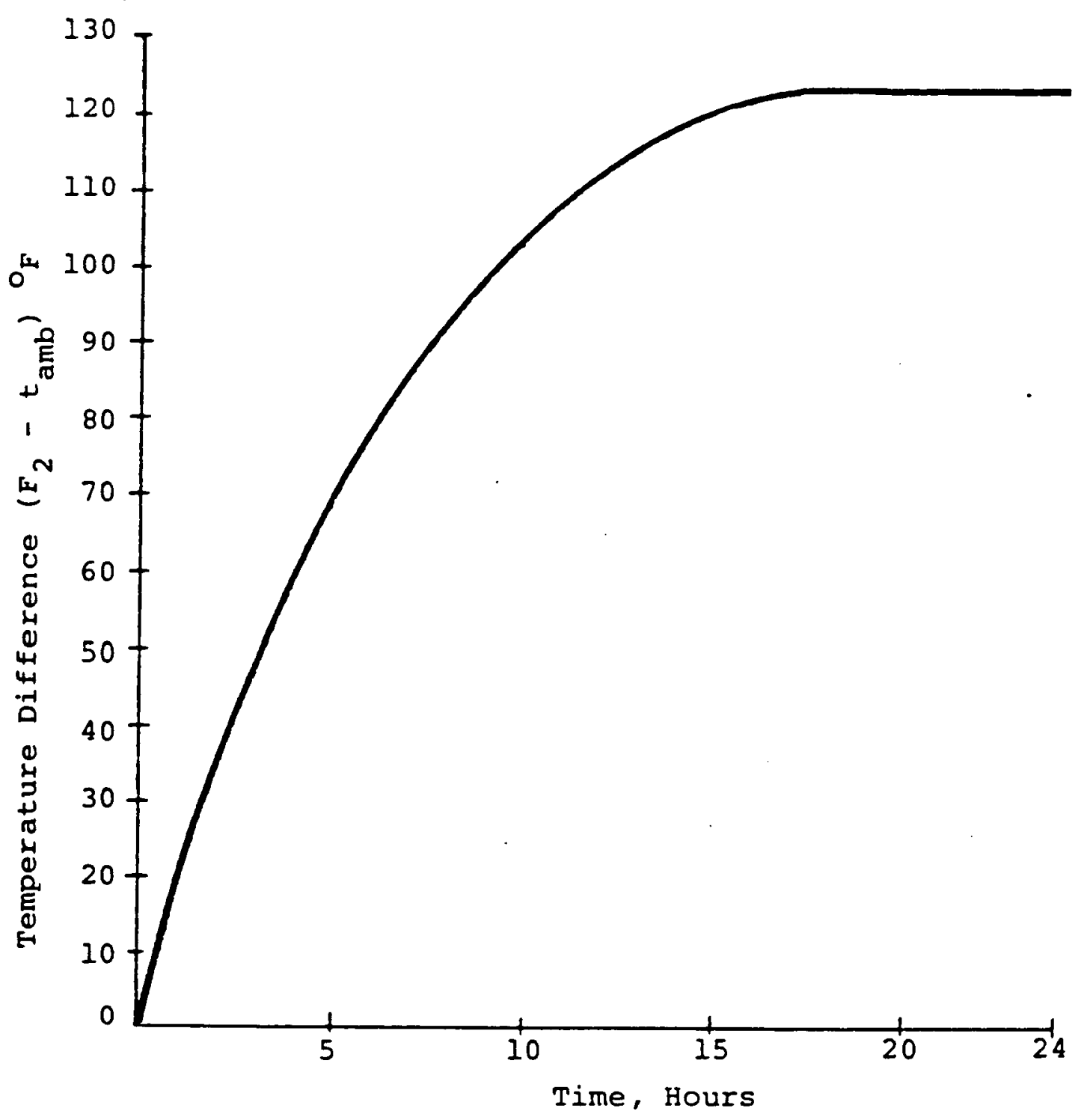

Temperature Difference (Thermocouple $F_{2}-t_{a m b}$ ) as a Function of Time (Heat Load $23.7 \mathrm{kw}$ )

Figure 28 


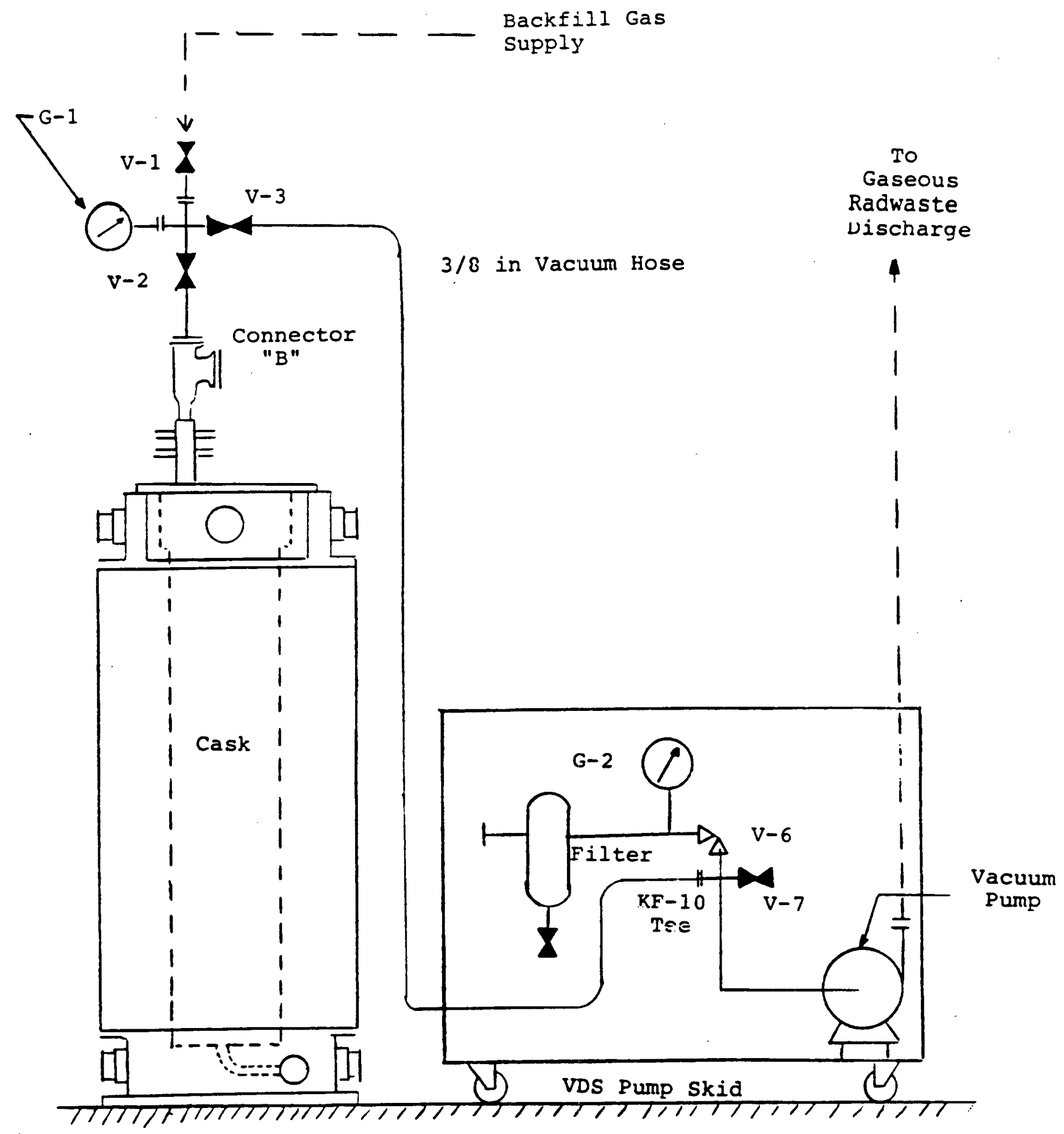

VDS In Backfill Mode

Fiqure 29 


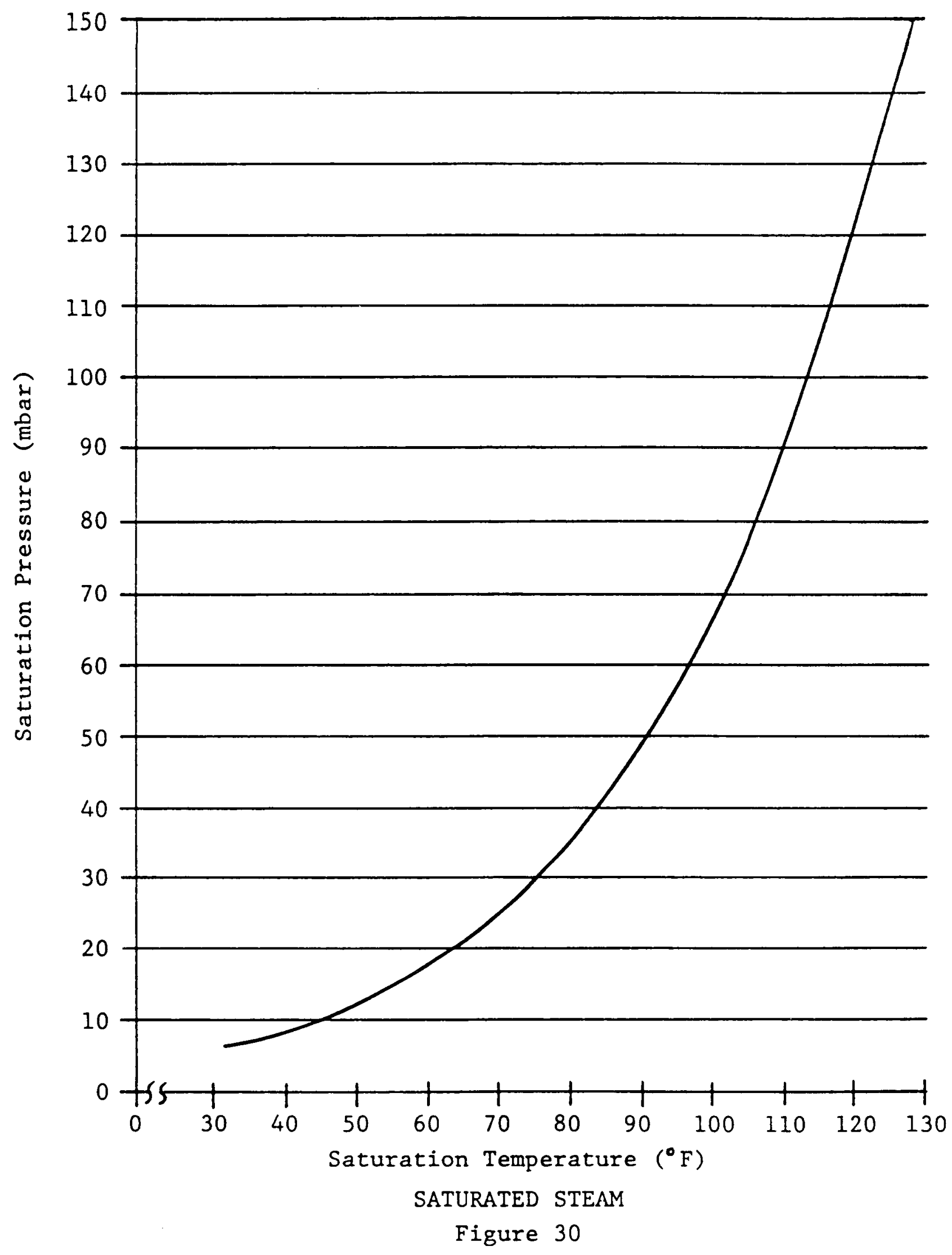




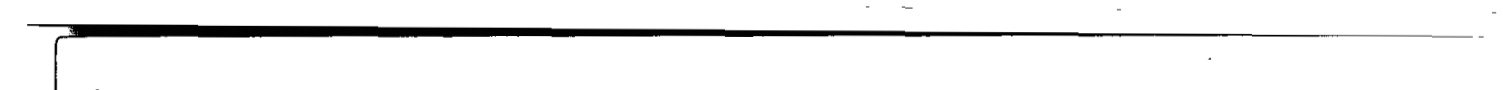


INTERNAL DISTRIBUTION

$\begin{aligned} \text { 1-5. } & \text { C. R. Attaway } \\ 6 . & \text { T. S. Baer } \\ 7 . & \text { J. Blomeke } \\ 8 . & \text { A. G. Croff } \\ 9 . & \text { C. W. Forsberg } \\ 10 . & \text { I. G. Harrison } \\ \text { 11. } & \text { E. } \text { K. Johnson } \\ 12 . & \text { D. S. Joy } \\ 13 . & \text { S. A. Meacham } \\ 14 . & \text { L. G. Medley } \\ 15 . & \text { J. R. Merriman } \\ 16 . & \text { J. H. Saling }\end{aligned}$

1-5. C. R. Attaway

8. A. G. Croff

9. C. W. Forsberg

10. I. G. Harrison

11. E. K. Johnson

12. D. S. Joy

13. S. A. Meacham

14. L. G. Medley

16. J. H. Saling
17-21. L. B. Shappert

22. J. E. Ratledge

23-27. R. R. Rawl

28. M. J. Rennich

29. C. S. Robinson

30-34. M. W. Wankerl

35. R. G. Wymer

36. Central Research Library

37. Document Reference Section

38-39. Laboratory Records

40. Laboratory Records - RC

\section{EXTERNAL DISTRIBUTION}

DOE-ORO, P. O. BOX E, Oak Ridge, TN 37831

41. J. A. Lenhard

42. S. G. Oxendine

DOE-HQ, Forrestal Building, 1000 Independence Avenue, S.W., Washington, DC 20585

43. D. H. Alexander

44. L. Barrett

45. E. F. Callaghan

46. J. Carlson

47. L. Dessel1

48. M. Frei

49. H. J. Hale

50. G. King

51. K. Klein

52. W. Lake

53. H. Saltzman

54. R. Stein

55. E. Wilmot

DOE- JH, 9800 S. Cass Ave., Chicago, Illinois 60439

56. C. Boggs-Mayes

57. J. Roberts

58. S. Kouba

59. J. Holm

DOE ID, 785 DOE Place, Idaho Falls, Idaho 83402

60. M. J. Barainca

61. C. Dwight

62-64. S. Hinschberger

65. T. Rowland 
Department of Transportation, 400 Seventh Street, S.W., Washington, DC 20590

66. A. W. Carriker

67. R. C. Hannon

68. M. Wangler

EG\&G, P. O. Box 1625, Idaho Falls, Idaho 83415

69. I. Hall

70. M. F. Jensen

Battelle/OTSP, 505 King Avenue, Columbus, Ohio 43201

71. J. Allen

72. S. Gupta

73. W. Pardue

74. R. Peterson

DOE - Office of Defense Waste and Byproducts Management, Research and Development and Byproducts Team, DP-123, Washington, DC 20585
75. F. Falci
76. R. F. Garrison
77. L. Harmon
78. J. Passaglia

Science Applications International Corporation, 300 Tulane Avenue, P. O. Box 2501, Oak Ridge, Tennessee 37830
79. R. Best
80. S. Grady
81. G. McCormick
82. R. Walker

83. G. Allen, Division 6323, Sandia National Laboratories, P. O. Box 5800, Albuquerque, New Mexico 87185

84. J. Boegle, Battelle/PNL, P. O. Box 999, Richland, Washington 99352

85. P. Bolton, Weston/Rogers, 955 L'Enfant Plaza, Washington, DC 20024

86. R. F. Brown, Systematic Management Services, 685C Emory Valley Road, Oak Ridge, Tennessee 37830

87. R. M. Jefferson, Consultant, 13136 Montgomery, N.E., Albuquerque, New Mexico 87111

88. R. H. Jones, Consultant, P. O. Box 1510, Los Gatos, California 95031-1510

89. S. C. Kline, The S. M. Stoller Corporation, 1919 14th St., Suite 500, Boulder, Colorado 80302

90. P. McCreery, Transnuclear, Inc., Route 2, Box 777, Aiken, South Carolina 29801

91-100. Technical Information Center, Oak Ridge, Tennessee 37830 